\title{
Assessment of the value
}

of woodland landscape function to local communities in Gorongosa and Muanza Districts, Sofala Province, Mozambique

Tim Lynam, Rob Cunliffe, Isaac Mapaure and Isau Bwerinofa 


\section{Assessment of the value of woodland landscape function to local communities in Gorongosa and Muanza Districts, Sofala Province, Mozambique}

Tim Lynam Rob Cunliffe Isaac Mapaure Isau Bwerinofa 
ISBN 979-3361-11-5

(c) 2003 by CIFOR

All rights reserved. Published in 2003

Printed by SMK Grafika Desa Putera, Indonesia

Cover and inside photos by Tim Lynam

Published by

Center for International Forestry Research

Mailing address: P.O. Box 6596 J KPWB, J akarta 10065, Indonesia

Office address: JI. CIFOR, Situ Gede, Sindang Barang,

Bogor Barat 16680, Indonesia

Tel.: +62 (251) 622622; Fax: +62 (251) 622100

E-mail: cifor@cgiar.org

Web site: http:// www.cifor.cgiar.org 


\section{Table of Contents}

Executive summary 1

Introduction

I. Site selection and description 9

A. Background to Muaredzi 10

$\begin{array}{ll}\text { B. Background to Nhanchururu } & 12\end{array}$

II. Community Landscape Valuations 15

A. Methods 15

1. Initial conceptual model 15

2. Spatial data management 16

3. Community information collection 16

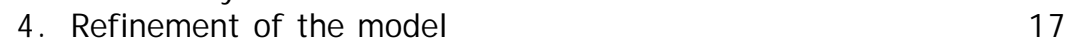

5. Field sampling for model confrontation $\quad 17$

6 Updating the models 20

B. Results and discussion 20

1. Initial conceptual model 20

$\begin{array}{ll}\text { 2. Muaredzi community assessments } & 21\end{array}$

3. Nhanchururu community assessments 36

4. Field Sampling for Model Confrontation 51

5. Confronting the models with reality 60

III. Vegetation inventory and assessments 65

A. Approach and methods 65

1. Vegetation survey 65

2. Assessment of explanatory variables 66

3. Data analyses 66

B. Results $\quad 66$

1. Muaredzi 66

$\begin{array}{ll}\text { 2. Nhanchururu } & 71\end{array}$

C. Discussion 76

1. Muaredzi 76

2. Nhanchururu $\quad 77$

D. Conservation values of vegetation in Muaredzi and Nhanchururu 78 
IV. Overlay of community valuations and conservation valuations 81

A. Introduction $\quad 81$

B. Methods $\quad 81$

C. Results $\quad 82$

1. Mauredzi 82

2. Nhanchururu $\quad 84$

D. Discussion and conclusions 85

V. Implications for land use planning 87

$\begin{array}{ll}\text { A. Community Evaluations } & 87 \\ \text { B. Biodiversity Evaluations } & 88\end{array}$

C. Modelling $\quad 89$

D. Overlay of Community and Biodiversity Evaluations 89

$\begin{array}{lr}\text { E. Synthesis } & 89\end{array}$

$\begin{array}{lr}\text { VI. Acknowledgements } & 91\end{array}$

VII. References $\quad 92$

VIII. Appendices $\quad 94$

1. Data sheets used for field sampling for model confrontation 94

2. Land types identified by the Muaredzi CRUAT 96

3. Summary of 75 Muaredzi field samples for model confrontation 97

4. Summary of 82 Nhanchururu field samples for model confrontation

5. GPS point data for the vegetation inventory sites in Muredzi and Nhanchururu 


\section{Executive summary}

\section{Assessment of the Value of Local Woodland Landscape Functions to Local Communities}

During the process of developing a management plan for Gorongosa National Park (GNP) in northern Sofala Province, Mozambique the presence of people within the park and in the areas immediately surrounding the park was identified as a major management concern. The maj or obj ective of the park was the conservation of ecosystems and biodiversity. Local people were recognised as users of natural resources but park management had set itself the objective of ensuring that the use of resources did not undermine the achievement of conservation, recreation and knowledge generation objectives. Little was know of the spatial patterns of use of resources by local communities nor what areas were likely to be heavily impacted by community use of resources.

The aim of the research was to develop and test an approach to estimating local values for landscape units and relate these to formal biodiversity conservation values. The Tropical Resource Ecology Program (TREP) team conducted participatory analyses in two village scale sites; Muaredzi that was entirely within the boundaries of GNP and the other, Nhanchururu that straddled the boundary of GNP. The team used a combination of participatory research methods, Bayesian probability modelling and spatial data analyses of baseline digital data sets and remotely sensed images, to iteratively improve understanding of the factors determining the value that local people assign to specific landscape elements or locations.

In parallel to this participatory process, an assessment was made of the vegetation diversity of the same areas using standard scientific methods of firstly interpreting satellite imagery and then field sampling to validate the resultant maps and to fill in the details of species composition in each vegetation type. Vegetation types were scored and ranked in order of conservation importance. Conservation importance values were derived as a function of relative area of each vegetation type, species diversity of each vegetation type and the presence of key species of conservation interest. The local landscape values were then overlain with the conservation importance indices to identify areas where conflicts between village use and conservation were likely to be high, i.e. where both conservation and village valuations were both high.

Community resource use assessment teams (CRUATS) were elected by the people of each village to work with the scientific team. The analysis followed the same pattern in each site. Firstly, the scientific team developed a prior model or hypothesis of the value, to local villagers, of each landscape unit. In this model landscape unit value was defined as being a function of the ratio of benefits derived from the unit to the costs of 
procuring benefits from the unit. The larger this ratio the more valuable the site. The CRUAT listed and scored, to reflect relative importance, the basic needs that households required for an adequate quality of life. The CRUAT then mapped the local landscape into locally identified and recognisable units and listed the goods and services that emanated from each unit. Using the scores allocated to basic needs an index of the gross value of a landscape unit was estimated as the weighted sum of goods and services derived from the landscape unit or location. The weightings were the local, relative importance scores for each good or service. The cost component of the model was estimated to be a function of the distance from the village to the location or landscape unit and any institutional or physical barriers which increased the labour costs of procuring or using resources. Local estimates of the relative contributions of each of these cost components were identified and then converted into spatial cost maps using the GIS. The final estimate of landscape value was then created as a spatial map of the Benefit-Cost model.

To explore the usefulness of the model it was confronted with real world data. Randomly selected locations were visited by members of the CRUAT who scored each location for all model components; benefits, costs and final value. The resulting data were used to confront the model and then update it.

\section{Basic needs and the natural environment}

The livelihood systems of both villages that participated in the local valuation of landscape functions project were dominated by natural resources based production with very few external inputs. Food was derived from local agricultural production based on a tree fallow system of nutrient replenishment, from forest products, from wild foods and from purchased commodities. The latter contribute only about $20 \%$ of the total food input although this increases in drought or flood years. Most household basics are also directly derived from natural resources; houses are constructed from cut trees bound with tree fibre and grass thatch rooves; water is drawn from shallow ground wells or rivers and cash is generated through the sale of grain, livestock and natural products. Nonagricultural food products become very much more important in drought and flood years, eventually supporting the household. Poorer households have a greater dependence on natural products than do wealthier households.

The landscape is also important from a cultural perspective. With local spiritual beliefs closely linked to the intercession of ancestors in matters of importance the burial of the dead is of great cultural significance. Hence cemeteries are very important local landscape features. People site the burial of their ancestors as a major reason why they would not be interested in moving from their current village areas.

\section{The value of woodland landscape units to local communities}

A very large number of products were used from the landscape of both village sites. The project team aggregated many of these into classes of product that satisfied specifically identified needs. There were for example, four different types of honey but these were all classed as honey, in the wild product category. The benefit side of the local valuation was therefore based on the supply of between 13 and 25 categories of goods.

The goods that contributed most to the values of landscape units were water, land for agriculture and houses, construction materials (these included poles, fibre, thatching grass and reeds), firewood, general household and craft materials (such as wood for tool handles, reeds for mat construction or materials for constructing pestle and mortars) and various wild foods. This pattern of importance values associated with the goods derived from natural resources are similar to those observed elsewhere in southern Africa. Villagers collected or used resources from areas of about $300 \mathrm{~km}^{2}$ for a village of 40 to 100 households. Again this is a similar area to results observed elsewhere in the region.

Important lessons that emerged from the analysis as to the factors governing local valuation of landscape functions or locations the project included the following:

- Village landscapes are valued for the bundles of ecosystem goods and services that people derive from each location in the landscape.

- In terms of predicting the value of a given location the preference-weighted sum of stocks of resources on a given site was a good predictor of the values local people assigned to that location. Costs did not contribute much to the values assigned by local users. Neither distance nor local (traditional) regulations or institutions played much of a role in determining the value of a location.

- Strictly enforced regulations, such as were prevalent in some areas of GNP and for some resources, did act to exclude users and hence greatly reduce the value assigned to the given location.

- The value assigned to a given site was completely determined by tangible benefit stocks. Non-visible ecosystem services, for 
example, were not identified as benefits and therefore did not contribute to the values assigned in this analysis.

\section{Biodiversity conservation values and potential conflicts between conservation and livelihood systems uses}

Both sites included a range of vegetation types from open grassland areas through various savanna woodlands to thickets and forests. Thirteen types were identified for Muaredzi as compared to seven for Nhanchururu, although the total number of plant species recorded was similar for both sites (231 for Muaredzi and 246 for Nhanchururu). For both sites it was the thicket and forest communities that were identified as being of greatest biodiversity conservation importance, both on the basis of their species composition and particularly their limited occurrence in the overall landscape.

For both village areas the thicket and forest ecosystem types had both the highest conservation value and the highest local livelihood values. These landscape units are likely to be under the greatest threat from village level consumptive use and thus where the greatest conflict is likely to occur in terms of meeting both conservation and livelihoods needs.

\section{Implications for land use planning}

Community use of resource areas can be divided into two broad classes; land transformation and multiple use. Land transformation comprised the conversion of woodland areas into cultivated fields or riverine gardens. This was clearly the most destructive process and would directly and negatively impact biodiversity and hence conservation objectives. Multiple use of given landscape units by the community could however, under certain management conditions, remain compatible with conservation objectives.

The expansion of human populations in and adjacent to the park will inevitably result in greater demands from people for agricultural land and for the resources that the park seeks to conserve. It would thus seem inevitable that conflict between the park and people whose livelihoods depend on park resources will intensify. Further conflict is likely to arise through the build up of wildlife populations, such as elephants and large predators.

One possible solution for the park management is to identify key ecosystem units, such as forest communities, and put in place fully enforced regulations governing the clearance of these areas for cultivation. Development of land use zones in collaboration with the affected local communities would be one way of achieving this. Once these areas of both high conservation and high local resource value have been identified, and their use regulated through zoning, co-management structures and institutions could be developed to provide sustainable multiple use opportunities to those communities with a high dependency and capacity to manage these resource units.

Secondly, the park management will need to develop and maintain functional relationships with these communities (i.e. relationships with low levels of conflict and high levels of co-operation), which will require significant management inputs. The maintenance of communities within the park will incur additional costs, including both direct costs such as the costs of maintaining ranger's posts in the areas in which the communities are, as well as indirect costs such as increased fire incidence. For some areas or ecosystem units these costs may be warranted, but for other areas these costs may not be warranted. In these instances GNP management may be better off seeking incentives to persuade communities to voluntarily relocate.

The coupling of park ecosystems to ecosystems outside of the park (particularly hydrological couplings with Gorongosa Mountain), and hence outside of GNP management control, means that for GNP to survive ecologically, park management must also seek to develop fully functional comanagement relationships with the local communities responsible for managing these external ecosystem elements. 


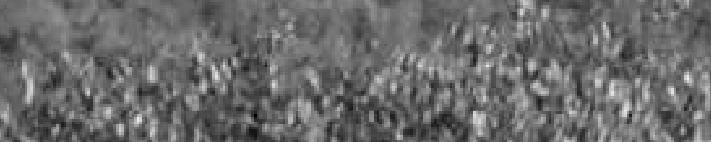

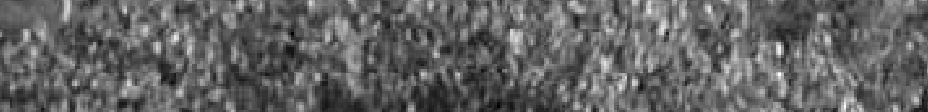

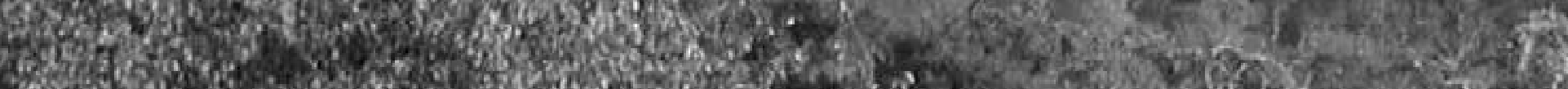

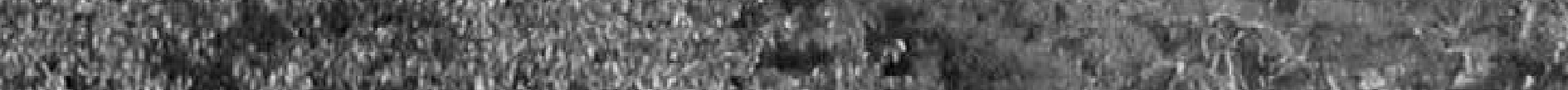

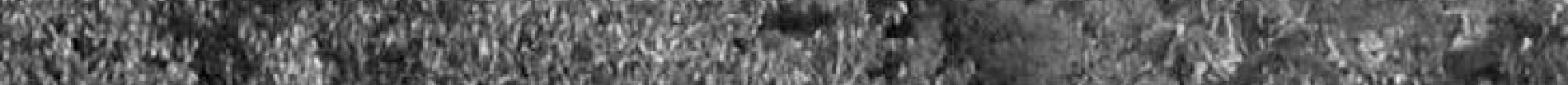

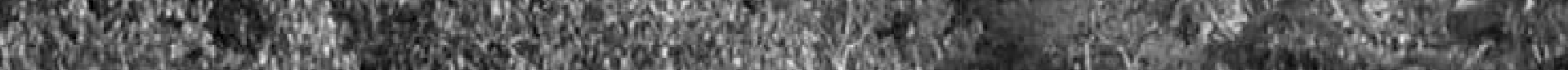

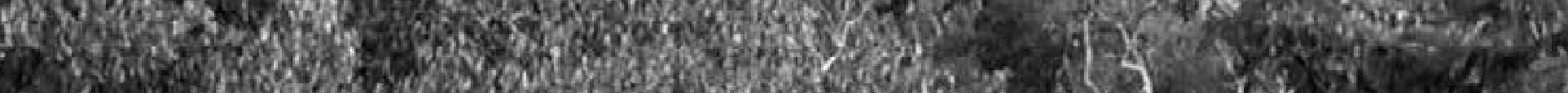
3.

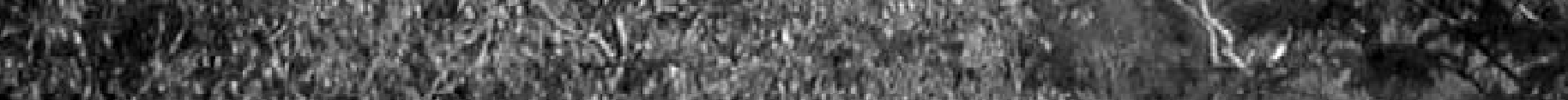

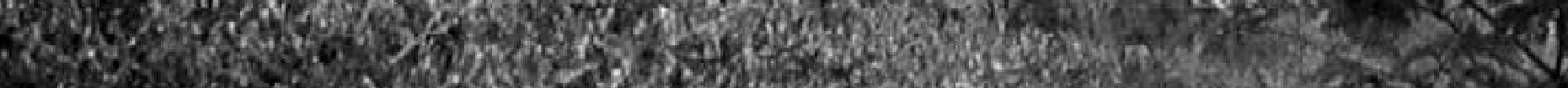
2. 1.

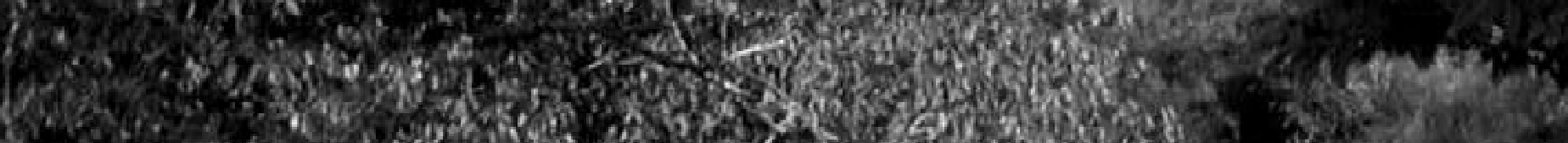

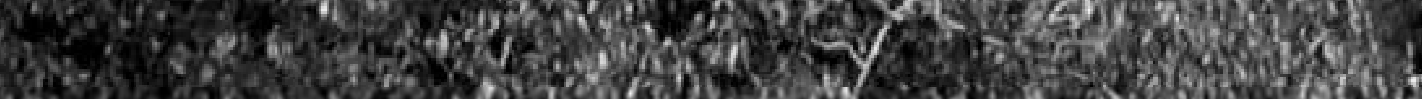

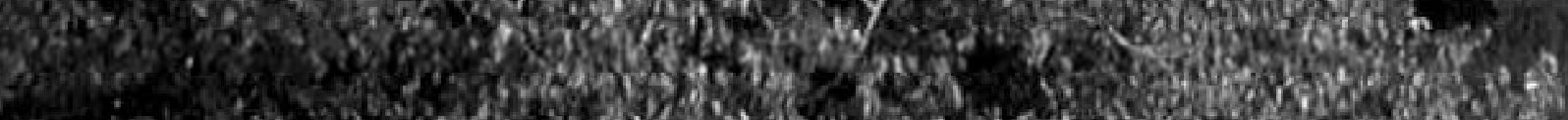
2. 19. 30 . Lex a 


\section{Introduction}

As part of CIFOR's project ${ }^{1}$ to identify the value of landscapes to local users the Tropical Resource Ecology Program (TREP) at the University of Zimbabwe was contracted to undertake a short term research project to establish the value of landscapes to local communities. A startup meeting was held in Harare, Zimbabwe on $29^{\text {th }}$ and $30^{\text {th }}$ of J anuary, 2001, at which the TREP team² presented their suggested approach, and also suggested implementing the project in Gorongosa National Park (GNP) in Mozambique. The principal reason for electing to implement the project in the logistically more difficult Mozambican site, was the opportunity for the project to directly contribute to the GNP planning activity in which the team leader (Dr. T. Lynam) was already involved.

Several communities live within the boundaries of GNP, whilst others straddle the boundaries, together amounting to an estimated total population of some 10 to 15 thousand people living within the park (Figure 1). The Administrator of GNP and other senior National Parks staff had clearly indicated the importance of addressing the question of people living within

\footnotetext{
${ }^{1}$ Assessment of the Value of Woodland Landscape Functions for Local Communities

${ }^{2}$ Tim Lynam, Team Leader; Rob Cunliffe and Isaac Mapaure.
}

and adjacent to the park. A notable component of the GNP planning activity was expected to be the development, in consultation with all relevant stakeholders, of a management strategy for the buffer zone or co-management areas of the GNP. Thus, the CIFOR project would be able to contribute directly to a real need, and hence had considerable support from the GNP Administration.

Conducting the assessment in and around GNP would serve three maj or purposes. The first was the provision of information to park planners and managers, on what is of value to the local communities living within and around the park, and some indication as to where these values might be in conflict with GNP management objectives. The second, and equally important objective, was to ensure that the views of local communities were clearly expressed in the park planning exercise. In essence this would involve working with the local communities and translating their needs and views into information that would be useful to the Park Administration. The third purpose was to enhance the capacity of Mozambican partners in the project to conduct similar assessments.

The approach adopted was to develop method to estimating local values for landscape units, to generate corresponding biodiversity conservation values, and then to compare these two sets of 
values. A combination of participatory research methods, Bayesian probability modelling and spatial data analyses of baseline digital data sets and remotely sensed images, were used to generate and iteratively improve understanding of the factors determining the value that local people assign to specific landscape elements or locations. Vegetation analyses of the same areas were carried out using standard scientific techniques of firstly interpreting satellite imagery and then carrying out ground sampling to validate the resultant maps and to provide details of species composition for each type. These data provided the basis for the subsequent generation of biodiversity conservation values. The local landscape values were then overlain with the conservation importance indices to identify areas where conflicts between village use and conservation were likely to be high.

It is important to clarify what is meant by the term value as used in this project. There is a considerable literature, both in the economic as well as in the social fields, as to what value means and how it is measured. It is not necessary for us to review that literature here. What is important is that we have a clear definition of what is meant by value and what limitations there are on the use of the term in the context of this project. We use the term value to reflect an index of preference ordering. The value of a good or service is the relative degree to which that good or service is preferred in comparison with other goods and services available at that time and

location. This last point is of fundamental importance. In our conception of the term there is no such thing as "THE VALUE". Value is a dynamic and relative concept - value varies across individuals, and varies through time as the relative abundances and needs for various goods and services change. What we have striven to obtain, in our implementation of this project, is a value estimate that is averaged across a community and is expressed by individuals selected by that community to represent their views - it is thus a social value. We have also sought to average that estimate of value across a limited time domain - perhaps only meaningful over at most a year or two. The important point to reflect upon is that the estimates we have succeeded in making are appropriate at a given time and in a given location - they are not necessarily generalisable across a wider spatial or temporal domain.

Following this introduction, the remainder of the report is structured into a further five main sections (Sections I-V). Section I describes the process of selecting research sites, and provides brief descriptions of the two chosen areas: Muaredzi and Nhanchururu. The following section deals with the community landscape valuations (Section II). This includes both methods and results concerning the development and confrontation of the models, the GIS data sets, and the participatory community assessments. Details of the vegetation assessments and generation of biodiversity conservation values are then presented in Section III. Section IV concerns the overlay of the community and biodiversity conservation valuations. The final section (Section V) comprises a synthesis which draws the various threads together and spells out the implications of the research findings in terms of the land use planning process for GNP. 

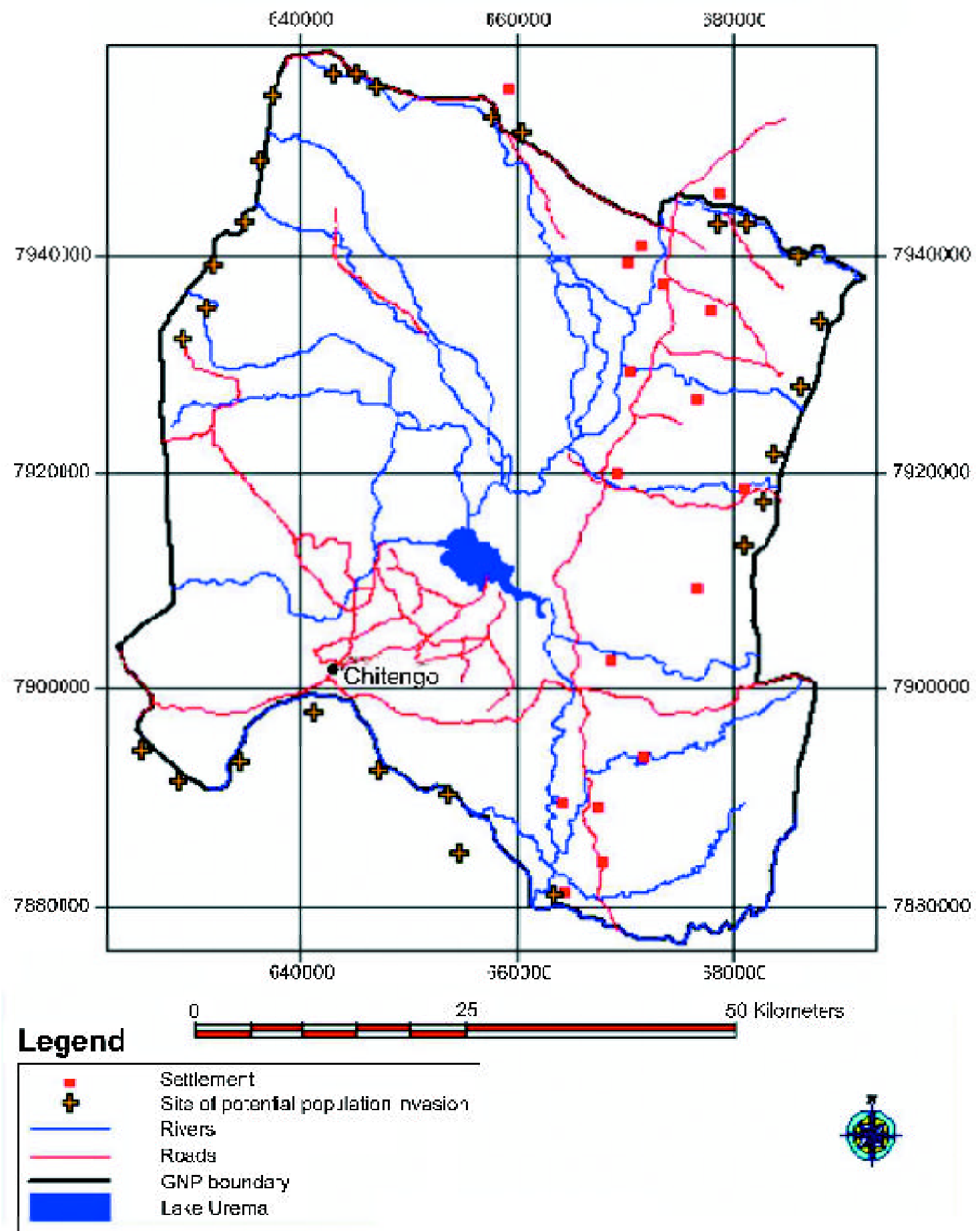

50 Kilormeters

Figure 1. Boundary of Gorongosa National Park with major tracks and roads as well as major areas of human settlement and possible human incursion into the park. 

M. 3 is

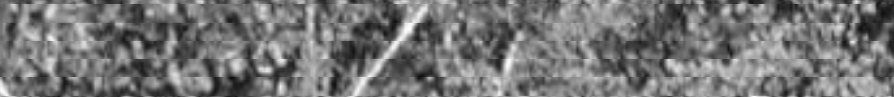

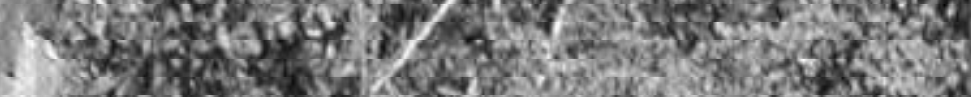
2. 7.

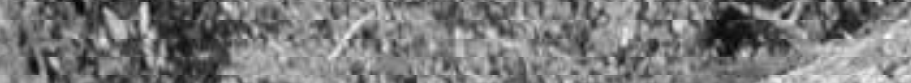

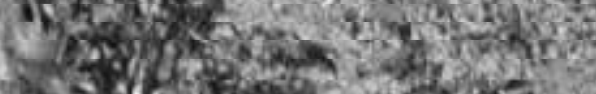

fotitis $46 x^{2} \times 5$

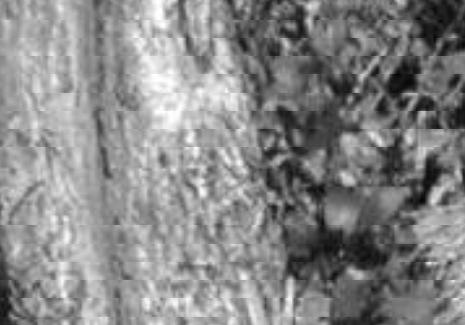

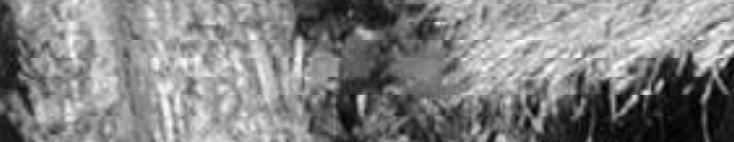
X.

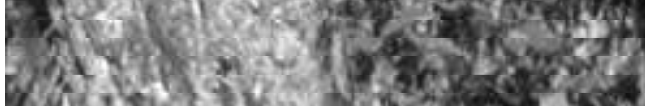
Mon 3 is

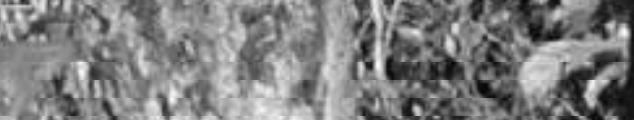

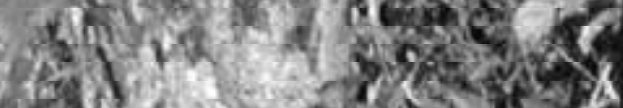
for $x=2+2 y$

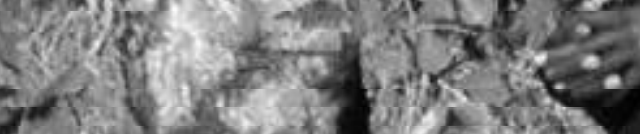

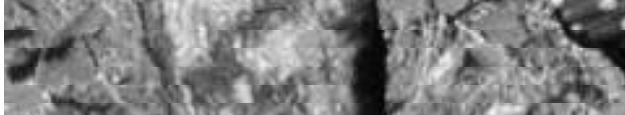

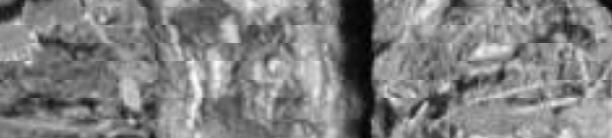
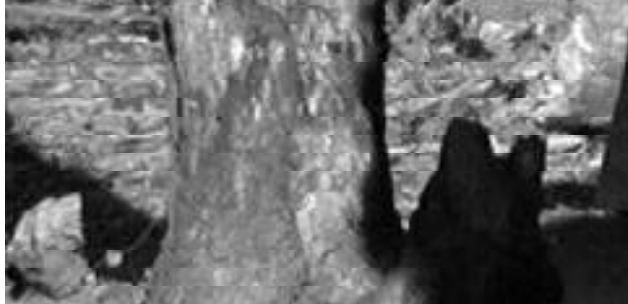

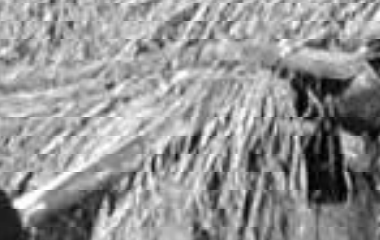

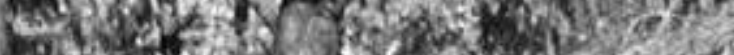
s.

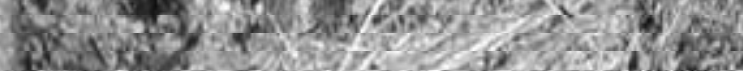
yeis.
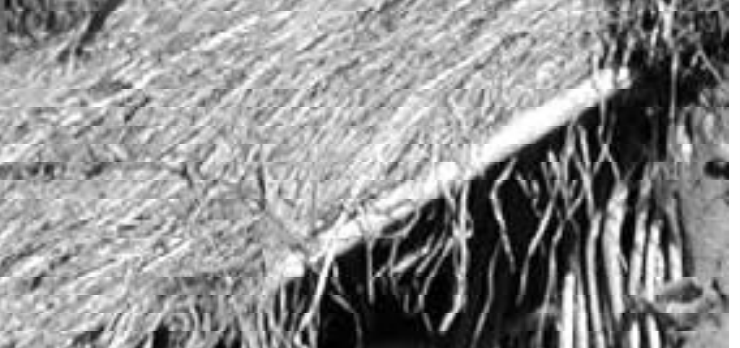
25) (1) 1 (1) a.s.
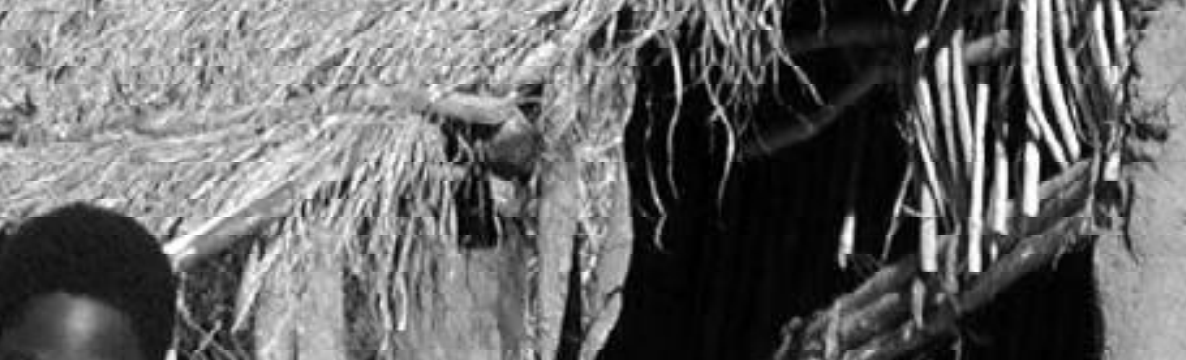
(1)

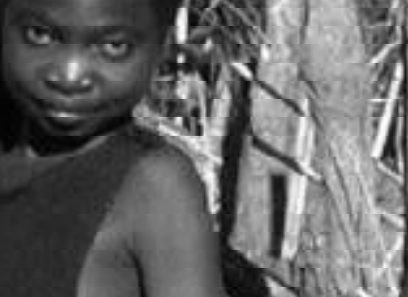

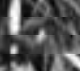
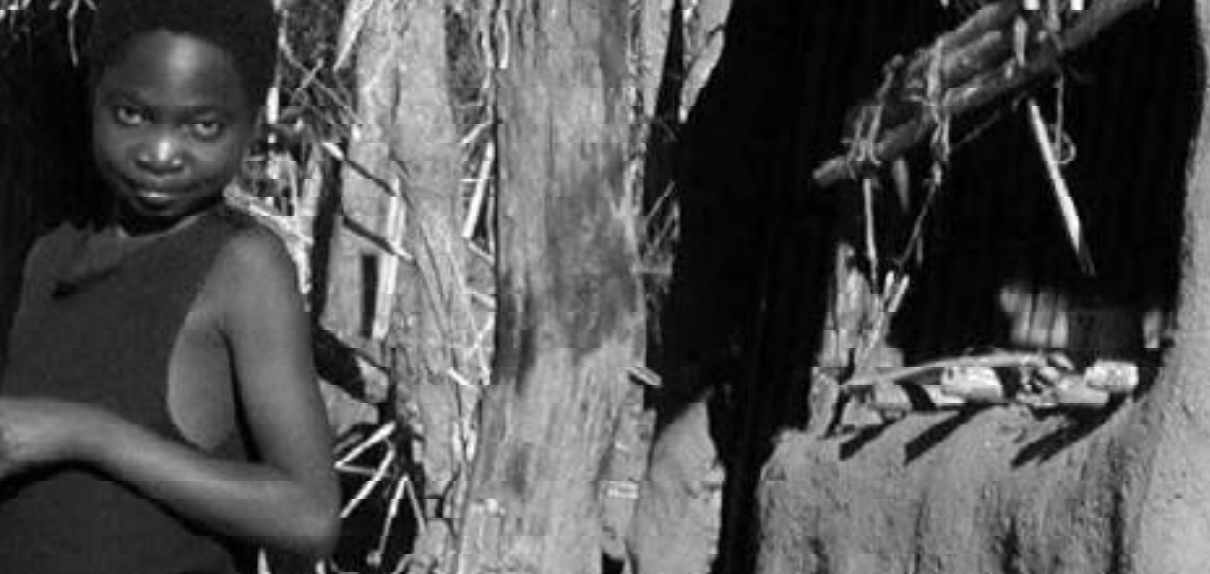
a.s.
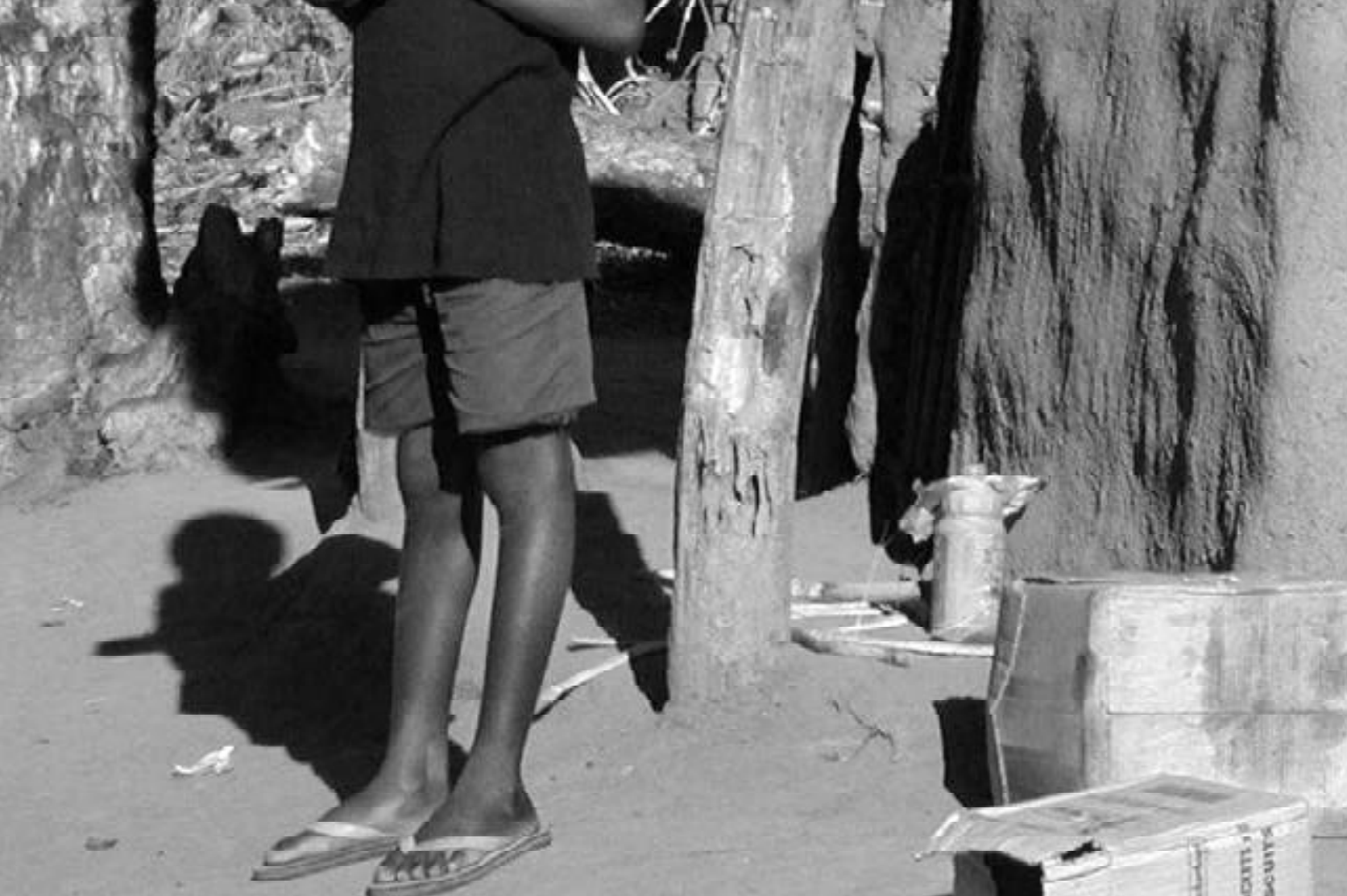

4.

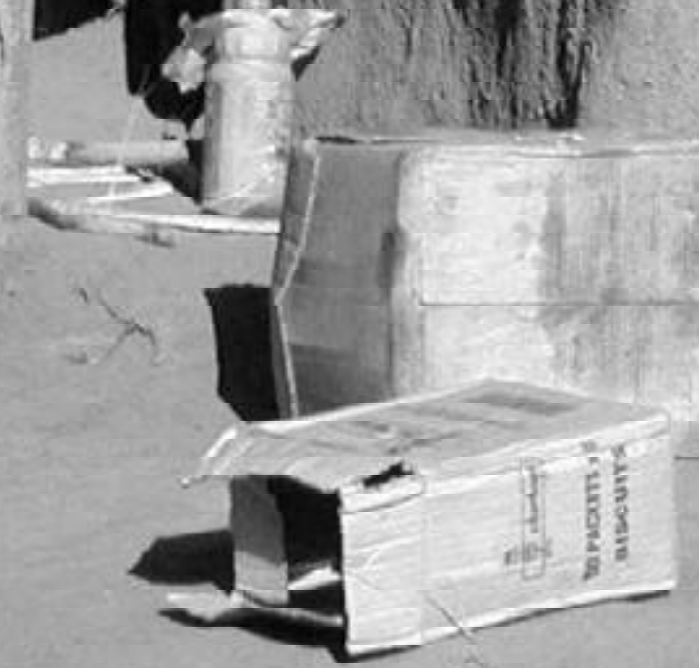




\section{Site selection and description}

Discussions were held between the TREP team and the Administrator of GNP to identify communities that would provide useful information for the development of the Park plan. The importance of community perspectives on the biophysical resources in the Park, and also their perspectives on resources outside of the Park but on which GNP was critically dependent, ${ }^{3}$ were discussed. Following these discussions reconnaissance trips were made to four different communities. The first of these potential sites was called Muaredzi and was entirely within the GNP (M-Figure 2). The second site (Nhanchururu) was on the western boundary of the GNP and hence in the foothills of Gorongosa Mountain with the community straddling the GNP boundary ( $\mathrm{N}$ Figure 2). The third and fourth sites (Vunduzi and Canda) were located on the eastern and western sides of Gorongosa Mountain respectively (V and C - Figure 2). The Vunduzi community was close to the GNP boundary whilst the Canda community was several kilometres from the GNP

${ }^{3} \mathrm{GNP}$ is critically dependent on the water that drains off Gorongosa Mountain and that which drains off Cheringoma Plateau. Both of these areas are outside of the GNP and hence not under the control of the park authorities.

${ }^{4}$ Regulo is the highest level of traditional leadership roughly equivalent to Chiefs in other parts of southern Africa. boundary. The Regulos ${ }^{4}$ governing these two communities were responsible for the traditional control of Gorongosa Mountain.

The traditional leaders from each of these communities were approached and asked if they would be willing to involve their communities in the research project. In all cases this permission was granted, although in the Canda site this permission was more guardedly given - apparently because previous research initiatives had yielded no tangible benefits for the community, and in fact once the researchers had left nothing was ever heard from them again.

In general the selections were made using the following criteria:

1. Willingness of community leaders to participate;

2. Degree of dependence of community on GNP resources;

3. Accessibility of the site.

Based on the reconnaissance visits it was decided that the project would start in Muaredzi and then carry on in the Nhanchururu site. The Vunduzi site, whilst offering the opportunity to work on the biologically very interesting Gorongosa Mountain, would be inaccessible after severe rains, whilst the Canda site was furthest from the park and hence reflected the least dependence on Park resources. Although 


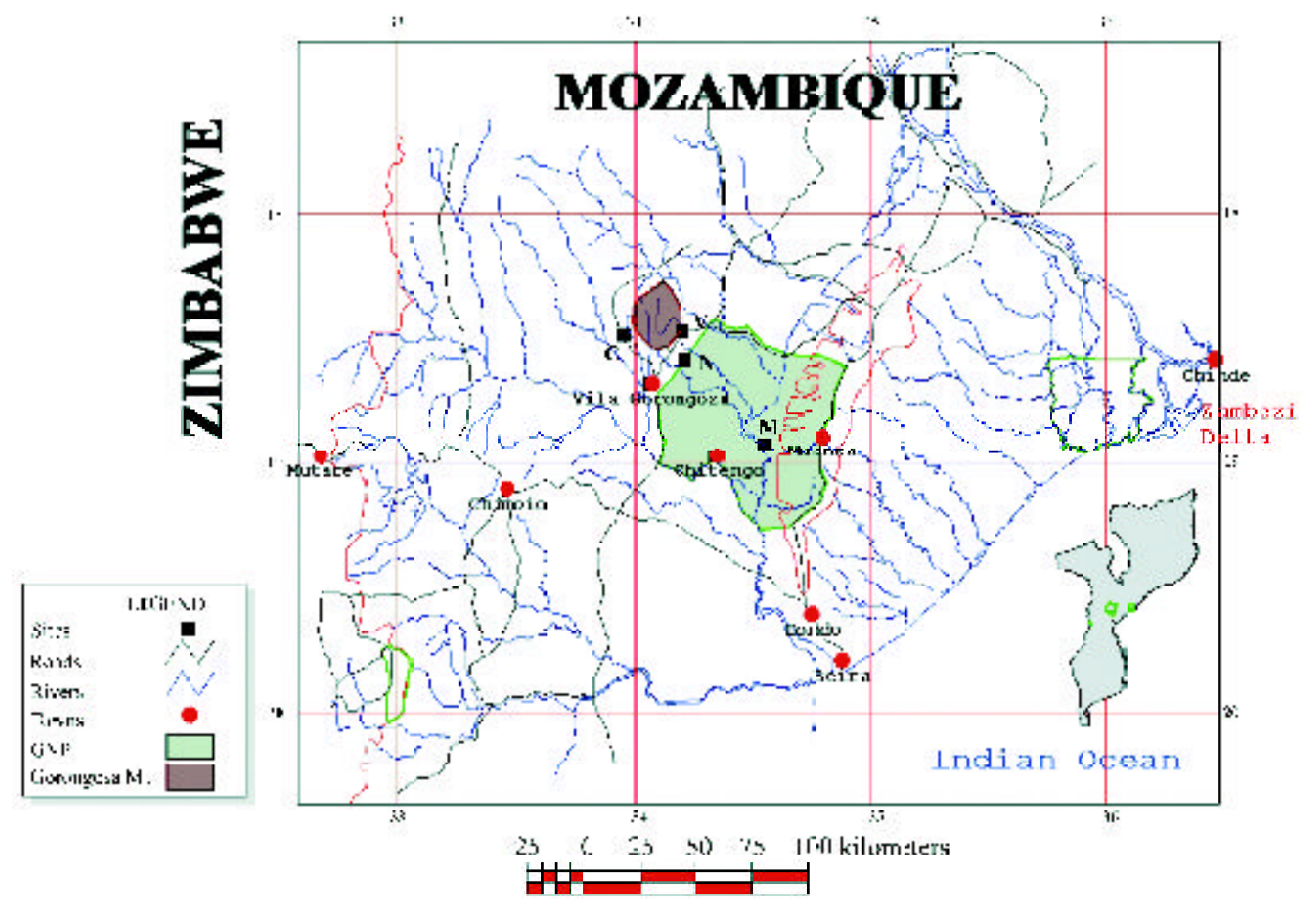

Figure 2. Map of central Mozambique showing Gorongosa Mountain, Gorongosa National Park (GNP) and the four preliminary sites considered for further investigation; $\mathrm{C}=\mathrm{C}$ anda, $\mathrm{V}=\mathrm{Vunduzi}, \mathrm{N}=$ Nhanchururu, and $\mathrm{M}=$ Muaredzi.

Gorongosa Mountain itself provides one of the most interesting biological sites in the region, due to the difficulty of working there (access is limited to a walk up lasting several hours and then camping at the top) it was decided to not attempt to implement the project there.

Once the Muaredzi and Nhanchururu sites were selected, the local leaders in each community were asked to assist in conducting the traditional ceremonies that were necessary for the ancestral spirits to accept the project.

\section{A. Background to Muaredzi}

The Muaredzi community is situated on the north and south sides of the Muaredzi River where it joins the Urema River, downstream of Lake Urema (Figure 3). Maunza, the nearest town, is approximately $35 \mathrm{~km}$ to the northeast and Chitengo the GNP headquarters is about the same distance to the west. There is no regular transport from Muaredzi to Maunza and, and other than the occasional visit by national parks staff, very few vehicles come to the village.

The village area, comprising all households and fields, is relatively compact, being contained within an area of about $2 \mathrm{~km}$ by $2 \mathrm{~km}$. In 1998 there were estimated to be 172 members in the community (Costa and Vogt, 1998). Although we do not have a full count of people living in Muaredzi, 40 households were identified in November 2001 . These were split roughly equally north and south of the Muaredzi River. The community falls under the jurisdiction of two different Regulos. Regulo Nguinha controls the area to the north of the Muaredzi River and Regulo Nhantaze controls the area to the south. Within Muaredzi there were four Fumos ${ }^{5}$.

Residents are forbidden by park regulations to venture to the west of the Urema River. The village area does not appear to have any clear boundaries to the east, south or north.

In addition to the road to Muanza, there are two other tracks leading away from Muaredzi. One leads north for some $18 \mathrm{~km}$ along the edge of the Urema floodplain to Goinha (also known as Maunza Baixo). The other comprises a path, which runs for some $5 \mathrm{~km}$ to the south of the village, to a crossing point on the Urema river known as $J$ angada. Across the river, this connects to the road to GNP headquarters at Chitengo, some $35 \mathrm{~km}$ to the west. Before the civil war there was a pontoon here (hence the name J angada), but now the only means of crossing is by a dugout canoe.

${ }^{5}$ Fumos are the next level of traditional leadership down from the Regulo. 


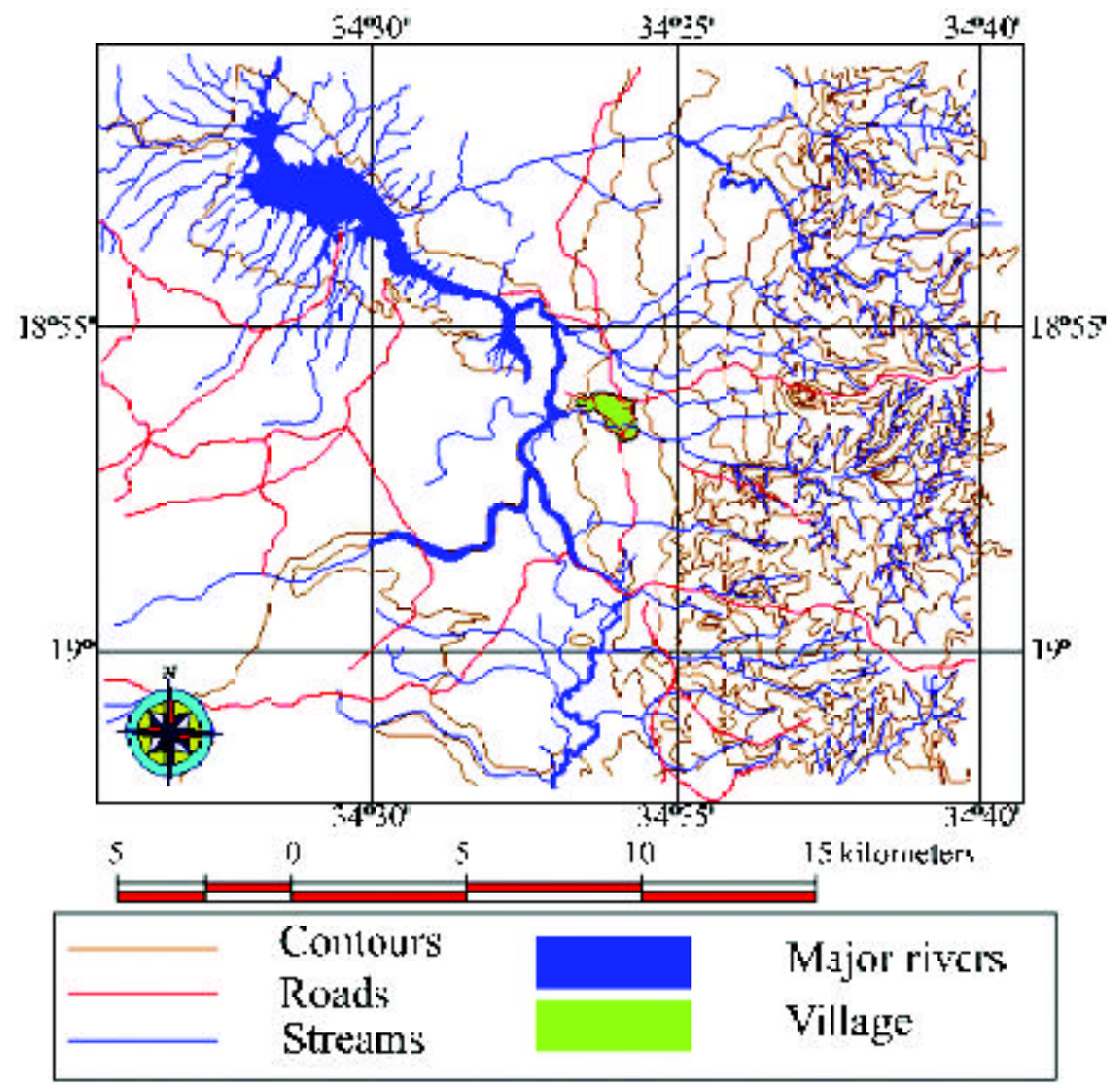

Figure 3. Muaredzi study site showing the major rivers, $10 \mathrm{~m}$ contours and major routes from the village centre.

The nearest neighbours to Muaredzi live within a small village comprising a few households situated several $\mathrm{km}$ to the south of J angada. To the north, the closest village is Goinha, which appears to be slightly larger than Muaredzi. Both of these are also within the National Park. There are no schools, clinics or shops within the village, such that people must travel to Muanza for these facilities. The lack of any buildings with tin roofs in Muaredzi, provides a further indicator of the limited extent of development.

Tinley (1977, Figure 7.2) did not indicate any settlement in the Muaredzi area at the time of his analyses (mid-1970's), although there were settlements north and south of Muaredzi along the Urema river basin. The 1:50,000 topographic map of the Muaredzi area (based on air photography of 1958/60) does however, indicate a small area of settlement a few km east of the present settlement. The inhabitants were essentially subsistence producers of sorghum, cassava and maize (as a cash crop). These crop yields would be supplemented with fish and wild life harvesting.

Situated towards the southern most end of the great rift valley $\left(18.9392^{\circ} \mathrm{S}, 34.5557^{\circ} \mathrm{E}\right)$, in what is called the Urema trough section of the rift valley, Muaredzi is low lying ${ }^{6}$ (approximately $30 \mathrm{~m}$ above sea level) and hot (mean annual temperatures of $\left.25.5^{\circ} \mathrm{C}\right)$. Rainfall is relatively high, but very variable (mean annual rainfall $850 \mathrm{~mm}$, coefficient of variation $67 \%$ ). Evaporation is high and greatly exceeds precipitation in the dry season months (mid-April to mid-October).

Geologically the Urema trough section of the rift valley was covered by alluvial fan deposits in Pleistocene to recent times. These deposits have given rise to black, hydromorphic clays interspersed with non-hydromorphic alluvia and grey, semi-impervious sandy soils. The soils are base rich and hence generally fertile (although often saline). In some areas underlying sand at 24 metres gives rise to gilgai micro-relief. Organic carbon is generally high (1.5-5\%) in the dominant soils of the Urema trough area and most of these soils are phosphorous rich.

The vegetation of the Lake Urema floodplain area is dominated by open grasslands. Tinley (1977) classified these into short, medium and tall floodplain grasslands. The short grasslands

${ }^{6}$ Most of the background data that is presented for both sites is drawn from Ken Tinley's (1977) remarkable PhD thesis that was based in the Gorongosa - Marromeu region of northern Sofala Province. Where data are from a different source this source is identified. 
comprise communities dominated by Sporobolus spp. (particularly S. kentrophyllus and S. ioclados) on saline soils, and others dominated by the Cynodon dactylon and Digitaria swazilandensis lawns. The latter form the bulk of the floodplains on the south and northwest sides of Lake Urema. The medium grassland largely comprises two communities - one dominated by Setaria eylesii and the other by Echinachloa stagina. The tall grasslands are characterised by a Vetiveria nigritana community, which grows to $225 \mathrm{~cm}$ in height. These different grassland communities occur as a mosaic that grades into the savanna areas above the floodplain. Historically there would have been a large biomass and diversity of herbivores associated with these grasslands, but during and after the war of independence these populations were completely decimated. Only small populations of mostly smaller herbivores such as impala now occur in the Muaredzi area. There are however, infrequent visits to the area from hippopotami and elephants. Tinley also noted an aquatic community based on seasonally flooded pans in the flood plain.

Tinley identified six savanna woodland types growing on the rift valley floor:

1. Mixed savanna (Acacia, Albizia, Lonchocarpus, Piliostigma, Sclerocarya);

2. Marginal floodplain woodland (Acacia albida, Acacia xanthophloea);

3. Knobthorn savanna (Acacia nigrescens);

4. Sand savanna (Burkea africana, Terminalia sericea);

5. Mopane savanna ( Colophospermum mopane);

6. Palm savanna (Hyphaene benguellensis, Borasus aethiopica).

Tinley also identified four thicket types and two forest types from the valley floor area. All thicket types (riverine, alluvial fan, tree-base and termitaria thickets) appear to occur in the Muaredzi area, but the forest types appear to be absent.

Historically there would have been a great number of large herbivores (elephant, buffalo, hippopotamus, zebra, waterbuck), with approximately 50 hippo counted at the Muaredzi/ Urema confluence in the 1969 dry season, about the same number of zebra, and with well over 1000 buffalo and about 50 elephant in the area during the following wet season. These were virtually all eliminated, such that by 1994 there were hardly any large herbivores in the GNP at all (Cumming et al. 1994). Although the larger herbivores are slowly reappearing, without introductions, rebuilding the populations to their former levels will probably take decades.
The GNP maintains a ranger's post in the village, from where there is radio contact to their headquarters at Chitengo (although this was not always functional). An overriding concern of the Muaredzi community is that the GNP would like them to relocate to outside of the park area. The park has previously attempted to force them to move, and has made it clear that they would still like to pursue this. Villagers are adamant that they want to remain where they are.

Being situated within the national park, the village is exposed to wildlife. Elephant move within the village area and surrounds, and clearly do cause some destruction to crops. A number of smaller animals were also commonly seen within close proximity to the village, including nyala, impala, bushbuck, oribi, warthog and wildpig. Lake Urema is reported to harbour a healthy population of crocodiles, and hippos are also present.

Community members are permitted to fish on parts of Lake Urema, although the GNP staff regulates such activities. Fishing is carried out with gill nets placed within Lake Urema. These are serviced by means of dugout canoes. Canoes are launched from a designated point, situated some $6 \mathrm{~km}$ to the north of the village. Fish extracted from the nets are brought back to the launch point, where they are gutted and laid out to dry in the sun. From here they are carried by foot or bicycle, initially back to the village, and subsequently out to Muanza, where they can be sold. This appears to be one of the few ways that people have of earning money.

During the period of the study, the only other direct involvement of any NGO's within Muaredzi was that of a food for work programme, being run by the World Food Programme. The work involved clearing and repairing the western part of the track from Muaredzi towards Muanza.

We are aware of two previous studies that have been carried out within the village. One comprised a community study carried out by three psychology students over four weeks during 1997 (Costa and Vogt, 1998). The other comprised a fishing project, implemented by the GNP authorities, the aim of which was to establish a fishing cooperative in Muaredzi and increase returns from fishing activities (Zolho et al . 1998). This has subsequently collapsed, apparently due to poor management.

\section{B. Background to Nhanchururu}

The Nhanchururu site is situated astride the western boundary of GNP, some $15 \mathrm{~km}$ to the southeast of Gorongosa Mountain, and some $25 \mathrm{~km}$ northeast of Villa Gorongosa. It comprises 


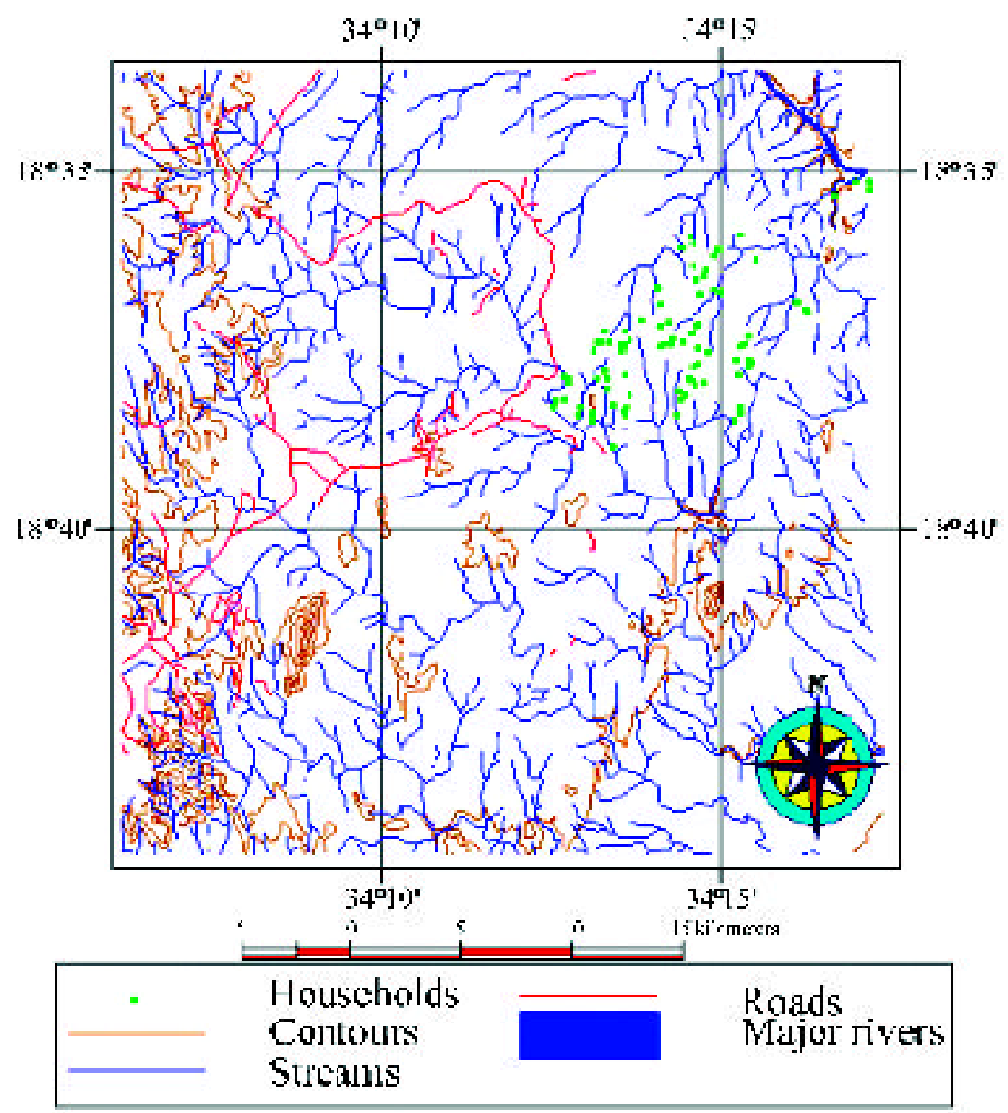

Figure 4. Nhanchururu study site showing the major rivers, $10 \mathrm{~m}$ contours and major routes from the village centre.

part of the Barue Plateau, the altitude of which varies between about 200 and 340 metres above sea level. The terrain is deeply dissected, with rivers draining south to the Mucodza River and north or north-east to the Vundudzi River ${ }^{7}$. The community is therefore on the upper portion of the rift escarpment, and on the watershed between the Mucodza and Vundudzi Rivers.

The rains fall for the most part in the hot wet season from November to April, with a mean annual rainfall of about $1,320 \mathrm{~mm}$ and a coefficient of variation of $26 \%$ (considerably lower than the $67 \%$ in the rift valley). The relative humidity varies from a mean of $63 \%$ in October to a mean of $78 \%$ in March. Evaporation was estimated to be between $37 \mathrm{~mm}$ in J une to 171 $\mathrm{mm}$ in December.

Geologically the area forms part of the Barue midlands, comprising eroding surfaces of granitic and migmatic gneiss of pre-Cambrian times. These

\footnotetext{
${ }^{7}$ There is some confusion over the naming of this river. Local people call it the Vunduzi but there is another Vunduzi river that runs south from Gorongosa Mountain to the Pungwe River. Tinley (1977) called this river that runs to the north of the Nhanchururu community the Vundudzi. We will use this latter name to avoid confusion with the river to the south.
}

rocks are of the oldest in the region and hence heavily weathered, yielding sandy soils that are generally infertile. The soils are largely shallow, brown granite-gneiss sands with pockets of hydromphic soils in the dambos along watercourses. Localised termitaria are important for local concentrations of nutrients in the otherwise base, and nitrogen, deficient soils.

The vegetation of the Nhanchururu area is largely miombo savanna woodland, but with some evergreen thickets on the deeper sands of the interfluve crests. The dominant woodland species are Brachystegia boehmii, B. spiciformis, Erythrophloeum africanum, Julbernardia globiflora, and Pterocarpus angolensis. There are some narrow patches of thick riverine forest along the Vundudzi and Mucodza Rivers but these are very limited in extent.

Following cultivation, a shrub thicket replaces the Brachystegia woodland, which then restores the limited soil fertility.

Wildlife populations in the region have always been low relative to the Rift valley, and characterised by limited dry-season movement of species from the rift valley up onto the escarpment for the new flush of leaf or water. There were previously a few elephant and some sable, but generally populations were low. 
Sketch maps drawn by community members provided more specific background data for Nhanchururu. The village area is roughly rectangular in shape, some $10 \mathrm{~km}$ south to north and some $8 \mathrm{~km}$ east to west (Figure 4). Nhanchururu is bounded to the east by the national park, to the west by Nhangeia village, to the south by Nhanthemba village and to the north by Safumira village. The boundaries with adjacent villages appear to be reasonably clear. These comprise the Mucodza river to the south, the Vunduzi river to the north and, to the west, a minor drainage called the Rio Nhachituzui.

To the east, the boundary between the village and the park is less clear. The community members were adamant that the entire village was outside of the park, and that the park started immediately to the east of the village, with the boundary being marked by a line of low hills and the small Rio Nhachiru. However, as one approaches the village along the main access road from the west, shortly after entering the village area one encounters an official sign stating that one is now entering Gorongosa National Park. According to this the bulk of the village falls within the national park. Regardless of this situation, the community members seemed to feel much more secure than the Muaredzi residents, and there was never any suggestion of fears that the park may in future attempt to move them.

Principal features included on the initial sketch map were five cemeteries; three churches; the primary school; the "local de julgamento" (the judgement tree where people gather to settle local disputes); the above mentioned Gorongosa National Park sign post; the fumos house; our meeting place; our camp; and the rangers post. Six internal drainages were also shown: three of these internal streams flow south to the Mucodza, and the other three drain north to the Vunduzi.

In terms of roads and maj or paths, the main access road follows the watershed between the Vunduzi and Mucodza rivers, bisecting the village into southern and northern portions. It leads through the village to the rangers post, and then continues east into the park (and in former times apparently all the way through to Chitengo). There were no other significant tracks to the east. To the south, there are two routes that cross the Mucodza River, both of which are located towards the western end of the village. One of these comprises a shortcut to Villa Gorongosa if travelling by foot or bicycle. As far as vehicles are concerned this route appears not to have been used for some time, is in a very poor state of repair, and the crossing over the Mucodza would not be passable until late into the dry season. To the west, in addition to the main access road, there is one other footpath that crosses the Rio Nhachituzui and continues to the neighbouring village. To the north there are a number of routes that lead off the main access road towards the Vunduzi river. Two of these reach to the Vunduzi, but neither of them appears to cross the river.

A total of 107 households were identified within the village, these being split roughly equally to either side of the main access road. Households tend to be scattered individually rather than clumped. Nhanchururu includes four fumos. Of these, Fumo Almeida appears to be the most influential, and the other three of lesser significance. The traditional ceremony was performed at Fumo Almeida's homestead, which is located at the eastern end of the village near the rangers' post. The responsible Regulo lives outside of the village to the south of the Mucodza River.

People were moved from the rift valley areas of Gorongosa National Park in the 1950's to the Barue plateau area, including what is now Nhanchururu. Further disruptions and movements occurred during the war for independence and the subsequent period of continued fighting.

Villagers reported the prior presence of two other non-governmental organizations. One of these was a logging company which apparently operated within the area from 1997-1998, and took out only mukwa (Pterocarpus angolensis) trees. Most of the village area appears to have been covered, and much evidence remains of their operations in the form of old tracks, tree stumps and felled logs. The area was reported to have been previously logged during the colonial period (1960-1970's).

The other organisation that was reported to have been operational within Nhanchururu was GTZ, who were reported to have run a project here during 1996-1998. Their activities included the construction of wells, construction of the primary school, and the promotion of agriculture including the introduction of new crops such as sunflower. 


\section{Community Landscape Valuation}

The primary thrust of the project was to develop a spatially explicit model of how community's value their local landscapes, and then to collect field information from the two study sites in order to refine, update and confront the model. Data collection and model development were mutually interactive and informing. The model wasinitially cast as a general understanding of landscape values and then made increasingly specific as field data were collected.

The modelling and data confrontations were carried out using Bayesian probabilities. Given this approach to probability, the mode of enquiry adopted was that of an iterative search for improved understanding. The process does not seek a true or false statement of the hypothesis as in the classical statistical sense, but rather to establish a degree of belief in the models. An added advantage of using the Bayesian approach to probability is that local, subjective estimates of probability are acceptable, whereas in the classical statistical paradigm subjective probabilities are not admissible evidence in any enquiry.

The general approach was to first develop an hypothesis of what were believed to be the crucial determinants of value of landscape units to community members. This formed the basis for development of an initial conceptual model, which in turn was used to guide the initial data collection. This data then informed changes in the structure and data content of the revised models, resulting in the development of "prior" models for each site. Additional field sampling was then carried out in order to produce real data with which to confront the models, and to further update them, thus resulting in the generation of final "posterior" models.

\section{A. Methods}

In this section the methods used in the collection and collation of information are described. The objective is to provide sufficient information that the reader can critically evaluate the results that are presented. Where methods are described in detail elsewhere, these references are provided and the methods descriptions are correspondingly brief.

\section{Initial conceptual model}

A preliminary conceptual model of the factors governing local valuation of landscape elements or units was presented to the CIFOR team in Harare in J anuary 2001. Based on the resulting discussions the model was refined and reformulated. A computer implementation of the conceptual model was subsequently developed using the software Netica (Norsys Software Corp www. norsys.com). The implementation was in the form of a Bayesian Belief Network (BBN). The model is seen as being a formalised state- 
ment of the TREP teams' prior understanding of the processes governing local valuation of landscapes.

\section{Spatial data management}

The model developed is spatially explicit, in the sense that it is designed to predict the value of a given location within either site relative to all other locations within that area. It was therefore, necessary to develop extensive spatial data sets for both sites, in order to provide the necessary data for spatial and probability analyses. The extent of the sample area for each site was selected on the basis of initial discussions with the Muaredzi community on how far they travelled to collect or use resources, together with subsequent discussions among the TREP team. For both sites this comprised a square, centred on the respective community, and $20 \mathrm{~km}$ on a side (giving a total sample area of $400 \mathrm{~km} 2$ for either site). These areas dictated the extent of the vegetation assessments and the development of spatial data sets for the two sites.

Topographic maps at 1:250,000 and 1:50,000 were obtained from the Mozambique government, and data sets were digitised within the $400 \mathrm{~km} 2$ area around either community. The 1:50,000 maps were based on rather old air photography of 1958 to 1960 . Additional data was obtained through field mapping using a number of handheld Garmin GPSs (using the WGS 84 datum). For both sites, the positions of households, and of all majoroads and paths, were recorded. The following data layers were developed for both sites:

1. Rivers and wetlands

2. Roads, paths and tracks

3. Contours (at $10 \mathrm{~m}$ intervals, from the $1: 50,000$ maps) and point heights

4. Settlements

The database was developed using the Microlmages Inc. , TNT-MIPS software (Version 6.5) that provided complete topology for all data.

Landsat 7 imagery (Scene 167/ 73, 22 August 1999) was procured for GNP, with the expectation that it could be used for both vegetation mapping and for community based mapping. However, the imagery received was of poor quality, with considerable cloud cover over the Muaredzi area, and was found to be unsuitable for community mapping of land types.

\section{Community information collection}

The same approach was followed for both sites, this being to first hold a traditional ceremony; then to hold an open community meeting; to select a representative group of community informants (community resource use assessment team, or CRUAT); to establish a modus operandi with the informant group and, thereafter, to proceed with the process of data collection. For Muaredzi this was achieved over a series of three field trips (September 2001, November 2001, and April 2002). For Nhanchururu the traditional ceremony was held in April 2002, and the remainder of the activities and collection of community livelihood data were carried out during a single field trip in May 2002.

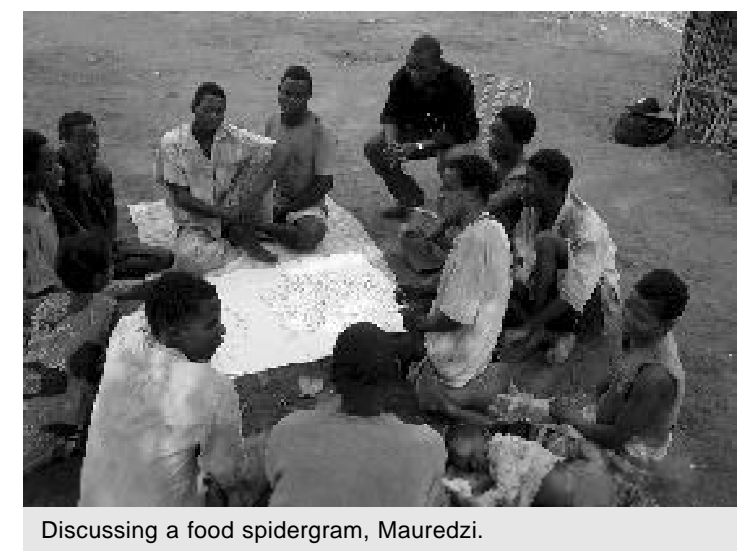

The holding of a traditional ceremony prior to the initiation of any new activity is customary within the rural areas of this part of Mozambique. The ceremony is performed by the local traditional leadership. Our role was limited to the provision of necessary items, as stipulated by the respective communities.

The initial community meetings provided opportunity to explain the aims and needs of the project to those present. The community members were told that the project sought an improved understanding of household and community livelihoods. It was also explained that we wished to work with a limited group of informants, and that these informants should be representative of the major socio-economic groups within the community. These representatives would form the CRUAT.

At Muaredzi this initial meeting was attended by some 38 villagers ( 28 men and 10 women), including the principal Fumos of the two villages within Muaredzi. For Nhanchururu the group comprised 42 community members, all of whom were men, and again including two Fumos.

At either site the nature and conditions of involvement with the project were explained, and then the assembled group was asked to nominate people to form the CRUAT. The initial response for both sites was that the community tradition was to ask for volunteers. For Muaredzi, this was done on the basis of a simple scoring activity that 
identified the relative frequency of households in each of three household categories (old people, younger people and widows - Table 1).

Table 1. Perceived proportions of households in three socio-economic categories in Muaredzi as identified by community members in a public meeting.

\begin{tabular}{lcc}
$\begin{array}{l}\text { Socio-economic } \\
\text { category }\end{array}$ & $\begin{array}{l}\text { Community } \\
\text { score }\end{array}$ & $\begin{array}{c}\% \text { of } \\
\text { households }\end{array}$ \\
\hline $\begin{array}{l}\text { Households headed } \\
\text { by older men }\end{array}$ & 3 & 20 \\
$\begin{array}{l}\text { Households headed } \\
\text { by younger men }\end{array}$ & 8 & 53 \\
$\begin{array}{l}\text { Households headed } \\
\text { by widows }\end{array}$ & 4 & 27 \\
\hline
\end{tabular}

The distribution of the above yielded only $27 \%$ women. As a general principle the approach developed for working with local communities (Lynam, 2001) has been to seek an equal representation of men and women in such CRUAT groups. The younger male group was therefore asked if half of them would send their wives instead. This would have been problematic for some households, so it was agreed that the three younger men that volunteered to send their wives could both send their wives and attend the workshop themselves. This resulted in a final group of 22 informants, comprising 14 men and 8 women.

A similar process was followed for Nhanchururu. The resulting group size there was 18 informants, comprising 10 men and 8 women, including 3 older men and one older women.

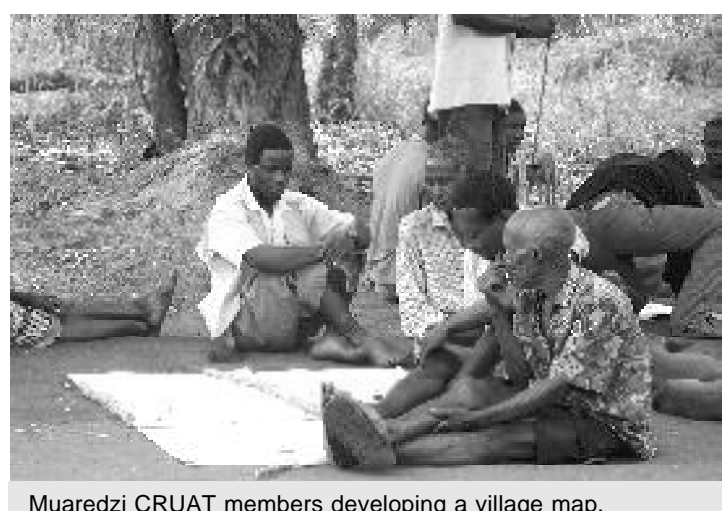

It was emphasised to CRUAT members that they would have the dual responsibilities of both providing information on resource use and livelihoods within the village, and also for reporting back to the community about the project and the exercises that we were doing.

The CRUATs for both study sites agreed to work for six hours per day. For Muaredzi, the group initially met each day from 8:00 until 12:00 and then again from 14:00 to 16:00. On subsequent trips the CRUAT insisted on a single session last- ing from 7:00 to 13:00. The Nhanchururu informants also chose to work from 7:00 to 13: 00 .

CRUAT members were paid a small daily allowance for their input into the project, amounting to about US\$ 1.30 for Muaredzi and US\$1.50 for Nhanchururu. These amounts were arrived at through discussion and agreement with the CRUAT members.

Group meetings were conducted in three different languages: English, Portuguese and Sena. The translation back and forth between these languages took time. For the first two trips to Muaredzi the process was crucially dependent on the single Portuguese - Sena translator (Mr. Camissa) and the single Portuguese - English translator (Mr. J ujuman). For the remaining trips Mr. J uj uman was replaced by three other translators/ facilitators, two of whom could translate from Portugese to English, and all three from Portugese to Sena.

Three basic tools were used for the analysis that was conducted - spidergrams, sketch mapping and open discussion. As each of these have been described in detail elsewhere (Lynam, 2001) they will not be described here.

\section{Refinement of the model}

Information obtained from the CRUATs was subsequently used to shape and update the model for both study sites. In particular, this enabled the detailing of both goods and services and also cost functions for each site, and the assignment of relative weights to each of these factors. The result was the development of specific prior models for either site. These models were thereby at a stage whereby through inputting information regarding the status of each of the peripheral nodes (goods and services and cost functions) for a particular point location, the model would provide an estimate of the most probable value for that location.

\section{Field sampling for model confrontation}

The final step in terms of collection of field data was to carry out a sampling process, in order to generate field data with which to confront the model, and to provide the basis for further refinement and updating of the model. The general approach was to visit a number of locations within each village, together with CRUAT members and, for each site, to record their scores for each of the goods and services present at the site, for all cost factors, and then an overall landscape value. The scores for goods and services and for cost factors were subsequently fed into the model, based on which 
the model generated an estimated value for each sample. These estimates were then compared against the CRUAT values for each sample.

The sampling procedure was tested at Muaredzi during April 2002, after which it was modified and refined. Sampling for both sites was carried out over a single field trip during J uly 2002. In order to increase the number of samples possible within the available time, the CRUAT group at each site was split into three or four subgroups. Each subgroup comprised several community members, plus a data recorder (facilitator). For Muaredzi, each subgroup comprised two men and four women, whilst for Nhanchururu the subgroup composition was two men and two women.

Sampling was done along line transects. Each subgroup would cover a single transect per day. The placement of transects was selected on the basis of providing overall coverage of each village area, coupled with logistical constraints, notably the existence of potential access paths and roads, (the start and end points for each transect needed to be accessible by path or road). The length of transects was decided according to the estimated time available for sampling i.e. total working time of six hours per day, less time required to travel to the starting point and to return from the end point. Lengths varied from about $1.5 \mathrm{~km}$ to
$4.5 \mathrm{~km}$. The sampling interval and number of samples per transect were decided in the field, once at the starting point for the transect, and were based on the estimated time available for sampling and the time it was likely to take to traverse the transect. Sampling intervals ranged from about 250 to $600 \mathrm{~m}$ and the number of samples per transect from 4 to 12 .

The placement of transects was decided so as to cover the principal land types within each area, and all different combinations of distances along paths and off paths (since the prior versions of the model had shown a high sensitivity to these parameters). Actual positions were first selected on satellite imagery. Thereafter, the co-ordinates of the start and end points were read off the GIS maps and entered into GPS's. Each day, the recorder for each group would be given a GPS within which the start and end points for that day's transect had been entered. The group would then move to the start point and do their first sample. Thereafter, they would use the GPS "Goto" function, to move directly towards the designated end point, recording additional samples at the agreed sample interval. In practice, recorders were required to use their personal judgement, if necessary, to modify their planned sampling procedure according to their

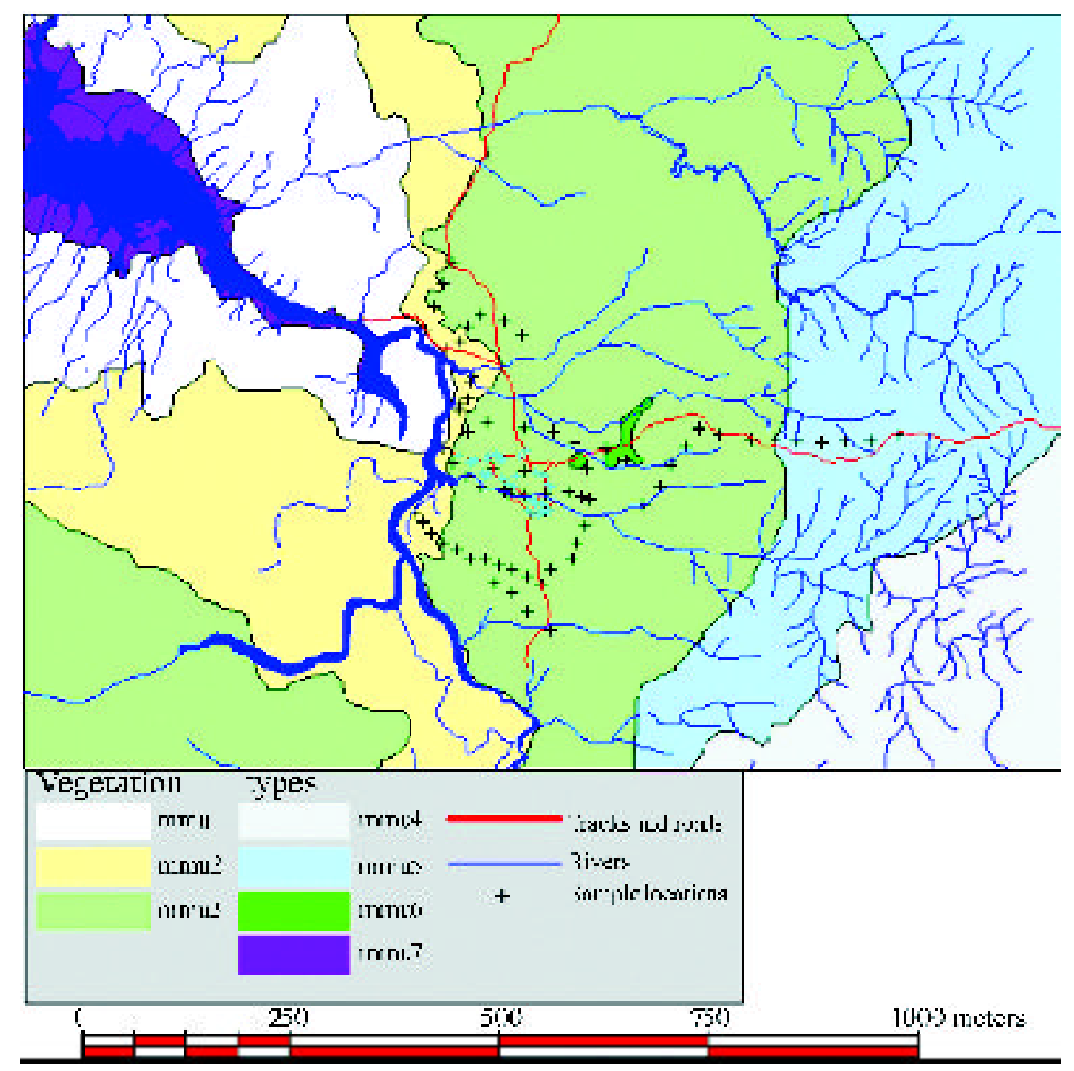

Figure 5. Positioning of samples for Muaredzi area superimposed on the vegetation map. 
rate of progress and distance to be covered for that day.

Sample size was taken as being a circle, roughly $30 \mathrm{~m}$ in radius (i.e. 0.28 ha in extent). The group would arrive at a sample point, and then score the necessary factors based on consideration of the resources and cost factors apparent within a $30 \mathrm{~m}$ radius. Sample areas were not systematically searched either prior to, or during, the scoring.

Individual data sheets were developed for Muaredzi and Nhanchururu to reflect the specific goods and services and cost factors for either site. Copies of these are attached in Appendix 1 . The first section comprises basic information such as the sample number, location, date, recorder, GPS co-ordinates, land type, soil type and vegetation type (forest, woodland, grassland or field). This is followed by a listing of goods and services and cost factors, each of which was rated under four possible categories (for goods and services: good, moderate, poor or none; for cost factors: high, moderate, low or none; and for distances: very far, far, close or very close). Following this an overall landscape value for the site was recorded, plus notes as to why this score was being given. The purpose of the notes was to provide a check to make sure that informants were not being unduly influenced by other factors not already captured on the data sheets.

Scoring of landscape values was open ended, and relative to the least important locality within the village area, which was allocated a value of one point. For either site, the reference point of lowest value was identified at the outset of the sampling process, and by the entire CRUAT group together. For Muaredzi, the CRUAT identified a certain occurrence of chipale, known as Nteca, as being the site of lowest value. For Nhanchururu, the CRUAT identified a certain range of hills within the national park area, as being the lowest value. CRUAT members reported being familiar with these sites, and the types of resources to be found there. However, in neither case had all the informants, particularly the women, ever been to these places, and nor were they visited as part of this exercise.

At the outset of the sampling process, for both sites, the sampling procedure was first discussed with the entire CRUAT group. Thereafter, several samples were completed either with the combined group or several subgroups, following which the results were presented to and discussed with the whole group. For Muaredzi, at the start of each day before setting off to sample, each subgroup first presented and discussed their results from the previous day to the combined CRUAT group. For Nhanchururu, there was no reporting back by subgroups to the main CRUAT group.

For Muaredzi, a total of 75 samples were recorded from 10 transects, over a three day period (Figure 5). For Nhanchururu, 82 samples were obtained from 13 transects, recorded over seven days (Figure 6). The lower rate of sampling for

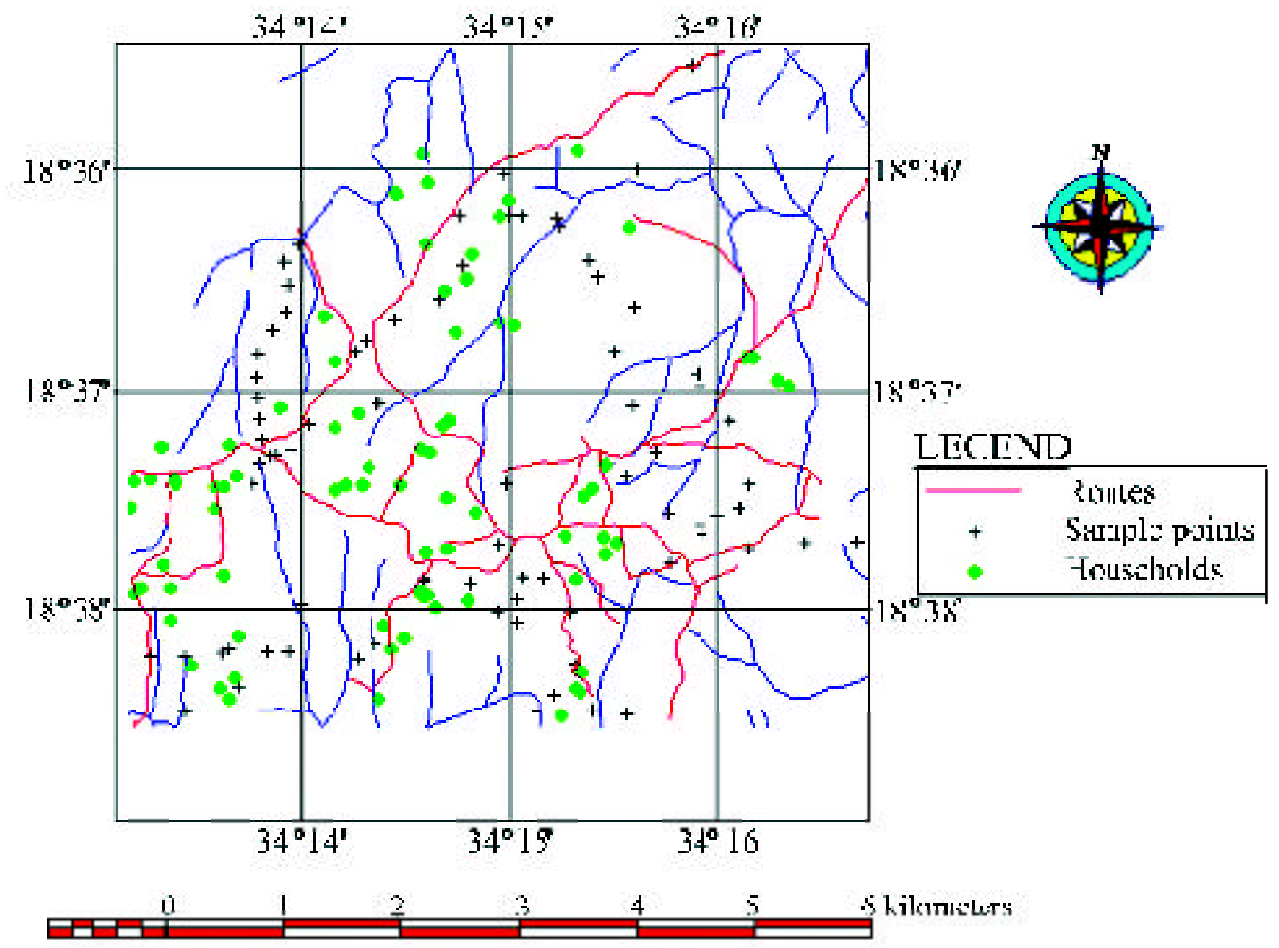

Figure 6. Positioning of samples for Nhanchururu area 
Nhanchururu as compared to Muaredzi was a result of starting here and being less familiar with the procedure; of the more difficult (broken and hilly) terrain; and of disruptions due to rain.

\section{Updating the models}

Field sample data was subsequently entered onto a spreadsheet to form a case file for each site. Each case file consisted of the total number of samples ( 75 for Muaredzi and 82 for Nhanchururu), with each sample having scores for all goods and services and for all cost factors. Based on this data, the model generated estimated landscape values for each sample location. These values were then compared against the values given for each sample by the CRUAT members.

The case files were then used to confront the models for each site. In each case the models were first confronted with the data in the case files, and the same case files were then used to update the probability structure of the model. The resulting (posterior) models were subsequently used to explore the sensitivity of the models to the collection of further information for each node, and also to explore the implications of the understanding gained for land use planning and policy decision making.

\section{B. Results and discussion}

In this section the field results obtained from the Muaredzi and Nhanchururu CRUATs are described, together with the various versions of the models. The presentation begins with a description of the initial conceptual model and the first computer implementations of the model (Section II.B.1). Presentations of the community assessment results then follow (Sections II.B. 2 and II. B. 3). Based on these results it was possible to update and refine the models for both sites, resulting in the formulation of the prior models. Results of the subsequent field sampling exercise, together with the updated posterior models, are presented in Section II.B.4. The final section provides comparisons between the community landscape valuations and the estimated values from the model (Section II. B. 5).

\section{Initial conceptual model}

In the initial model the value of a landscape unit to a local community member was expressed as a simple ratio of benefits to costs (i.e. benefits divided by costs - B/ C - Figure 7). Thus the larger the $B / C$ ratio the more valuable the landscape unit or location was expected to be. The benefit side of the model was defined as a function of three inputs: i) the relative importance or pref- erence for each of the goods and services (GS) derived from a given landscape unit or location; ii) the number of such GS; and iii) by the density of GS per unit area in the landscape unit. Thus the gross benefit derived from a unit of the landscape was a simple weighted sum of the importance value and density across all GS (Equation 1).

$$
B ? \stackrel{?}{i ? 1}^{n}\left(P_{i} * D_{i}\right) \quad \text { Equation } 1 .
$$

Where:

$B=$ the total, gross benefit derived from a landscape unit or element;

$\mathrm{P}_{\mathrm{i}}=$ the preference weighting (RIW) for the ith good or service;

$D_{i}=$ the density of the ith good or service, where density ranges between 0 (none) and 1 (very high).

The cost component of the model was deemed to be a function of three major cost sources. Firstly, the distance travelled to obtain the good or service, where this distance was the weighted sum of distances along major routes and distances off-routes (Figure 7). Clearly the off-route distances would be more costly. The second cost source were physical barriers such as rivers, wetlands or steep terrain. The third cost contributing source comprised the institutional barriers or rules and regulations governing access to a given resource or landscape unit. Clearly this latter group was complicated by the elements associated with institutional costs - in the context of this project the probability of transgressions being discovered and then the associated fine or punishment for deviations. This was simplified in the model to reflect only an opportunity cost associated with regulations - the value of the resource use opportunities forgone due to the regulations.

The conceptual model (Figure 7) defined the TREP team' s expectations of the determinants of landscape value. Explicitly the expectations derived from the model were that the value of landscapes would be highest where there were high value, multiple goods and services that were not governed by limiting institutions, which were close to the household or community, and where there were no barriers impeding access. Low value landscape units or locations would occur under the reverse conditions. Clearly there would be a range of intermediate $\mathrm{B} / \mathrm{C}$ states in between. Confrontation of the model would require that the TREP team undertake the following steps:

1. Identify the GS deemed useful or valuable by the community and their relative importance or preference for each; 
Importance

value 
implements, clothes, sewing machines, blankets, furniture, mosquito nets, beds), and a football for recreation. The two institutional components (rules and traditions and local leaders) were only added after prompting. There is good general correspondence between these needs and those identified previously by Costa and Vogt (1998).

Table 2. Goods or services that make up the set of basic needs required by an average household living an adequate quality of life in Muaredzi. Importance scores reflect the relative importance of each good or service to achieving this standard of living. All scores are relative to the least important factor (football).

\begin{tabular}{lccc} 
Basic needs & RIW & RIWS & RIWC \\
\hline School & 35 & 0.098 & 0.098 \\
Food & 28 & 0.078 & 0.176 \\
Water & 27 & 0.075 & 0.251 \\
Agricultural tools & 20 & 0.056 & 0.307 \\
Work & 20 & 0.056 & 0.363 \\
Traditions and rules & 19 & 0.053 & 0.416 \\
Shops & 18 & 0.050 & 0.466 \\
Equipment for fishing & 18 & 0.050 & 0.517 \\
Tin sheets for roofs & 16 & 0.045 & 0.561 \\
Market & 16 & 0.045 & 0.606 \\
Fish & 15 & 0.042 & 0.648 \\
Livestock & 15 & 0.042 & 0.690 \\
Household implements & 15 & 0.042 & 0.732 \\
Hospital & 13 & 0.036 & 0.768 \\
Tractor for ploughing & 12 & 0.034 & 0.802 \\
Grinding mill & 11 & 0.031 & 0.832 \\
Seeds & 10 & 0.028 & 0.860 \\
Clothes & 10 & 0.028 & 0.888 \\
Local leaders & 8 & 0.022 & 0.911 \\
Transport (to Mwanza) & 7 & 0.020 & 0.930 \\
Sewing machines & 5 & 0.014 & 0.944 \\
Household bedding & 4 & 0.011 & 0.955 \\
Household furniture & 4 & 0.011 & 0.966 \\
Borehole & 3 & 0.008 & 0.975 \\
Mosquito nets & 2 & 0.006 & 0.980 \\
Bed and mattress & 2 & 0.006 & 0.986 \\
Bakery & 2 & 0.006 & 0.992 \\
Saws & 2 & 0.006 & 0.997 \\
Football & 1 & 0.003 & 1.000 \\
\hline Totals & 358 & 1.000 & 1.000 \\
\hline Rw (Reative & & &
\end{tabular}

RIW (Relative Importance Weight)

RIW S (Standardised RIW)

RIWC (Cumulative Standardised RIW)

Food sources. Food was rated as being the second most important need, after that of a school (Table 2). The group was therefore asked to identify "What are the main sources of food for households within Muaredzi?" Three main sources were identified: cultivated products, wild fruit, and other forest products. There appeared to be some initial confusion as to whether the question was to identify main types of food, or just those produced or collected locally from the environment, as opposed to those brought in from outside. This was resolved by adding a fourth group comprising imported foods.

Each of the three local food sources was then explored individually. For each class of food the question was posed "What are the most important sources of this type of food within Muaredzi?" A total of 39 food crops were identified. The five most important types were all starches (sorghum, maize, rice, millet, casava) and collectively accounted for $37 \%$ of the total importance mass. Sweet potato, three types of beans, and a squash together made up a further $18 \%$ of the total importance mass, with the remaining $45 \%$ being split among the other 29 products.

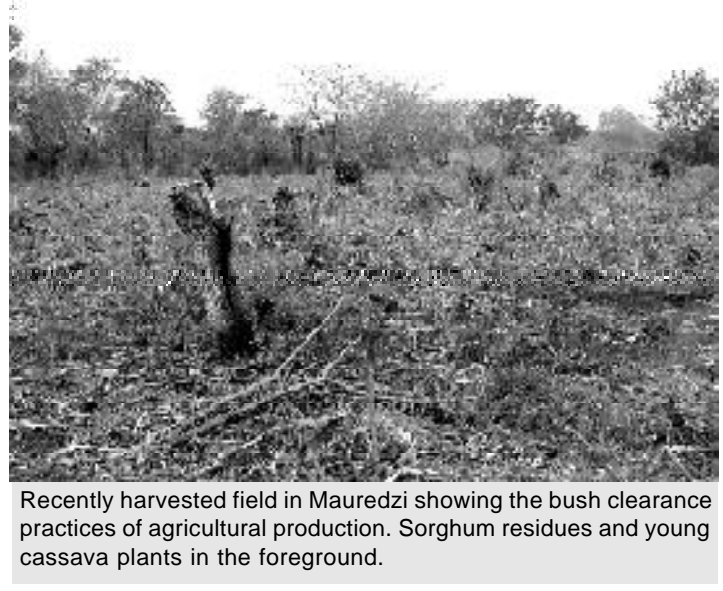

Excluding wild fruit, a total of 41 forest products were identified as food sources. The principal products included grains, tubers, honey, salt, oil, vegetables (leaves) and insects. A total of 25 wild fruits were identified. The top ten fruits collectively accounted for $67 \%$ of the overall importance mass.

Following from these results, an attempt was made to establish the relative importance of the different sources of food, and under different circumstances. Before doing this, a fourth food category was added, comprising purchased food items. The initial question asked was "How important are the different types of food to an average household within Muaredzi achieving an adequate supply of food?" A bounded scoring approach was used, with five points being allocated for each of the four types, giving a total of 20 points. Crops were identified as being the most important food source (8 points) followed by forest products ( 6 points), while purchased foods ( 4 points) and wild fruit ( 2 points) were considered less important.

The CRUAT was then asked whether these scores al ways remained the same, or whether they could identify any conditions under which these scores were likely to change. Two possibilities were identified - conditions of drought and floods. In order to get people thinking about 
these conditions, they were first asked to list such years, working back from the present. Five drought years (1994, 1993, 1988, 1987 and 1977 ) and four flood years (2001, 1996, 1992, 1989) were identified during the previous 25 years. These data should not be considered particularly reliable, as discussion was curtailed concerning the relative intensities of such events and as to what should or should not be considered a drought or flood year. The purpose of this exercise was merely to get people thinking about such conditions. During both drought and flood years it was reported that food crops become less important, and people rely more heavily on purchases and forest products (both wild fruits and other forest products, Table 3 ).

Table 3. Perceived relative importance of different sources of food within Muaredzi, to Muaredzi households, under normal conditions, drought and flood conditions. A bounded scoring approach was used, with an allocation of five points per factor, giving an overall total of 20 points for each set of circumstances.

\begin{tabular}{lccc}
$\begin{array}{l}\text { Source } \\
\text { of food }\end{array}$ & $\begin{array}{l}\text { Normal } \\
\text { conditions }\end{array}$ & $\begin{array}{c}\text { Drought } \\
\text { years }\end{array}$ & $\begin{array}{c}\text { Flood } \\
\text { years }^{\mathbf{2}}\end{array}$ \\
\hline Fields & 8 & 2 & 2 \\
Forest Products & 6 & 7 & 4 \\
Purchased & 4 & 8 & 8 \\
Wild Fruit & 2 & 3 & 6 \\
\hline Total & 20 & 20 & 20 \\
\hline
\end{tabular}

${ }^{1}$ Drought years: 1994, 1993, 1988, 1987, 1977

${ }^{2}$ Flood years: 2001, 1996, 1992, 1989

Livelihood activities. CRUAT members were asked to identify activities engaged in by households in Muaredzi in order to satisfy their basic needs. The group identified 16 such activities (Table 4). These equate to components of their livelihood systems. Over $70 \%$ of the identified importance mass was associated with agriculture, grinding meal, house construction, well digging and fishing. Surprisingly, fishing, which appeared to be a major community activity, was not scored more highly. The dominant livelihood activities cast this community as largely a subsistence production community, with food needs largely being met from agricultural production and to a lesser extent fishing.

Overall goods and services. At a later stage, after having thought in some detail as to the types of goods and services associated with different types of land, and also of the relative importance of these different factors, the CRUAT group was asked to draw up a composite list of all goods and services. The relative importance of each of these was scored as regards its contribution towards an average family within Muaredzi living an adequate life. These results are presented in Table 5. The most important factors came out as water and agriculture, together accounting for one third of the overall importance mass. Construction materials, firewood, fish, the selling of excess agricultural produce, and grinding sticks/ stones, accounted for a further $46 \%$ of the importance mass. The remaining seven resources were considered to be of lesser importance, collectively accounting for the final $25 \%$ of the importance mass. Two other resources that could have been added to the listing, but were not considered, are artefacts and fishing materials. The identification of good and services and their relative scoring is largely consistent with results obtained previously concerning livelihood activities. The most dramatic change is for firewood, but this results largely through a change in emphasis from the selling of firewood to home consumption.

Table 4. Activities that households in Muaredzi undertake as part of their livelihood systems. Scores reflect the relative importance of each activity to household well being. All scores are relative to the least important activity (selling firewood).

\begin{tabular}{lccc} 
Activity & RIW & RIWS & RIWC \\
\hline Agriculture & 20 & 0.164 & 0.164 \\
Making grinding sticks & 18 & 0.148 & 0.311 \\
House construction & 16 & 0.131 & 0.443 \\
Digging wells & 12 & 0.098 & 0.541 \\
Grinding meal with pestle & 11 & 0.090 & 0.631 \\
and mortar & & & \\
Fishing & 10 & 0.082 & 0.713 \\
Sales of food surpluses & 7 & 0.057 & 0.770 \\
Traditional medicines & 6 & 0.049 & 0.820 \\
Grinding meal with stones & 5 & 0.041 & 0.861 \\
Making clay pots & 4 & 0.033 & 0.893 \\
Bee keeping & 3 & 0.025 & 0.918 \\
Making palm leaf products & 3 & 0.025 & 0.943 \\
Wild fruit collection & 2 & 0.016 & 0.959 \\
Bartering & 2 & 0.016 & 0.975 \\
Production of palm wine & 2 & 0.016 & 0.992 \\
Selling firewood & 1 & 0.008 & 1.000 \\
\hline Total & 122 & 1.000 & 1.000 \\
\hline
\end{tabular}

Table 5. Final set of goods and services that were identified by Muaredzi CRUAT. Standardised RIW used in the BBN.

\begin{tabular}{lccc} 
Final goods and services & RIW & RIWS & RIWC \\
\hline Water & 20 & 0.163 & 0.163 \\
Agriculture & 20 & 0.163 & 0.325 \\
Construction materials & 16 & 0.130 & 0.455 \\
Firewood & 15 & 0.122 & 0.577 \\
Fish & 13 & 0.106 & 0.683 \\
Grinding sticks/ stones & 10 & 0.081 & 0.764 \\
Clay products & 8 & 0.065 & 0.829 \\
Palm leaf products & 6 & 0.049 & 0.878 \\
Palm wine & 5 & 0.041 & 0.919 \\
Honey & 4 & 0.033 & 0.951 \\
Medicine & 3 & 0.024 & 0.976 \\
Wild foods & 2 & 0.016 & 0.992 \\
Wild fruits & 1 & 0.008 & 1.000 \\
\hline Totals & 123 & 1.000 & 1.000 \\
\hline
\end{tabular}




\section{b) Muaredzi land types}

During the first data collection field trip the CRUAT was asked "What types of land are found in this area?" After considerable discussion a total of eight land types were identified (gombe, madimba, thando, planicie, chipale, nsitu, planalto and murmuchea - Appendix 2), and these were subsequently scored in terms of relative importance. During the second data collection trip the discussion concerning land types was restarted by posing the following question: "Are you satisfied that these eight land types are an accurate reflection for Muaredzi Village?" After lengthy debate, it was proposed that three categories should be done away with. Chipale (bare ground) was lumped together with nsitu (forest), as these were considered to always occur in association with one another; thando (floodplain) was merged with planicie (plains) due to difficulties in separating these from one another; and madimba (dry season cropping areas) was included with gombe (areas with water). Planalto (uplands) and murmuchea (termite mounds) were retained unchanged. Some of the aspects that came up during the discussion were whether gombe should be split into lakes, rivers etc; the possibility of including specific soil types as discrete land units; and where the different types are found.

The group was then asked to score the resulting five types in terms of importance and abundance (Table 6). Importance ratings were similar to those obtained on the previous field trip, particularly for gombe/madimba (high), and murmuchea and planalto (both low). Nsitu received a somewhat higher relative rating than before. The greatest discrepancy was the markedly lower rating for planicie/ thando. This score of 4 points seems unrealistic given that it was later revealed that all homesteads and machambas (fields) are located within planicie, and that more goods and services are derived from planicie than from any of the other land types.

Two scoring exercises were carried out to establish local perceptions of the relative abundance of land types within Muaredzi (Table 7). Initially the CRUAT members were asked to score the abundance of the five composite types as identified above. Surprisingly, murmuchea was considered to be the most abundant land type ( 9 points). When queried, the CRUAT remained adamant about this rating, on the basis that termite mounds were common in planicie, nsitu and planalto. Planicie/ thando, gombe/ madimba and nsitu/chipale were considered to of similar abundance $(6,5$ and 4 points respectively). The low abundance of planalto (1 point) suggests that people were taking a relatively limited perspective of the village area, and
Table 6. Importance of principal land types found within the Muaredzi area, according to their contribution towards satisfying the basic needs for an average family within Muaredzi village. Two scoring exercises were carried out during separate field trips, but which were based on different baskets of land types. For both exercises a bounded scoring approach was used, with an allocation of five points per land type.

\begin{tabular}{|c|c|c|c|}
\hline \multirow{2}{*}{$\begin{array}{l}\text { Local } \\
\text { description }\end{array}$} & \multirow[b]{2}{*}{ Land type } & \multicolumn{2}{|c|}{ RIW } \\
\hline & & $1 \mathrm{ft} *$ & $2 \mathrm{ft}$ \\
\hline Gombe & Wet areas & 8 & - \\
\hline Madimba & Dry season crop areas & s 8 & - \\
\hline $\begin{array}{l}\text { Gombe } \\
\text { (+Madimba) }\end{array}$ & $\begin{array}{l}\text { Wet areas plus } \\
\text { adjacent dry season } \\
\text { crop areas }\end{array}$ & (16) & 10 \\
\hline Nsitu & Forests & 6 & - \\
\hline Chipale & Bare areas & 1 & - \\
\hline Nsitu (+Chipale) & $\begin{array}{l}\text { Forests plus } \\
\text { accompanying bare } \\
\text { areas }\end{array}$ & (7) & 7 \\
\hline Planicie & Lowlands & 8 & - \\
\hline Thando & $\begin{array}{l}\text { Seasonally flooded } \\
\text { areas }\end{array}$ & 3 & - \\
\hline Planicie (+Thando) & $\begin{array}{l}\text { Lowlands including } \\
\text { areas of seasonal } \\
\text { flooding }\end{array}$ & (11) & 4 \\
\hline Murmuchea & Termite mounds & 4 & 3 \\
\hline Planalto & Upland areas & 2 & 1 \\
\hline Total & & 40 & 25 \\
\hline
\end{tabular}

* Scores in parentheses are the sums of the scores of the aggregated land types.

RIW (Relative Importance Weight)

lft (First field trip)

2ft (Second field trip)

which is perhaps linked to the fact that relatively few goods and services appear to be derived from the planalto area.

The second scoring exercise was carried out the following day, after completion of a sketch map of land types (see below). This time the basket of types comprised the six elements that were mapped as discrete units. Murmuchea were excluded on the basis that it was not possible to map their occurrence. The maj or differences as compared to the previous scoring were the considerably higher ratings for both planicie/ thando (together 12 points) and the upland planalto areas (8 points). Ratings for gombe/ madimba and nsitu/ chipale remained much the same. This second lot of abundance scores is probably a more realistic reflection of the actual situation, particularly in that it was carried out after the land unit mapping exercise, which had necessitated considerable thought as to the occurrence and distribution of the various types.

Mapping of land types. A subgroup was tasked with drawing a sketch map to show the occurrence of the various land types within Muaredzi. As a first step the group sketched in a basic reference 
Table 7. Abundance of the principal land types found within the Muaredzi area. Two scoring exercises were carried out, on different days and including different combinations of land types. In both cases a bounded scoring approach was used, with an allocation of five points per land type.

\begin{tabular}{|c|c|c|c|}
\hline $\begin{array}{l}\text { Local } \\
\text { description }\end{array}$ & Land type & $\begin{array}{l}\text { ndance } \\
\text { //10/01 }\end{array}$ & $\begin{array}{r}\text { Abundance } \\
01 / 11 / 01^{*}\end{array}$ \\
\hline Murmuchea & Termite mounds & 9 & - \\
\hline $\begin{array}{l}\text { Planicie/ } \\
\text { Thando }\end{array}$ & $\begin{array}{l}\text { Lowlands including } \\
\text { areas of seasonal } \\
\text { flooding }\end{array}$ & 6 & (12) \\
\hline Planicie & Lowlands & - & 7 \\
\hline Thando & $\begin{array}{l}\text { Seasonally } \\
\text { flooded areas }\end{array}$ & - & 5 \\
\hline $\begin{array}{l}\text { Gombe/ } \\
\text { Madimba }\end{array}$ & $\begin{array}{l}\text { Wet areas plus } \\
\text { adjacent dry } \\
\text { season crop areas }\end{array}$ & 5 & (6) \\
\hline Gombe & Wet areas & - & 5 \\
\hline Madimba & Dry season crop are & eas- & 1 \\
\hline $\begin{array}{l}\text { Nsitu/ } \\
\text { Chipale }\end{array}$ & $\begin{array}{l}\text { Forest plus } \\
\text { accompanying bare } \\
\text { areas }\end{array}$ & 4 & 4 \\
\hline Planalto & Upland areas & 1 & 8 \\
\hline Total & & 25 & 30 \\
\hline
\end{tabular}

* Scores in parentheses reflect the sum of the aggregated groups.

frame for the village. This comprised the Urema and Muaredzi rivers; the main Beira-Inhaminga road and the access road from Muanza to Muaredzi; and secondary routes from the crossing point on the Urema (J angada) to the Beira road (Estrada Milha Cinco, no longer in use), and from Goinha (Muanza Baixo) to Muaredzi (Estrada Muanza Baixo), and continuing across to Estrada Milha Cinco (although again the portion to the south of the main Muanza access road is no longer in use).

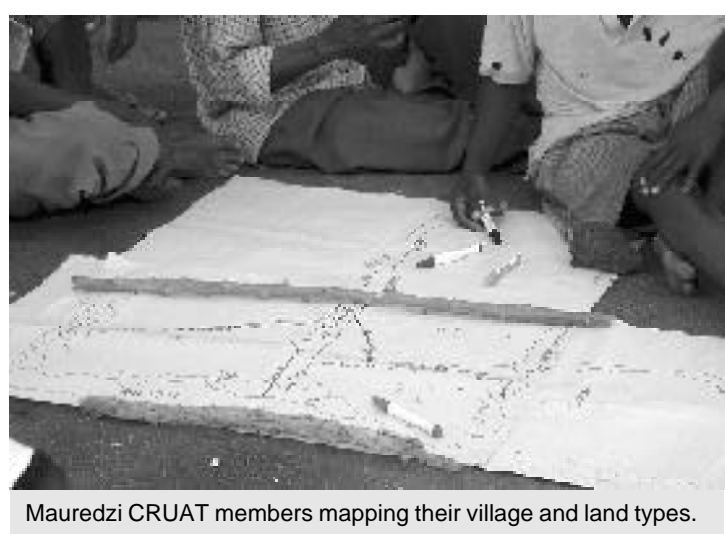

The initial depiction of land types was of planalto and planicie, with the boundary between these being drawn along the Estrada Muanza Baixo. Next the Urema and Muaredzi rivers were labeled as gombe. Madimba was subsequently depicted as a narrow strip alongside these. Nsitu was then separated out from the planalto, as a strip occurring to the east of the Estrada Muanza Baixo. It was not considered feasible to map chipale, as this occurs as small scattered patches in association with the nsitu forest areas. After some discussion it was decided to separate thando from planicie. This was depicted as a strip separating the Urema river and the planicie, although it was explained that in reality this was much less regular, being thicker in some areas and thinner in others. It was not possible to map the occurrence of murmuchea, but these were indicated generally as occurring throughout the planalto, nsitu and planicie.

Goods and services by land types. Two complementary approaches were adopted as regards the identification of goods and services obtained from different land types. One subgroup was tasked with identifying the goods and services derived from each land type, one at a time. For each type, the resources were then scored, on the basis of their contribution to an average family within Muaredzi leading an adequate life. This resulted in the generation of six spidergrams one each for planalto, nsitu, planicie, thando, gombe and murmuchea (Table 8). Chipale, for this exercise, was considered as part of nsitu, whilst madimba was included together with gombe.

Table 8. Summary table of goods and services derived from different land types within Muaredzi village.

\begin{tabular}{lrcrc} 
Land Type & $\begin{array}{c}\text { No. of } \\
\text { G/S }\end{array}$ & $\begin{array}{c}\text { No. of G/S } \\
\text { once aggregated }\end{array}$ & $\begin{array}{c}\text { Highest } \\
\text { score }\end{array}$ & $\begin{array}{c}\text { Total } \\
\text { score }\end{array}$ \\
\hline Planalto & 8 & 4 & 8 & 23 \\
Nsitu & 12 & 5 & 10 & 59 \\
Planicie & 28 & 9 & 10 & 56 \\
Thando & 5 & 4 & 8 & 24 \\
Gombe & 9 & 6 & 20 & 75 \\
Murmuchea & 7 & 3 & 11 & 48 \\
\hline
\end{tabular}

There was some confusion as to potential goods and services versus those that are actually obtained from a particular type. For example, planalto was identified as being suitable for particular crops, but on subsequent questioning it was confirmed that although this is the case elsewhere, no cultivation of planalto land is carried out within the village. Also, for some land types, considerable effort was put into generating long lists of particular goods, such as different types of crops grown on planicie, or types of wild fruit gathered from nsitu. This made it more difficult to make comparisons between the different land types.

Planicie was identified as providing the most goods and services ( $n=28$, Table 8 ), followed by nsitu $(n=12)$ and gombe $(n=9)$. Following the amalgamation of goods and services (e.g. the lumping together of all food crops, or of all products made from clay), planicie still supported the greatest variety of uses $(n=9)$, followed by 
gombe, nsitu, planalto and thando, although the differences between these four types were small (4-6 uses for each).

The second subgroup were asked to identify goods and services, and then to mark in a table the land types from which each of these was obtained (Table 9). These data were not scored. Planicie, once again was identified as providing the most goods and services ( $n=11)$, followed by nsitu (8) and thando (7), with gombe, planalto, murmuchea and madimba each supporting a lesser variety of goods and services (2-5 each).

The most widely distributed resources were wild fruit and wild foods, presumably because both of these include a large number of disparate products. Both were said to be derived from all types except madimba. Resources obtained from the least number of land types were grinding stones (only from planalto), water (by definition only from gombe, even if it was a well site within a planicie area), and firewood (only from planicie, because this was where all households were located, rather than not being available elsewhere).

The value of different land types can be depicted as being defined by two axes - on the first there are a few, but very high value goods and services that give the land type a high value. Gombe and madimba are two such examples where water and fish give the land types their high values. The second are those land types that have a large number of relatively low value goods and services - planicie and thando are in this category.

Resource gradients within land types. Working as two separate groups, the CRUAT members were asked to consider one land type at a time, to identify the types of goods and services obtained from that particular land type, and then regardless of abundance, to assess whether each resource is distributed evenly or patchily across that particular land type. Emphasis was placed on assessment of the distribution of resources, rather than on identification of resources, since the latter had already been tackled on the previous field trip. These results are shown in Table 10. No resource gradients were reported for gombe or thando. For the six other types, the numbers of unevenly distributed resources varied from two for nsitu, planicie, madimba and murmuchea, to four for chipale and five for planalto, as detailed below.

Nsitu - The distribution of trees suitable for construction of canoes was reported to be patchy, as was the occurrence of bamboo, which can be expected to be confined to the forest margins.

Planicie - The two resources within planicie that were identified as having uneven distributions were honey, (which was said to be concentrated in more heavily wooded areas and scarcer in the more open areas), and salt (which was said to only be obtained from a certain small river, not everywhere). The occurrence of fish was questioned. These were reported to occur within small depressions within the planicie (pans) and which, although not common, were said to scattered throughout the planicie. All other resources were reported to be relatively evenly distributed.

Madimba - Uneven distributions were reported for sedges used to make mats, and for Setaria grasses used for construction purposes. The distribution of both these species are likely to be related to the positioning of the water table and to patterns of seasonal flooding.

Table 9. Types of goods and services derived from different land types within Muaredzi village.

\begin{tabular}{|c|c|c|c|c|c|c|c|}
\hline Goods and services & Planalto & Nsitu & Planicie & Thando & Gombe & Madimba & Murmuchea \\
\hline Agriculture & - & $x$ & $x$ & - & - & $x$ & - \\
\hline Fish & - & - & - & $x$ & $x$ & - & - \\
\hline Construction materials & - & $x$ & $x$ & $x$ & - & $x$ & - \\
\hline Clay products & - & - & $x$ & $x$ & - & - & $x$ \\
\hline Palm products & - & $x$ & $x$ & $x$ & $x$ & - & - \\
\hline Palm wine & - & - & $x$ & $x$ & - & - & - \\
\hline Wild fruit & $x$ & $x$ & $x$ & $x$ & $x$ & - & $x$ \\
\hline Honey & $x$ & $x$ & $x$ & - & - & - & $x$ \\
\hline Grinding sticks & $x$ & $x$ & $x$ & - & - & - & - \\
\hline Grinding stones & $x$ & - & - & - & - & - & - \\
\hline Medicines & $x$ & $x$ & $x$ & - & - & - & - \\
\hline Firewood & - & - & $x$ & - & - & - & - \\
\hline Water & - & - & - & - & $x$ & - & - \\
\hline Wild foods & $x$ & $x$ & $x$ & $x$ & $x$ & - & $x$ \\
\hline Total $(n=14)$ & 5 & 8 & 11 & 7 & 5 & 2 & 4 \\
\hline Sum of RIWS & 0.162 & 0.504 & 0.692 & 0.415 & 0.342 & 0.293 & 0.122 \\
\hline Ranked by value & 6 & 2 & 1 & 3 & 4 & 5 & 7 \\
\hline
\end{tabular}

Standardised RIW (RIWS) taken from Table 5 were multiplied by 1 where the GS was present. These values were then summed for each land type. 
Murmuchea - Most of the resources associated with termite mounds were reported to occur wherever such mounds are found. However, women reported that they use clay from some mounds but not others, and similarly that edible termites (inswa) are obtained from some mounds but not others.

Chipale - The distribution of resources within chipale was perceived as being the most patchy of all the land types. The explanation given for this was that chipale occurs between gombe (open grassland) and thando (wooded areas). Thus, areas in proximity to gombe are devoid of tree related resources, such as medicines and palms, whereas these do occur in portions that border against thando. Similarly the distribution of water (pans) was said to be patchy, and it was suggested that this was the cause for the perceived irregular occurrence of wildlife within this land type.

Planalto - Four resources were reported to be particularly associated with the lower lying portions of planalto, namely arable areas, thatching grass, well sites and bamboo. Grinding stones were said to be found only on isolated rocky hills. There was some discussion concerning firewood, which was said to only occur where there are trees but not where trees are absent. Although not absolutely certain, it seems that people were thinking about small open areas within the planalto, rather than significant portions of the landscape.

It is possible that respondents may have experienced some confusion in trying to separate out the spatial occurrence of resources from their abundance. The bulk of resources within each land type were reported to be abundant. Almost invariably those resources that were reported to be abundant were said to be found everywhere within a land type, whilst those that were identified as having patchy distributions tended to be the less abundant items.

However, the main conclusion is that the bulk of resources within most land types are reported to be relatively evenly distributed in space (52/ 69 , or $75 \%$ of all resource/ land type combinations). The implication is that resource gradients within land types need not be of any great concern as regards development of the model.

Careful examination of Table 10 will reveal the inclusion of hunting as one of the resources obtained from various land units. The group went to great lengths to explain that this information was based on hunting activities that they used to carry out in the past, during the civil war, but that they longer do so now. CRUAT members seemed to be slightly more open to talking about such issues than on previous field trips, possibly due to the absence of Mr. J uj uman or any other park personnel.

Table 10. Distribution patterns of resources within each of the 8 land types of Muaredzi village. The symbol $x$ indicates an even distribution of a resource within a particular land type, uneven indicates an uneven distribution, and - indicates the absence of a resource from that land type.

\begin{tabular}{|c|c|c|c|c|c|c|c|c|}
\hline Resources & Planalto & Nsitu & Planicie & Thando & Gombe & Madimba & Murmuchea & Chipale \\
\hline Arable land & uneven & $x$ & $x$ & - & - & $x$ & $x$ & - \\
\hline Fish & - & - & $x$ & $x$ & $x$ & - & - & - \\
\hline Construction materials & x & $x$ & $x$ & - & $x^{1}$ & Uneven $^{2}$ & - & - \\
\hline Grass for thatching & uneven & - & $x$ & $x$ & - & - & - & - \\
\hline Clay for making household items & $\mathrm{x}$ & - & $x$ & $x$ & - & - & uneven & $x$ \\
\hline Palm leaves & - & $x$ & $x$ & $x$ & & - & $\mathrm{x}$ & uneven \\
\hline Palm wine & - & - & $x$ & - & - & - & $x$ & - \\
\hline Wild fruit & $x$ & $x$ & $\mathrm{x}$ & - & - & - & - & - \\
\hline Honey & $x$ & $x$ & uneven & - & - & - & $x$ & - \\
\hline Grinding sticks & $x$ & $x$ & $\mathrm{x}$ & - & - & - & - & - \\
\hline Grinding stones & uneven & - & - & - & - & - & - & - \\
\hline Medicines & $\mathrm{x}$ & $x$ & $x$ & - & - & - & $x$ & uneven \\
\hline Firewood & $x$ & $x$ & $x$ & - & - & - & $x$ & - \\
\hline Water & uneven & - & - & - & $x$ & - & - & uneven \\
\hline Wild foods & - & $x$ & $x$ & $x$ & $x$ & - & Uneven ${ }^{3}$ & - \\
\hline Wild animals for hunting & $\mathrm{x}$ & $\mathrm{x}$ & - & $x$ & $x$ & - & - & uneven \\
\hline Bamboo & uneven & uneven & - & - & - & - & - & - \\
\hline Rope from bark & x & - & - & - & - & - & - & - \\
\hline Trees for canoes & $x$ & uneven & - & - & - & - & - & - \\
\hline Salt & - & - & uneven & - & - & - & - & - \\
\hline Grass for mats & - & - & - & - & $x$ & uneven & - & - \\
\hline Uneven/Total & $5 / 15$ & $2 / 12$ & $2 / 14$ & $0 / 6$ & $0 / 6$ & $2 / 3$ & $2 / 8$ & $4 / 5$ \\
\hline
\end{tabular}

\begin{tabular}{l} 
Uneven/Total \\
\hline${ }^{1}$ reeds; ${ }^{2}$ grasses; ${ }^{3 i n s w a}$
\end{tabular} 


\section{c) Factors limiting access to resources within} Muaredzi

The approach adopted for investigating potential cost factors was to start with a general discussion of factors limiting access to resources. Thereafter, particular resources were examined in more detail (agricultural production, canoes, plant products and fish), in order to get a better understanding of the various cost factors, and to check whether there were any other important aspects that might initially have been over looked. Three factors were then singled out for more in depth discussion: government regulations, traditional regulations, and distance. The final step was to generate an overall listing of cost factors and to score the relative weights of these.

General discussion of limiting factors. The CRUAT members were asked if there were any factors that limited access to natural resources within Muaredzi, and if so what these were? The immediate response was yes, in the form of official regulations, government controls and the rules imposed by the GNP scouts living in the village. Some of the responses were that the GNP scouts make it difficult for us to hunt animals; we are not allowed to burn the grass, or to cut trees, not even for making chairs to sit on; we have been told that we must move from this area; even the collection of honey is prohibited, that is the reason why we put bee hives in the village; we are not free to kill even mosquitoes and moths in our houses; if one comes across a tortoise one cannot pick it up; and we are not allowed to harvest any birds. It was further explained that previously, particularly during the civil war, it was very easy to access all these resources, to move around freely, to hunt, and to cut trees, but that the problems started once the government came back after the war. Now they are given limits. For example, if anyone is caught on the other side of the Urema River they have to pay a fine.

Following some prompting, the discussion shifted to trying to identify other limiting factors. With further questioning, people agreed that some resources were simply too far away to utilise. Examples included that the best rope for use in building houses (bwaze) is obtained from the planalto, but because this is too far away palms are instead used for this purpose. Grinding stones are only found in the planalto but it is difficult to get them to the village; and the same applies to stones for the hearth. The difficulties posed by the absence of any transport were pointed out.

Four additional factors were mentioned, these being: lack of equipment for agriculture and for fishing, traditional regulations, and lack of rainfall. Two other factors were discussed but omitted. These were the destruction of crops by wildlife, particularly elephants, and the occasional occurrence of too much water (flooding). The latter, although recognised as limiting access to certain resources, was omitted on the basis of not comprising normal circumstances.

The issue of whether the community would be allowed to remain where they were, or would be forced to move to outside of GNP, resurfaced again, but discussion on this was deliberately curtailed. People obviously view this as potentially being an over riding limitation as regards access to resources.

The Urema River would appear to comprise a significant physical barrier as regards access to any resources on the opposite side from the village. This issue was raised indirectly several times, but without any response, and then directly. People acknowledged that there may be useful resources across the Urema (without identifying them), but explained that since they are prohibited under park regulations from ever going there, no-one ever did, and thus the barrier effect of the river was not of any significance to them.

Factors limiting access to particular resources. In order to try and gain further insights into potential limiting factors, the group was asked to consider specific resources in detail. The men and women were separated for this exercise. Each subgroup was asked to choose a resource, to identify any barriers that serve to limit access to or reduce the availability of the particular resource within the Muaredzi area, and then to score these factors in terms of relative importance. An open scoring technique was used, in which the group first identified the least important factor, then scored each of the remaining factors relative to this one. The women initially chose agricultural production and the men canoes. Once completed, the two groups were asked to select a further resource and repeat the process. This time the women chose forest products and the men fish.

Agricultural production. Five factors were identified as limiting agricultural production: destruction by wild animals, droughts, floods, official regulations, and the lack of agricultural equipment (Table 11).

Of these, official regulations were perceived to be least important, and was allocated a single point. The impact of official regulations was reported to be felt only in that residents were prevented from cultivating anywhere to the west of the Urema River. Portions of "madimba" are known to occur there, but loss of access to these areas was not seen as being particularly important. It was claimed that there were no laws regulating crop production on the village side of the Urema (i.e. to the east of the Urema), and specifically that residents are free to clear 
fields as they require and where they require. The same was reported to apply to the raising of livestock. The current paucity of livestock was said to be a function of difficulties in acquiring animals, and of safeguarding them against the depredations of wild animals, rather than due to any official restrictions. The issue of insecurity surfaced again, with respondents claiming that the park officials wanted to see them leave this place. However, the CRUAT emphasized that since their fathers and grandfathers had died here, it would be impossible for them to move, and that they too should stay here until their deaths. People claimed that the park was at war with them, and that the park officials were pleased when wild animals came and destroyed their crops and animals .

The occurrence of droughts ( 2 points) and floods ( 3 points) were identified as the next two factors. These were acknowledged as being of nearly equal importance. Destruction by wild animals was rated more highly (5 points), on the basis that this is a problem that is faced every year, whereas droughts and floods are more sporadic. During the current field trip elephants were reported to have passed through the village on several nights (we heard them clearly one night). There were also abundant signs of damage caused by wild pigs, and which were claimed to "operate" on a nightly basis. The highest score (10 points) was allocated to the lack of equipment. It was mentioned that various NGOs would sometimes donate implements, but that these were often "diverted" en route, such that they failed to arrive at the village.

Table 11. Factors limiting agricultural production in Muaredzi. Importance scores reflect the relative importance of each factor as regards its contribution towards limiting agricultural production by an average household within Muaredzi village. All scores are relative to the least important factor (official regulations - prohibition of any cultivation to the west of the Urema river).

\begin{tabular}{lccc} 
Limiting factors & RIW & RIWS & RIWC \\
\hline Lack of agricultural implements & 10 & 0.476 & 0.476 \\
Destruction by wild animals & 5 & 0.238 & 0.714 \\
Occurrence of floods & 3 & 0.143 & 0.857 \\
Occurrence of droughts & 2 & 0.095 & 0.952 \\
Cultivation not permitted to the & 1 & 0.048 & 1.000 \\
west of the Urema river & & & \\
\hline Total & 21 & 1.000 & 1.000 \\
\hline
\end{tabular}

Canoes. The first statement to emerge concerning canoes was that without canoes it is not possible to catch fish. Canoes were reported to be made out of particular trees, these being either palm trees (Borassus aethiopicum) or, preferably, hardwood species including "maqueissa" (Afzelia quanzensis), "mbawa" (Khaya nyasica), "mfura" (Sclerocarya birrea), "ngonha" (Breonadia microcephala), and "ntondo" (Cordyla africana). Out of the group of 8 men, only one claimed to personally own a canoe, and this was made from a palm tree. In fact, virtually all the canoes used in Muaredzi were said to be made from palms, the only exceptions being two which had been washed down from elsewhere (one of which is the canoe that is used to cross the Urema at J angada). Cutting of any trees to the west of the Urema was said to be prohibited by the park authorities. But respondents claimed that they had been given special permission by the District Administrator to cut a limited number of hardwood trees to the east, on the understanding that these were to be specifically used for canoes. Suitable trees were reported to occur in this area, but not to the west of the Urema, whilst suitable palm trees were said to have previously been found in the village area, but are now restricted to the west of the Urema. However, the availability of suitable trees was seen as being the least important problem (Table 12).

Table 12. Factors limiting access to canoes in Muaredzi. Importance scores reflect the relative importance of each factor as regards its contribution towards limiting access to canoes by an average household within Muaredzi village. All scores are relative to the least important factor (the difficulty of accessing suitable trees).

\section{Limiting factors}

RIW RIWS RIWC

\begin{tabular}{llll}
\hline Lack of canoe makers & 6 & 0.500 & 0.500 \\
Lack of tools & 5 & 0.417 & 0.917 \\
Difficult to access to suitable trees & 1 & 0.083 & 1.000
\end{tabular}

\begin{tabular}{lrrr}
\hline Total & 12 & 1.000 & 1.000 \\
\hline
\end{tabular}

The real limitations were said to be that none of the villagers had the necessary tools, nor did any of them know how to go about making a canoe. These problems were seen as being of roughly equal importance, on the basis that it would be necessary to solve both in order to be able to make canoes locally. For now, in order to obtain a canoe it was said to be necessary to go either north beyond Muanza, or else west to beyond Chitengo. For both these options the lack of transport presents a major obstacle.

Plant products. Only four factors were identified in terms of restricting access to plant products in Muaredzi (Table 13). The least important of these was said to be "preguica" (laziness, weakness, or the lack of will or strength), and was allocated a single point. Official regulations were admitted, but were seen as being of relatively limited importance (4 points). The impression given was that although some regulations do exist, these are not vigorously enforced, such that one simply has to do things quietly and out of sight. Examples of regulations were that no utilization 
is permitted to the west of the Urema river; no timber trees are allowed to be cut (such as "mahogany" Afzelia quanzensis, "panga panga" Millettia stuhlmannii and "mukwa" Pterocarpus angolensis - "not important as we don't make canoes, nor tables, chairs or any other timber items"); and that cutting of trees in madimba is prohibited (which appears to be due to a restriction on streambank cultivation). It was also claimed that the local rangers prohibit the collection of wild fruits and traditional medicines, but without much conviction. Witchcraft was seen as being a more important issue ( 6 points), together with a lack of tools for cutting trees (8 points). An example of witchcraft was that if one were bewitched, when one cut a tree, instead of it falling to one side it would come to fall on top of you. Costa and Vogt (1998) suggest that there is a high incidence of witchcraft within the village. This is supported by the observation that almost all individuals, from babies to adults, were seen to wear small bands around their legs, arms or necks. As regards the lack of tools, it was eloquently put that "even if one is to run away from the "fiscais", without tools it is not possible to do anything".

Table 13. Factors limiting access to forest products in Muaredzi. Importance scores reflect the relative importance of each factor as regards its contribution towards limiting access to forest (tree) resources by an average household within Muaredzi village. All scores are relative to the least important factor (weakness or laziness).

\begin{tabular}{lrrr} 
Limiting factors & RIW & RIWS & RIWC \\
\hline Lack of tools & 8 & 0.421 & 0.421 \\
Witchcraft & 6 & 0.316 & 0.737 \\
Official regulations & 4 & 0.211 & 0.947 \\
Weakness (or laziness) & 1 & 0.053 & 1.000 \\
\hline Total & 19 & 1.000 & 1.000 \\
\hline
\end{tabular}

Fish. The seven men present all claimed to be fishermen. Fishing was reported to be carried out throughout the year. Official controls were seen as being the principal constraint to fishing (Table 14). These controls come in a number of forms, including restrictions imposed by the park authorities as to where people are allowed or not allowed to fish. In particular, people are restricted from fishing the western portion of Lake Urema. It is necessary to obtain permission from the local GNP scouts, and who might also set limits on the amount of fish to be taken (although this was not entirely clear). It was further claimed, at least to begin with, that Muaredzi residents were only allowed to catch fish for their own consumption and not for sale outside of the village. Later this was refuted, and it was explained that people from Muaredzi could catch as much fish as they wanted and sell it to the outside, but that no other people were allowed to come and fish here. In addition, it was reported that people were not allowed to come and buy fish from the village, but that instead the fish had to be carried out to Muanza for sale there. This was said to be a park regulation aimed at excluding traders, who the park administration claim were previously responsible for the poaching of animals.

Table 14. Factors limiting catches of fish in Muaredzi. Importance scores reflect the relative importance of each factor as regards its contribution towards limiting catches of fish by an average household within Muaredzi village. All scores are relative to the least important factor (the need for water).

\begin{tabular}{lccc} 
Limiting factors & RIW & RIW & RIW \\
\hline Restrictions on where to fish & 6 & 0.240 & 0.240 \\
Lack of canoes & 5 & 0.200 & 0.440 \\
$\begin{array}{l}\text { Damage to nets by crocodiles } \\
\text { Failure to secure permission }\end{array}$ & 4 & 0.160 & 0.600 \\
$\begin{array}{l}\text { from park rangers } \\
\text { Lack of nets }\end{array}$ & 0.160 & 0.760 \\
Lack of poles for canoes & 2 & 0.120 & 0.880 \\
Lack of water & 1 & 0.080 & 0.960 \\
\hline Total & 25 & 1.000 & 1.000 \\
\hline
\end{tabular}

Other factors mentioned were the lack of canoes (5 points) and of poles for canoes ( 2 points); the lack of nets ( 3 points); the presence of crocodiles, which cause damage to nets (4 points); and the fact that without water there cannot be any fish (1 point). Other factors that were discussed, but dismissed as not being of significance were the occurrence of droughts or floods; the distance from the village to the fishing grounds (1.5 hours walk either direction); and the fact that the place where they had been shown to launch their canoes was now covered with grass, making access difficult.

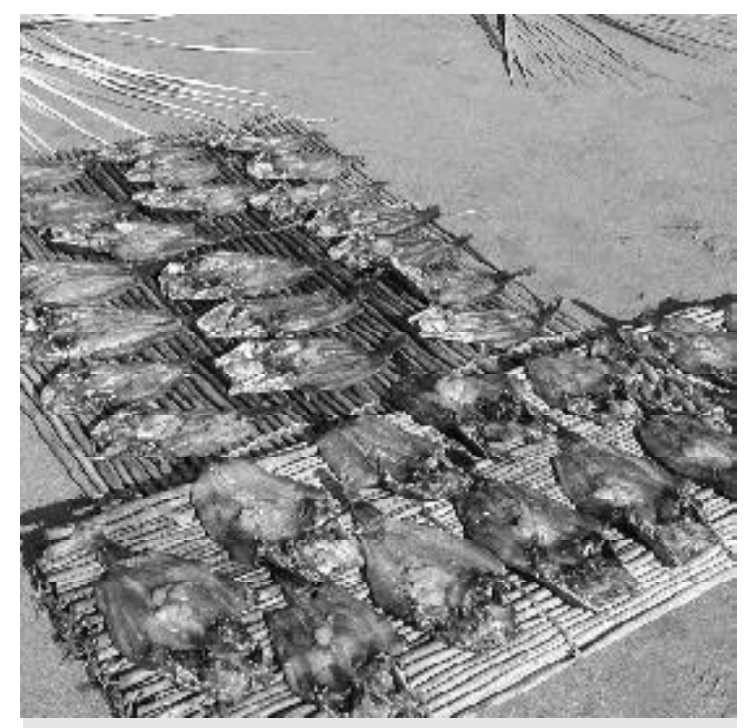

Fish from Lake Urema drying in Mauredzi 
It is interesting that for all four resources, the lack of means of production was seen as being a greater obstacle than any lack of resources, or any physical or institutional barriers as regards access to the resources.

Three aspects were singled out for further investigation: government rules, traditional regulations and distance. The question was asked as to which resources each of these factors impacted upon. Members were then asked to score the impact of these factors as regards limiting access to particular resources.

Official regulations. Resources for which the CRUAT reported that there were no official restrictions regarding their use were water; cultivation (other than not cultivating along stream banks); rearing of livestock, and the selling of agricultural produce to outside the village. It was agreed that permission was required from the GNP scouts in order to catch fish or collect any other wild products (such as fruits or other foods). GNP regulations forbid the killing of any animals, and specifically crocodiles, turtles and certain bird species. The cutting of timber species was also prohibited. This is the reason why villagers are forced to make canoes from Borassus palms or from bark, both of which are considered to be very poor second choices as compared to timber species. Burning was also reported to be prohibited. However, community members were observed to be openly burning piles of wood generated during the clearing of new fields and, at least this year, virtually everything that could burn in the Muaredzi area had done so.

A different scoring technique was used in order to investigate the degree to which these laws restrict access to resources (Table 15). The current level of use for each resource was given an allocation of 5 points, and members were asked to score the relative level of use they would anticipate in the absence of existing laws. The greatest limitation appeared to be on the construction of canoes, followed by fish, the cutting of timber trees, and the collection of nontimber forest products (fruits and other wild foods). For other regulated resources, such as meat, crocodiles, birds, turtles and fire, since the current level of use was considered to be nil, the group felt that it was not possible to score these in this manner.

Whilst carrying out field work, a few wire snares and other animal traps were encountered in close proximity to the village, indicating that at least some level of utilisation of game was being carried out. However, a number of smaller animals (including impala, oribi, bushbuck, warthog and wild pigs) were commonly observed within relatively close proximity to Muaredzi village. The presence of these animals and their apparent lack of fear suggested that they are not being subj ected to high levels of utilisation. There also appeared to be a high degree of compliance as regards prohibitions on the construction of canoes from timber species, with all canoes seen being made from either bark or Borassus palms. The overall impression gained was that village residents were trying hard to comply with official regulations, in order to avoid the situation whereby park officials could use their non-compliance as an excuse to evict them from the area.

Table 15. Impact of official rules and regulations on local access to natural resources by members of Muaredzi community. Scores indicate the extent to which use of particular resources would increase or decrease in the absence of any official rules and regulations. Current level of use was set at 5 points, and people were asked to score the level to which use would be expected to increase or decrease if the rules were removed. It was not possible to score those products for which the current level of use was reported to be 0 .

\begin{tabular}{lrc} 
Official rule & Score & EI $^{*}$ \\
\hline Construction of canoes & $5-20$ & 4 \\
Fish & $5-13$ & 2.6 \\
Cutting of timber species & $5-9$ & 1.8 \\
Wild products & $5-8$ & 1.6 \\
Crocodiles & - & Unknown \\
Birds & - & Unknown \\
Meat & - & Unknown \\
Turtles & - & Unknown \\
Fire & - & Unknown \\
\hline
\end{tabular}

El (Estimated increase)

* Multiplier of current

Traditional rules. The CRUAT group was similarly asked which resources are impacted by traditional rules, and to what extent these regulations impacted on each resource. Initially members seemed reluctant to speak about traditions. This was partly overcome through $\mathrm{Mr}$. Camissa explaining some of the traditions that operate within his home area. Further confidence appeared to be gained through explaining that we were not interested in the actual details of the traditions, but merely wanted to know on which resources they operated, and the extent to which they decreased or increased access to each type of resource.

Seven factors were identified as being affected by local traditions (Table 16). It was explained that in order to access these particular resources, it was necessary to first carry out certain traditional ceremonies. After doing so people would then be free to use the resources. For the purpose of scoring, the group considered the existence of traditional regulations to be positive, in that carrying out the necessary 
ceremonies would have the effect of enhancing access to resources. Ceremonies appeared to be most important as regards rainfall, access to cemeteries, fish, grinding stones, honey, places to settle and, to a lesser extent, the harvesting of forest products. No traditions were identified as specifically restricting access to resources.

Table 16. The impact of traditional regulations governing access to natural resources by members of Muaredzi community. Scores indicate the extent to which use of particular resources is increased (or decreased), from a base level of 5 points, through carrying out of traditional ceremonies.

\begin{tabular}{lcc}
$\begin{array}{l}\text { Factor influenced by } \\
\text { local institutions }\end{array}$ & Score & El* $^{*}$ \\
\hline Rainfall & $5-20$ & 4.0 \\
Access to cemeteries & $5-20$ & 4.0 \\
Access to fish & $5-18$ & 3.6 \\
Access to grinding stones & $5-17$ & 3.4 \\
Access to honey & $5-16$ & 3.2 \\
Access to a plot of land & $5-15$ & 3.0 \\
Access to forest products & $5-9$ & 1.8 \\
\hline
\end{tabular}

Distance. The CRUAT group was asked to score how far members of an average household in Muaredzi travelled in order to access particular resources (Table 17). Water and fields (both machamba and madimba) were considered to be the closest resources (1 point), followed by firewood, artefacts, palm products and clay from termite mounds ( 2 points). Fish, palm wine, wild fruit and traditional medicines were given intermediate scores ( 3 - 5 points). Resources for which people travelled the furthest were construction materials, honey, canoes, grinding sticks and stones, and nonfruit forest foods (6-10 points).

In an attempt to get some estimate of absolute distances, members were subsequently asked to estimate the actual time taken to access specific resources. It was clearly explained that here we were interested only in the travel time and not the time taken for collection or harvesting of the resource. Time taken to access water resources (1 point) was estimated as 25 minutes, and for firewood ( 2 points) as one hour. At the other end of the scale it was estimated to take some three hours to access trees suitable for the manufacture of grinding sticks (9 points), whilst it may take as much as five hours to access certain non-fruit forest foods. The time to reach Muanza (c. $30 \mathrm{~km}$ ) was estimated as being a minimum of 7 hours.

Using the estimate of the time taken to travel to Muanza and the data in Table 17 it was possible to develop an estimate of the approximate distances for each score. The travel time to Muanza of 7 hours implies an average distance covered per hour of $4.28 \mathrm{~km}$. Using the four resources in Table 17 for which there were time estimates (wa ter, firewood, grinding sticks and non-fruit wild foods), it was possible to estimate a mean distance per point $(1.87 \mathrm{~km}$ per point $=[1.78+2.14+1.42+2.14] /$ 4). Rounding this average to $2 \mathrm{~km}$ per point we were able to obtain rough estimates of the distances. Thus the maximum distance that a community member was likely to travel in order to gather natural resources was about $20 \mathrm{~km}$.

At the end of the field trip, whilst driving out from Muaredzi to Muanza, three passengers from the village (two of whom were CRUAT members) were asked how far they would come in order to collect resources. In the planalto escarpment zone, roughly $10 \mathrm{~km}$ from Muaredzi, they responded that they would come this far to collect honey and certain plant resources, but only in times of food shortages. At a point within the tall miombo woodland some $20 \mathrm{~km}$ distant from Muaredzi, they replied that this was now too far, and that they would never come here for anything. This maximum distance claim was consistent with the calculated maximum from the data of Table 17. The estimated distance to the fishing site using this calculation was $6 \mathrm{~km}$, whilst the measurement made from the centre of the village to the fishing site using the geo-referenced positions captured with a GPS and then measuring the distance in the GIS, was $5.8 \mathrm{~km}$ along the route taken.

Table 17. Relative distance traveled in order to access various goods and services derived through use of natural resources within Muaredzi village.

\begin{tabular}{lrrr} 
Resource & $\begin{array}{l}\text { Distance } \\
\text { score }\end{array}$ & $\begin{array}{l}\text { Time } \\
\text { taken } \\
\text { to walk }\end{array}$ & $\begin{array}{l}\text { Estimated } \\
\text { distance } \\
(\mathbf{k m})\end{array}$ \\
\hline Water & 1 & 25 min. & 2 \\
Fields & 1 & - & 2 \\
Fields in wet places & 1 & - & 2 \\
Firewood & 2 & 1 hour & 4 \\
Clay from termite mounds 2 & - & 4 \\
Artefacts & 2 & - & 4 \\
Baskets & 2 & - & 4 \\
Fish & 3 & - & 6 \\
Palm wine & 3 & - & 6 \\
Wild fruit & 4 & - & 8 \\
Traditional medicines & 5 & - & 10 \\
Construction materials & 6 & - & 12 \\
Honey & 7 & - & 14 \\
Canoes & 8 & - & 16 \\
Grinding sticks & 9 & 3 hours & 18 \\
Grinding stones & 10 & - & 20 \\
Non-fruit wild foods & 10 & 5 hours & 20 \\
*To reach Mwanza by foot was estimated to take 7 hours or more
\end{tabular}

** See text for details of the calculations

On path and off path distances. For the purpose of the model, distance was perceived as being a composite factor consisting of on path and off path elements. The grass layer for much 
of the year is extremely difficult to walk through, particularly when wet, and because of its considerable height $(2-4 \mathrm{~m})$ as soon as one leaves the path it becomes extremely difficult to keep ones bearings and know where one is. The result is a marked reluctance to leave the path, which reinforces the proposed breakdown of distance into on path and off path elements.

The first exercise was to investigate the relative distances travelled on path and off path in order to access particular resources. Informants were asked to classify the respective on path and off path distances for each resource into one of four categories: very close, close, moderately far, and very far. The first step was to establish an understanding of these categories. This served a dual purpose, in that it also comprised a training exercise for the subsequent scoring of the field samples, for which each of the potential resources and costs were similarly classified according to a four class system.

A line was drawn on the ground and divided into four unequal categories, which were labelled as above. Thereafter, the CRUAT members were asked to place known points in respect to these categories. In retrospect, it would have been better to start the other way round, with the known points and then to ask the CRUAT to define categories. Nevertheless, clear markers were established for two of the three boundaries. Distances up to the crossing point on the Urema river, or to the fishing grounds, were considered to be moderately far (coutali), whilst anything beyond these points was classified as being very far (coutali reto). Similarly the edge of the village, as defined by the locations of our camp and of Mr. Sixpence Fazenda's homestead, was considered to be the boundary between close (duzi) and moderately far (coutali). The third boundary between close (duzi) and very close (duzi duzi) was less well defined, but through using examples of particular homesteads it was agreed that anything within reach of roughly three minutes walking on the path should be considered to be very close. These categories correspond approximately to the following distances: very close is anything up to $250 \mathrm{~m}$; close $=250 \mathrm{~m}-2 \mathrm{~km}$; far $=2-6 \mathrm{~km}$, whilst very far covers anything further than $6 \mathrm{~km}$.

Having established these categories, the group was then asked to rate the distances travelled on path and off path in order to access particular resources (Table 18). Most resources were ranked as being obtainable either very close or close on the paths, and usually very close off the paths. The principal exceptions were trees suitable for canoes and honey, both of which were reported to be very far both for on path and off path distances. For grinding stones and wild foods, it was considered necessary to travel very far from the village on the path, but then such resources would be easily obtainable in very close proximity to the path. Fishing grounds were ranked as moderately far, but directly accessible by path.

Resource categories, which included groupings of individual resources, such as wild fruits, wild foods and traditional medicines, proved difficult to score. This is to be expected since, for example, some kinds of wild fruits were readily obtainable close by, whilst for others it was necessary to travel much further afield.

Results of this exercise are in broad agreement with those obtained on the previous trip, when the group were asked to score how far members of an average household in Muaredzi have to travel in order to access particular resources (Table 17). The two most obvious deviations are for construction materials and grinding sticks. These

Table 18. Relative distance travelled in order to access various goods and services derived through use of natural resources within Muaredzi village. Distances on and off path were estimated according to four distance categories: very close, close, moderately far, or very far.

\begin{tabular}{lllc} 
Resource & $\begin{array}{l}\text { Distance } \\
\text { on path }\end{array}$ & $\begin{array}{l}\text { Distance } \\
\text { off path }\end{array}$ & $\begin{array}{c}\text { Distance score } \\
\text { (previous trip) }\end{array}$ \\
\hline Water & close & very close & 1 \\
Fields (machamba) & very close & direct & 1 \\
Fields in wet places & - & - & 1 \\
Firewood & close & close & 2 \\
Clay from termite mounds & close & very close & 2 \\
Palm leaves & very close & very close & 2 \\
Fish & moderately far & direct & 3 \\
Palm wine & close & close & 3 \\
Wild fruit & close & very close & 4 \\
Traditional medicines & close & very close & 5 \\
Construction materials & very close & very close & 6 \\
Honey & very far & very far & 7 \\
Canoes & very far & very far & 8 \\
Grinding sticks & close & very close & 9 \\
Grinding stones & very far & very close & 10 \\
Non-fruit wild foods & very far & very close & 10 \\
\hline
\end{tabular}


were said to be obtainable either close or very close to the village, but previously had been given high scores, indicating considerable distances from the village. When queried on these points it was explained that some types of construction poles are obtainable from the immediate surrounds of the village, but for certain kinds one has to travel further, for example to the forest areas. For grinding sticks and bowls, it was explained that although suitable trees are located within close proximity to the village, most people purchase these items from Muanza rather than making their own ones, hence the apparent discrepancy.

Time taken to access particular resources. Participants were asked to estimate the actual time taken to access various goods and services derived from natural resources. These estimates are for the total time taken from leaving the homestead until returning to the homestead, i.e. include both travel time and collection or working time.

The longest time was reported for fishing (24 hours), since people said that they typically go to the fishing grounds, spend the night there, and only return the following day (Table 19). Other activities which received high scores were the collection of honey ( 7 hours); of wild foods ( 6 hours); working in fields (machambas 4 hours, and madimbas 2 hours); accessing trees for canoe building (3.5 hours); grinding stones ( 3 hours); and construction materials ( 1.5 hours). J ourneys for all other resources were estimated to require one hour or less.

For the next exercise, the group was asked to score the amount of time spent travelling versus the amount of time spent collecting each resource. A closed scoring system was used. Each resource was allocated a total of 10 points, which participants were asked to split between travel time and collection time (Table 19). For the bulk of resources more time is spent on collecting and harvesting than travelling. The exceptions were for fetching water, collecting grinding stones, and procuring traditional medicines (for which collection and travel times were allocated equal weights). For 10 out of the 16 resources investigated, more than two thirds of the overall time is spent on collection ( 7 - 9 points) and less than one third on travel ( 1 - 3 points). If one divides the overall trip times between collection and travel times, according to their relative scores, then for 11 out of 16 resources the travel time works out as being less than 30 minutes. Resources for which the travel times are more considerable were for fish, honey, grinding stones, wild foods and trees for canoes.

The group was now asked to subdivide the travel time into time spent moving on the path versus off the path. The same closed scoring system was used, whereby the overall travel time for each resource was allocated 10 points, which the group was tasked with subdividing between on path and off path times (Table 19). For most resources the on path component accounts for the bulk of the travel time. Negligible amounts of time ( 0 or 1 point) are required for off path travel for 10 of the 16 resources. The two cases for which off path travel time was scored as greater than on path, were for the collection of honey and for the securing of suitable trees for making canoes. These results are consistent with those presented in Table 18.

Relative weights of limiting factors. At this point the group was asked to reconsider the overall list of barriers regarding access to natural

Table 19. Time taken to access various resources within Muaredzi village. Total time comprises the estimated time for a single journey from leaving the household until returning to the household. A closed scoring system was used for the relative times with 10 points being allocated per resource to be divided between collection time and travel time, and similarly between on path and off path components of travel time.

\begin{tabular}{lccccc} 
& $\begin{array}{c}\text { Total time } \\
\text { (hours: } \text { mins) }\end{array}$ & Collection & Travel & On path & Off path \\
\cline { 2 - 6 } & $0: 15$ & 4 & 6 & 10 & 0 \\
Water & $4: 00$ & 9 & 1 & 10 & 0 \\
Fields (machamba) & $2: 00$ & 8 & 2 & 10 & 0 \\
Fields in wet places & $0: 30$ & 7 & 3 & 8 & 2 \\
Firewood & $0: 45$ & 8 & 2 & 7 & 3 \\
Clay for pots & $0: 25$ & 8 & 2 & 10 & 0 \\
Palm leaves & $24: 00$ & 6 & 4 & 10 & 0 \\
Fish & $1: 00$ & 6 & 4 & 10 & 0 \\
Palm wine & $0: 20$ & 9 & 1 & 9 & 1 \\
Wild fruit & $0: 05$ & 5 & 5 & 10 & 0 \\
Traditional medicines & $1: 30$ & 7 & 3 & 8 & 2 \\
Construction materials & $7: 00$ & 7 & 3 & 1 & 9 \\
Honey & $3: 30$ & 8 & 2 & 4 & 6 \\
Canoes & $1: 00$ & 8 & 2 & - & - \\
Grinding sticks & $3: 00$ & 2 & 8 & 7 & 3 \\
Grinding stones & $6: 00$ & 6 & 4 & 10 & 0 \\
Non-fruit wild foods & & & & &
\end{tabular}


resources, and if appropriate to add any factors, or perhaps to lump others together, and then to score the relative importance of these. Simple leading questions were asked in order to guide this process. Problems relating to the lack of equipment, tools or instruments were lumped under a single category, as were all state regulations regardless of whether they were set by the local rangers, the park administration, or other government bodies (such as agricultural officials or the district administration). Difficulties posed by crocodiles to fishing, and the destruction of crops by herbivores, were similarly lumped under a single category of wild animals. Other factors retained were those of drought and floods, witchcraft and laziness, and the lack of any canoe makers. I queried whether the lack of canoe makers could be cast in more general terms as a lack of knowledge. This was rej ected, but I was not clear as to whether this was because people felt that this only applied to canoes and not to other resources, or because people were not getting my point (i.e. translation difficulties).

The result was an overall list of nine barriers (Table 20). Of these, "weakness" was identified as being of least significance and thus allocated a single point. All other factors were then scored relative to the effect of "weakness". The two most important aspects were seen as being the lack of tools or equipment (11 points), and the restrictions imposed through the various official regulations ( 10 points). These were followed by a lack of canoe makers (8 points), witchcraft and wild animals (both with 6 points), and the occurrence of droughts ( 5 points). The reason for ranking droughts above floods (3 points) instead of the other way round, as was presented in discussion of agricultural production, was not followed up. Interestingly, the impact of distance was considered to be of only relatively

Table 20. Overall factors limiting access to natural resources in Muaredzi. Importance scores reflect the relative importance of each factor as regards its contribution towards limiting access to natural resources by an average household within Muaredzi village. All scores are relative to the least important factor (weakness).

\begin{tabular}{lrrr} 
Limiting factors & RIW & RIWS & RIWC \\
\hline $\begin{array}{l}\text { Lack of tools or equipment } \\
\text { Restrictions due to official }\end{array}$ & 11 & 0.204 & 0.204 \\
regulations & 10 & 0.185 & 0.389 \\
Lack of canoe makers & 8 & 0.148 & 0.537 \\
Occurrence of witchcraft & 6 & 0.111 & 0.648 \\
Destruction by wild animals & 6 & 0.111 & 0.759 \\
Occurrence of droughts & 5 & 0.093 & 0.852 \\
Distance to access resources & 4 & 0.074 & 0.926 \\
Occurrence of floods & 3 & 0.056 & 0.981 \\
Weakness or laziness & 1 & 0.019 & 1.000 \\
\hline Total & 54 & 1.000 & 1.000 \\
\hline
\end{tabular}

minor importance (4 points), accounting for only $7.4 \%$ of the overall importance mass.

\section{d) Muaredzi prior model}

Once the initial fieldwork had been completed in Muaredzi the data were used to update the prior model for Muaredzi (Figure 8). Firstly, this entailed the addition of nodes to reflect the specific benefits that the CRUAT had identified. Secondly, the relative important weights that the CRUAT had used to indicate their preferences for these goods and services were used to weight each good and service (see equation 1). Lastly, the weights and additional nodes required to update the cost side of the model were also added.

The initial model was then used to identify the sensitivity of the Benefit/Cost node to findings at each of the other nodes (Table 21). These results were used to inform subsequent field data collection, on the basis that the most critical information to collect would be that relating to the factors to which the Benefit/ Cost node showe greatest sensitivity. The BC node was most sensitive to additional information on the costs, the benefits and then to most of the cost components of the model.

Table 21. Sensitivity of the node BCLandscape to findings at each of the other nodes - Muaredzi prior model.

\begin{tabular}{lc} 
Node & $\begin{array}{c}\text { Variance } \\
\text { Reduction }\end{array}$ \\
\hline BCLandscape & 1.3960 \\
Costs & 0.5354 \\
Benefits & 0.4696 \\
Otherbenefits & 0.2482 \\
Distance & 0.2363 \\
DistanceFromRoute & 0.1638 \\
OfficialRegulations & 0.1498 \\
PlantProducts & 0.1049 \\
Agricultural Land & 0.0835 \\
WellSites & 0.0835 \\
HouseholdConstructionMaterials & 0.0566 \\
DistanceAlongMajorRoutes & 0.0562 \\
Fishing & 0.0372 \\
GrindingStickMateria & 0.0223 \\
Barriers & 0.0223 \\
Institutions & 0.0208 \\
Clay & 0.0137 \\
SesteriaProductMater & 0.0082 \\
PalmWinePalms & 0.0056 \\
Honey & 0.0031 \\
TraditionalMedicines & 0.0020 \\
WildFood & 0.0007 \\
WildFruits & 0.0002 \\
Firewood & 0.0000 \\
\hline
\end{tabular}



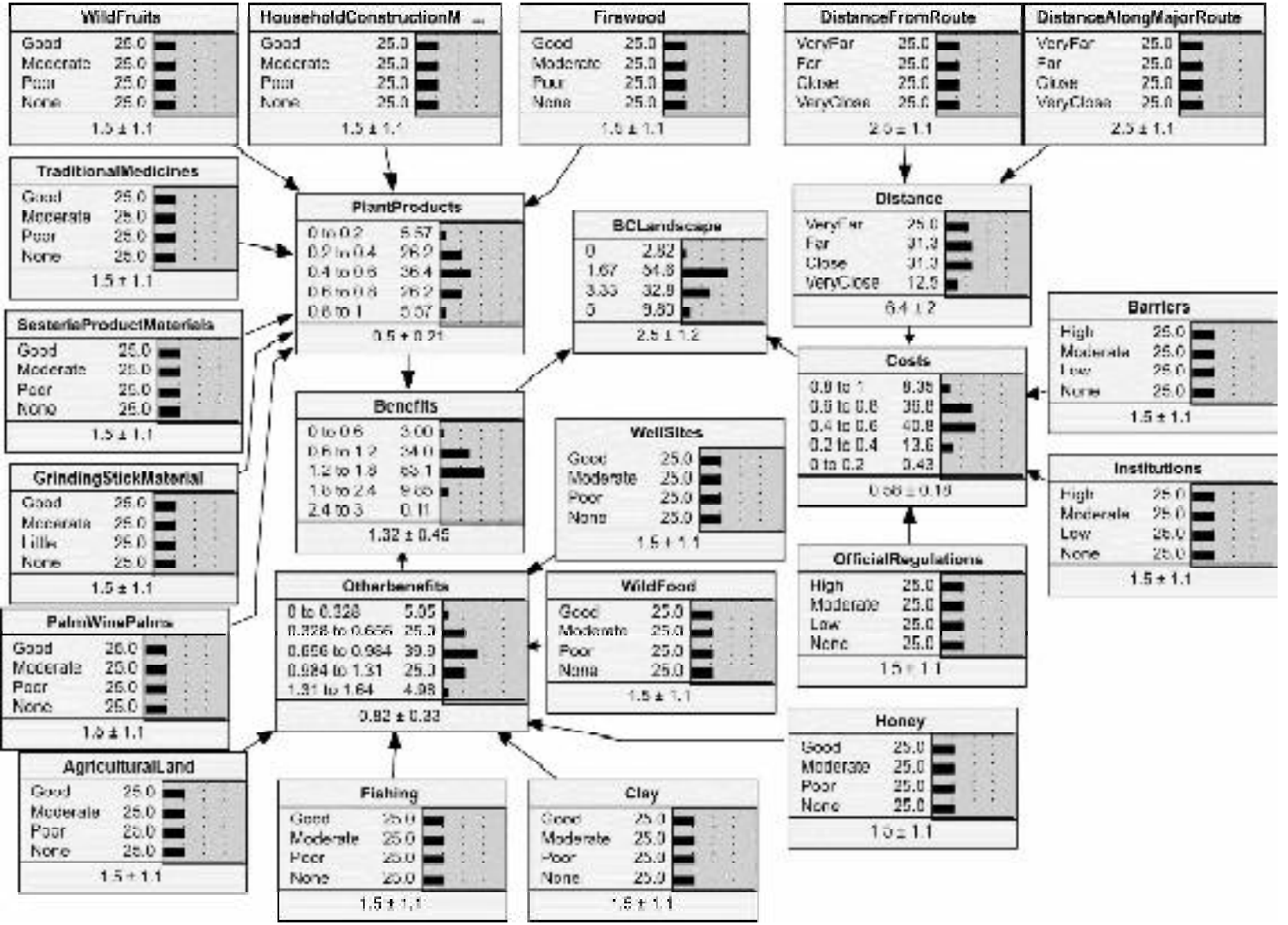

Figure 8. Prior BBN for Muaredzi showing the nodes and their relationships. The uniform probability distributions in peripheral nodes indicates no prior knowledge as to the state of these variables.

\section{Nhanchururu community assessments}

The presentation of community assessment results for Nhanchururu is covered under four sections, following the same format as for Muaredzi.

\section{a) Nhanchururu basic needs and use of natu- ral resources}

As for Muaredzi, the initial exercise undertaken by the CRUAT was to identify the basic needs required for an average household within Nhanchururu to live an adequate life within their community. Additional information was then sought on five important groups of resources - these being sources of food, water, land and soil, forest products, and grasses. Each of these aspects was explored individually. CRUAT members were asked to identify the different uses made of each resource within the village area, and to score the relative importance of these. Following this, an overall list of natural resources was prepared, and the relative importance of each item scored. The final exercise within this section was to ask the CRUAT to identify any natural resources that were taken to be sold outside of the village, and to score the relative importance of these items in terms of overall sales.
Basic needs. The CRUAT identified a list of 26 basic needs (Table 22). As for Muaredzi, these comprised a mix of basic requirements (such as shelter, food, water, firewood, employment, sleeping mats, regulations); agricultural requirements (seeds, equipment, markets); infrastructure, most of which is currently lacking (school, hospital, grinding mill, access road, church, transport, shops), plus school materials, household utensils and furniture, clothes, tin sheets, alcohol, and fish, cattle and goats. There are virtually no cattle in the village at present. People say that this is due to difficulties in obtaining cattle (not available locally and high prices), rather than the area not being well suited to the production of cattle (e.g. veterinary problems).

Sources of food. A number of different sources of food were identified. These were explored individually through compiling lists of each type of product, and scoring the relative importance of these. Six spidergrams were developed, these being for cultivated foods, including crops grown in fields, in wet areas, vegetables and fruits; foods collected from the wild that require cooking (mushrooms, tubers, leaves, seeds); foods from the wild that do not require cooking (honey and wild fruits); wildlife (comprising both animals and birds); domestic 
animals, and food purchased from outside of Nhanchururu. The final step was to score the relative importance of these different sources of food. Hunting of birds and animals was reported to be prohibited both in the village area and particularly in the park area - so the importance score for these resources is likely to have been underplayed. Had more time been available it would have been desirable to explore how these importance scores might change under conditions of drought and floods. Casual comments suggested that the wild foods become more important during these times.

A total of 33 food crops were identified. This included grains, fruits, beans, oil seeds, vegetables, tubers and sugar cane. The principal crops grown were reported to be sorghum, maize and millet, followed by bananas, beans, sunflowers and rice. Collectively, these seven crops accounted for $50 \%$ of the overall relative importance mass.

In terms of wild foods that require cooking, a total of 28 products were identified. These comprised tubers, beans, mushrooms, leaves, roots and seeds. A number of the tubers are obtained from moist areas along drainage lines. The most important products were six kinds of tubers, two mushrooms, and a type of wild beans,

Table 22. Basic needs for an average household within Nhanchururu to live an adequate life. Importance scores reflect the relative importance of each good or service to achieving this standard of living. All scores are relative to the least important factor (household furniture).

\begin{tabular}{lrrr} 
Resource & RIW & RIWS & RIWC \\
\hline Housing & 21 & 0.056 & 0.056 \\
Food & 20 & 0.053 & 0.110 \\
Water & 20 & 0.053 & 0.163 \\
Seeds for crops & 20 & 0.053 & 0.217 \\
Agricultural implements & 20 & 0.053 & 0.270 \\
Firewood & 19 & 0.051 & 0.321 \\
School & 19 & 0.051 & 0.372 \\
Hospital & 19 & 0.051 & 0.422 \\
Grinding mill & 19 & 0.051 & 0.473 \\
Access road & 19 & 0.051 & 0.524 \\
Employment & 18 & 0.048 & 0.572 \\
Sleeping mats & 17 & 0.045 & 0.618 \\
Regulations & 17 & 0.045 & 0.663 \\
School materials & 16 & 0.043 & 0.706 \\
Household implements & 15 & 0.040 & 0.746 \\
Clothes & 15 & 0.040 & 0.786 \\
Church & 14 & 0.037 & 0.824 \\
Transport & 12 & 0.032 & 0.856 \\
Fish & 11 & 0.029 & 0.885 \\
Sales of agricultural produce & 10 & 0.027 & 0.912 \\
Cattle & 9 & 0.024 & 0.936 \\
Goats & 8 & 0.021 & 0.957 \\
Tin sheets for roofing & 6 & 0.016 & 0.973 \\
Shops & 5 & 0.013 & 0.987 \\
Drink (alcoholic) & 4 & 0.011 & 0.997 \\
Household furniture & 1 & 0.003 & 1.000 \\
\hline Total & 374 & 1.000 & 1.000 \\
\hline
\end{tabular}

which collectively accounted for $63 \%$ of the overall relative importance mass.

Types of wild fruit and honey were listed and scored together (wild foods that do not require cooking). The main products were three types of honey and two wild fruits, which together accounted for $65 \%$ of the overall relative importance mass. The remaining two types of honey and 21 wild fruits were considered to be of lesser importance. Honey is both collected from the wild and produced using domestic beehives. During our time within the village we saw numerous beehives and also large trees that had been ring barked in order to provide the bark for making the beehives. One of the wild types of honey is specifically associated with termite mounds, the others are obtained from nests in trees.

A total of 27 species of wild animals and 16 species of birds were identified as being harvested within Nhanchururu. These were scored together. The identity of most of the animal species is tentative and requires further confirmation. Identification of the birds is thought to be better, although a couple are obviously incorrect (way out of their distribution ranges). Four small antelope species were the most important of the animals, followed by "fungo", porcupine, baboons and monkeys. Other animal species utilised included cane rats, shrews, rats, bushbaby, rabbit, leguavaan, turtles, genet, mongoose, honey badger and squirrel. The 16 bird species collectively accounted for only $18 \%$ of the overall wildlife relative importance mass. The principal ones were francolin, guineafowl, green pigeons and hornbills.

In terms of domestic animals, chickens, goats, pigs, ducks and pigeons were observed in the village. The CRUAT also included guineapigs, but gave these a much lower score than any of the above species. Chickens were identified as being the most important type of domestic animal. This was followed by goats, although it was pointed out that only relatively few households were fortunate enough to own goats. As noted before, cattle were effectively absent from the village, and so were not included here.

A wide variety of products, 33 in total, were identified as being purchased from outside of the village. This included various staples (salt, maize, beans, rice, sugar, oil); proteins (goat, chicken, beans, fish, tinned fish); vegetables (tomato, rape, cabbage, onion, sweet potato); fruit (orange, banana), and manufactured items (pasta, bread, biscuits, cake, sweets, chewing gum). The most important items were the staples and proteins, whilst the vegetables, fruit and manufactured items were generally considered to be of lesser importance. 
The perceived importance of these different sources of food were then scored relative to one another (Table 23). Cultivated foods (crops and fruits) were identified as being the most important food sources, together accounting for $52 \%$ of the overall relative importance mass. Relatively high importance was also given to livestock (19\% of the overall importance mass). Foods harvested from the wild (wild animals, wild foods and fruits) collectively accounted for only $22 \%$ of the importance mass, with purchased foods being confined to only $7 \%$

Table 23. Relative importance of different sources of food. Importance scores reflect the relative importance of each source of food to an average household within Nhanchururu satisfying their food requirements. All scores are relative to the least important source (help from others).

\begin{tabular}{lrrr} 
Resources & RIW & RIWS & RIWC \\
\hline Food crops & 70 & 0.302 & 0.302 \\
Cultivated fruits & 50 & 0.216 & 0.517 \\
Livestock & 45 & 0.194 & 0.711 \\
Foods from the wild & 25 & 0.108 & 0.819 \\
Purchased foods & 16 & 0.069 & 0.888 \\
Wild animals & 15 & 0.065 & 0.953 \\
Wild fruits and honey & 10 & 0.043 & 0.996 \\
Help from others & 1 & 0.004 & 1.000 \\
\hline Total & 232 & 1.000 & 1.000 \\
\hline
\end{tabular}

Water. Eleven uses of water were identified. The five most important functions were for drinking, cooking, medical treatments, bathing and washing clothes. Collectively, these uses accounted for $72 \%$ of the overall relative importance mass. Watering vegetables and plastering houses were seen as being of lesser importance. Wild products derived from aquatic systems, such as reeds, fish, other aquatic animals, and aquatic food plants were seen as being of only minor importance in comparison to other uses of water.

Land and soil. Seven uses of land and soil were identified. The three most important aspects were for cultivation, sites for living, and for cemeteries. These uses were all given similar scores. These were followed, in terms of scores, by the use of clay for making pots, and of soil for plastering houses. The other two uses of sand and making bricks were seen as being of only minor significance. Very few brick structures were observed within the village.

Forest products. A total of 13 uses of natural woodland areas were identified. The use of trees for making handles for implements such as hoes and axes was given the highest importance rating ( $14 \%$ of the overall RIW). This result was consistent with subsequent exercises, in which handles were consistently rated as being one of the most important natural products. Other important uses of woodland areas were for cemeteries; for firewood; for grass; for timber (including the use of trees for making pestle and mortars for grinding grain); for traditional medicines, and for collecting wild foods and fruits. These were followed by construction materials (poles, bamboo and bark for rope) and honey. Hunting was stated as being the least important use. The collection of palm wine was given two points, although in later exercises people denied that any palms are to be found within Nhanchururu. There may an element of confusion, in that some people go outside of the village area, for example into the adjacent park area or to neighbouring villages, to obtain certain products.

Grasses. The principal uses of grass were for thatching houses (apart from the school, the use of zinc roofing sheets within the village was extremely limited), and for the construction of large oval structures for storing sorghum grain ("chigua"), including protective mats that are placed underneath these structures ("ncuputu"). Other important uses were for grazing by livestock, and for making protective rings to be placed on the head when carrying heavy products, particularly water containers. Additional uses comprised the construction of bathrooms and toilets, and making nests for chickens. Roof decorations were seen as being of least importance.

The principal grass species used were Hyparrhenia sp. (20 points), Themeda triandra (20 points), Digitaria sp. (16 points), Heteropogon sp. (10 points) and Panicum maximum (1 point). All of these were observed to grow commonly within the village area. In addition, Phragmites reeds and Setaria incrassata were commonly used for construction of bathrooms and toilets. Bamboo, which is used for construction purposes, and Cyperus reeds (or "jungu"), which are used for making sleeping mats, were considered to be separate resources from grasses.

Overall list of natural resources. A total of 30 natural resources were identified as being utilised within Nhanchururu (Table 24). Some of these could perhaps be combined together, for example the five types of honey, or "matope" and "nongo" which are two different types of clay soils but which are both found in wet places and used for cultivation. The most important resources were seen as being land ( $9 \%$ of RIW), water ( $8 \%$ of RIW), firewood and wood for handles (7\%each of RIW). These were followed by 14 resources, each of which were given scores ranging from 19 to 10 points, and which collectively accounted for a further $56 \%$ of the overall relative importance mass. These included food sources (livestock, cultivated fruits and food from the wild); reeds for sleeping mats; 
a variety of forest products (grinding sticks and bowls, timber, poles, bamboo, bark for rope, grass and traditional medicines); as well as clay for making pots; grinding stones and reeds for construction purposes. The remaining $14 \%$ of the importance mass was split amongst a further 12 resources, comprising: aquatic related soils (matope and nongo), aquatic animals and plants, various types of honey, wild fruits, wildlife, and sand.

Table 24. Overall list of natural resources used within Nhanchururu. Importance scores reflect the relative importance of each resource to an average household within Nhanchururu achieving an adequate standard of living. All scores are relative to the least important resources (wildlife, aquatic plants and two types of honey).

\begin{tabular}{lrrr} 
Resources & RIW & RIWS & RIWC \\
\hline Land for housing and fields & 35 & 0.093 & 0.093 \\
Water & 30 & 0.080 & 0.172 \\
Firewood & 26 & 0.069 & 0.241 \\
Wood for handles & 25 & 0.066 & 0.308 \\
Livestock & 19 & 0.050 & 0.358 \\
Reeds for mats & 18 & 0.048 & 0.406 \\
Grinding sticks and bowls & 17 & 0.045 & 0.451 \\
Timber & 17 & 0.045 & 0.496 \\
Poles for construction & 16 & 0.042 & 0.538 \\
Bamboo for construction & 16 & 0.042 & 0.581 \\
Rope for construction & 16 & 0.042 & 0.623 \\
Grass for thatching & 16 & 0.042 & 0.666 \\
Cultivated fruits & 16 & 0.042 & 0.708 \\
Clay for pots & 15 & 0.040 & 0.748 \\
Traditional medicines & 14 & 0.037 & 0.785 \\
Grinding stones & 12 & 0.032 & 0.817 \\
Reeds for construction & 11 & 0.029 & 0.846 \\
Foods from the wild & 10 & 0.027 & 0.873 \\
Mud for cultivation & 9 & 0.024 & 0.897 \\
Honey & 8 & 0.021 & 0.918 \\
Fish and other aquatic animals & 7 & 0.019 & 0.936 \\
Wild fruits & 6 & 0.016 & 0.952 \\
Sand & 5 & 0.013 & 0.966 \\
Type of wild honey & 4 & 0.011 & 0.976 \\
Slippery clay (for cultivation) & 3 & 0.008 & 0.984 \\
Type of wild honey & 2 & 0.005 & 0.989 \\
Type of wild honey & 1 & 0.003 & 0.992 \\
Type of wild honey & 1 & 0.003 & 0.995 \\
Wildlife & 1 & 0.003 & 0.997 \\
Aquatic plants for food & 1 & 0.003 & 1.000 \\
\hline Total & 377 & 1.000 & 1.000 \\
\hline & & & \\
\hline
\end{tabular}

Sales of natural resources. Eleven resources were identified as being sold to outside of Nhanchururu (Table 25). The most important of these were livestock and crops, together accounting for $42 \%$ of the overall importance mass. Of the various resources harvested from the wild, grinding sticks and bowls were seen as being the most important, followed by reeds for mats and bamboo. These three items accounted for a further $36 \%$ of the overall importance mass. Resources of lesser commercial value included clay pots, fish, honey, traditional medicines, handles, and bark for rope.
Table 25. Natural resources sold to outside of Nhanchururu. Importance scores reflect the relative importance of sales of each resource to an average household within Nhanchururu achieving an adequate standard of living. All scores are relative to the least important resource (bark for rope).

\begin{tabular}{lrrr} 
Resources & RIW & RIWS & RIWC \\
\hline Livestock & 22 & 0.220 & 0.220 \\
Crops & 20 & 0.200 & 0.420 \\
Grinding sticks and bowls & 18 & 0.180 & 0.600 \\
Reeds for mats & 10 & 0.100 & 0.700 \\
Bamboo & 8 & 0.080 & 0.780 \\
Clay pots & 6 & 0.060 & 0.840 \\
Fish & 5 & 0.050 & 0.890 \\
Honey & 5 & 0.050 & 0.940 \\
Traditional medicines & 3 & 0.030 & 0.970 \\
Wood for handles & 2 & 0.020 & 0.990 \\
Bark for rope & 1 & 0.010 & 1.000 \\
\hline Total & 100 & 1.000 & 1.000 \\
\hline
\end{tabular}

The impression gained from various discussions was that all of the resources mentioned on the overall list (Table 24), do occur and are harvested within Nhanchururu. However, some residents go outside of the village area to seek certain resources such as honey, reeds for mats, fish, wildlife and traditional medicines. Likewise neighbouring people sometimes come to collect certain resources from within Nhanchururu, such as bark for rope, bamboo, poles, timber (both for planks and for making grinding sticks and bowls) and honey.

\section{b) Nhanchururu Land Types}

This section concerns the identification of land types and soil types within Nhanchururu; the spatial occurrence of these (sketch map and GPS mapping); the types of resources that are obtained from the different land types; and their relative abundance and importance. A final aspect was to investigate the spatial distribution of resources within land types - to the extent whether each resource within a land type was relatively evenly distributed, or whether it had an uneven, patchy or clumped distribution.

Identification of land and soil types. The question was posed, "are there different types of land within Nhanchururu or is it all the same?" Four types of land were identified: baixa (low places), planicie (flat or sloping areas between baixa and planalto), planalto (high areas, at the top of slopes), and montanhas (mountains). The baixa and montanhas appear to be relatively well defined, but whilst moving in the field no clear distinction was discernible between planicie and planalto. Planalto was described as being higher than planicie (i.e. the tops of slopes were considered to be planalto, regardless of their actual elevation). Baixa comprises both lower 
slopes and valley bottoms. The location of Nhanchururu is such that it is an actively eroding area and there is little build up of alluvium along drainage lines, with the result that adjacent soil types typically persist almost directly onto the drainage lines. Regardless of the size of the drainage, the extent of baixa was sometimes considered to be precisely confined to the riparian community (often $10 \mathrm{~m}$ or less in width), but in other situations was considered to include substantial portions of the adjacent miombo woodland on the lower slopes.

The CRUAT members pointed out that within each of these land types the soils were varied. They then proceeded to identify the different soils found within each of the land types (Table 26). Three soil types were identified from baixa, and four from each of the other types. Baixa includes two types of clay soils ("matope" or mud, and "nongo" described as slippery clay soil) and sand. Planicie was identified as having black soil, red soil, termite mounds, and sand. Some days later, after we had covered substantial areas whilst mapping roads and paths and not come across any sand areas (although there were substantial portions of soil mixed with sand), the CRUAT members agreed that this was an error and removed this category. For planalto, the four soil types were black soil, red soil, termite mounds, and soil mixed with small stones. The latter soil type was not considered to be suitable for agriculture. Mountains were said to also have both black and red soils, and soils mixed with small stones, as well as areas that were predominantly rocky.

Soil types by land types. The CRUAT were subsequently asked to consider one soil type at a time and, using a bounded scoring technique, to indicate the distribution of that particular soil type amongst the four land types (Table 27). The first four types red soil, black soil, black soil with sand and black soil with small stones were all identified as occurring commonly in planicie, planalto and baixa but not the mountains. Black soil with stones occurs in baixa, planalto and the mountains, but not planicie. Dongo was only recorded from planicie, despite the fact that termite mounds were also reported to occur in the planalto. Matope and nongo were confined to baixa. Stones were reported to occur in baixa (along drainage lines), in planalto and the mountains, but only to a limited extent in planicie.

Sketch map of soil types. The CRUAT balked at the idea of mapping land types, on the basis that these typically occur as a mosaic in close proximity to one another rather than covering large discrete portions of landscape. However, they did produce a credible map of soil types. Nine units were mapped. The largest of these was black soil with sand (as belts to the west and east of the village); followed by red soil (the south central portion onto the Mucodza river); then black soil and black soil mixed with stones (the north central portion onto the Vunduzi river). Minor occurrences of matope and nongo were mapped along some of the drainage lines. The occurrence of dongo

Table 26. Initial identification of land and soil types found within Nhanchururu.

\begin{tabular}{ll} 
Local nomenclature & Translation \\
\hline BAIXA & LOW AREAS \\
Matope & Mud \\
Nongo & Slippery clay soil \\
Areia & Sand \\
PLANICIE & FLAT AREAS \\
Terra preta & Black soil \\
Terra vermelha & Red soil \\
Murmuchea & Termite mounds \\
Areia & Sand \\
PLANALTO & HIGH AREAS \\
Terra preta & Black soil \\
Terra vermelha & Red soil \\
Mestura com pedras & Soil with stones \\
Murmuchea & Termite mounds \\
MONTANHAS & \\
Terra preta & MOUNTAINS \\
Terra vermelha & Black soil \\
Mestura com pedras & Red soil \\
Pedras & Soil with stones \\
\hline & Stones \\
\hline
\end{tabular}

Table 27. Occurrence of soil types within the four principal land types of Nhanchururu. A bounded scoring approach was used, with an allocation of five points per land type, to give a total of 20 points for each soil type.

\begin{tabular}{lccccc} 
Soil Type & Baixa & Planicie & Planalto & Montanhas & Total \\
\hline Red soil & 4 & 9 & 6 & 1 & 20 \\
Black soil & 5 & 6 & 8 & 1 & 20 \\
Black soil with sand & 7 & 8 & 4 & 1 & 20 \\
Black soil with small stones & 4 & 6 & 9 & 1 & 20 \\
Black soil with stones & 5 & 1 & 6 & - & 20 \\
Clay (dongo) & - & 20 & - & - & 20 \\
Mud (matope) & 20 & - & - & 8 & 20 \\
Slippery clay soil (nongo) & 20 & - & 6 & & 20 \\
Stones & 5 & 1 & & & 8 \\
\hline
\end{tabular}


(termite mounds) was indicated in the zones of black soil with sand, red soil, and black soil with stones, but not for the portion of black soil. Stones were shown in association with the "mountain" areas to the extreme east of the village, and which were considered to mark the boundary between the village area and the national park. A portion of sandy soil was initially mapped to the south east of the village, but having done some GPS mapping in this area and not found any sands, the CRUAT agreed that this was an error and that it should be changed to black soil mixed with sand. The final map thus indicated only eight soil units.

GPS mapping of land and soil types. Whilst mapping roads and paths within the village, together with CRUAT members, for many of the points information was also recorded on land types and soil types. Such data was recorded from a total of 261 points, providing coverage of much of the village (i.e. the bulk of the network of major routes). Points were recorded at about 200 pace intervals. Assuming this to be about $150 \mathrm{~m}$, this would give an overall distance of about $40 \mathrm{~km}$, which if done in straight lines would roughly equate to five transects through the village area. Although this data obviousl y comprises a biased sample, it does give some indication as to the occurrence and patterning of the various land types and soil types.

According to these results (Table 28), planicie is the most common land type ( $49 \%$ of the overall points), followed by planalto (36\% of the points). Baixa accounted for some $13 \%$ of the points, with montanhas being represented by only 4 points or $2 \%$

In terms of soils, a total of 17 soil types were described, the most common ones being black soil with sand (33\% of points), black soil ( $21 \%$ ), and black soil with stones or small stones (another $21 \%$ ). The most striking difference as compared to the community map was the poor representation of red soils. Only $5 \%$ of points were classed as red soil, although a further $16 \%$ were labeled as various mixtures of red soil with black soil, sand, stones or small stones. The other types were all very rare, typically comprising only one or two points. These were mainly associated with baixa areas, and comprised various forms of matope and nongo, and sand.

Resources by land types. Two different exercises were carried out in terms of identifying the use of natural resources from land types. The first of these was to consider one land type at a time, to identify the resources obtained from that type, and then to score the relative importance of these (Table 29). A total of 27 resources were identified. Baixa and planicie provided 17 and 16 resources respectively, whilst 13 were reported
Table 28. Frequency of land types and soil types from 261 GPS points recorded within Nhanchururu whilst mapping roads and paths within the village.

\begin{tabular}{lrr} 
Land types & Frequency & $\%$ \\
\hline Baixa & 34 & 13 \\
Planicie & 128 & 49 \\
Planalto & 94 & 36 \\
Montanhas & 5 & 2 \\
Total & 261 & 100 \\
Soil Types & Frequency & $\%$ \\
\hline Black soil & 54 & 21 \\
Black soil with sand & 85 & 33 \\
Black soil with stones & 28 & 11 \\
Black soil with small stones & 26 & 10 \\
Mixture of black and red soils & 5 & 2 \\
Red soil & 12 & 5 \\
Red soil with sand & 7 & 3 \\
Red soil with stones & 1 & - \\
Red soil with small stones & 15 & 6 \\
Mixture black and red soils & 12 & 5 \\
with small stones & & \\
Black soil with sand and small stones & 6 & 2 \\
Black soil with sand and nongo & 2 & 1 \\
Sand & 2 & 1 \\
Matope & 2 & 1 \\
Black soil with stones and matope & 2 & 1 \\
Black soil with sand and matope & 1 & - \\
Sand and stones & 1 & - \\
\hline Total & 261 & 102 \\
\hline
\end{tabular}

to be obtained from planalto, but only four from montanhas. Fourteen resources were obtained from two or more land types, with the other 13 being only obtained from one type. The bulk of the resources limited to a single type comprised aquatic related resources, and were confined to baixa (water, matope, reeds for mats, bananas, fish, aquatic plants, sand, reeds for construction and nongo). Planicie was identified as being the sole area for football fields, clay for pots and timber, although all of these could probably be obtained from planalto too (certainly timber). The identification of honey only from planalto is a misleading result, as for some of the other types this was included under wild foods and fruits.

In terms of relative importance, the key resource from baixa was water (Table 29), followed to a lesser extent by matope (for cultivation), reeds for sleeping mats, and construction materials (poles, grass, rope and bamboo). The most important aspect of planicie was use for fields, followed by wood for handles, livestock, firewood, pestle and mortars, sites for houses, clay for pots, and then construction materials. For planalto, the principal resources were use for fields, and pestle and mortars, whilst for the mountains it was the gathering of wild foods and fruits and traditional medicines.

The second exercise was to consider one resource at a time and, using a bounded scoring 
technique, to indicate the importance of land types as a source for that particular resource (Table 30). Of the 25 resources examined, planicie was identified as being the principal source for 12 of these, baixa for 10, planalto for 3, and none from the mountains. For planalto, these were sites for houses, soil for plastering and grazing for livestock. For baixa, the bulk of the resources were aquatic related items, plus bamboo, grass for thatching, grinding stones (from river beds), honey and wild fruits. Planicie was identified as being the main source of land for fields, firewood, wood for handles, wood for timber and grinding sticks and bowls, poles, bark for rope, clay for pots, traditional medicines, wild foods and wildlife.

Results of the two exercises were inconsistent on some aspects (Tables 29 and 30). For example, as regards whether houses were located predominantly in planicie or planalto, or whether planicie or planalto were more important in terms of fields for cultivation. This may partly relate to the lack of clear separation between these two types. Results of grazing for livestock also varied markedly.

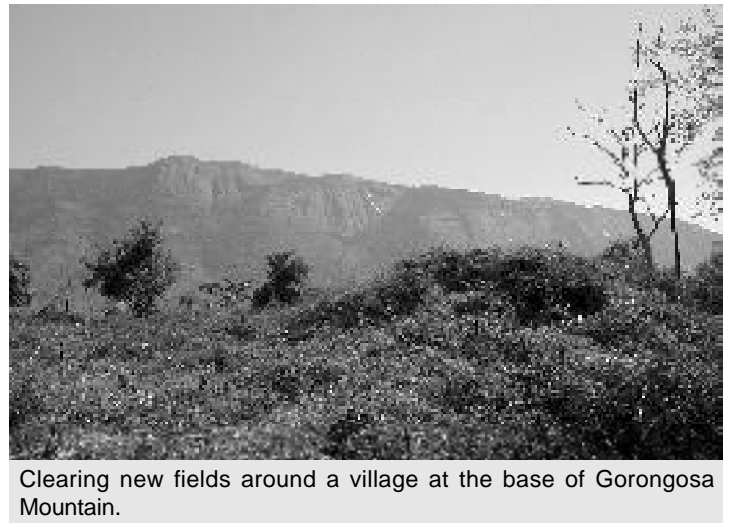

Relative abundance and importance of soil types and land types. The CRUAT group was asked to score the relative abundance and importance of soil and land types. A bounded scoring approach was used for both the abundance scores, and for the importance of soil types, but for the importance of land types an open scoring system was used.

In terms of abundance of soil types (Table $31)$, red soil was perceived as being most common (10 points), followed by black soil ( 9

Table 29. Natural resources obtained from each of the four land types within Nhanchururu. Each land type was scored separately. Importance scores reflect the relative importance of each resource obtained from that land type as regards an average household within Nhanchururu achieving an adequate standard of living. All scores are relative to the least important resource for each land type (traditional medicines for baixa and planalto, football field for planicie, and wildlife for montanhas).

\begin{tabular}{|c|c|c|c|c|}
\hline \multirow[t]{2}{*}{ Resource } & \multicolumn{4}{|c|}{ Relative Importance Weight (RIW) } \\
\hline & Baixa & Planicie & Planalto & Montanhas \\
\hline Land for cultivation & - & 39 & 50 & - \\
\hline Water & 45 & - & - & - \\
\hline Grinding sticks and bowls & - & 26 & 35 & - \\
\hline Wood for handles & - & 30 & 15 & - \\
\hline Grazing for livestock & - & 29 & 10 & - \\
\hline Firewood & 6 & 27 & 12 & - \\
\hline Wet areas for crops (matope) & 26 & - & - & - \\
\hline Sites for houses & - & 25 & 9 & - \\
\hline Reeds for mats & 25 & - & - & - \\
\hline Poles for construction & 20 & 15 & 16 & - \\
\hline Grass for thatching & 20 & 15 & - & - \\
\hline Bark for rope & 20 & 15 & 16 & - \\
\hline Bamboo & 20 & 15 & - & - \\
\hline Wild foods and fruits & 3 & 13 & 17 & 20 \\
\hline Clay for pots & - & 19 & - & - \\
\hline Bananas & 18 & - & - & - \\
\hline Traditional medicines & 1 & 10 & 1 & 18 \\
\hline Fish & 16 & - & - & - \\
\hline Grinding stones & 12 & - & 5 & 15 \\
\hline Wildlife for hunting & - & 12 & 8 & 1 \\
\hline Aquatic plants for food & 10 & - & - & - \\
\hline Sand & 9 & - & - & - \\
\hline Timber & - & 9 & - & - \\
\hline Reeds for construction & 7 & - & - & - \\
\hline Honey & - & - & 7 & - \\
\hline Clay for cultivation (nongo) & 2 & - & - & - \\
\hline Football field & - & 1 & - & - \\
\hline Total resources & 17 & 16 & 13 & 4 \\
\hline
\end{tabular}


Table 30. Occurrence of natural resources within the four principal land types of Nhanchururu. A bounded scoring approach was used, with an allocation of five points per land type, to give a total of 20 points for each resource.

\begin{tabular}{|c|c|c|c|c|c|}
\hline Natural resource & Baixa & Planicie & Planalto & Montanhas & Total \\
\hline Land for fields & 3 & 15 & 2 & - & 20 \\
\hline Land for houses & - & 6 & 14 & - & 20 \\
\hline Water & 20 & - & - & - & 20 \\
\hline Firewood & 2 & 13 & 4 & 1 & 20 \\
\hline Wood for handles & 2 & 13 & 4 & 1 & 20 \\
\hline Grazing for livestock & - & 5 & 15 & - & 20 \\
\hline Reeds for mats & 20 & - & - & - & 20 \\
\hline Grinding sticks and bowls & 4 & 10 & 6 & - & 20 \\
\hline Timber & 1 & 16 & 3 & - & 20 \\
\hline Poles & 4 & 14 & 2 & - & 20 \\
\hline Bamboo & 18 & 2 & - & - & 20 \\
\hline Bark for rope & 5 & 13 & 2 & - & 20 \\
\hline Grass for thatching & 13 & 6 & 1 & - & 20 \\
\hline Cultivated fruits & 2 & 15 & 3 & - & 20 \\
\hline Clay for pots & - & 20 & - & - & 20 \\
\hline Traditional medicines & 3 & 16 & 1 & - & 20 \\
\hline Grinding stones & 17 & - & 3 & - & 20 \\
\hline Reeds for construction & 20 & - & - & - & 20 \\
\hline Food from the wild & 4 & 13 & 2 & 1 & 20 \\
\hline Mud for cultivation (matope) & 20 & - & - & - & 20 \\
\hline Honey & 13 & 4 & 2 & 1 & 20 \\
\hline Fish and other aquatic foods & 20 & - & - & - & 20 \\
\hline Wild fruits & 11 & 4 & 3 & 2 & 20 \\
\hline Wildlife & 4 & 8 & 6 & 2 & 20 \\
\hline Soil for plastering houses & - & 3 & 17 & - & 20 \\
\hline Total & 206 & 196 & 90 & 8 & 500 \\
\hline
\end{tabular}

points), black soil with sand (7 points) and soil with small stones ( 6 points). These four types, together accounted for $80 \%$ of the overall area. In comparison with the GPS data (Table 28), the CRUAT appear to have strongly overstated the abundance of red soil.

In terms of importance, black and red soils were rated as being equally important ( 9 points each), since both types were considered to be suitable for both fields and houses. Soil with small

Table 31. Relative abundance and importance of the principal soil types found within Nhanchururu. Importance scores reflect the relative importance of each soil type as regards an average household within Nhanchururu achieving an adequate standard of living. For both aspects a bounded scoring approach was used, with an allocation of five points per soil type.

\begin{tabular}{llrr} 
Local description & Soil type & RIWA & RIWI \\
\hline Terra vermelha & Red soil & 10 & 9 \\
Terra preta & Black soil & 9 & 9 \\
Mestura terra preta & Blacksoil with & 7 & 5 \\
com areia & sand & & \\
Mestura terra & Soil with & 6 & 2 \\
com pedra & small stones & & \\
Pedra & Stones & 4 & 4 \\
Dongo & Clay & 2 & 7 \\
Matope & Mud & 1 & 3 \\
Nongo & Slippery clay soil & 1 & 1 \\
Total & & 40 & 40 \\
\hline
\end{tabular}

RIWA Abundance RIW RIWI Importance RIW stones was given a much lower importance rating ( 2 points) than anticipated from its abundance ( 6 points), on the basis that these soils are perceived as being unsuitable for cultivation. Conversely, clay for pots (dongo) was given a much higher importance rating (7 points) than suggested by its abundance ( 2 points). The abundance and importance ratings of all other soil types are closely comparable.

Planalto was rated as being the most common land type (9 points), followed by planicie ( 6 points), then baixa (4 points) and montanhas (1 point) (Table 32). By comparison, the GPS data gives equivalent scores of 7 for planalto, 10 for planicie, 3 for baixa, and 0 for montanhas (Ta ble 28).

Table 32. Relative abundance and importance of the principal land types found within Nhanchururu. A bounded scoring approach was used for abundance, with an allocation of five points per land type. Importance scores reflect the relative importance of each land type as regards an average household within Nhanchururu achieving an adequate standard of living. Each type was scored relative to the least important type (mountains).

Local

description Land type

RIWA RIWI

\begin{tabular}{llll}
\hline Baixa Low places & 4 & 15
\end{tabular}

Planicie Mid slopes/level terrain 620

$\begin{array}{lll}\text { Planalto High places } & 9 & 10\end{array}$

Montanhas Mountains $\quad 1 \quad 1$


As regards importance, planicie was rated as being of greatest importance ( 20 points), followed by baixa (15 points), and then planalto (10 points). Mountains were rated as being of only very minor significance (1 point). These results accord well with the data on occurrence of resources within land types (Tables 29 and 30).

Spatial distribution of resources within land types. The final exercise within this section was to investigate the spatial distribution of each resource within each land type. Informants were asked to classify each resource within a land type as being either evenly or unevenly distributed (Table 33). Almost all resources from baixa and montanhas were seen as being unevenly distributed, whilst the majority of those from planicie and planalto were seen as being evenly distributed. Intuitively, this is what one might expect, with low lying baixa areas varying significantly from minor seeps to perennial rivers, and mountain areas being similarly diverse according to elevation and local conditions, whilst the intervening areas might be expected to be more regular. The perceived even distribution of fields within both planicie and planalto is of interest, as were the different ratings of sites for houses (some sites on planicie are potentially subject to flooding, so it is wiser to build on planalto) and soil for plastering (all planicie soils are suitable but some planalto soils are too stony for plastering). These results are of considerable relevance to the spatial formulation of the model and the assumption of even resource distributions throughout land types.

\section{c) Factors limiting access to resources within Nhanchururu}

The approach adopted for investigation of factors limiting access to resources was to open with a general discussion and identification of potential limiting factors; to follow this with more detailed investigations of limiting factors acting on specific resources (land, crops, water, firewood and bamboo); and of specific cost factors (government regulations, traditional regulations, distances and times); and then finally to try and draw these facets together through generation of an overall listing of limiting factors, and to score the relative importance of these.

Initial identification of limiting factors. Initial discussions concerning factors that limit access to natural resources resulted in the identification of five aspects, in the following order: lack of agricultural implements, lack of household utensils, government regulations, distance, and traditional regulations. These were not scored.

Factors limiting access to land. Eight factors were identified as limiting access to land for cultivation (Table 34). These were scored using a bounded scoring system. Significant weighting were given to the lack of basic equipment (hoes 10 points, axes 9 points, pangas 5 points, and sickles 4 points) and to the lack of seeds ( 6 points).

Table 33. Spatial distribution of natural resources within land types. The symbol T indicates an even distribution of a resource within a particular land type, $\mathrm{V}$ indicates an uneven or clumped distribution, and - indicates the absence of the resource from that land type.

\begin{tabular}{lcccc} 
Resource & Baixa & Planicie & Planalto & Montanhas \\
\hline Land for cultivation & - & $\mathrm{T}$ & $\mathrm{T}$ & - \\
Water & $\mathrm{V}$ & - & - & - \\
Wood for handles & - & $\mathrm{T}$ & $\mathrm{T}$ & - \\
Firewood & $\mathrm{V}$ & $\mathrm{T}$ & - & - \\
Wet areas for crops (matope) & $\mathrm{V}$ & - & - & - \\
Wet areas for crops (nongo) & $\mathrm{V}$ & - & $\mathrm{T}$ & - \\
Sites for houses & - & $\mathrm{V}$ & - & - \\
Reeds for mats & $\mathrm{V}$ & - & $\mathrm{T}$ & - \\
Poles for construction & $\mathrm{V}$ & $\mathrm{T}$ & - & - \\
Grass for thatching & $\mathrm{V}$ & $\mathrm{T}$ & $\mathrm{T}$ & - \\
Bark for rope & $\mathrm{V}$ & $\mathrm{T}$ & - & $\mathrm{V}$ \\
Bamboo & $\mathrm{T}$ & $\mathrm{V}$ & $\mathrm{T}$ & $\mathrm{T}$ \\
Wild foods & $\mathrm{V}$ & $\mathrm{T}$ & $\mathrm{T}$ \\
Honey & $\mathrm{V}$ & $\mathrm{T}$ & $\mathrm{T}$ & - \\
Wild fruits & $\mathrm{V}$ & $\mathrm{T}$ & - & $\mathrm{V}$ \\
Clay for pots & - & $\mathrm{T}$ & $\mathrm{V}$ & - \\
Traditional medicines & $\mathrm{V}$ & $\mathrm{T}$ & - & $\mathrm{V}$ \\
Fish & $\mathrm{V}$ & - & - & $\mathrm{V}$ \\
Grinding stones & $\mathrm{V}$ & - & $\mathrm{T}$ & - \\
Wildlife for hunting & - & $\mathrm{T}$ & - & - \\
Aquatic plants for food & $\mathrm{V}$ & - & $\mathrm{V}$ & - \\
Soil for plastering & - & $\mathrm{T}$ & - & - \\
Timber & - & $\mathrm{T}$ & - & 6 \\
Reeds for construction & 17 & 16 & 12 & \\
\hline Total resources & & &
\end{tabular}


The other three factors were government regulations, distance and traditional regulations, all of which were considered to be of relatively minor importance.

Table 34. Factors limiting access to land. Importance scores reflect the relative importance of each factor as regards its contribution towards limiting access to land by an average household within Nhanchururu. A bounded scoring approach was used, with an allocation of five points per factor, to give a total of 40 points.

\begin{tabular}{lrrr} 
Cost factors & RIW & RIWS & RIWC \\
\hline Lack of hoes & 10 & 0.250 & 0.250 \\
Lack of axes & 9 & 0.225 & 0.475 \\
Lack of seeds & 6 & 0.150 & 0.625 \\
Lack of pangas & 5 & 0.125 & 0.750 \\
Lack of sickles & 4 & 0.100 & 0.850 \\
Government regulations & 3 & 0.075 & 0.925 \\
Distance & 2 & 0.050 & 0.975 \\
Traditional regulations & 1 & 0.025 & 1.000 \\
\hline Total & 40 & 1.000 & 1.000 \\
\hline
\end{tabular}

Factors limiting production of crops. Thirteen factors were identified here and scored using a bounded scoring system (Table 35). Drought conditions were given the highest score of 10 points. The bulk of the factors concerned a lack of inputs (seeds, poor fertility) or equipment (hoes, axes, sickles, pangas, tractors, ploughs and oxen). Other factors mentioned were uncontrolled burning (due to its negative impact on fertility), traditional regulations (need to negotiate for access to land), and the need to apply water to certain crops such as vegetables or fruit trees. Informants maintained that there were no government restrictions on the clearing of land within Nhanchururu, but that this was prohibited within the park area (outside of and to the east of the village area).

Factors limiting access to water. Five factors were identified as limiting access to water, and scored using an open scoring system (Table 36). The lack of containers was seen as being the least important factor (1 point). The highest score was given to drought conditions (12 points), under which circumstances a number of water points were reported to run dry. During extreme droughts the Vunduzi river apparently reduces to a minor trickle but does not actually stop flowing, whilst the Mucodza was said to stop flowing but to maintain a series of pools. Most other sources apparently run dry. "Dangers" (10 points) include those of crocodiles ( 2 attacks in the last 20 years); snake bites ( 2 cases in the last 4 years); and bee stings; as well as slipping on slopes or clay soils, tripping on stumps, and falling into holes. The lack of wells (5 points) reflects a lack of constructed wells rather than any lack of potential well sites. The low score given to distance ( 2 points) is surprising, given that informants subsequently maintained that an average trip to fetch water required a total of 3 hours.

Table 35. Factors limiting the production of crops. Importance scores reflect the relative importance of each factor as regards its contribution towards limiting the production of crops by an average household within Nhanchururu. A bounded scoring approach was used, with an allocation of five points per factor, to give a total of 65 points.

\begin{tabular}{lrrr} 
Cost factors & RIW & RIWS & RIWC \\
\hline Drought conditions & 10 & 0.154 & 0.154 \\
Lack of seeds & 9 & 0.138 & 0.292 \\
Lack of hoes & 8 & 0.123 & 0.415 \\
Lack of axes & 7 & 0.108 & 0.523 \\
Poor fertility & 6 & 0.092 & 0.615 \\
Lack of sickles & 5 & 0.077 & 0.692 \\
Lack of pangas & 5 & 0.077 & 0.769 \\
Uncontrolled burning & 4 & 0.062 & 0.831 \\
Lack of tractors & 3 & 0.046 & 0.877 \\
Lack of ploughs & 3 & 0.046 & 0.923 \\
Traditional regulations & 2 & 0.031 & 0.954 \\
Lack of oxen & 2 & 0.031 & 0.985 \\
Need to apply water & 1 & 0.015 & 1.000 \\
\hline Total & 65 & 1.000 & 1.000 \\
\hline
\end{tabular}

Table 36. Factors limiting access to water. Importance scores reflect the relative importance of each factor as regards its contribution towards limiting access to water by an average household within Nhanchururu. All scores are relative to the least important factor (lack of containers).

\begin{tabular}{lrrr} 
Cost factors & RIW & RIWS & RIWC \\
\hline Drought conditions & 12 & 0.400 & 0.400 \\
Dangers from animals & 10 & 0.333 & 0.733 \\
Lack of wells & 5 & 0.167 & 0.900 \\
Distance & 2 & 0.067 & 0.967 \\
Lack of containers & 1 & 0.033 & 1.000 \\
\hline Total & 30 & 1.000 & 1.000 \\
\hline
\end{tabular}

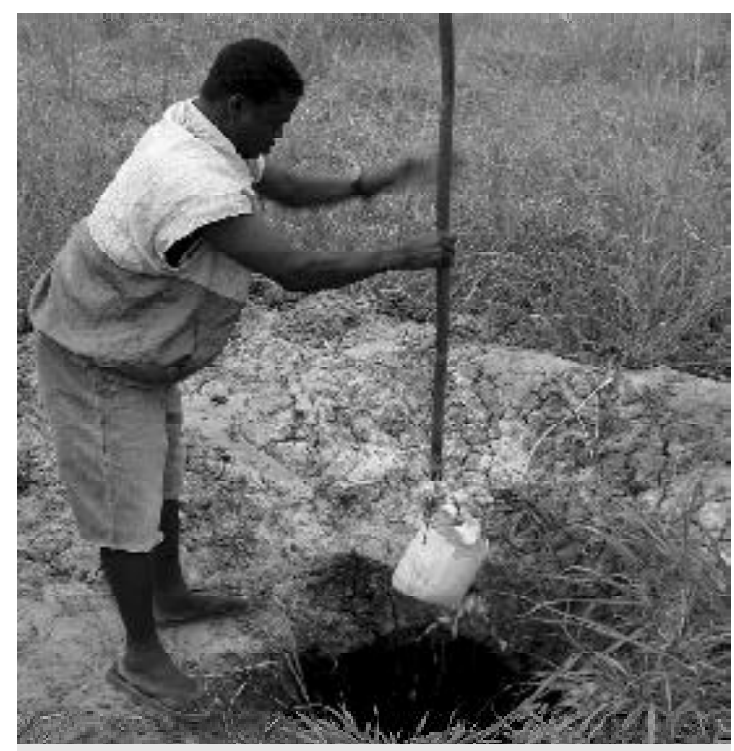

Drawing water from a shallow ground well in Mauredzi 
Factors limiting access to firewood. Firewood was selected as an example of a nontimber forest product. Nine limiting factors were identified (Table 37). These were scored relative to the least important factor, traditional regulations ( 1 point, it is forbidden to cut in cemeteries, and to cut four particular species). "Dangers" were given the highest score (35 points). This was followed by a lack of axes ( 30 points), and a lack of pangas ( 20 points). Fires were seen as acting negatively on the supply of firewood ( 25 points), as was the opening of fields (10 points). The difficulty of carrying a heavy load was scored at 15 points, and distance as 13 points. Government regulations were seen as being relatively insignificant (2 points), the only restrictions being on the use of specified timber species, and the collection of firewood from within the park area.

Table 37. Factors limiting access to firewood. Importance scores reflect the relative importance of each factor as regards its contribution towards limiting access to firewood by an average household within Nhanchururu. All scores are relative to the least important factor (traditional regulations).

\begin{tabular}{lrrc} 
Cost factors & RIW & RIWS & RIWC \\
\hline Dangers & 35 & 0.232 & 0.232 \\
Lack of axes & 30 & 0.199 & 0.430 \\
Uncontrolled burning & 25 & 0.166 & 0.596 \\
Lack of pangas & 20 & 0.132 & 0.728 \\
Difficulty of carrying & 15 & 0.099 & 0.828 \\
Distance & 13 & 0.086 & 0.914 \\
Opening of fields & 10 & 0.066 & 0.980 \\
Government regulations & 2 & 0.013 & 0.993 \\
Traditional regulations & 1 & 0.007 & 1.000 \\
\hline Total & 151 & 1.000 & 1.000 \\
\hline
\end{tabular}

Factors limiting access to bamboo. Five factors were identified, and scored using a bounded scoring system (Table 38). All five were included amongst the set of 9 factors previously identified as limiting access to firewood. In terms of the relative importance of these factors, the maj or difference between the two resources was the high weighting given to government regulations for bamboo (8 points) versus firewood ( 2 points). The reason for this was stated as being that some people move out of Nhanchururu into the park area to collect bamboo, but before doing this they must first get permission from the park rangers, who are likely to impose some "charge" for giving the necessary permission. Factors that were identified for firewood but not bamboo, were "dangers", difficulty of carrying, the opening of fields, and traditional regulations.

Impact of government regulations. The CRUAT identified 12 aspects of government regulations limiting access to natural resources (Table 39). These were scored using an open system, and relative to the least important factors
(1 point each for protection of pangolins, no selling of land, and problems with women). Restrictions concerning the smoking of mbanje was given the highest score (10 points). Some regulations apply to both the village and park areas, such as no burning ( 7 points); no hunting ( 6 points); and no cutting of timber species ( 2 points), whilst others were seen as applying only to the park area and not the village area (collection of reeds - 5 points; wild fruits, foods and honey - 3 points; firewood 2 points; and catching fish - 2 points). For the first group it is not possible to get permission to carry out these activities, whilst for the latter group the GNP scouts are able to authorize the harvesting of these resources from within the park area. The two factors of no stealing and "problemas" (social problems - like beating your neighbour, or sleeping with someone else's wife) are not of any direct relevance here. The restriction against selling of land was acknowledged, but considered to be of only minor significance (1 point).

Table 38. Factors limiting access to bamboo. Importance scores reflect the relative importance of each factor as regards its contribution towards limiting access to bamboo by an average household within Nhanchururu. A bounded scoring approach was used, with an allocation of five points per factor, to give a total of 25 points.

\begin{tabular}{lccc} 
Cost factors & RIW & RIWS & RIWC \\
\hline Government regulations & 8 & 0.320 & 0.320 \\
Lack of pangas & 7 & 0.280 & 0.600 \\
Lack of axes & 5 & 0.200 & 0.800 \\
Uncontrolled burning & 4 & 0.160 & 0.960 \\
Distance & 1 & 0.040 & 1.000 \\
\hline Total & 25 & 1.000 & 1.000 \\
\hline
\end{tabular}

Table 39. Impact of government regulations as regards limiting access to natural resources. Importance scores reflect the relative importance of each factor as regards its contribution towards limiting access to natural resources by an average household within Nhanchururu. All scores are relative to the least important factors (respect for pangolins, no selling of land, and problems with women).

\begin{tabular}{lrrr} 
Government regulations & RIW & RIWS & RIWC \\
\hline No smoking of mbanje & 10 & 0.238 & 0.238 \\
No uncontrolled burning & 7 & 0.167 & 0.405 \\
No hunting of wildlife & 6 & 0.143 & 0.548 \\
Collection of reeds for mats & 5 & 0.119 & 0.667 \\
Collection of wild fruits, wild & 3 & 0.071 & 0.738 \\
foods and honey & & & \\
Collection of firewood & 2 & 0.048 & 0.786 \\
Harvesting of timber & 2 & 0.048 & 0.833 \\
Catching fish & 2 & 0.048 & 0.881 \\
Theft & 2 & 0.048 & 0.929 \\
Problems with women & 1 & 0.024 & 0.952 \\
No selling of land & 1 & 0.024 & 0.976 \\
Respect for pangolins & 1 & 0.024 & 1.000 \\
\hline Total & 42 & 1.000 & 1.000 \\
\hline
\end{tabular}


Impact of traditional regulations. Traditiona regulations were recognised as potentially limiting access to resources in nine different ways (Table 40). These were scored using a bounded scoring system. Five factors appear to be of only marginal interest as regards natural resources, these being: no smoking of mbanje ( 8 points), no sleeping with wives of others ( 7 points), no stealing (7 points), no drinking/ brewing of "nipa" (4 points) and no premature marrying (1 point). Three of the other regulations are highly specific: no killing of crocodiles ( 8 points - as their parts are used for witchcraft), no killing of pangolins (3 points), and no cutting of four particular tree species ( 2 points). The other factor, no uncontrolled burning (5 points), acts on a much wider spectrum of resources. The level of concordance with the previous government regulations (five common factors) was surprising.

Table 40. Impact of traditional regulations as regards limiting access to resources by an average household within Nhanchururu. A bounded scoring approach was used, with an allocation of five points per factor, to give a total of 45 points.

\begin{tabular}{lccc} 
Traditional regulations & RIW & RIWS & RIWC \\
\hline No smoking of mbanje & 8 & 0.178 & 0.178 \\
No killing of crocodiles & 8 & 0.178 & 0.356 \\
No sleeping with wives of others & 7 & 0.156 & 0.511 \\
No stealing & 7 & 0.156 & 0.667 \\
No burning & 5 & 0.111 & 0.778 \\
No drinking of nipa & 4 & 0.089 & 0.867 \\
No taking of pangolins & 3 & 0.067 & 0.933 \\
No using of four types of trees & 2 & 0.044 & 0.978 \\
No premature marrying & 1 & 0.022 & 1.000 \\
\hline Total & 45 & 1.000 & 1.000 \\
\hline
\end{tabular}

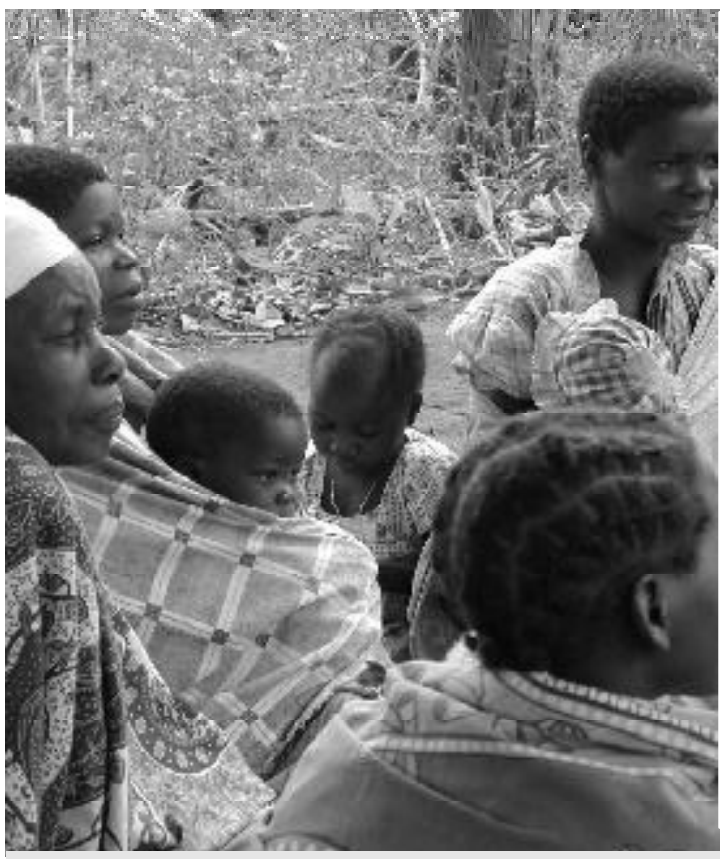

Women from the Nhanchururu CRUAT during a discussion session
On and off path distances. The group was asked to score the relative distances that had to be covered on path and off path in order to access each type of resource. A bounded scoring approach was used with an allocation of 10 points per resource (Table 41). A number of resources were reported to be directly accessible by path. These included key resources that are used frequently, such as water, fields and fields in wet areas (matope and nongo), as well as less significant resources such as clay for pots, reeds for construction, soil for plastering of houses, and aquatic food plants. For all other resources the off path distance was consistently estimated to be greater than the on path distance.

Table 41. Relative distances travelled on path and off path by an average household within Nhanchururu in order to access natural resources. A bounded scoring approach was used, with 10 points being allocated to each resource to be divided between on path and off path distances.

\begin{tabular}{lcc} 
& \multicolumn{2}{c}{ Relative distance } \\
\cline { 2 - 3 } Natural resource & On path & Off Path \\
\hline Wildlife & 3 & 7 \\
Fish & 1 & 9 \\
Wild foods & 3 & 7 \\
Bamboo & 4 & 6 \\
Water & 10 & - \\
Wild fruits & 3 & 7 \\
Honey & 2 & 8 \\
Reeds for mats & 3 & 7 \\
Grass for thatching & 3 & 7 \\
Poles & 4 & 6 \\
Firewood & 2 & 8 \\
Timber including trees for & 2 & 8 \\
grinding sticks and bowls & & \\
Bark for rope & 2 & 8 \\
Fields & 10 & - \\
Wood for handles & 4 & 6 \\
Fields in wet areas (matope) & 10 & - \\
Fields in wet areas (nongo) & 10 & - \\
Clay for pots & 10 & - \\
Grinding stones & 2 & 8 \\
Reeds for construction & 10 & - \\
Soil for plastering & 10 & - \\
Aquatic plants for food & 10 & - \\
\hline
\end{tabular}

Time taken to access resources. Two exercises were carried out concerning the time required to access each type of resource (Table 42). Informants were initially asked to estimate the actual time taken for a single trip to collect a particular resource, this being the time taken from leaving the house to returning to the house. For the second exercise, the CRUAT were asked to split 10 points for each resource, according to the relative time spent whilst travelling to the area to find the resource, to that of the time spent harvesting or collecting the particular resource. 
The most surprising result was the estimate of three hours required to access water. When queried why it took so much longer to access water than other aquatic resources, such as aquatic plants, nongo and matope, it was explained that although there are many low lying baixa areas where these resources can be found, many of these sites do not offer suitable sources of water, and for which one must go further afield. Of the 24 resources considered, 16 (two thirds) can be obtained during a two-hour period or less (i.e. for both traveling and collection of the resource). Those resources that require longer periods included reeds for mats, honey, wild fruits and water (all 3 hours), bamboo and wild foods (4 hours), fish (5 hours) and wildlife ( 6 hours).

Table 42. Time taken to access natural resources. Initial estimates are for the actual time required for an average household within Nhanchururu to travel from the household to collect a particular resource and return home again. For the relative times, a bounded scoring approach was used, with 10 points being allocated to each resource to be divided between travel time and collection time.

\begin{tabular}{lrrr} 
Natural resource & TTT & RTT & RTC \\
\hline Wildlife & 6 & 4 & 6 \\
Fish & 5 & 4 & 6 \\
Wild foods & 4 & 4 & 6 \\
Bamboo & 4 & 4 & 6 \\
Water & 3 & 7 & 3 \\
Wild fruits & 3 & 3 & 7 \\
Honey & 3 & 3 & 7 \\
Reeds for mats & 3 & 4 & 6 \\
Grass for thatching & 2 & 2 & 8 \\
Poles & 2 & 2 & 8 \\
Firewood & 2 & 3 & 7 \\
Timber including trees for grinding & 2 & 2 & 8 \\
sticks and bowls & & & \\
Bark for rope & 1 & 2 & 8 \\
Fields & 1 & 1 & 9 \\
Wood for handles & 1 & 1 & 9 \\
Fields in wet areas (matope) & 1 & 1 & 9 \\
Fields in wet areas (nongo) & 1 & 1 & 9 \\
Clay for pots & 1 & 1 & 9 \\
Grinding stones & 1 & 4 & 6 \\
Reeds for construction & 1 & 5 & 5 \\
Soil for plastering & 1 & 1 & 9 \\
Aquatic plants for food & 1 & 3 & 7 \\
Traditional medicines & 1 & 2 & 8 \\
Settlements & 30 mins & - & - \\
\hline TTT Totatime per trip (hous) & & &
\end{tabular}

TTT Total time per trip (hours)

RTT Relative time travel (hours)

RTC Relative time collection (hours)

When it came to comparisons of travel time versus collection time, the group were consistent in allocating more time to collecting than travel. The only exceptions to this were for water ( 7 points to travel versus 3 for collection) and for the harvesting of reeds for construction (5 points for both travel and collection). This implies that, other than for the resources that take the most time to access, all other resources are available within relatively close proximity of homesteads. For example, if it takes four hours to access bamboo, of which 4/ 10 is spent on travel, this implies a total travel time of 96 minutes or roughly 45 minutes each way.

Overall list of limiting factors. As the final exercise the CRUAT group was asked to generate an overall listing of limiting factors, and to score the relative importance of these using an open scoring technique (Table 43). In doing this the group referred back to the above exercises looking at individual resources. A final list of 16 factors were drawn up, the least important of which was considered to be the need to water

Table 43. Overall listing of factors limiting access to natural resources. Importance scores reflect the relative importance of each factor as regards its contribution towards limiting access to natural resources by an average household within Nhanchururu. All scores are relative to the least important factor (the need to water vegetable gardens).

\begin{tabular}{lrrr} 
Factor & RIW & RIWS & RIWC \\
\hline Droughts & 22 & 0.182 & 0.182 \\
Lack of agricultural implements & 20 & 0.165 & 0.347 \\
Lack of seeds & 11 & 0.091 & 0.438 \\
Lack of tractors & 10 & 0.083 & 0.521 \\
Poor soil fertility & 9 & 0.074 & 0.595 \\
Lack of wells & 9 & 0.074 & 0.669 \\
Lack of household implements & 7 & 0.058 & 0.727 \\
Uncontrolled burning & 6 & 0.050 & 0.777 \\
Difficulty of carrying & 6 & 0.050 & 0.826 \\
Government regulations & 5 & 0.041 & 0.868 \\
Distance & 4 & 0.033 & 0.901 \\
Lack of oxen & 4 & 0.033 & 0.934 \\
Lack of ploughs & 3 & 0.025 & 0.959 \\
Traditional regulations & 2 & 0.017 & 0.975 \\
Dangers (wild animals) & 2 & 0.017 & 0.992 \\
Need to water vegetable gardens & 1 & 0.008 & 1.000 \\
\hline Total & 121 & 1.000 & 1.000
\end{tabular}

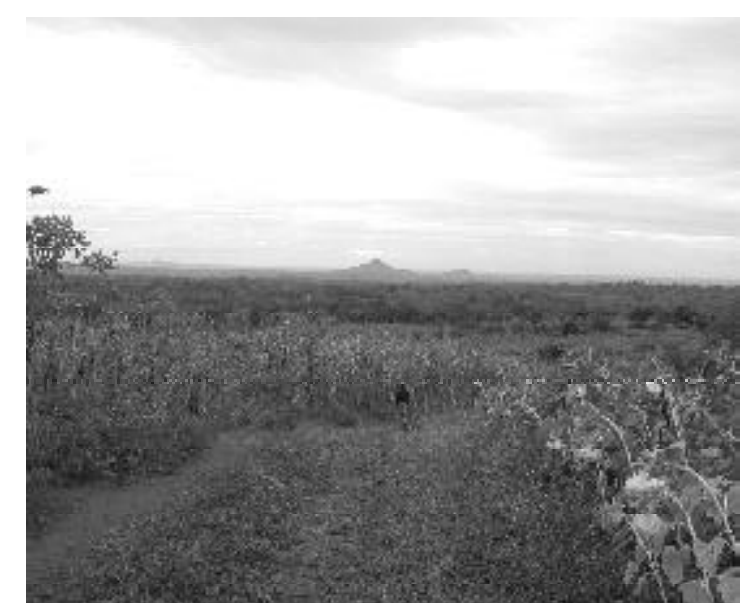

Main road through Nhanchururu showing fields of sorghum and sunflowers. Mt. Bunga in the centre background is in GNP. 
vegetables and fruits (1 point). Drought was identified as being the most important factor ( 22 points), followed closely by the lack of agricultural implements (hoes, axes, pangas, sickles - 20 points). Another 6 factors relate specifically to crop production, these being the lack of seeds (11 points); lack of tractors (10 points); poor soil fertility ( 9 points); lack of oxen ( 4 points); the lack of ploughs ( 3 points); and the need to apply water to certain crops (1 point). In terms of other resources, the lack of wells was rated most highly (9 points); followed by the lack of household utensils ( 7 points); uncontrolled burning ( 6 points), and the difficulty of carrying ( 6 points). Government regulations (5 points), distance (4 points) and traditional regulations ( 2 points) were all seen as being relatively minor importance, together with "dangers" (2 points).

In terms of physical barriers, no absolute barriers were identified either by the CRUAT group or whilst moving in the field. The dissected terrain is likely to make some areas more difficult to access than others, but not to provide any absolute barriers. The so-called "mountains" are not marked enough to provide any meaningful obstacles. The two boundary rivers, particularly the Vunduzi, are likely to be difficult to cross when in flood.

\section{d) Nhanchururu prior model}

As was done with the Muaredzi assessment, the initial field data were used to refine the prior model developed for Nhanchururu (Figure 9). The process was the same as that described for Muaredzi. In general, the goods and services identified by the CRUAT from Nhanchururu were similar to those identified in Muaredzi. There was some difference in the detail on components such as household construction materials. There were also a greater variety of types of honey identified (these were later amalgamated when field data was collected for model confrontation).

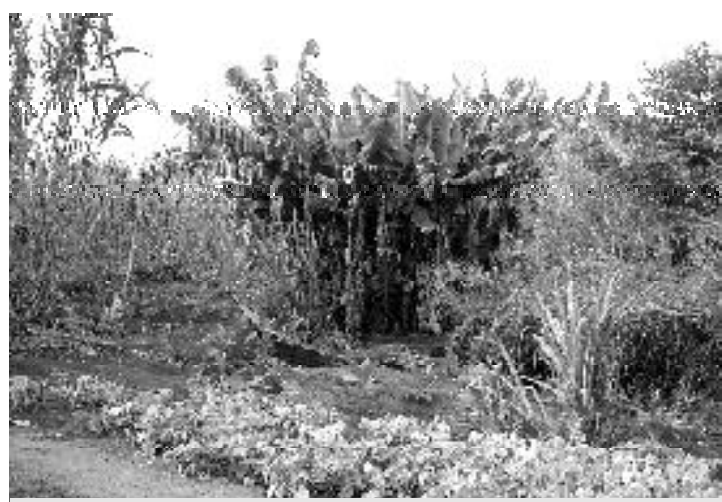

The sensitivity analysis for the prior BBN from Nhanchururu yielded much the same results as obtained for Muaredzi. The cost and benefit nodes had the greatest impact as regards the benefit/ cost estimates, and these were again followed by the individual cost factors (Table 44).

Table 44. Results of the sensitivity analysis for the prior BBN from Nhanchururu.

\begin{tabular}{|c|c|}
\hline Node & $\begin{array}{l}\text { Variance } \\
\text { reduction }\end{array}$ \\
\hline BClandscape & 0.223800 \\
\hline Costs & 0.077240 \\
\hline Benefits & 0.058560 \\
\hline Distance & 0.037560 \\
\hline DistanceAlongMaj orRoutes & 0.021220 \\
\hline Otherbenefits & 0.017690 \\
\hline PlantProducts & 0.013920 \\
\hline DistanceFromRoute & 0.011750 \\
\hline Institutions & 0.011510 \\
\hline Government & 0.008050 \\
\hline WoodProducts & 0.005852 \\
\hline Landandsoil & 0.004151 \\
\hline Water & 0.004084 \\
\hline Land & 0.003362 \\
\hline HouseholdConstructionMaterials & 0.002751 \\
\hline Dangers & 0.002574 \\
\hline ClayStones & 0.002445 \\
\hline TraditionalRegs & 0.002317 \\
\hline Firewood & 0.001956 \\
\hline AnimalsandFish & 0.001910 \\
\hline LandFields & 0.001508 \\
\hline LandHouses & 0.001508 \\
\hline Livestock & 0.001419 \\
\hline WoodforHandles & 0.001229 \\
\hline CultivatedFruits & 0.001218 \\
\hline ClayForPots & 0.001172 \\
\hline GrindingStones & 0.000828 \\
\hline Timber & 0.000714 \\
\hline GrindingStickMaterial & 0.000714 \\
\hline Foodltems & 0.000512 \\
\hline Poles & 0.000510 \\
\hline Bark & 0.000510 \\
\hline Bamboo & 0.000510 \\
\hline ConstructionReeds & 0.000510 \\
\hline Honey & 0.000464 \\
\hline WildFood & 0.000322 \\
\hline Fish & 0.000301 \\
\hline Honey_Mel & 0.000278 \\
\hline ThatchingGrass & 0.000249 \\
\hline MudForCultivation & 0.000200 \\
\hline HomeProducts & 0.000173 \\
\hline WildFruits & 0.000137 \\
\hline Sand & 0.000129 \\
\hline Honey_pasi & 0.000076 \\
\hline ClayForCultivation & 0.000067 \\
\hline ReedsForSleepingMats & 0.000060 \\
\hline TraditionalMedicines & 0.000044 \\
\hline Honey_cacecha & 0.000016 \\
\hline Honey_dowe & 0.000006 \\
\hline Honey_pumbuzi & 0.000006 \\
\hline Wildlife & 0.000006 \\
\hline AquaticPlantsforFood & 0.000005 \\
\hline
\end{tabular}




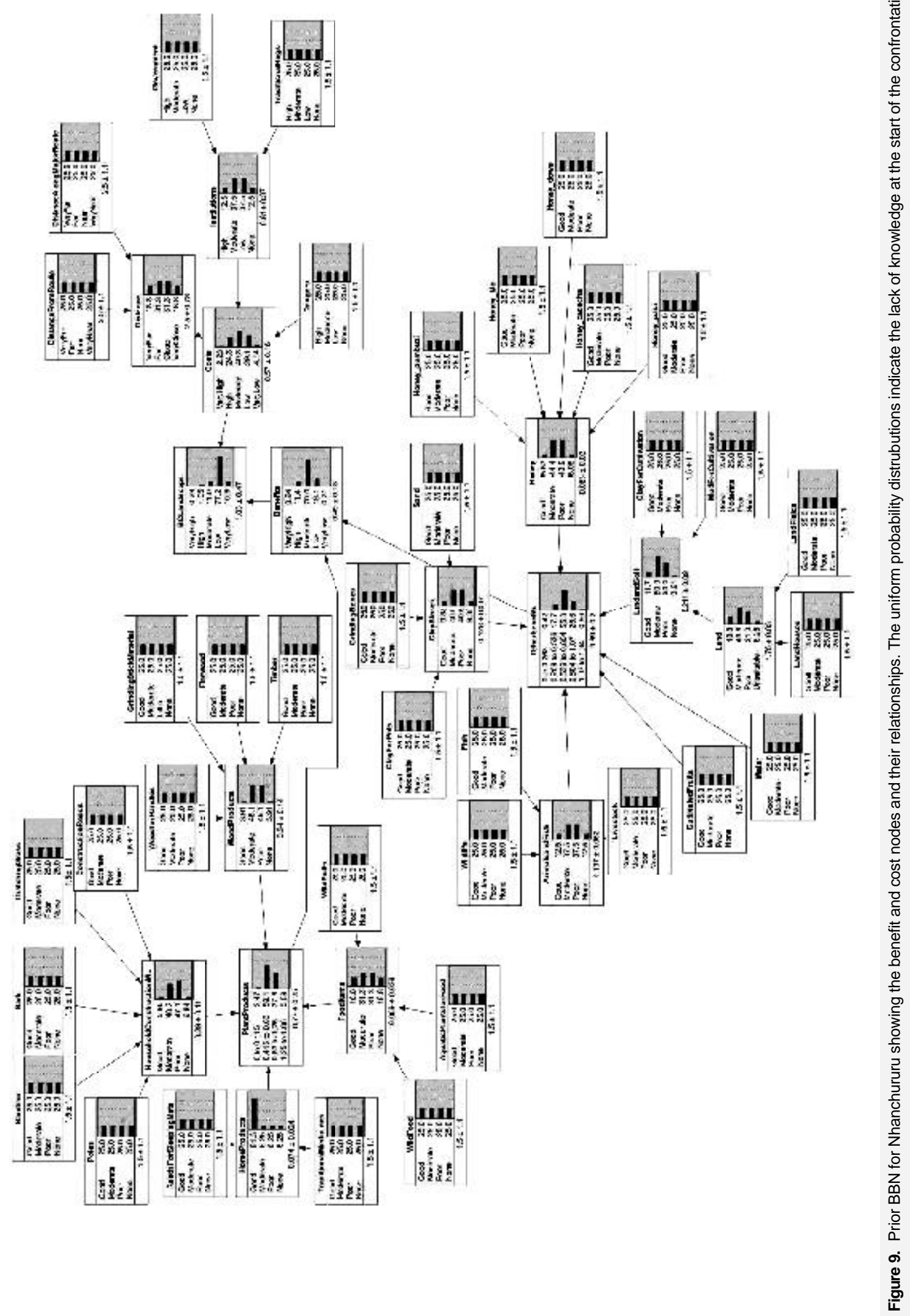




\section{Field Sampling for Model Confrontation}

Results of field sampling are presented for Muaredzi and Nhanchururu (Sections II. B. 4. a and II.B.4.b). For each village the initial section provides a brief analysis of the occurrence of goods and services. This is followed by consideration of factors potentially limiting access to resources. Thereafter, attention is turned to the overall landscape values and their breakdown by enumerators and land types. Brief consideration is also given as to the evidence for enumerator bias within these results. These results are then drawn together and summarised in the form of a comparison between sites (Section II. B. 4.C).

\section{a. Muaredzi}

Sampling was carried out over a three-day period, during which the four recorders enumerated a total of 75 samples from ten transects. Mr. Sizinho recorded 6 samples from a single transect. The other three recorders each covered three transects (one per day). Mr Camissa achieved 26 samples, Ms. Perreira 25, and Mr. Casse 18. The locations of these samples are shown in Figure 5. A summary of the data obtained is presented in Appendix 3.

Goods and services. A total of 15 goods and services were scored for each sample, these being derived from the overall list of resources obtained for Muaredzi (Table 5). Land was separated into two categories, land for houses and land for fields, and these were scored separately. For each sample recorders enquired as to the presence of any additional resources not included on the data sheet. Thatching grass was the only resource identified in this respect. Two groups (Camissa and Perreira) included thatching grass as part of construction materials. The other two groups (Casse and Sizinho) followed a narrower interpretation of construction materials (as being confined to wood for poles), such that thatching grass where present was noted separately.

Firewood was the most frequently occurring resource being recorded from $88 \%$ of samples (Table 45). Ten other resources were recorded from between $20 \%$ and $70 \%$ of samples. The remaining four resources were each recorded from less than $20 \%$ of samples, these being: fish (13\%), wild foods (12\%), clay for pots (7\%) and grinding stones $(1 \%)$. The single occurrence for grinding stones was recorded from a household within the village. The five occurrences of clay for pots all came from samples in relatively close proximity to settlements. Scores for fish were not entirely clear. Some records obviously relate to aquatic environments, but others appear not to be. It is possible that these latter occurrences were from areas where fish get left behind in pools after floods, and from where they are easily harvested as the pools dry up. The low occurrence of wild foods was surprising. Given their low relative importance, it is possible that their presence may have been overlooked for some plots.

Table 45. Frequency of occurrence of resources (good, moderate or poor) from 75 samples recorded from Muaredzi.

\begin{tabular}{lccc} 
Resource & Occ. & $\mathrm{f}$ & \%RI \\
\hline Firewood & 66 & 88 & 0.122 \\
Land for cultivation & 50 & 67 & 0.163 \\
Construction materials & 50 & 67 & 0.130 \\
Traditional medicines & 44 & 59 & 0.024 \\
Land for houses & 44 & 59 & not scored \\
Wild fruit & 37 & 49 & 0.008 \\
Palm leaf products & 36 & 48 & 0.049 \\
Wood for grinding sticks & 32 & 43 & 0.081 \\
Water/ well sites & 28 & 37 & 0.163 \\
Palm wine & 26 & 35 & 0.041 \\
Honey & 18 & 24 & 0.033 \\
Fish & 10 & 13 & 0.106 \\
Wild foods & 9 & 12 & 0.016 \\
Clay for pots & 5 & 7 & 0.065 \\
Grinding stones & 1 & 1 & 0.081 \\
\hline
\end{tabular}

Occ. (Occurrences $n=75$ )

$f$ (Frequency)

\%II (\% Relative Importance, from Table 5)

The mean number of resources per sample was 6.1 , with the overall range being between 1 and 12 resources per plot. These lowest and highest numbers of resources were both recorded by Perreira. The case of a single resource was given an overall landscape value of 3 points. At the other end of the scale, the sample with 12 resources was given a landscape value of 22 points. These data suggest that there is likely to be a relationship between the number of resources per sample and the overall landscape value for that sample. This possibility is further supported in that all recorders commonly noted that the landscape score for a particular sample was given "because of the number of resources that occur there" (either few for low scores, or many for high scores).

Factors limiting access to resources. Information was recorded for five potential cost factors: traditional regulations, government regulations, physical barriers, and both on path and off path distances. A summary of the occurrence of these factors is presented in Tables 46 and 47.

Table 46. Frequency of occurrences of factors limiting access to resources for 75 samples recorded from Muaredzi.

Limiting Factors High Moderate Low None

\begin{tabular}{lrrrr}
\hline Traditional regulations & 0 & 0 & 0 & 75 \\
Government regulations & 29 & 39 & 3 & 4 \\
Physical barriers & 3 & 2 & 3 & 67 \\
\hline
\end{tabular}




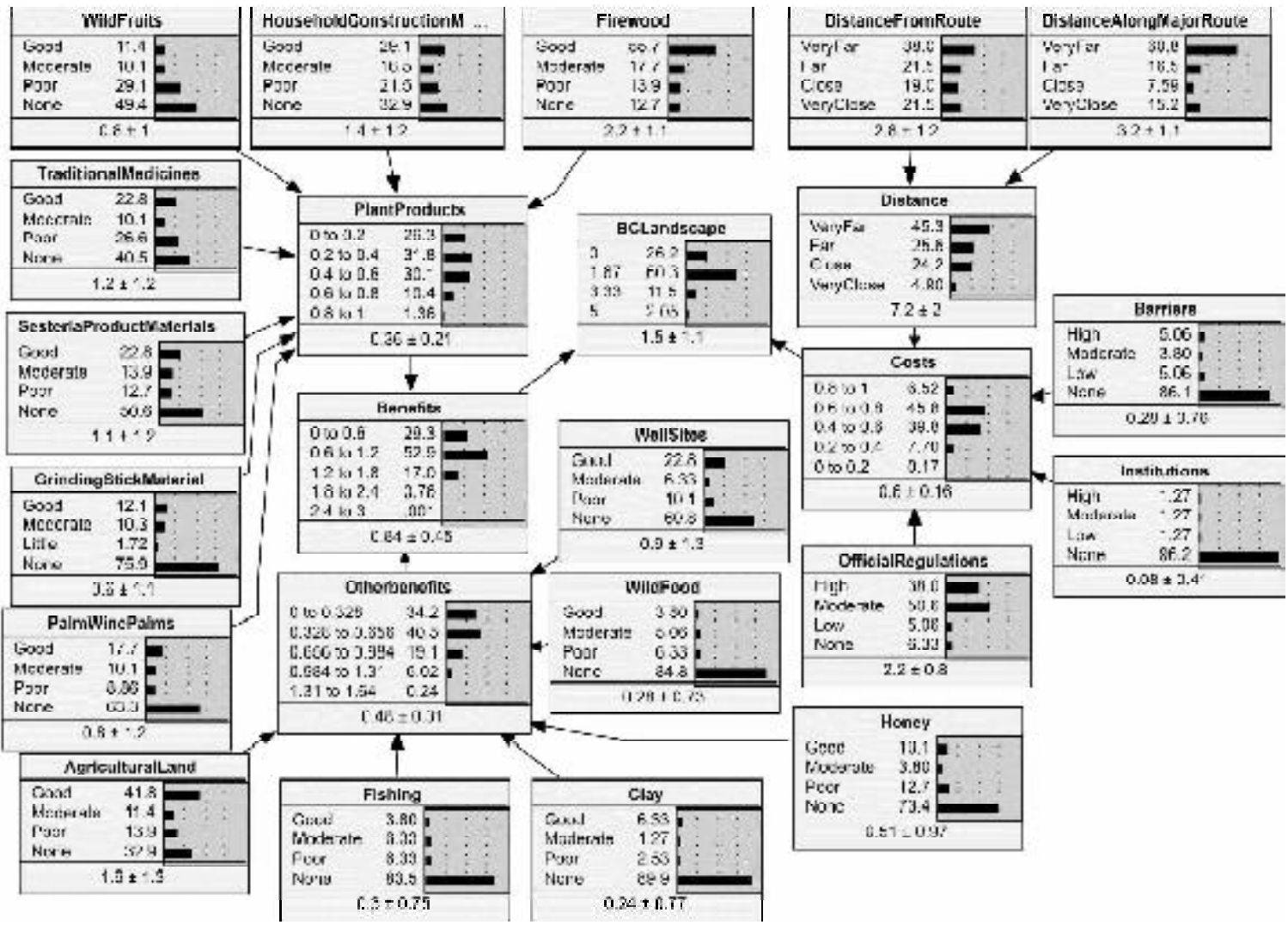

Figure 10. Posterior BBN for Muaredzi showing the changes in the peripheral node probability structures due to the incorporation of the field case samples.

The category of traditional regulations proved not to be very useful, as these were not recorded for any samples. This is consistent with information previously obtained from the CRUAT, who explained that traditions serve to secure or increase access to resources rather than to limit availability in any manner.

Table 47. Distribution of 75 samples recorded from Muaredzi according to on path and off distances for each sample.

\begin{tabular}{lrrrrr} 
& \multicolumn{5}{c}{ Distance on path } \\
\cline { 2 - 6 } $\begin{array}{l}\text { Distance } \\
\text { off path }\end{array}$ & $\begin{array}{l}\text { Very } \\
\text { far }\end{array}$ & Far & Close & $\begin{array}{l}\text { Very } \\
\text { close }\end{array}$ & Total \\
\hline Very far & 28 & 0 & 0 & 0 & 28 \\
Far & 5 & 7 & 2 & 3 & 17 \\
Close & 8 & 3 & 0 & 3 & 14 \\
Very close & 6 & 2 & 3 & 5 & 16 \\
\hline Total & 47 & 12 & 5 & 11 & 75 \\
\hline
\end{tabular}

Government regulations were recorded as being either high (Casse and Sizinho) or moderate (Camissa and Perreira) for 68 samples. The remaining seven samples were rated as being either low $(n=3)$ or none $(n=4)$. Five of these atypical scores come from Camissa's initial transect, and one from Perreira's initial transect.
There is no apparent reason as to why government regulations should have been rated less highly here than for the other samples.

Physical barriers were recorded from 8 samples. For two of these (Samples 36 and 44), there was no obvious reason as to why the presence of physical barriers should have been recorded here. Five of the remaining samples came from thando or madimba plots situated near the Urema river (Samples 05-06 and 51-53), and the final one was from the Muaredzi river (Sample 75). These results suggest that access is sometimes restricted to low lying areas in proximity to the two main rivers, presumably due to flooding.

Each sample was scored in terms of its distance on path from the village and its distance from the nearest path (off path distance). A reasonably good spread of samples was obtained in terms of distances off path, but less so for distances along path (Table 47). Some $47 \mathrm{sam}$ ples were scored as being very far from the village on path, with the remaining 28 samples being spread amongst the three closer categories. Casual inspection of the raw data reveals at least seven samples for which the distance scores appear questionable. It would be useful to compare the CRUAT distance ratings against the map of the village paths and roads. 
The case files were used to update the probability structure of the prior BBN model and the results reflect the revised probabilities of the states of each input node (Figure 10). Nodes for honey, clay, fishing, grinding stick material and wild food show that most sites had little to none of these GS. Household construction materials were very unevenly distributed across the landscape, whilst firewood was generally found at good levels throughout the landscape. GS such as well sites, "sesteria" palm products and agricultural land were generally found either in very good quantities or there were none at all.

On the cost side of the model there were few sites in which resource access was constrained by either barriers or by local institutions. However, it was clear that the CRUAT perceived that access to many resources was constrained by official (i.e. Park) regulations. It was also clear that the sampling was biased towards sites that were far from the village - both along routes and off routes.

Landscape values. The Muaredzi sampling was carried out after that for Nhanchururu, so by the time it came to Muaredzi the recorders were already well versed with the sampling process. At the start of the Muaredzi sampling the CRUAT team was divided into three subgroups. Each subgroup carried out a trial sample in close proximity to one another. Following this trial, the CRUAT reconvened as a complete group and discussed the results obtained, particularly the landscape scores. In addition, at the start of each subsequent day, before setting off to sample each subgroup would first present and discuss their results from the previous day to the entire CRUAT group, thus providing a mechanism for checking scores between groups. Given this process, it would not seem necessary to standardise the landscape scores recorded by the different groups.

The overall range for landscape values was from 1 to 22 points, with mean and median values of 8.2 and 7 points, respectively (Table 48). Comparing results between recorders, mean and median values for Perreira (9.4 and 9) and Casse (9.3 and 9) were very similar. Camissa recorded a similar overall range of values (2 - 17 points), but his mean and median values ( 6.5 and 4 ) were considerably lower than for the previous two recorders. Examination of Camissa' s samples reveals that a high proportion of samples came from thando and planalto, both of which tended to be given relatively low scores, irrespective of recorder. Sizinho's values were also lower than those for Perreira or Casse, but were based on only a limited number of samples $(n=6)$.

For each sample, the subgroup was asked to justify the landscape value that they had given for that sample. Three of the four subgroups (Perreira, Casse and Sizinho) consistently attributed their scores to the presence or absence of resources. Camissa's subgroup, for some samples, also brought up factors such as the productivity of the soil; prohibitions due to park regulations; distance from the village; the presence of wild animals; proximity to water; and problems due to flooding. Based on discussion within Casse's group, soil type appeared to be an important consideration when it came to scoring the landscape value. This is likely to have applied to the other subgroups too. Although not specifically examined, there appeared to be a strong relationship between soil types and land types.

Table 48. Analysis of landscape values by recorders for 75 samples recorded from Muaredzi.

\begin{tabular}{lrrcc} 
Recorder & $\begin{array}{c}\text { No of } \\
\text { samples }\end{array}$ & Range & Mean & Median \\
\hline Camissa & 26 & $1-20$ & 6.5 & 4.0 \\
Perreira & 25 & $2-22$ & 9.4 & 9.0 \\
Sizinho & 18 & $4-14$ & 7.7 & 6.5 \\
Casse & 6 & $2-17$ & 9.3 & 9.0 \\
\hline Total & 75 & $1-22$ & 8.2 & 7.0 \\
\hline
\end{tabular}

Placement of transects was specifically planned so as to provide coverage of all the principal land types within Muaredzi. This was achieved, although for a number of types (gombe/ madimba, nsitu and chipale) the number of samples obtained was relatively low (Table 49). Murmuchea (termite mounds) were specifically targeted. However, because the sample area (circle of $30 \mathrm{~m}$ radius) was much larger than individual mounds (c. 2-5m diameter), the results obtained were heavily influenced by the surrounding terrain, such that these samples were instead classified according to the land type of the adjacent area.

Landscape values varied markedly for the different land types (Table 49). Planalto was given the lowest scores in terms of both mean and median values, followed in order of increasing value by thando, then chipale, gombe/ madimba, planicie and nsitu.

Table 49. Analysis of landscape values by land types for 75 samples recorded from Muaredzi

\begin{tabular}{lrrrr} 
Landtype & $\begin{array}{c}\text { No of } \\
\text { samples }\end{array}$ & Range & Mean & Median \\
\hline Gombe/madimba & 6 & $4-20$ & 7.8 & 6.0 \\
Thando & 11 & $2-11$ & 5.4 & 5.0 \\
Planicie & 38 & $2-22$ & 10.6 & 9.5 \\
Nsitu & 4 & $10-15$ & 13.0 & 13.5 \\
Chipale & 3 & $2-9$ & 6.0 & 7.0 \\
Planalto & 13 & $1-6$ & 2.8 & 3.0 \\
Overall & 75 & $1-22$ & 8.2 & 7.0 \\
\hline
\end{tabular}

Thirteen samples were recorded from planalto, mainly by Camissa but also Casse. These all comprised woodland areas, situated on sandy or mixed sandy soils. Landscape values were consistently low, ranging between 1 and 6 points. 
Scores for the 11 thando samples varied between 2 and 11 points. Some samples comprised woodland areas, others open grasslands. Some included palm trees, others did not. However, there was no obvious pattern between these factors and landscape values, nor in terms of different recorders (Camissa and Perreira).

Only three samples were recorded for chipale. The scores given for these samples were 2, 7 and 9 points, which were higher than might have been expected. This is likely to have been due at least in part to the spatial distribution of chipale, which typically occurs as small irregular open patches within surrounding woodland or forest areas. Thus, the chipale samples probably also include representation of the surrounding areas, so increasing the range of resources present and the overall score.

Samples from gombe and madimba, based on the advice of CRUAT members, were combined. Five of the six samples were given scores of between 4 and 7 points. The other sample was allocated 20 points. The reason for this greatly different score is not immediately apparent, although several more resources were recorded from this sample than any of the other five plots.

Only four samples were recorded for nsitu. However, the three different groups (Perreira, Casse and Sizinho) were consistent in giving these samples relatively high values (range of 10-15 and mean of 13.0 points).

Planicie accounted for half the overall samples $(n=38)$, which is consistent with its dominant occurrence in the immediate vicinity of the village area. The range in values (2-22 points) was greater than for any of the other land types. The samples included 9 samples from fields or houses, with the remainder coming from woodland areas $(n=29)$. The 10 lowest scores all came from woodland areas. At the other end of the scale woodland samples also accounted for 7 of the top 10 highest scores. The bulk of the samples were recorded as having black soil, or black soil mixed with sand. The three samples with sandy soils were all given low scores (2-6 points each). The scores do not show any obvious patterns in terms of recorders, other than the lack of any high scores by Sizinho (but who only recorded 4 samples from planicie).

There was surprisingly little variation in terms of numbers of resources recorded per sample from the different land types (Table 50). The least resources were recorded from chipale and gombe/ madimba, in terms of both mean and median values. Thereafter, in terms of median values, there was little difference between nsitu, planalto, planicie, or thando, but the mean value for planicie was higher than for the other three land types (6.7 resources per sample versus 5.3 to 5.8 ).
Table 50. Numbers of goods and services recorded from different land types within Muaredzi.

\begin{tabular}{lrrrc} 
Landtype & $\begin{array}{c}\text { No of } \\
\text { samples }\end{array}$ & Range & Mean & Median \\
\hline Gombe/madimba & 6 & $3-8$ & 5.2 & 5.0 \\
Thando & 11 & $1-8$ & 5.3 & 6.0 \\
Planicie & 38 & $3-12$ & 6.7 & 6.5 \\
Nsitu & 4 & $4-7$ & 5.8 & 6.0 \\
Chipale & 3 & $5-5$ & 5.0 & 5.0 \\
Planalto & 13 & $3-8$ & 5.7 & 7.0 \\
Overall & 75 & $1-12$ & 6.1 & 6.0 \\
\hline
\end{tabular}

This data suggests that the overall number of resources per sample is not necessarily an important determinant of landscape value. For example, planalto has a moderate number of resources per plot, but scores are consistently lower than for gombe/ madimba or thando, both of which have fewer resources. It is possible that a better correlation may be achieved if the types of resources are taken into account, through weighting each resource according to its perceived relative importance.

Possible enumerator bias. Analysis of records of occurrences by recorders do not suggest any obvious cases of enumerator bias for the maj ority of the 15 goods and services. There are a few exceptions. For example, 16 of the 18 occurrences of honey were recorded by Camissa, and the nine occurrences of wild foods were spread amongst only three recorders, with Casse not showing any records among his 18 samples. Results for government regulations also clearly show some enumerator bias, but there are no obvious patterns in terms of landscape values.

\section{b) Nhanchururu}

Sampling was carried out with four recorders over a seven day period, during which a total of 82 samples were recorded from 10 transects. Mr. Camissa achieved 13 samples from a single transect. The other three recorders each covered four transects, from which 26 samples were captured by Perreira, 18 by Sizinho, and 25 by Casse. The locations of these samples are shown in Figure 6. A summary of the data obtained is presented in Appendix 4. The bulk of the samples were from undisturbed areas, although a number of samples from fields were included for the three principal land types, particularly for baixa.

Goods and services. A total of 27 goods and services were scored for each sample, these being derived from the overall list obtained for Nhanchururu. Land was separated into two categories, land for houses and land for fields, which were scored separately, whilst the five types of honey were lumped under a single category. 
Four resources were recorded as being present (good, moderate or poor) for more than $80 \%$ of all samples, these being traditional medicines, firewood, poles for construction and grazing for livestock (Table 51). At the other end of the scale, 11 resources were recorded from less than $20 \%$ of samples. These were, in order of diminishing occurrence, wood for grinding sticks and bowls, bamboo, aquatic food plants, reeds for sleeping mats, honey, mud for cultivation, clay for cultivation, grinding stones, fish, water and clay for pots. Apart from wood for grinding sticks and bowls, honey, grinding stones, and clay for pots, the remainder of these least frequent resources are specifically associated with water or low lying moist baixa areas. Their low frequencies will thus be a function of the relatively limited occurrence of baixa within the village area and thus the sample pool.

Table 51. Frequency of occurrence of resources (good, moderate or poor) for 82 samples recorded from Nhanchururu.

\begin{tabular}{lrrl} 
Resource & Occ. & f & \% R \\
\hline Traditional medicines & 80 & 98 & 0.037 \\
Firewood & 76 & 93 & 0.069 \\
Poles for construction & 68 & 83 & 0.042 \\
Grazing for livestock & 68 & 83 & 0.050 \\
Bark for rope & 63 & 77 & 0.042 \\
Wood for handles & 62 & 76 & 0.068 \\
Land for fields & 61 & 74 & 0.093 \\
Thatching grass & 51 & 62 & 0.042 \\
Land for houses & 50 & 61 & 0.093 \\
Sand & 33 & 40 & 0.013 \\
Wild fruits & 28 & 34 & 0.016 \\
Wildlife & 24 & 29 & 0.003 \\
Wild foods & 22 & 27 & 0.027 \\
Cultivated fruits & 21 & 26 & 0.042 \\
Wood for timber & 19 & 23 & 0.045 \\
Reeds for construction & 17 & 21 & 0.029 \\
Wood for grinding sticks & 12 & 15 & 0.045 \\
Bamboo & 8 & 10 & 0.042 \\
Aquatic plants for food & 7 & 9 & 0.003 \\
Reeds for sleeping mats & 6 & 7 & 0.048 \\
Honey & 5 & 6 & 0.021 \\
Mud for cultivation & 4 & 5 & 0.024 \\
Clay for cultivation & 4 & 5 & 0.011 \\
Grinding stones & 3 & 4 & 0.032 \\
Fish & 2 & 2 & 0.019 \\
Water & 2 & 2 & 0.080 \\
Clay for pots & 1 & 1 & 0.040 \\
\hline Occ. (Occurrences n=82) & & & \\
f (Frequency) & & & \\
\%l (\% Relative Importance) & & &
\end{tabular}

One resource that was not captured during the sampling process was the use of bark for making beehives. This requires mature trees with large diameters. A ring of bark about one metre in height is taken from the main trunk, effectively ring barking the tree. Such hives were commonly observed around the village, as were trees from which bark had been removed. Many of these trees had either already died, or appeared likely to do so in the future.

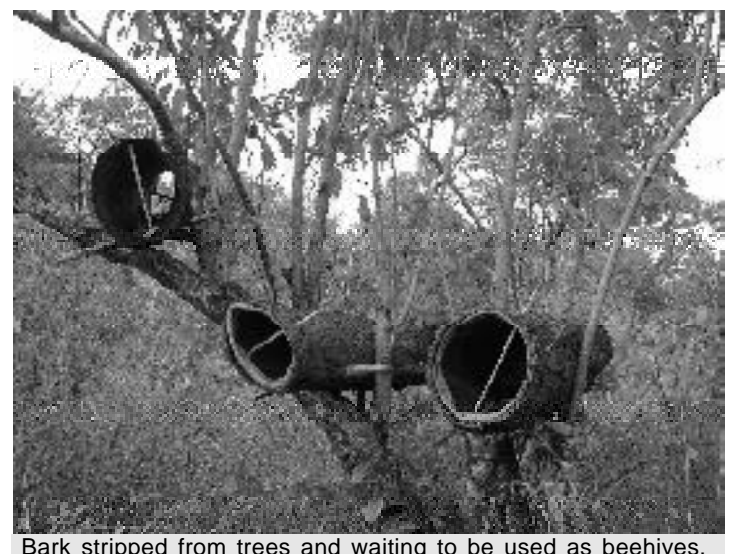

Bark stripped from trees and waiting to be used as beehives Nhanchururu.

The number of resources per sample varied from a minimum of 5 to a maximum of 20 , the mean value being 9.6 resources per plot. Notes suggest that overall landscape values are likely to be, at least in part, related to the number of resources recorded per sample. All recorders commonly noted that the landscape score for a particular sample was given "because of the number of resources that occur there" (either few for low scores, or many for high scores). This being so, there may be expected to be a relationship between the number of resources per sample and the overall value for that plot.

It is also likely that landscape values will be influenced by the types of resources that occur in each plot, and particularly the perceived importance of the various resources. In this respect, it is interesting that the four most commonly recorded resources all have relatively high importance values, ranging from 0.040 (standardised RIW) for traditional medicines to 0.069 for firewood (Table 51). The bulk of the middle group of 12 resources, that were recorded from between $20 \%$ and $80 \%$ of plots, were also of relatively high importance. Within this group the less important goods and services were wildlife, sand, wild fruits, wild foods and reeds for construction purposes. Amongst the 11 least commonly occurring resources, water stands out as being of particularly high importance (standardised RIW of 0.080 ), and to a lesser extent reeds for sleeping mats (0.048), wood for grinding sticks and bowls (0.045), bamboo (0.042), and clay for pots $(0.040)$. The remaining resources all have standardised RIW's of less than 0.040 .

Factors limiting access to resources. Information was recorded for five potential cost factors: dangers, government regulations, traditional regulations, and on path and off path distances. A summary of the occurrence of these factors is presented in Tables 52 and 53. 
Table 52. Frequency of occurrences of factors limiting access to resources for 82 samples recorded from Nhanchururu.

\begin{tabular}{lcrrc} 
Factor & High & Moderate & Low & None \\
\hline Government regulations & 79 & 1 & 2 & 0 \\
Traditional regulations & 30 & 51 & 1 & 0 \\
Dangers & 40 & 29 & 12 & 1 \\
\hline
\end{tabular}

Government regulations were perceived as being high throughout the sample area $(n=79)$. Three atypical cases were recorded, two being for the first two "learning" samples (sample numbers 01 and 02 , both low), and the other for sample 23 (moderate). There is no obvious explanation for this latter case.

For traditional laws, a single sample was recorded as being low (sample number 02), whilst all others were either moderate $(n=51)$ or high $(n=30)$. The differences between moderate and high can be explained in terms of enumerators. Two recorders (Camissa and Casse) consistently gave "moderate" ratings for traditional regulations, whilst Sizinho consistently scored this as "high". The implication is that traditional laws were considered to operate throughout the area, and with equal magnitude all over.

The factor "dangers" resulted in a wider spread of values, with 40 samples being rated as high, 29 as moderate and 12 as low. These results can also be partly explained in terms of enumerators. Camissa (except for his first training sample) and both Sizinho and Casse, consistently rated dangers as moderate or high, whilst Perreira recorded roughly equal numbers of cases of high $(n=6)$, moderate $(n=6)$ and low $(n=9)$. For her first and fourth transects Perreira mainly recorded dangers as being high (with two samples being moderate). These two transects passed through quite different terrain, the one being relatively steep and well wooded, the other passing through an area of gentler terrain with many fields. For her middle two transects, Perreira predominantly rated dangers as being either low or moderate, apart from one record of high. Visual examination of the data does not suggest any relationship between the "danger" ratings of these 25 samples and either of the two distance functions.

A good spread of samples was obtained for both the "on path" and "off path" distance functions. When looking at the combination of these factors (Table 53), the spread of samples was again reasonable, albeit somewhat scanty for factors of very far along path by very close or close off path, and also very close along path by close, far or very far off path.

No obvious patterns emerge as regards the recording of distance scores by the different recorders. It would be interesting to check the distance ratings against the map of routes for the village. Although distance received a relatively low importance score in terms of the overall listing of potential limiting factors (Table 43), it is possible that the two distance functions may have had a relatively large influence on the overall landscape values given during this sampling process. For example, samples 52, 53 and 54, despite all being from similar terrain, show decreasing scores (13, 11 and 10, respectively) with increasing distance away from the settled portion of the village.

Table 53. Distribution of 82 samples recorded from Nhanchururu according to on path and off distances for each sample.

Distance on path

\begin{tabular}{lrrrrr} 
& \multicolumn{5}{c}{ Distance on path } \\
\cline { 2 - 6 } $\begin{array}{l}\text { Distance } \\
\text { off path }\end{array}$ & $\begin{array}{l}\text { Very } \\
\text { far }\end{array}$ & Far & Close & $\begin{array}{c}\text { Very } \\
\text { close }\end{array}$ & Total \\
\hline Very far & 12 & 8 & 6 & 2 & 28 \\
Far & 8 & 2 & 4 & 1 & 15 \\
Close & 2 & 5 & 6 & 1 & 14 \\
Very close & 2 & 5 & 12 & 6 & 25 \\
\hline Total & 24 & 20 & 28 & 10 & 82 \\
\hline
\end{tabular}

Landscape values. The overall range for landscape values was from 1 to 25 (Table 54). Three samples (numbers 55, 56 and 57, all recorded by Casse) were given scores of one point each, despite having similar levels of resources to the previous three samples which were valued at 10 , 11 and 13 points. The CRUAT group explained that this was because these three samples were situated within the national park area, and were thus subject to additional government regulations as compared to all other samples from within the village area. These three samples were omitted for the purpose of calculations of means and medians, both for the subset of samples recorded by Casse and for the overall set of samples.

The overall mean landscape value was 9.9 points, and the median value was 10 points (Table 54). There was considerable variation between recorders in terms of ranges of scores, means and medians. Thus, for comparative purposes, it may be necessary to first standardise the landscape scores for the different recorders. There are different ways of doing this. One possibility is to divide the scores for each recorder by the highest score obtained by that recorder, thus effectively standardising the scores for each recorder to a range of between 0 and 1 . However, this places strong emphasis on the highest scores obtained by each recorder, which can be expected to genuinely vary from one group to the next. For example, the highest score of 25 points, awarded by Perreira for sample number 69 , appears anomalous on the basis of the moderate numbers and levels of resources recorded from this plot, together with typical levels for cost factors. 


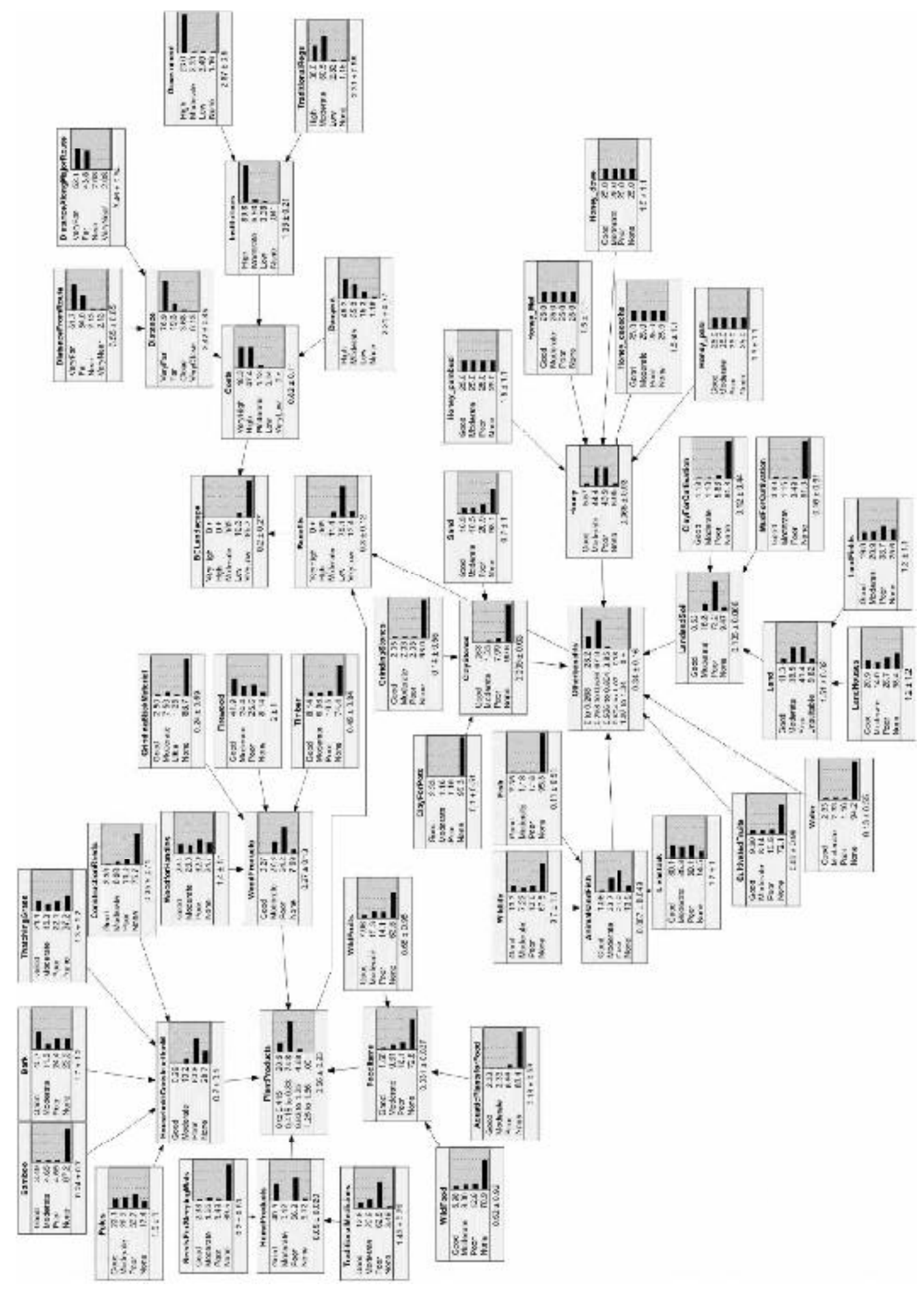


An alternative approach could be to increase or decrease the scores of each recorder, so as to standardise the median scores for each subset. This would require the addition of two points to each of Camissa' s scores, and the subtraction of three points from each of Casse's scores, such that the median value for each recorder would then be standardised at 9 points.

Table 54. Analysis of landscape values by recorders for 82 samples recorded from Nhanchururu.

\begin{tabular}{lccrc} 
Recorder & $\begin{array}{l}\text { No of } \\
\text { Samples }\end{array}$ & Range & Mean & Median \\
\hline Camissa & 13 & $2-14$ & 6.8 & 7 \\
Perreira & 26 & $5-25$ & 10.2 & 9 \\
Sizinho & 18 & $3-18$ & 9.3 & 9 \\
Casse ${ }^{*}$ & 22 & $8-20$ & 11.8 & 12 \\
\hline Total * & 79 & $2-25$ & 9.9 & 10 \\
\hline
\end{tabular}

* Three samples by Casse were given scores of 1 on the basis of being within the park area. These samples were excluded for the purpose of calculating mean and median values for Casse and for the overall group.

Analysis of the raw landscape values in terms of land types is presented in Table 55 . A reasonable number of samples were obtained from each of the three principal land types (baixa, planicie and planalto). Only two samples were obtained from mountain areas, and given the location of one of these (sample number 59), its classification as montanhas seems questionable.

Table 55. Analysis of landscape values by land types for 82 samples recorded from Nhanchururu.

\begin{tabular}{lcrrc} 
Landtype & $\begin{array}{c}\text { No of } \\
\text { Samples }\end{array}$ & Range & Mean & Median \\
\hline Baixa $^{*}$ & 22 & $5-15$ & 8.8 & 9 \\
Planicie $^{*}$ & 38 & $2-25$ & 10.4 & 10 \\
Planalto $^{*}$ & 17 & $6-14$ & 10.4 & 11 \\
Montanhas & 2 & $5-12$ & na & na \\
Overall $*$ & 79 & $2-25$ & 9.9 & 10 \\
\hline
\end{tabular}

* Three samples were given scores of 1 on the basis of being within the park area, one each for baixa, panicie and planalto. These samples were excluded for the purpose of calculating mean and median values for these three land types and for the overall group.

The mean value for planicie was the same as that for planalto (10.4 points for each). However, planicie has a greater overall range of values than planalto, and includes both the lowest six scores and the highest five scores from the overall data set. So it appears that planicie is more variable than planalto, but much the same in terms of overall value. Intuitively this is what one might expect, in that planalto is limited to higher lying areas including the upper portions of slopes, whereas planicie covers a wider range of situations, between the upper slopes and lower lying valley areas.

The overall range of values for baixa was similar to that of planalto, but its mean (8.8 points) and median values (9 points) were lower than for planalto and planicie. It should be noted that baixa includes samples from both drainage lines at the bottoms of valleys, as well as woodland areas on lower portions of slopes.

Similar numbers of resources were recorded from each land type (Table 56). The range of values for baixa samples (5-20 resources per sample) was greater than for planicie or planalto (ranges of 6-13 and 5-3 resources respectively), but there was little difference in terms of mean values: 10.1 resources per sample for baixa versus values of 9.3 and 9.4 for planicie and planalto.

Possible enumerator bias. Data obtained for factors limiting access to resources show some clear examples of enumerator bias. It has also been suggested that there may have been differences in the way that the four subgroups were allocating landscape values, hence the suggestion to possibly standardise the scores. What is the evidence in terms of goods and services?

Table 56. Numbers of goods and services recorded from different land types within Nhanchururu.

\begin{tabular}{lcrrr} 
Landtype & $\begin{array}{c}\text { No of } \\
\text { Samples }\end{array}$ & Range & Mean & Median \\
\hline Baixa & 23 & $5-20$ & 10.1 & 10.0 \\
Planicie & 39 & $5-13$ & 9.3 & 10.0 \\
Planalto & 18 & $6-13$ & 9.4 & 9.0 \\
Montanhas & 2 & $8-14$ & 11.0 & 0.0 \\
Overall & 82 & $5-20$ & 9.6 & 9.5 \\
\hline
\end{tabular}

As a first attempt to examine this question, the responses for each resource were examined in terms of the frequency of different levels of occurrence recorded by the four recorders (Table 57). This reveals some clear examples of recorder bias. No clear patterns emerged for those resources that were recorded least frequently (11 resources with 15 or less occurrences). However, for the remaining 16 more frequent resources, 13 of these show possible suggestions of recorder bias in terms of unlikely distributions of numbers and nature of records amongst the four recorders. For example, 15 of the 22 occurrences of wild foods were recorded by Casse, as were 21 of the 24 records of wildlife, whilst Sizinho recorded 13 out of 17 occurrences of reeds for construction.

\section{c) Comparison between Muaredzi and Nhanchururu}

Similar numbers of samples were achieved for both sites. The Nhanchururu sampling took considerably longer, principally because this is where we started and the recorders were not yet familiar with the sampling process and, particularly, with using GPS's. Difficult terrain and poor access to certain areas were encountered at both sites. 
Table 57. Possible cases of enumerator bias as regards occurrence of goods and services among 82 samples from Nhanchururu.

\begin{tabular}{lcll} 
Resource & Frequency & Bias & Note \\
\hline Traditional medicines & 98 & Yes & DC only poor, others=range \\
Firewood & 93 & $?$ & DC lower values than others \\
Poles for construction & 83 & $?$ & DC only poor/ none, others= range \\
Grazing for livestock & 83 & $?$ & DC=poor/ none; ES = moderate; RC=good \\
Bark for rope & 77 & $?$ & DC only poor/ none, others=range \\
Wood for handles & 76 & $?$ & DC only poor/ none, others=range \\
Land for fields & 74 & $?$ & ES lacks none (nearly all are poor) \\
Thatching grass & 62 & $?$ & DC=none, (poor/ good); FP=none, (poor/moderate/ \\
& & & good); RC=moderate/ good, (none/ poor); ES=range \\
Land for houses & 61 & No & \\
Sand & 40 & No & \\
Wild fruits & 34 & Yes & RC=15/28 occurrences \\
Wildlife & 29 & Yes & RC=21/24 occurrences \\
Wild foods & 27 & Yes & RC=15/22 occurrences \\
Cultivated fruits & 26 & $?$ & ES=0/21 occurrences \\
Wood for timber & 23 & No & \\
Reeds for construction & 21 & $?$ & ES=13/ 17 occurrences \\
Wood for grinding sticks & 15 & No & \\
Bamboo & 10 & No & \\
Aquatic plants for food & 9 & No & \\
Reeds for sleeping mats & 7 & No & \\
Honey & 6 & No & \\
Mud for cultivation & 5 & No & \\
Clay for cultivation & 5 & No & \\
Grinding stones & 4 & No & \\
Fish & 2 & No & No \\
Water & 2 & No & \\
Clay for pots & 1 & & \\
\hline
\end{tabular}

Goods and services. The overall number of G/ S for Muaredzi ( $n=15)$ was markedly lower than for Nhanchururu ( $n=27)$. However, this was largely due to differences in how the respective communities defined their resources, rather than to real differences in the occurrence and use of resources. Some of the obvious differences were that in Nhanchururu livestock were more abundant than in Muaredzi, and low lying aquatic areas (baixa) and the associated resources were more evenly distributed across the landscape than for Muaredzi, whilst fish were more abundant in Muaredzi than Nhanchururu.

For both sites, the bulk of GS were reasonably common, being recorded in over $20 \%$ of the samples. The less frequent resources were those that have confined distributions within the landscape, particularly those associated with aquatic systems and drainage lines, but also others such as bamboo, grinding stones and clay for pots.

The mean number of resources per sample was considerably lower for Muaredzi than Nhanchururu, but presumably this was largely a function of scoring different baskets of resources (15 for Muaredzi versus 27 for Nhanchururu). For both sites there was a positive relationship between the number of resources and landscape values per sample.

Most resources for Muaredzi were considered to have reasonably even spatial distributions within the individual land types within which they occur, but there were marked differences between land types in terms of the resources to be found there. Those resources for which uneven distributions within landtypes were reported, tended to be the less common resources. The position for Nhanchururu was that most resources within baixa and montanhas were considered to have reasonably even distributions within these types, whereas for planicie and planalto a number of resources were seen as being unevenly distributed. However, the occurrence of resources from planalto and planicie, which together account for the bulk of the overall landscape, were seen as being similar.

Factors limiting access to resources. The two sites yielded similar results in terms of factors limiting access to resources. Government regulations were recorded as being high and relatively consistent over the whole landscape, although for both sites there were areas where these were seen to pose an overriding constraint as regards access to resources (to the west of the Urema river for Muaredzi, and to the east of the rangers camp for Nhanchururu).

Traditional regulations were scored differently for the two sites, but this does not necessarily imply any major differences as regards access to resources. For Muaredzi, traditional regulations were recorded as absent, not because they did 
not exist but rather because they were not considered to imply any restrictions on access to resources (on the contrary traditions were described as enhancing access to resources). For Nhanchururu, traditional regulations were seen as being moderate to high throughout the area, but on the basis that traditional authority extends over the entire village landscape, rather than resulting in any marked restrictions on access to resources.

Physical barriers were of little consequence for either site, the most notable occurrence being seasonal flooding of low-lying areas within Muaredzi. Dangers were identified as an additional cost factor for Nhanchururu, and these were considered to show greater variation across the landscape.

The impacts of the on path and off path distance functions, as regards limiting access to resources is less clear. Sampling for Muaredzi was biased towards sites that were far from the village and well off routes. Both sites are considered to be relatively well endowed with resources, and the bulk of the principal resources appear to be available within reasonable proximity of settlements, such that the distance functions may not be that important here.

Landscape values. In terms of overall range, mean and median values, were marginally higher for Nhanchururu than Muaredzi. The process of coming together to report and discuss landscape values was carried out for Muaredzi but not Nhanchururu. Also, by the time it came to Muaredzi, the recorders were more familiar and experienced with the sampling process. This may account for the greater variation in landscape values among subgroups for Nhanchururu, as opposed to the more uniform results obtained for Muaredzi.

Landscape vlaues varied markedly with land types for Muaredzi (nsitu and planice were highest in value, gombe and madimba intermediate, and thando and planalto of lowest value). Differences for Nhanchururu were less marked, with planalto and planicie receiving very similar scores, and baixa only a little lower. For both sites, there was surprisingly little variation from one land type to the next in terms of mean numbers of resources per sample (range $=5.0$ for chipale to 6.7 for planicie for Muaredzi, and for Nhanchururu 9.3 in planicie to 11.0 in montanhas).

Differences in resource scores and landscape values between recorders are to be expected, in that different recorders were sampling in different localities. Nevertheless, there is some evidence of enumerator bias, but more in terms of scores given to resources rather than the presence or absence of resources. The variations between recorders are greater for Nhanchururu, where the recorders were less experienced

\section{5) Confronting the models with reality}

Both models were confronted with the information that was collected by the field teams. The data sheets were used to generate case files that were then used to explore the degree to which the models accurately predicted what was found in the real world. Thereafter the case files were used to update the models. In this section the results of confronting the BBN's with field data are presented. We start with presentations of the confrontations for each site and then explore the implications of merging the two data sets to generate a broader and more general understanding.

\section{a) Mauredzi}

The score that local people assigned to each sampling location in the Mauredzi site was positively correlated with the number of resources found in that site (Figure 12). Although not a strong relationship (Pearson correlation coefficient $r=0.495, n=75$ ) the positive relationship was consistent with expectations.

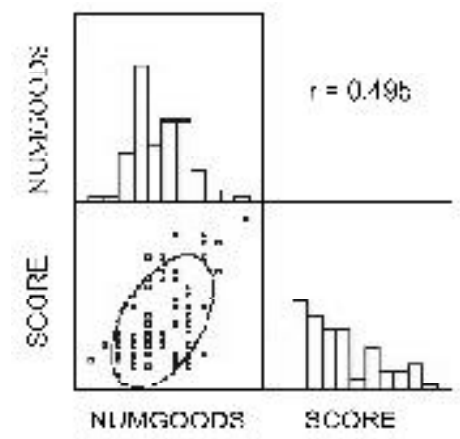

Figure 12. Correlation between the total number of goods at a sample location (NUMGOODS) and the valuation score (SCORE) given to that location for Muaredzi (Pearson correlation coefficient $r=0.495, n=75$ ).

A similar positive relationship was observed between the local valuation score and the total benefits score that was estimated using a simple summation of the scores that were allocated to each resource at a site (Figure 13; Pearson's correlation coefficient $r=0.628, n=75$ ).

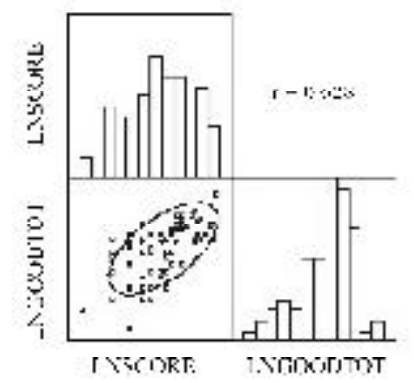

Figure 13. Correlation between the natural log of the total benefit score at a sample location (LNGOODTOT) and the natural logarithm of the local valuation score (LNSCORE) given to that location for Muaredzi (Pearson correlation coefficient $r=0.628, n=75$ ). 
The expected negative relationship between the value score given for a sampling location and the total costs score for that location was not that clear. Although negative the correlation was very weak (Figure 14; Pearson's correlation coefficient $r=0.317, n=75$ ).

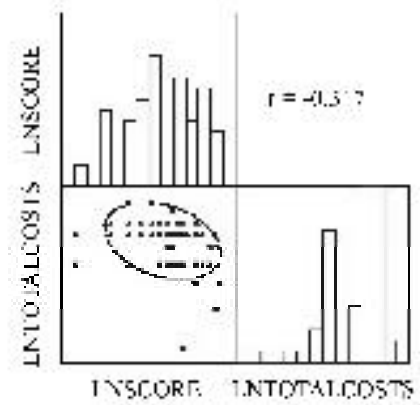

Figure 14. Correlation between the natural log of the total costs score at a sample location (LNTOTALCOSTS) and the natural logarithm of the local valuation score (LNSCORE) given to that location for Muaredzi (Pearson correlation coefficient $r=-0.317, n=75$ ).
The relationship between the score given to the sample location and the benefit cost value estimated by the BBN was consistent with expectations showing a strong positive correlation (Figure 15; Pearson's correlation coefficient $r=0.617, n=75$ ).

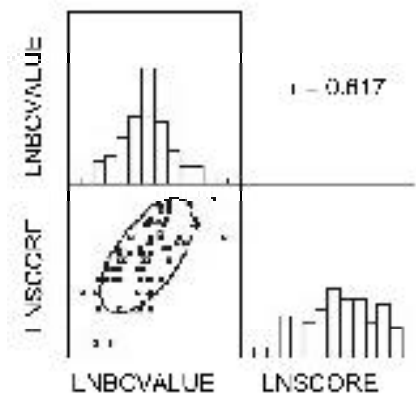

Figure 15. Correlation between the natural log of the benefit cost value calculated by the BBN model at a sample location (LNBCVALUE) and the natural logarithm of the local valuation score (LNSCORE) given to that location for Muaredzi (Pearson correlation coefficient $r=0.617, n=75$ )

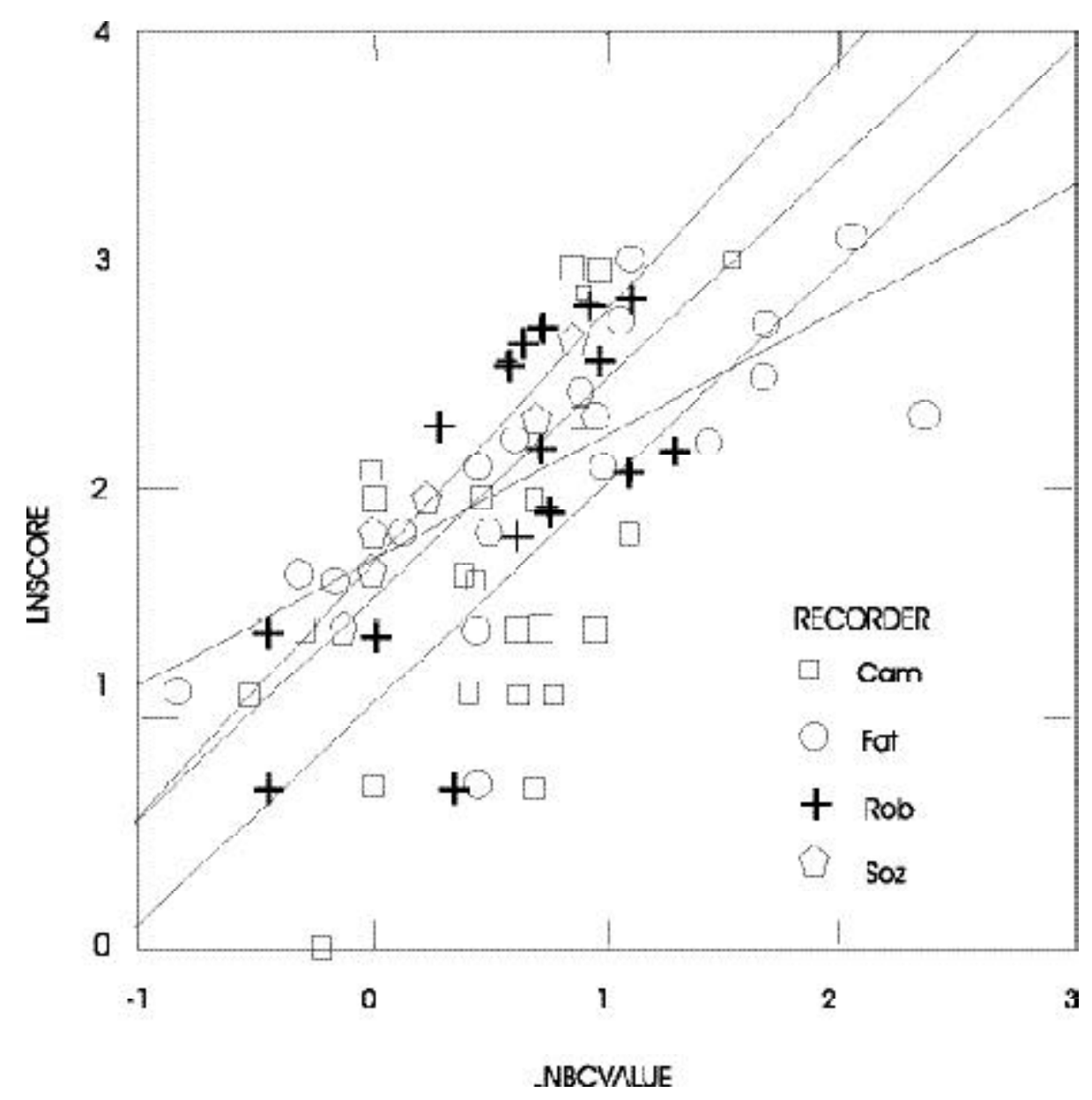

Figure 16. Scatterplot of the natural logarithm of local sample unit scores plotted against the natural logarithm of derived benefit cost scores for Muaredzi with least sqaures lines fit for each enumerator. 
It would appear that a good deal of the noise in the relationship between local scores and other variables is attributable to differences in the scores for locations that were generated by groups working with specific enumerators. In figure 16 the correlation between the scores and benefit values generated by each enumerator are shown.

When the Muaredzi prior model was tested using the Muaredzi field data the error rate when the predicted benefit cost value was compared with the actual benefit cost value was $46.67 \%$ (Table 58). One would expect the predicted and actual values to lie along the diagonal from top left to bottom right of the table. Overall the model appears to be predicting slightly lower values than were found in the field.

Table 58. Confusion matrix for the Muaredzi model when confronted with field data.

\begin{tabular}{|c|c|c|c|c|}
\hline \multicolumn{4}{|c|}{ Predicted BC state } & \multirow[t]{2}{*}{ Actual BC state } \\
\hline 0 & 1.67 & 3.33 & 5 & \\
\hline 6 & 3.00 & 0.00 & 0 & 0.00 \\
\hline 13 & 32.00 & 0.00 & 3 & 1.67 \\
\hline 1 & 11.00 & 2.00 & 4 & 3.33 \\
\hline 0 & 0.00 & 0.00 & 0 & 5.00 \\
\hline
\end{tabular}

\section{b) Nhanchururu}

The score that local people assigned to each sampling location in the Nhanchururu site was positively correlated with the number of resources found in that site (Figure 17) but the relationship was weak (Pearson correlation coefficient $r=0.362, n=82$ ) the positive relationship was however, consistent with expectations.

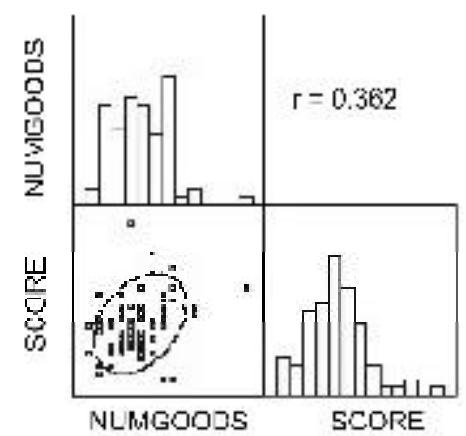

Figure 17. Correlation between the total number of goods at a sample location (NUMGOODS) and the valuation score (SCORE) given to that location for Nhanchururu (Pearson correlation coefficient $r=0.362, n=82$ ).

A weak positive relationship was observed between the local valuation score and the total benefits score that was estimated using a simple summation of the scores that were allocated to each resource at a site (Figure 18; Pearson's correlation coefficient $r=0.355, n=82$ ). This relationship was weaker than expected and much weaker than the relationship found in Muaredzi.

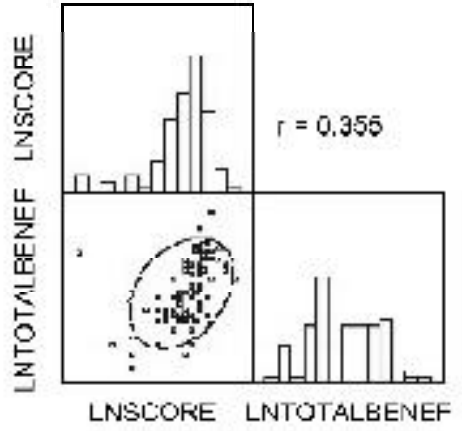

Figure 18. Correlation between the natural log of the total benefit score at a sample location (LNTOTALBENEF) and the natural logarithm of the local valuation score (LNSCORE) given to that location for Nhanchururu (Pearson correlation coefficient $r=0.355, n=82$ ).

The expected negative relationship between the value score given for a sampling location and the total costs score for that location was evident but very weak (Figure 19; Pearson's correlation coefficient $r=0.252, n=82$ ).

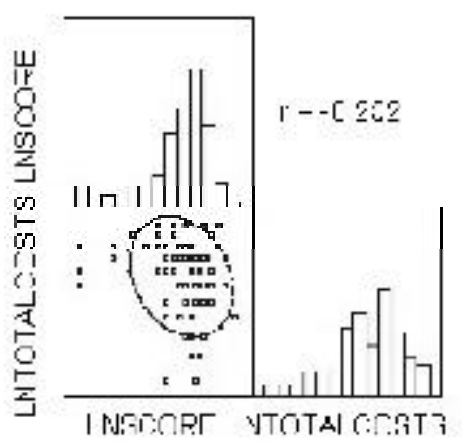

Figure 19. Correlation between the natural log of the total costs score at a sample location (LNTOTALCOSTS) and the natural logarithm of the local valuation score (LNSCORE) given to that location for Nhanchururu (Pearson correlation coefficient $r=-0.252, n=82$ ).

The relationship between the score given to the sample location and the benefit cost value estimated by the BBN was consistent with expectations but the relationship was much weaker than expected (Pearson's correlation coefficient $r=0.416, n=82$ ). However when the three outlier samples that were placed within the boundary of Gorongosa National Park were removed the correlation was greatly improved and stronger than the Muaredzi relationship (Figure 20; Pearson's correlation coefficient $r=0.727, n=79$ ).

The performances of individual CRUAT subgroups were quite varied. In general, the correlation's between local valuations and the model estimates of value were reasonable but varied greatly across groups (Pearson correlation co-efficient varied from 0.5 to 0.9 ).

More worrying for the method and approach was the variation in the relationships for each subgroup (Figure 21). Different subgroups appeared to be using different baselines ( $a$ in 


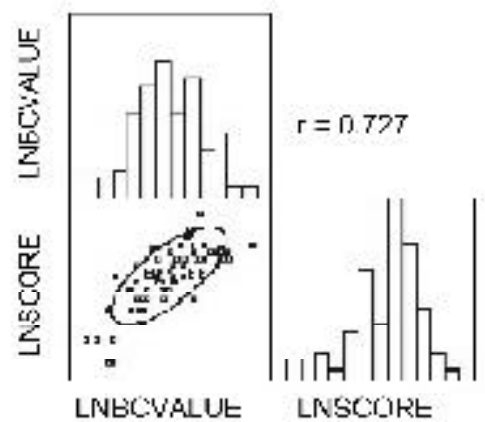

Figure 20. Correlation between the natural log of the benefit cost value calculated by the BBN model at a sample location (LNBCVALUE) and the natural logarithm of the local valuation score (LNSCORE) given to that location for Nhanchururu (Pearson correlation coefficient $r=0.727, n=79$ )

the equation $y=a+b x)$ and show different rates of change in the relationships between local value and model estimated value (b). Although apparent in the Muaredzi field results, these differences were most notable in Nhanchururu. This may be because of the unfamiliarity of the enumerators with the techniques when they were in Nhanchururu, whereas by the time they got to Muaredzi they were better practised.

When confronted with field data the Nhanchururu model proved reasonably accurate with an error rate of only $21 \%$ However, unlike with the Muaredzi model, the Nhanchururu data were all clustered in the moderate to very low quadrant of the value space (Table 59).

Table 59. Confusion matrix for the Nhanchururu model when confronted with field data. Comparisons of predicted $B C$ values with actual values.

Predicted $\mathrm{BC}$ value

\begin{tabular}{crrrrl}
\hline $\begin{array}{l}\text { Very } \\
\text { high }\end{array}$ & High & Moderate & Low & low & Actual value \\
\hline 0 & 0 & 0 & 0 & 0 & VeryHigh \\
0 & 0 & 0 & 0 & 0 & High \\
0 & 0 & 0 & 1 & 0 & Moderate \\
0 & 0 & 1 & 57 & 13 & Low \\
0 & 0 & 0 & 2 & 8 & Very Low \\
\hline
\end{tabular}

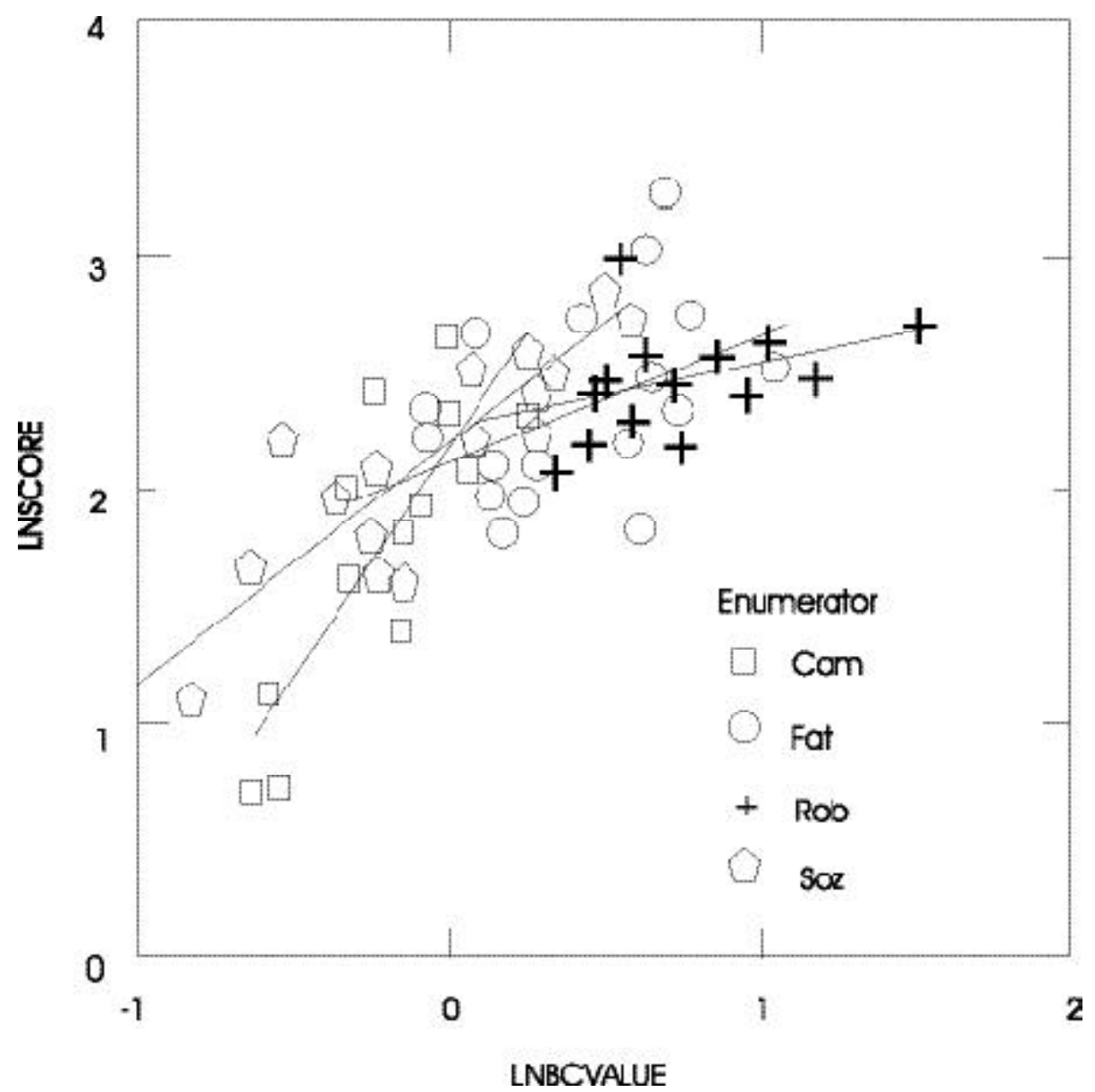

Figure 21. Scatterplot of the natural logarithm of local sample unit scores plotted against the natural logarithm of derived benefit cost scores for Nhanchururu with least sqaures lines fit for each enumerator. 
Thus despite the inadequacies of the models and the methods used for collecting the local value data the models and field data collection procedures produced encouraging results.

It is clear that the local valuation results are strongly, positively related to the benefit streams that local people derive from a given location and less strongly related to the costs of procuring these benefits. Although the latter are of the expected negative relationship they were weak and not useful in predicting ultimate value of a given location. It is likely that we could improve our methods of estimating costs, perhaps through allocating separate cost relationships to each benefit rather than to a location as a whole. However, the strong relationships between the value given and the benefit streams suggest that in many cases the local value of a landscape location could be usefully predicted through simple summations of the benefit streams likely to be derived from that location. 


\section{Vegetation inventory and assessments}

\section{A. Approach and methods}

Interpretation of Landsat images (Scene 167/ 73; 22 August 1999) and aerial photographs was done by carefully examining paper copies of the Landsat image and aerial photographs, as well as on-screen interpretation of the image. The study areas were initially demarcated on the image to form a $10 \times 10$ $\mathrm{km}$ square but were revised according to boundaries indicated by communities in the respective areas. Image and aerial photograph interpretation resulted in the production of preliminary vegetation associations evident from differences in colour and texture on the aerial photographs and images. This formed the basis upon which the vegetation was stratified and enabled sampling within each vegetation stratum. Fieldwork was carried out in the Muaredzi area between 3 and 14 September 2001, and between 6 and 18 May 2002 in Nhanchururu area. Groundtruthing of vegetation boundaries and further assessments were done between 8 and 19 April 2002 in Muaredzi area. The ground-truthing exercise was deemed unnecessary for Nhanchururu because of the simplicity of the mapping units.

\section{Vegetation survey}

\section{a) Muaredzi}

Four main transects covering the area were identified according to the directions of the main access roads. Taking the Rangers' Post as a reference point, these were: the track towards the confluence of the Urema and Muaredzi rivers (western direction); the road towards Goinha village (northern direction); the road towards Muanza town (eastern direction); and the road towards the Urema crossing to Chitengo (southern direction). In addition, a number of smaller access tracks were followed but much of the inventory was done along the main roads. The positioning of the roads seemed to adequately cover much of the variation in the vegetation evident on the Landsat image.

\section{b) Nhanchururu}

In Nhanchururu, there was better access to places compared to Muredzi. The former site, due to the widely scattered homesteads, had more tracks and paths ramifying the area, allowing better access to sample areas. A number of these paths were followed and assessments of vegetation done.

\section{c) Inventory procedure}

For both sites, a plot-less sampling procedure similar to that of Timberlake et al. (1993) was followed when inventorying the vegetation. Sites were selected within the stratified zones according to how representative they were of the vegetation type under consideration. At each 
site, a starting point was randomly selected and a circular area covered around this central point, recording all plant species until no new species were encountered within the defined area, which was usually between 0.25 and 0.5 ha., depending on species richness. This approach follows the concept of the species-area curve (Connor and McCoy, 1979), which ensures that an adequate area to record all species is sampled. Care was taken to avoid roadside margins and to ensure that no obvious environmental boundaries were traversed to avoid straying into different vegetation units. A cover abundance value for each species was estimated according to the Braun-Blanquet scale (Mueller-Dombois and Ellenberg, 1974). Average heights of the canopy, sub-canopy, shrub and grass layers were estimated and the dominant species noted. Forty-seven sample points (including 9 on termite mounds) were inventoried in Muaredzi while 50 sample points (including 5 on termite mounds) were inventoried in Nhanchururu. In addition, notes were taken at various other points in the two sites. The location of each sample point was entered onto a global positioning system (Appendix 5).

\section{Assessment of explanatory variables}

A number of explanatory variables were assessed as follows: Assessments of soil colour, texture, surface capping, land-use, grazing intensity (none, light, heavy, overgrazed), and vegetation condition (undisturbed, disturbed or degraded) were done. Any evidence of previous fires was also recorded. Evidence of fire occurrence was taken from the presence of charred stems and burnt stumps of trees.

\section{Data analyses}

Hierarchical Cluster Analysis (HCA) using average linkage method (van Tongeren, 1995) was performed on a matrix of 47 plots by 228 species for Muredzi, and a matrix of 50 plots by 246 species for Nhanchururu, using species cover-abundance data. This was done to produce a classification of the vegetation based on floristic and structural similarities/ dissimilarities among them. HCA was performed using MINITAB version 13.1 statistical software (Minitab Inc., 2000). Detrended Correspondence Analysis (DCA) (ter Braak, 1986; 1995, Gauch, 1982), an indirect gradient analysis technique, was performed on species cover abundance data to elucidate relationships amongst the various plant associations and underlying environmental gradients. CANOCO Version 4 for Windows package (ter Braak, 1988; ter Braak, 1991; ter Braak and Smilauer, 1997) was used for this analysis. CANODRAW package, available in CANOCO, was used to calculate the Shannon diversity and richness indices (Ludwig and Reynolds, 1988; Magurran, 1988) for each inventoried site. The absolute richness values for each site were calculated as the total number of species recorded at the site.

The conservation importance value (CIV) for each map unit was calculated by multiplying the relative abundance value of the unit (RAV) by its mean diversity index (MDI), and then weighting the value obtained through multiplying by the relative proportion of unique/important plant species found within the unit (RPspp). Thus CIV=RAV*MDI*RPspp. The relative abundance value for each map unit was calculated using the formula RAV =1-(map unit area/total area). The total area excluded water bodies. This approach is justified since the smaller the area, the higher the priority for conservation (Timberlake et al. 1991). The MDI comprises the mean diversity value for all the sites that make up each unit. Use of the MDI alone in the calculation of the conservation importance values is justified, on the basis that the diversity index takes into account both species richness and evenness (Magurran, 1988). The number of important species was expressed on a scale of $1-5$, where no important species $=1$; 1-2 species $=2 ; 3-4$ species $=3 ; 5-6$ species $=4$; and $>6$ species $=5$. RPspp scores for each unit were derived through dividing the scale value (1-5) by the highest scale value (5). Finally, standardized conservation values were calculated for each unit by dividing the CIV by the highest CIV, thus giving values between zero and one. Water or river systems were arbitrarily assigned conservation values of 0.0001 .

\section{B. Results}

\section{Muaredzi}

\section{a) Vegetation types}

Much of the vegetation falls within two of the five broad physiographic units categorised by Tinley (1977) along his idealised Gorongosa-Cheringoma transect. The physiographic units found within the study area are the Midlands and Rift Valley within which Tinley (1977) identified various types of forest, thicket and scrub-thicket, savanna, rockfaces, grassland and freshwater systems. Similarities to some of Tinley's (1977) vegetation types are noted in the descriptions below. Physiognomic classes used in this report follow Pratt et al. (1966). 


\section{b) Vegetation classification}

Four broad categories of vegetation communities were identified, each of which comprises one or more vegetation types. The Hierarchical Cluster Analysis separated the vegetation into 13 vegetation types (Figure 22) based on floristic composition and cover abundance. These are described below.

\section{A: FORESTS ANDTHICKETS}

A1: Millettia stuhlmannii mixed dry forest, Two patches of dry forest dominated by Millettia stuhlmannii were identified at the base of the escarpment along the road to Muanza. These are what local communities refer to as Nsitu. It is possible that more patches could occur on similar sites within the area. They are structurally similar to the dry forests often referred to as 'jesse thickets' or dry layered forests in Zimbabwe (Timberlake et al. 1993). The dry forests described by Tinley (1977) are different from the ones occurring in the area. The dry forests occur on sandy soils and depict distinctive vertical stratification of the canopy, sub-canopy and shrub layers. There are very few grasses in the forest.

Total woody cover is $90-100 \%$ The upper canopy trees reach up to $20 \mathrm{~m}$, the sub-canopy is about $10 \mathrm{~m}$ and shrubs are more than $3 \mathrm{~m}$ in height. Other common trees in the canopy layer are Afzelia quanzensis, Guibourtia conjugata and Diospyros mespiliformis. The sub-canopy layer is dominated by Cleistoclamys kirkii, Tabernaemontana elegans and Strychnos henningsii. Common shrubs are Dovyalis macrocalyx, Alchornea laxiflora, Tricalysia jasminiflora, Diospyros senensis and Grewia sulcata. Occasional thickets of Combretum pisoniiflorum, Artabotrys brachypetalus, Hippocratea africana and Acacia schweinfurthiana are scattered within the forest. Large termitaria are common in the dry forests, supporting vegetation described below as type $A 3$.

A2: Spirostachys africana mixed dry forest, A number of small patches of dry forests dominated by Spirostachys africana are found along the roads to the Urema crossing and to Goinha village. They occur on grey sandy clay loams on raised ground. Total woody cover is between 80 and $90 \%$ The vegetation is very thick in places with virtually no grass layer and exhibits clear vertical stratification of the tree and shrub layers. Emergent trees reach up to $15 \mathrm{~m}$ but the general canopy height is about $8 \mathrm{~m}$ while shrubs are generally 2-3m in height. Other common trees include Afzelia quanzensis, Xeroderris stuhlmannii, Dalbergia melanoxylon and Diospyros mespiliformis. The shrub layer is dominated by Rhus dentata, Dichrostachys cinerea, Diospyros senensis and Deinbolia xanthocarpa. A number of climbers or scandent plants occur, including Combretum pisoniiflorum, Cissus quadrangularis, Combretum mossambicense, Capparis tomentosa and Artabotrys brachypetalus. Termitaria are common in this vegetation type, supporting a vegetation type described in $\mathrm{A} 3$ below.

A3: Mixed Cleistoclamys kirkii woodlandthickets, Tinley (1977) emphasised the importance of termitaria in most vegetation types within the Rift valley. Local communities also recognise their importance and specifically single out murmuchea (termite mounds) as an important land unit. Termitaria are a common feature within vegetation types $A 1$ and $A 2$, but are also scattered in the type B woodlands. They support woodlandthickets of slightly different species composition and structure from the rest of the dry forest proper. There are also slight differences in the composition of the woodland-thickets between the two dry forest types, $A 1$ and $A 2$. The vegetation is of mixed dominance but Cleistoclamys kirkii is a common dominant on almost all inventoried termitaria. Tamarindus indica is al so common on termitaria in vegetation type A2. Other common trees include Trichilia capitata, Diospyros mespiliformis, Xeroderrisstuhlmanii, Berchemia discolor, Ziziphus mucronata, and Lannea schweinfurthiana, among others. The sub-canopy layer is usually dominated by Deinbolia xanthocarpa, Tricalysia jasminiflora, Markhamia zanzibarica, Rhus gueinzii and Diospyros senensis. Caparris tomentosa, Combretum mossambicense, Tiliacora funifera, J asminum fluminense and Cissus quadrangularis sometimes form more closed associations on the termite mounds. There are virtually no grasses in the woodland-thickets.

\section{B: WOODLANDS}

B1: J ulbernardia globiflora-Brachystegia spiciformis (miombo) woodland, Miombo woodland dominated by J ulbernardia globiflora and Brachystegia spiciformis is found on the escarpment in the eastern part of the study area. This land type was identified as planalto by local communities, and is a distinct landscape markedly different from the Rift Valley. This vegetation type is more extensive outside the study site, especially along the road to Muanza. It comprises tall trees of up to $14 \mathrm{~m}$ in height and occurs on brown sandy clay loams. Total woody cover is between $70-80 \%$ It is a well-structured woodland with clear stratification of the tree, shrub and grass layers. The sub-canopy layer is composed of a wide range of tree species including Diplorhynchus condylocarpon, Stereospermum kunthianum, Pterocarpus rotundifolius and Combretum zeyheri. Dichrostachys cinerea, Ximenia caffra, Pterocarpus brenanii, Dalbergia melanoxyl on and 
Lippia javanica are common in the shrub layer. Grass cover is sparse, due to the dense woodland, where Hypathelia sp. and Heteropogon melanocarpus are prominent.

B2: Combretum adenogonium-Sclerocarya birrea mixed woodland, The most extensive vegetation type found in the study area is dominated by Combretum adenogonium and Sclerocarya birrea. The latter species occurs mainly as emergents while the former species are the main canopy trees. Although Combretum adenogonium is the dominant species in most places, local variations in the co-dominant tree species are evident. Total woody cover varies considerably from one locality to another, ranging between $50 \%$ and $70 \%$ Emergent trees are generally between 15 and $18 \mathrm{~m}$ in height, while the main canopy is generally around $8 \mathrm{~m}$ high. Average height of the shrub layer is between 2 and $3 \mathrm{~m}$. The vegetation type occurs on dark brown sandy clay loams and sandy clays on undulating terrain but sometimes on flat land in the planicie land type. Common trees include Ziziphus abyssinica, Combretum zeyheri, Acacia sp., Pteleopsis myrtifolia and Acacia nigrescens. The shrub layer is usually thick, dominated by Tricalysia jasminiflora, Rhus gueinzii and Grewia sulcata, and is complemented by dense grass cover dominated by Heteropogon melanocarpus and Hypathelia species. This vegetation type has high species richness, with some sites registering up to 50 species.

B3: Acacia polyacantha-Piliostigma thonningii mixed woodland, This woodland occurs in a number of limited areas. Exemplary patches are found around Muaredzi village. It is dominated by Acacia polyacantha and Piliostigma thonningii and occurs on heavy clay soils in the planicie. It grades into Setaria incrassata wooded grassland. There are local variations in species composition but the dominants remain relatively unchanged. Total woody cover is around $60 \%$ The canopy is generally low (about $8 \mathrm{~m}$ tall) but emergent trees (especially Acacia polyacantha) may reach up to $12 \mathrm{~m}$. Other tree species often encountered include Combretum adenogonium, Sclerocarya birrea, Combretum imberbe and Hyphaene petersiana. Shrubs are generally 2-3m in height and comprise mainly young Sclerocarya birrea, Hyphaene petersiana, Piliostigma thonningii and Combretum imberbe. The grass layer is dominated by Setaria incrassata. Much of this vegetation type around Muaredzi village is currently being cleared for cultivation.

B4: Hyphaene petersiana -Salvadora persica open woodland, Along the fringes of some grassland areas in the thando land type, occurs a woodland dominated by Hyphaene petersiana and Salvadora persica. Soils, which are grey sandy clay loams, are apparently salty as evidenced by the dominance of Salvadora persica (Aronson, 1989). It is an open woodland with a total woody cover of between 20 and $30 \%$ The woody vegetation largely occurs in localised clumps, with widespread open areas supporting a short grass sward. The open areas are heavily utilised by warthog. Tree canopy height is less than $6 \mathrm{~m}$ but occasional Acacia trees are taller than this. Other common species are Acacia xanthophloea, Lonchocarpus capassa, Flueggia virosa and Euclea natalensis. Capparis tomentosa forms a layer over most of the clumps of trees and shrubs. The main grass, which is heavily grazed by warthog, is Eriochloa stapfiana, while Panicum maximum is found under the clumps of vegetation.

B5: Combretum zeyheri-Acacia karroo mixed woodland, This vegetation type is dominated by Combretum zeyheri and Acacia karroo, and exhibits a wide mixture of species.

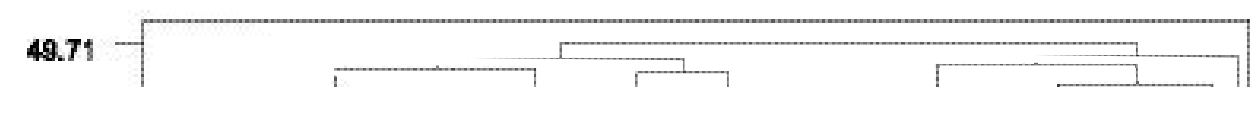


It comprises species found in Combretum-dominated woodlands of the rift valley and those found in the miombo woodlands on the escarpment. It occurs on light-textured loamy soils in both planalto and planicie. It is an open woodland with total woody cover of up to $60 \%$. Scattered termitaria, supporting clumps of evergreen and semi-evergreen species, are found in places. Tall trees reach up to $14 \mathrm{~m}$ in height but the canopy layer is generally between 8 and $10 \mathrm{~m}$. Other common trees include Combretum adenogonium, Piliostigma thonningii, Commiphora africana, Diplorhynchus condylocarpon, Pericopsis angolensis, Pterocarpus rotundifolius and Erythroxylum zambesiacum. The shrub layer is sparse and dominated by Tricalysia jasminiflora, Bauhinia galpinii, Maytenus senegalensis and Acacia karroo. Aristida junciformis and Heteropogon contortus are the dominant grasses.

B6: Mixed riverine woodland, Riverine woodland, of mixed dominance, extends from the Millettia stuhlmannii dry forests to higher altitudes into the miombo woodlands. It occurs along one or two major seasonal rivers, and covers a sizeable belt of up to $40 \mathrm{~m}$ on either side of the river channels. Woody cover is about $70-80 \%$ The upper canopy layer rises to about $14 \mathrm{~m}$, while the sub-canopy is up to $10 \mathrm{~m}$. Shrubs are up to $3 \mathrm{~m}$ tall, while the grass layer is poorly developed and sometimes non-existent. Dominant tree species are Manilkara mochisia, Strychnos henningsii, Diospyros mespiliformis and Strychnos madagascariensis. Other common trees include Teclea nobilis, Spirostachys africana, Dovyalislucida and Millettia stuhlmannii. Common shrubs are Grewia sulcata, Ehretia obtusifolia, Euclea divinorum, Dalbergia melanoxylon and Tricalysia jasminiflora

\section{C: FLOODPLAIN VEGETATION}

The C-vegetation types, described below, occur in the thando, planicie, madimba and gombe land types.

C1: Phragmites mauritianus reed communities, This vegetation type is dominated by Phragmites mauritianus reeds. It forms a narrow fringe (usually $<10 \mathrm{~m}$ wide) along the banks of the Urema and Muaredzi rivers. It occurs on a variety of soil types, ranging from coarse sandy soils in parts of Muaredzi riverbed to black heavy clays in some sections of the Urema. Few scattered trees also grow within and close to the reed communities. These include Acacia sieberiana, Antidesma venosum, Acacia xanthophloea and Combretum imberbe. Total woody cover is less than $1 \%$ Eichorrnia crassipes is found floating on the water in some sections of Urema River. The main grasses associated with this vegetation type are Setaria incrassata and Echinochloa haploclada.
C2: Echinochloa haploclada grassland, This grassland is dominated by Echinochloa hapoclada and is mainly found in the flood zone of lake Urema. It is an extensive grassland forming thick, deep mats getting to almost knee-height. Soils are black alluvial clays. Few scattered shrubs of Sesbania sesban and Mimosa pigra occur in some places, attaining a total woody cover of less than $1 \%$ Occasional Faidherbia albida trees and Hyphaene petersiana shrubs occur at the fringes of the grassland where it grades into the Setaria incrassata wooded grassland (C3).

C3: Setaria incrassata wooded grassland, An extensive wooded grassland dominated by Setaria incrassata occurs in low-lying areas. These areas become waterlogged during the rainy season, resulting in the death of some grass tussocks as evidenced in the area close to the Muaredzi-Urema confluence. Soils are heavy, black loamy clays of alluvial origin and crack during the dry season. Grass height is $>2 \mathrm{~m}$. This vegetation type forms almost pure grassland in wetter areas but the woody component becomes significant on better-drained soils. Total woody cover is less than $5 \%$ Common trees, some of which reach up to $20 \mathrm{~m}$ in height, include Combretum imberbe, Faidherbia albida, Acacia sieberiana, Acacia xanthophloea and Kigelia africana. Common, scattered shrubs (up to $3 \mathrm{~m}$ in height) are Antidesma venosum, Hyphaene petersiana and Mimosa pigra.

\section{D: FALLOW LAND VEGETATION}

D1: Lippia javanica -Piliostigma thonningii mixed shrubland, This vegetation type is found on fallow lands of various ages. It is largely a shrubland dominated by Lippia javanica and Piliostigma thonningii. Species composition varies considerably due to both the age of fallow and the initial composition before the land was cleared. The structure tends towards a woodland on older fallows, which are characterised by even-aged trees of Piliostigma thonningii and Acacia polyacantha. Tall trees (about $12 \mathrm{~m}$ in height) are scattered throughout the shrubland. These trees are presumably remnants of the original woodland before clearing. Shrubs are generally $2-3 \mathrm{~m}$ in height on young fallows but the canopy reaches up to $8 \mathrm{~m}$ on older fallows. Other common trees are Sclerocarya birrea, Kigelia africana and Acacia xanthophloea. The shrub layer is usually thick with occasional thickets of Combretum microphyllum. Other common shrubs include Solanum incanum, Cajanus caj an (cultivated), Hyphaene petersiana, Ocimum canum, Senna singueana, Cassia sp. and Ozoroa obovata. The grass layer is somewhat sparse but tall, with Panicum maximum and Setaria incrassata dominant. Roettboelia cochinchinensis is widespread in the younger fallows. 


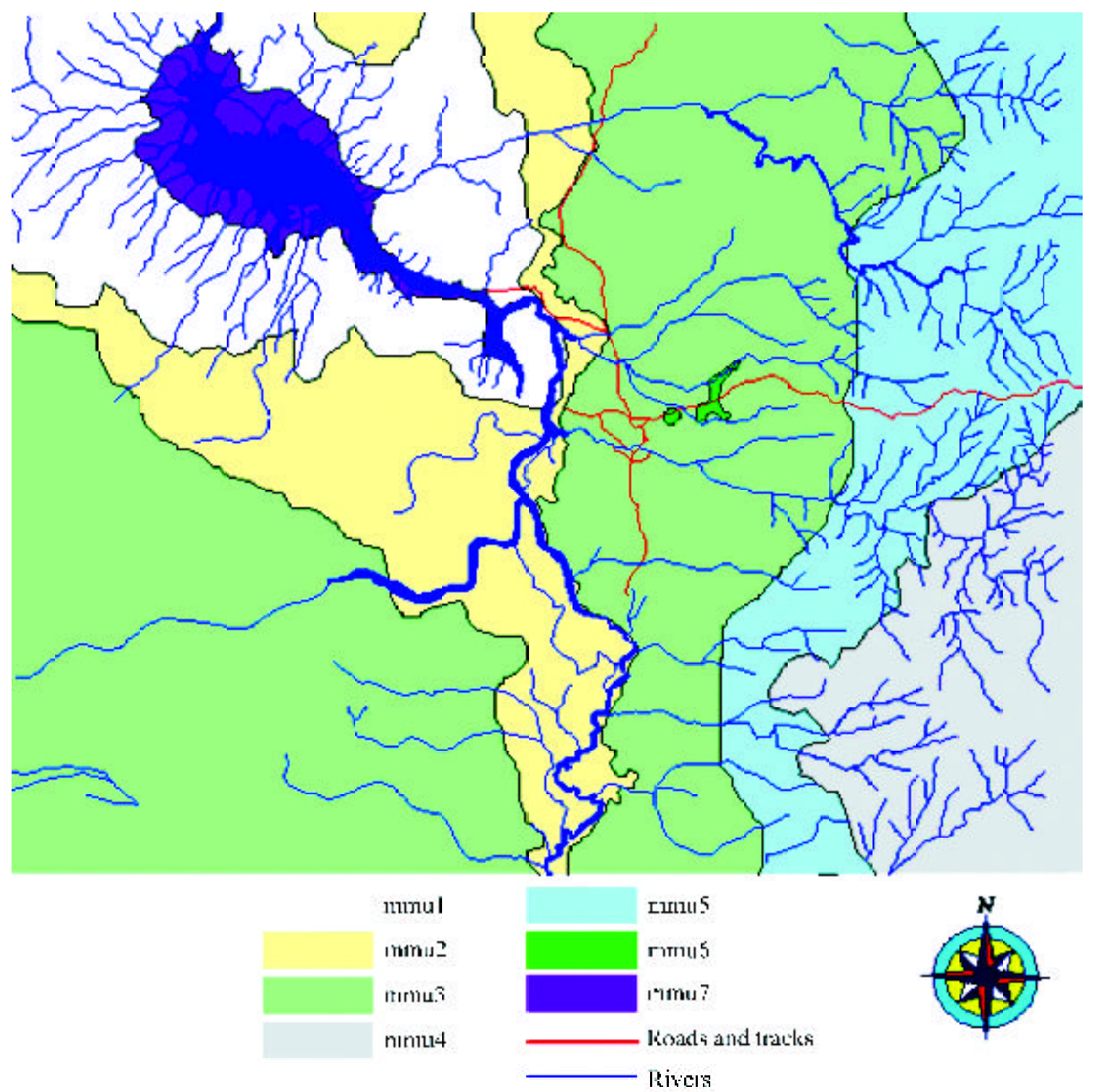

Figure 23. Vegetation map of Muaredzi. See text and Table 60 for descriptions of mapping units, mmu1 to mmu7.

\section{c) Mapping units}

The vegetation map (Figure 23) presents six mapping units (MMU1-MMU6), and a seventh one indicating fresh water (MMU7). It was not possible to map each vegetation type due to the scale of presentation, given that some of the types only cover very limited areas. Each mapping unit, therefore, consists of a number of vegetation types as indicated in Table 60 below.

\section{d) Main gradients in vegetation composition and structure}

Detrended Correspondence Analysis shows more separation of the plots along axis 1 than along axis 2 (Figure 24). These two axes accounted for $92.2 \%$ and $56.9 \%$ respectively, of the variation in species data. Separation of the plots is such that the floodplain vegetation $(\mathrm{C} 1, \mathrm{C} 2, \mathrm{C} 3)$ is found to the left of the diagram and the forests ( $\mathrm{A} 1, \mathrm{~A} 2$, A3) to the extreme right. Separation along axis 2 distinguishes Phragmites mauritianus reed communities (C1) and Echinocloa haploclada grassland (C2) from each other and from the other vegetation types.

\section{e) Species richness, diversity and conservation importance ranks of vegetation mapping units}

The total number of species recorded in the area was 228. The Shannon diversity indices indicate very low mean diversity in the grassland and Phragmites mauritianus reed communities and higher diversity in Combretum adenogoniunSclerocarya birrea-Acacia types and the dry 
forests. Richness indices follow a similar pattern (Table 61). Generally, richness was significantly higher in woodlands and dry forests than in wooded grasslands, grasslands and reed communities $(\mathrm{F}=5.67, \mathrm{p}<0.001)$. Diversity was also significantly lower in type $C$ vegetation than in the other vegetation types $(F=16.17, p \measuredangle 0.001)$.

Based on the diversity indices above (Table 61) and the relative abundance of the vegetation types, the standardized conservation importance indices of the mapping units are shown in Table 62 below. Important species (cited in the Mozambique Red Data List (SABONET, 2001)) identified in the area are Afzelia qaunzensis (low risk), Cola mossambicensis (near endemic, vulnerable), Dalbergia melanoxylon (threatened), Diospyros mespiliformis (threatened), Guibourtia conjugata (threatened), Spirostachys africana (threatened), and Sterculia quinqueloba (vulnerable). The Mixed dry forests and thickets (MMU6) have the highest calculated conservation value, mainly due to their limited extent and the existence of a higher number of important species, while the Echinocloa haploclada-Phragmites mauritianus communites
(MMU1) have the lowest calculated conservation value because they have low diversity and no important species.

\section{Nhanchururu}

\section{a) Vegetation types}

Much of the vegetation falls within Tinley's (1977) moist Brachystegia savanna woodlands within the Midlands physiognomic unit. Physiognomic classes used in the following descriptions follow Pratt et al. (1966).

\section{b) Vegetation classification}

The Hierarchical Cluster Analysis separated the vegetation into five vegetation types ( $A 1, A 2, B 1$, $B 2$ and $C 1$ ) (Figure 25) based on floristic composition and cover abundance. One of the types (A1) comprises three sub-types (Ala, Alb and $\mathrm{AlC}$ ). The vegetation types, though mainly woodlands and woodland-thickets, include cultivated land. 
Table 61. Means and standard errors (SE) of diversity indices, richness indices and absolute richness of the vegetation types found in Muaredzi.

\begin{tabular}{ccccc} 
Vegetation type & Diversity index & Richness index & Absolute richness & Sample size $(\mathbf{n})$ \\
\hline A1 & $2.711( \pm 0.18)$ & $3.351( \pm 0.33)$ & $35.0( \pm 4.9)$ & 3 \\
A2 & $2.062( \pm 0.32)$ & $2.664( \pm 0.51)$ & $20.0( \pm 8.3)$ & 4 \\
A3 & $1.980( \pm 0.07)$ & $2.784( \pm 0.14)$ & $13.8( \pm 1.2)$ & 6 \\
B1 & $2.084( \pm 0.06)$ & $2.332( \pm 0.15)$ & $22.0( \pm 2.0)$ & 2 \\
B2 & $2.485( \pm 0.13)$ & $3.443( \pm 0.15)$ & $33.0( \pm 4.5)$ & 5 \\
B3 & $2.082( \pm 0.14)$ & $2.842( \pm 0.17)$ & $17.7( \pm 3.2)$ & 3 \\
B4 & $2.183( \pm 0.03)$ & $2.890( \pm 0.00)$ & $18.0( \pm 0.0)$ & 2 \\
B5 & $2.169( \pm 0.05)$ & $3.303( \pm 0.07)$ & $27.3( \pm 2.0)$ & 3 \\
B6 & $1.913( \pm 0.45)$ & $2.496( \pm 0.55)$ & $14.0( \pm 7.0)$ & 2 \\
C1 & $1.066( \pm 0.24)$ & $2.092( \pm 0.11)$ & $8.3( \pm 1.0)$ & 4 \\
C2 & $0.833( \pm 0.07)$ & $2.394( \pm 0.09)$ & $11.0( \pm 1.0)$ & 2 \\
C3 & $1.157( \pm 0.14)$ & $2.226( \pm 0.18)$ & $9.6( \pm 1.4)$ & 9 \\
D1 & $2.510( \pm 0.13)$ & $3.135( \pm 0.36)$ & $28.5( \pm 2.5)$ & 2 \\
\hline
\end{tabular}

Table 62. Standardized conservation indices and biodiversity conservation importance ranks of the mapping units in Muaredzi. The standardized conservation indices for each map unit are relative to the map unit with the highest weighted conservation index.

\begin{tabular}{|c|c|c|c|c|c|c|c|c|c|}
\hline \multirow{2}{*}{$\begin{array}{l}\text { Map } \\
\text { unit }\end{array}$} & \multirow{2}{*}{$\begin{array}{c}\text { Relative } \\
\text { abundance }\end{array}$} & \multicolumn{2}{|c|}{ Diversity index } & \multicolumn{3}{|c|}{ Important species } & \multicolumn{2}{|c|}{ Conservation value } & \multirow[b]{2}{*}{ BCRI } \\
\hline & & Mean & se & $\mathrm{n}$ & $\mathrm{n}$ & Weight & Weighted & Standardized & \\
\hline MMU1 & 0.8543 & 0.9880 & 0.1640 & 6 & 0 & 0.2 & 0.1686 & 0.0776 & 6 \\
\hline MMU2 & 0.8600 & 1.3440 & 0.1700 & 11 & 1 & 0.4 & 0.4623 & 0.2129 & 5 \\
\hline MMU3 & 0.5675 & 2.3689 & 0.0961 & 10 & 4 & 0.6 & 0.8065 & 0.3714 & 3 \\
\hline MMU4 & 0.8784 & 2.0840 & 0.0610 & 2 & 1 & 0.4 & 0.7323 & 0.3372 & 4 \\
\hline MMU5 & 0.8417 & 2.0660 & 0.1560 & 5 & 5 & 0.8 & 1.3911 & 0.6405 & 2 \\
\hline MMU6 & 0.9990 & 2.1740 & 0.1320 & 13 & 7 & 1.0 & 2.1719 & 1.0000 & 1 (highest) \\
\hline MMU7 & - & - & 然 & - & - & - & - & 0.0001 & 7 (lowest) \\
\hline
\end{tabular}

BCRI: Biodiversity conservation ranking importance

\section{A: WOODLANDS}

A1: Miombo woodland, The miombo woodlands found in the area comprise three subtypes, based on the dominant species as follows:

Ala: Brachystegia spiciformis-dominated, miombo woodland

A tall woodland dominated by Brachystegia spiciformis occurs on undulating terrain on moderately- to well-drained sandy clay loams. Emergents of Burkea africana reached up to $20 \mathrm{~m}$. Canopy cover values range between $70 \%$ and $90 \%$ Common species in the canopy layer include Diplorhynchus condylocarpon, Pterocarpus rotundifolius, Sclerocarya birrea, Pseudolachnostylis maprouneifolia, Xeroderris stuhlmannii, Albizia versicolor and Brachystegia boehmii. Erythrophleum africanum is sometimes found in places on sandier soils. The shrub layer is generally more than $3 \mathrm{~m}$ tall. Common species in this layer are Holarrhena pubescens, Sclerocarya birrea, Annona senegalensis and Dalbergia nitidula. Friesodielsia obovata, Zanha africana and Carphalea pubescens may be encountered in some localities. Dominant grasses are Themeda triandra, Heteropogon melanocarpus, Panicum maximum and Digitaria milanjiana.

Scattered termitaria are found throughout these woodlands, and these support the vegetation type described in $\mathrm{B} 2$ below. There is evidence of annual fires which burn through the area. Occasional clumps of vegetation, consisting of Rhoicissus revoilii, Artabotrys brachypetalus, Dalbergia lactea and Bauhinia galpinii, are encountered in this woodland.

Alb: Brachystegia boehmii-dominated miombo woodland, A tall (18-20m) woodland, dominated by Brachystegia boehmii, occurs on undulating terrain on moderately-drained sandy clay loams. Emergents of Burkea africana are scattered throughout the woodland and reach up to $24 \mathrm{~m}$ in height. Canopy cover averages between $70 \%$ and $80 \%$ Common associated tree species in the canopy layer include Diplorhynchus condylocarpon, Crossopteryx febrifugum, Pseudolachnostylis maprouneifolia, Xeroderris stuhlmannii, Pterocarpus angolensis, Pterocarpus rotundifolius and Brachystegia spiciformis. This woodland has a well-defined sub-canopy layer dominated by Ochna species, Erythrophleum africanum, Julbernardia globiflora and, sometimes, Schinziophyton rautanennii. The shrub layer is relatively dense, averaging more than $3 \mathrm{~m}$ in height. The common species in the shrub layer include Dalbergia melanoxylon, Lannea discolor, Annona senegalensis, Holarrhena pubescens, Rhus tenuinervis, Pavetta schumanniana, Pericopsis angolensis, Carphalea pubescens and Turraea nilotica. The 


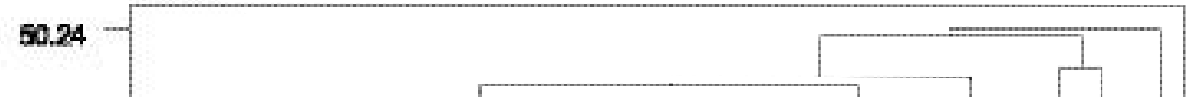

Figure 25. Hierarchical Cluster Analysis dendrogram showing a classification of the vegetation of Nhanchururu area, based on fifty (1-50) sample points inventoried.

shrub layer contains lots of young plants of the canopy dominants. The grass layer is thick and tall $(>2 m)$. Dominant species in this layer are Themeda triandra, Panicum maximum, Diheteropogon amplectens var katangensis, Heteropogon melanocarpus and Hyparrhenia filipendula. Pogonarthria squarrosa is found in on sandier soils, particularly in the northern areas.

Termitaria, supporting a vegetation type described in B2 below, are scattered within the woodland. Fire is also a common feature of these woodlands. Occasional thickets of Bauhinia galpinii, Rhynchosia minima and Dal bergia lactea are found in places.

Alc: Mixed miombo woodland, This miombo woodland occurrs on rocky, pebbly and gravely ridges throughout the study area. The geology is apparently doleritic, as evidenced by rounded boulders on the surface. This woodland has a mixture of co-dominants characterising a miombo woodland. The canopy rises to $14 \mathrm{~m}$, with Brachystegia spiciformis emergents reaching up to $22 \mathrm{~m}$ in height. Common trees include Pseudolachnostylis maprouneifolia, Pterocarpus rotundifolius, Brachystegia boehmii, Sclerocarya birrea and Pterocarpus angolensis. The subcanopy layer comprises mainly Combretum adenogonium, Ozoroa obovata, Xeroderris stuhlmanii, Pterocarpus brenanii, Combretum zeyheri and Stereospermum kunthianum. The shrub layer is more than $3 \mathrm{~m}$ high and dominated by Holarrhena pubescens, Millettia stuhlmannii and Diplorhynchus condylocarpon. Other shrubs include Brachylaena rotundata, Dalbergia melanoxylon, Carphalea pubescens and Grewia bicolor. Grasses reach more than $3 \mathrm{~m}$ in height, the common species being Sorghum arundinaceum, Roettboelia cochinchinensis,
Hypathelia species, Panicum maximum, Diheteropogon amplectens var katangensis and Heteropogon contortus.

A2: Mixed riverine woodlands, This woodland is the most varied both in species composition and structure. Its cover ranges between $5 \%$ and $80 \%$ and is characterised by disj unct associations of various woody and non-woody species. In most cases, the riverine fringe is not well-defined since the area comprises mainly the erosional upper reaches of rivers, hence there are no extensive alluvial deposits. Some areas along the main rivers (such as the Nhathui and Mucodza) support associations of tall (up to $25 \mathrm{~m}$ ) trees of Khaya anthotheca, Kigelia africana, Trema orientalis, Breonardia salicina and Erythrophleum suavelons. In some areas, only scattered trees of Acacia polyacantha and Albizia versicolor are found. Markhamia obtusifolia, Vitex doniana and Piliostigma thonningii are also found in some areas. Grasses comprise Hypathelia species, Panicum maximum and, occasionally in closed riverine woodland, Oplismenus hirtellus. The shrub layer, where found, is mostly thick, with Combretum microphyllum, Phyllanthus reticulatus, Lippia javanica, Rhustenuinervis and Brachylaena rotundata dominating. Clumps of bamboo are also found in some localities. Spatially limited associations of Setaria incrassata, Phragmites mauritianus and Dioscorea species (yam) also occur along some banks of the major rivers, where the terrain is flatter and the soils wetter for much of the year.

\section{B: WOODLAND-THICKETS}

B1: Millettia stuhlmannii-Bauhinia galpinii woodland-thickets, Closed woodland-thickets dominated by Millettia stuhlmannii and Bauhinia galpinii are mostly found on ridges composed of 
reddish-brown clayey soils. Quartz pebbles are sometimes found on the surface. Woody cover is up to $100 \%$ and the height is up to $10 \mathrm{~m}$, with emergents of Xeroderris stuhlmannii and Sclerocarya birrea occasionally reaching up to $14 \mathrm{~m}$. Other common tree species include Markhamia obtusifolia, Pterocarpus rotundifolius, Schrebera trichoclada, Cleistoclamyskirkii, Vitex payos, Brachystegia boehmii and Brachystegia spiciformis. The shrub layer is usually thick and consists mainly of shrubs $>3 \mathrm{~m}$ in height. Dominant shrub species are Friesodielsia obovata, Holarrhena pubescens, Xanthoxylum capense, Annona senegalensis, Markhamia obtusifolia and Tricalysia jasminiflora. Thicker associations of Artabotrys brachypetalus, Rhoicissus revoilii and Bauhinia galpinii are also common. The grass layer is sparse, except in the few openings found in some of the woodland-thickets where Setaria homonyma, Panicum maximum, Heteropogon contortus and Oplismenus hirtellus may be found. Fire is of common occurrence in some of the more open woodland-thickets.

B2: Friesodielsia obovata mixed woodlandthickets, Scattered termitaria are found in most of the vegetation types described above. The termitaria range in height from $1.5 \mathrm{~m}$ to $3 \mathrm{~m}$ and the diameter is usually $>5 \mathrm{~m}$. Most termitaria support both woody and non-woody plants, the composition of which varies considerably with soil type and surrounding vegetation type. The physiognomy of the vegetation tends to be woodland-thickets, mostly dominated by Friesodielsia obovata and/ or Combretum mossambicense. Other common species include Bauhinia galpinii, Sclerocarya birrea, Azanza garckeana, Albizia harveyi, Deinbolia xanthocarpa, Maytenus heterophylla and Carissa edulis. Commonly encountered grasses are Panicum maximum, Digitaria milanjiana and Setaria homonyma.

\section{C: CULTIVATED LANDS}

C1: Mixed vegetation in cultivated lands, Much of the plateau area is cultivated, particularly the reddish-brown soils which seem to be more fertile than the rest. Sorgum bicolor (sorghum) and Zea mays (maize) are the main crops. These are usually intercropped with perennial fruit, legume or other crops such Cajanus cajan (pigeon pea), Carica papaya (paw paw) and Manihot esculenta (cassava). Bananas ( Musa paradisiaca), yams (Dioscorea spp.) and other crops are cultivated along drainage lines. In addition to weedy plants, a number of indigenous woody and non-woody plants persist in the cultivated lands, mainly as coppice shrubs. These include Sclerocarya birrea, Markhamia obtusifolia, Diplorhynchus condylocarpon, Rhynchosia minima,
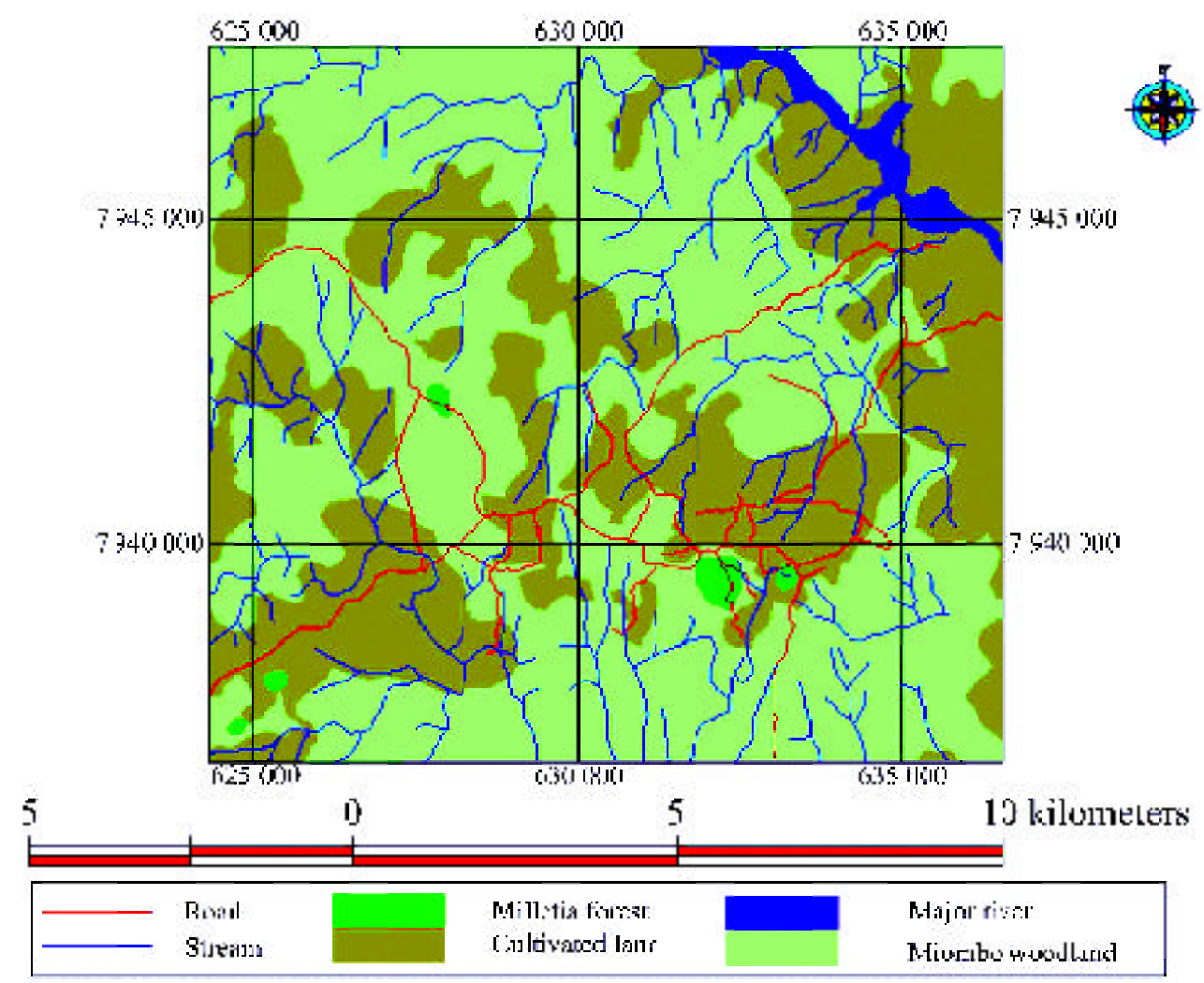
Table 63. Descriptions of the mapping units used in the vegetation map of Nhanchururu (NMU=Nhanchururu Mapping Unit).

\begin{tabular}{cll} 
Mapping unit & Description & Vegetation types \\
\hline NMU1 & Miombo woodlands & Ala, A1b, A1c, A2, B2 \\
NMU2 & Millettia stuhlmannii-Bauhinia galpinii woodland-thickets & B1 \\
NMU3 & Cultivated lands & C1 \\
NMU4 & River & - \\
\hline
\end{tabular}

Stereospermum kunthianum, Albizia versicolor, Flueggia virosa and Holarrhena pubescens. Roettboelia cochinchinensis is the main grass found in cultivated areas.

\section{c) Mapping units}

Due to the limited spatial extent of most of the vegetation types described above, and the lack of clarity of boundaries between the three miombo sub-types on the ground, only four mapping units are presented, one of which is a river (Figure 26). The mapping units are described in Table 63 below.

\section{d) Main gradients in vegetation composition}

A DCA ordination of the sample plots (Figure 27) indicates a clear separation of the plots along axis 1 , which accounted for $79.2 \%$ of the total variation in species data. Axes 2, 3 and 4 accounted for $44.1,37.7$ and $21.2 \%$ of the variation, respectively. The analysis separated the plots into three main groupings, I, II and III.
The maj or groupings identified above seem to be associated with two main gradients. DCA axis 1 is associated with a disturbance gradient, with highly modified (cultivated) areas in Group III and the riverine samples, which were less modified, in Group I. The bulk of the miombo samples fall in Group II, within which there is evidence of variable disturbance impacts.

DCA axis 2 seems to be associated with an edaphic gradient, mainly soil texture. Sample points taken on more clayey soils are grouped closer to zero along that axis while those containing more sand fraction are found further away from zero on the positive side of the axis. Termitaria samples, which have higher clay content and richer soils, are at the bottommost end of DCA axis 2.

\section{e) Species diversity, richness and conservation importance ranks of vegetation mapping units}

The total number of species recorded in the area was 246. Miombo woodlands and the Millettia

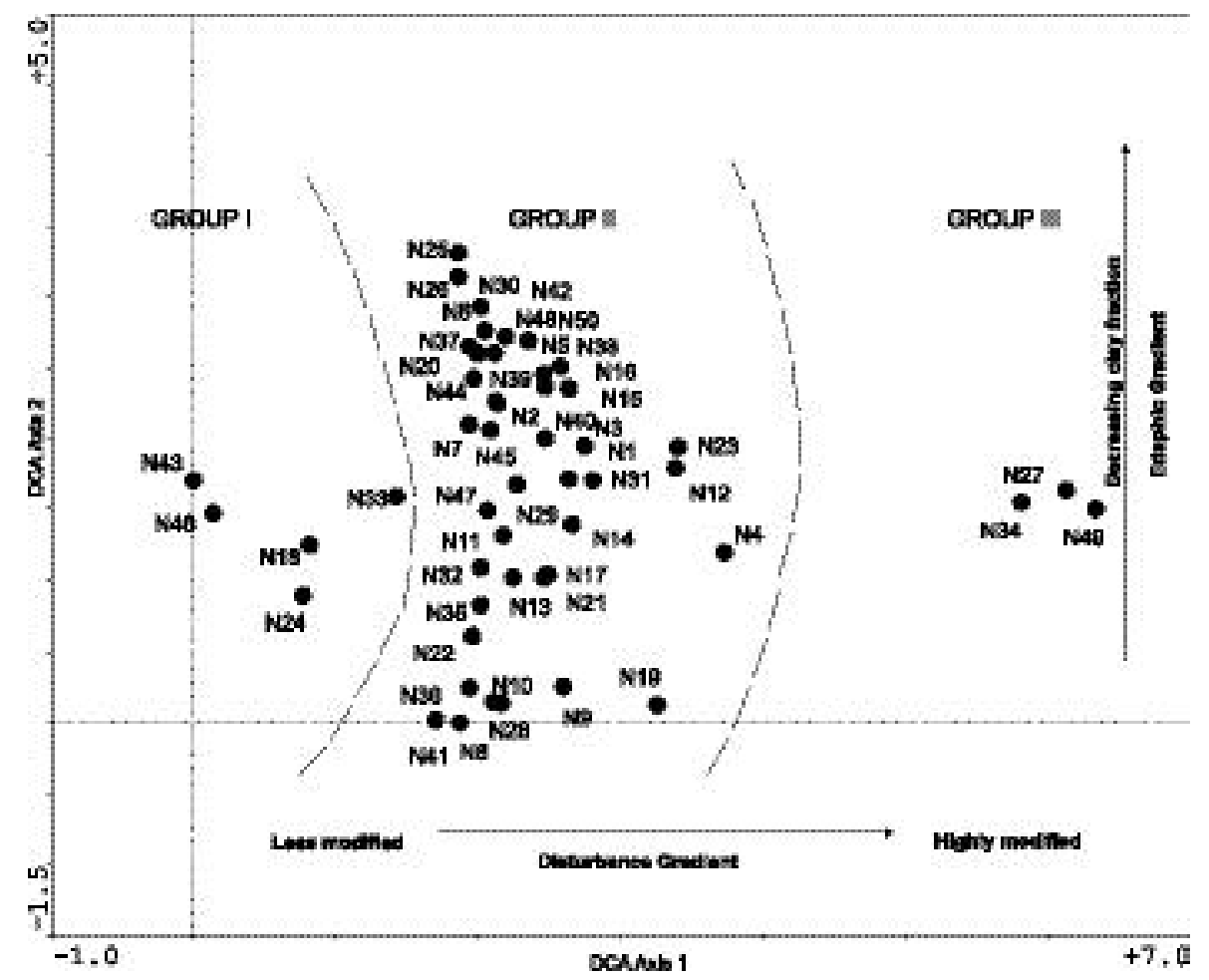

Figure 27. DCA ordination diagram indicating the separation of vegetation plots which mainly conforms to disturbance and edaphic gradients. 
Table 64. Means and standard errors (SE) of diversity indices, richness indices and absolute richness of the vegetation types found in Nhanchururu.

\begin{tabular}{cccrr} 
Vegetation type & Diversity index & Richnessindex & Absolute richness & Sample size (n) \\
\hline Ala & $2.850( \pm 0.05)$ & $3.760( \pm 0.05)$ & $42.4( \pm 2.1)$ & 7 \\
A1b & $2.672( \pm 0.05)$ & $3.620( \pm 0.05)$ & $38.4( \pm 2.2)$ & 10 \\
A1c & $2.685( \pm 0.06)$ & $3.521( \pm 0.09)$ & $34.6( \pm 2.9)$ & 7 \\
A2 & $2.407( \pm 0.10)$ & $3.313( \pm 0.09)$ & $28.5( \pm 2.3)$ & 11 \\
B1 & $2.659( \pm 0.10)$ & $3.584( \pm 0.09)$ & $36.7( \pm 2.6)$ & 7 \\
B2 & $2.062( \pm 0.18)$ & $2.890( \pm 0.13)$ & $18.6( \pm 2.6)$ & 5 \\
C1 & $1.330( \pm 0.25)$ & $2.225( \pm 0.22)$ & $9.7( \pm 1.9)$ & 3 \\
\hline
\end{tabular}

Table 65. Standardized conservation indices and biodiversity conservation importance ranks of the mapping units in Nhanchururu. The standardized conservation importance indices for each map unit are relative to the map unit with the highest relative conservation index.

\begin{tabular}{|c|c|c|c|c|c|c|c|c|c|}
\hline \multirow{2}{*}{$\begin{array}{l}\text { Map } \\
\text { unit }\end{array}$} & \multirow{2}{*}{$\begin{array}{c}\text { Relative } \\
\text { abundance }\end{array}$} & \multicolumn{3}{|c|}{ Diversity index } & \multicolumn{2}{|c|}{ Important species } & \multicolumn{2}{|c|}{ Conservation value } & \multirow[b]{2}{*}{ BCRI } \\
\hline & & Mean & se & $n$ & $n$ & Weight & Weighted & Standardized & \\
\hline NMU1 & 0.8421 & 2.5564 & 0.0545 & 40 & 5 & 0.8 & 1.7222 & 1.0000 & 1 (highest) \\
\hline NMU2 & 0.9876 & 2.6590 & 0.1010 & 7 & 3 & 0.6 & 1.5757 & 0.9149 & 2 \\
\hline NMU3 & 0.1702 & 1.3300 & 0.2500 & 3 & 0 & 0.2 & 0.0453 & 0.0263 & 3 \\
\hline NMU4 & - & - & - & - & - & - & - & 0.0001 & 4 (lowest) \\
\hline
\end{tabular}

BCRI: Biodiversity conservation ranking importance

stuhlmannii-Bauhinia galpinii woodland-thicket had higher species richness and diversity than the rest of the vegetation types (Table 64). Cultivated lands had the least number of species and species diversity. Vegetation types Ala, Alb, Alc, A2 and B1 were significantly richer in species than $B 2$ and $C 1(F=14.5, p<0.001)$. Differences in richness and diversity are shown in Table 64 below. Important species (cited in the Mozambique Red Data List (SABONET, 2001)) identified in the area are Afzelia quanzensis (low risk), Dalbergia melanoxylon (threatened), Diospyros mespiliformis (threatened), Khaya anthotheca (low risk) and Sterculia quinqueloba (vulnerable). The Miombo woodlands (NMU1) have the highest calculated conservation value, mainly due to their high diversity and the existence of a higher number of important species, while the Cultivated lands (NMU2) have the lowest calculated conservation value because they have low diversity and no important species.

Based on the diversity indices above (Table 64), the relative abundance of the mapping units and the number of important species, the standardized conservation indices of the mapping units are shown in Table 65 below.

\section{Discussion}

\section{Muaredzi}

a) Factors influencing vegetation structure and composition

Soil moisture and flooding. From the DCA ordination diagram (Figure 24 ) it is clear that the plots are separated along a soil moisture gradient. Drier plots are found on the right of the diagram while wetter plots are placed on the opposite end. Apart from showing the relative proximity of the respective plot groupings to maj or rivers, the results show increasing sand fraction in the soil, which confirms the importance of soil moisture in influencing vegetation composition. Soils in the valley floor, which usually get flooded, are heavier in texture (more clay) than the ones found towards the escarpment, which are sandier. The length of flooding of any particular area determines the balance between the woody and grass components of the vegetation. Where an area is flooded for a longer period, the vegetation becomes predominantly grassland while the woody component becomes dominant where there is no flooding, or where flooding period is shorter. Availability of water along river courses results in the dominance of Phragmites mauritianus communities which form a fringe along most of the perennial rivers and streams. There is clear zonation of vegetation with increasing distance from the main rivers such as the Urema. Echinochloa haplocladadominated grasslands are found in the flood zone while Setaria incrassata, and Hyphaene-AcaciaCombretum and miombo complexes (in that order) dominate vegetation communities as one moves away from the floodplain to the escarpment.

Soil texture and geology. There is an apparent association between soil texture and vegetation composition. Areas with heavy black clay soils of alluvial origin tend to support complexes of Acacia-Piliostigma woodlands, sometimes with Hyphaene petersiana and Setaria incrassata. Common Acacia species were A. sieberiana, A. karroo, A. nigrescens and A. 
polyacantha. Other species indicative of heavy soils include Combretum imberbe, Piliostigma thonningii and Lonchocarpus capassa. Sandier soils are mainly found along low ridges and these tend to support thicker woodlands with tall emergents. Common indicative species encountered were Sclerocarya birrea, Terminalia sericea, Spirostachys africana and mixed dry forests. On soils of medium texture (presumably colluvial), occur complexes of a wide range of vegetation types but these are largely dominated by Combretum species, particularly Combretum adenogonium. The vegetation complexes show marked local variations in species dominance as stated in the descriptions of the vegetation types.

Altitude and rainfall. There is a major difference between vegetation types within the Rift valley and those occurring on the escarpment. The latter areas support tall J ulbernardiaBrachystegia miombo woodlands while the rest of the vegetation types described above occur in the Rift valley. Altitude has an influence on the rainfall pattern, thereby indirectly influencing vegetation composition. Tinley (1977) noted differences in rainfall along the Gorongosa-Cheringoma transect indicating lower rainfall in the Rift valley. Rainfall is therefore an important factor and appears to increase with altitude, particularly when one compares the Midlands and the Rift valley. There are differences in geology, from the flood plain to the escarpment, which interacts with altitude and rainfall to influence vegetation composition as outlined in V.A.1.b and V.A.1.c above.

Fire. Is a common occurrence in the area and may play an important role in the dynamics of the woodlands. It was evident that a large percentage of the area burns annually. There were huge fires in the area during the time of conducting fieldwork. Fire may cause changes in the size class structure and species composition of the woodlands. A large body of literature has discussed how fire influences the structure and composition of woodlands (e.g. Frost and Robertson, 1987; Trollope, 1982; 1984).

\section{b) Concluding remarks}

From the preceding account, it can therefore be concluded that soil moisture, soil texture and geology, altitude and fire have a major influence on the floristic composition and structure of the vegetation in the area. These factors may act in interaction with each other. Therefore, the dominant gradient influencing vegetation in the area may be labelled as a 'complex gradient', since it may consist of a combination of a number of factors.

\section{2) Nhanchururu}

\section{a) Factors influencing vegetation structure and composition}

From observations in the field, together with patterns emerging from the DCA ordination (Figure 24), a number of factors which influence the structure, species composition and dynamics of the woodlands in the area can be identified. These can be divided into anthropogenic disturbances and edaphic (including geology) factors.

Timber extraction. There is overwhelming evidence of timber extraction in the area. Logged stumps of Pterocarpus angolensis and Millettia stuhlmannii were seen scattered throughout the miombo woodlands. In fact, the mixed-dominance miombo woodlands could have resulted from the removal of the previous dominants. The local people indicated that the area was logged during the war (1970s) and again after the war in 19971998. A pile of six Pterocarpus angolensis logs (still in good condition), averaging $6 \mathrm{~m}$ long, and of average diameter $50 \mathrm{~cm}$, was encountered at S18039'32.0", E34015'40.8". A quick estimate of stocking density of this species in the area was about 7 trees per hectare, meaning that the loggers extracted about $8.2 \mathrm{~m} 3 \mathrm{ha}-1$. This has resulted in changes in the species dominance structure and composition in the affected areas. There is also small-scale extraction of construction timber by the locals, as indicated in the list of resources they obtain from the landscape.

Fire. Almost every vegetation type described above is affected by fire. The intensity of fire depends on the season of burning, the prevailing ambient conditions and the type and amount of fuel available to carry a fire (Frost, 1996). Woodlands opened up through timber extraction show increased grass growth, and this will result in hotter, more intense fires. The various ecological impacts of fire on savanna woodlands are discussed at length by Frost (1996) and Frost and Robertson (1987) and interactive effects of woodland thinning and fire on miombo woodland structure and dynamics were discussed by Mapaure (2001). Most fires are apparently caused by honey gatherers and burning of areas for cultivation.

Bark removal. There is evidence of a number of trees dying due to bark removal by local people. This is mainly for making beehives, and the affected species are mainly Brachystegia spiciformis and Brachystegia boehmii. Most of the affected trees are large, usually more than $30 \mathrm{~cm}$ in basal diameter. Up to 8 beehives, awaiting to be mounted up on trees, were heaped at one old homestead (at S18037'25.5", 
E34016'25.9"). If the practice continues, it will have a significant effect on the structure and functioning of the woodlands. The death of debarked trees may be accelerated by fire, and this has been demonstrated in a Burkea af ricana savanna (Yeaton, 1988). From interviews with the local communities it emerged that honey was one of the important wild products obtained from the landscape by the local community. Bark has also been stripped for ropes but this seems to have a lesser ecological impact than that of beehive-making.

Land clearing. Much of the area on reddishbrown soils is cultivated. There is evidence of new clearing in some areas, while places of old habitation are re-vegetating, largely to grassdominated woodlands. Land-clearing results in habitat loss, habitat fragmentation and, sometimes, loss of biodiversity (McNeely et al. 1995). This activity is more prevalent in the miombo woodlands and thickets on more fertile soils than elsewhere.

Soils and geology. It appears that soils and geology are important determinants of vegetation structure and composition in the area. This is evidenced by the grouping of the sample points on ordination diagram (Figure 27), where the second axis appears to be associated with an edaphic gradient. The Millettia stuhlmannii woodland-thickets are confined to reddish-brown, clayey soils which appear to be doleritic intrusions, while all the miombo woodlands occur on what appear to be gneissic soils of sandier texture. Due to the lack of a detailed geological map of the area, these observations remain unconfirmed. Tinley (1977) broadly described the geology in the area as preCambrian metamorphic rocks of magmatites, paragneiss, amphibolites and schists of the Zambezian system.

\section{D) Conservation values of vegetation in Muaredzi and Nhanchururu}

Scientific valuation of the conservation importance of vegetation in Muredzi and Nhanchururu is based on the diversity of plants. This is because the variety of living organisms in any area is so great that it is impracticable to inventory and identify all of them, hence the use of 'indicator groups' (UNEP, 1996) as surrogates for the whole biological diversity. We have therefore taken one group of living organisms as a surrogate for the overall biodiversity in these areas. Whilst this approach slightly differs from taxon-based biodiversity surrogates (Williams, 2001), it is a valid scheme since it focuses on a biological entity, the plant community (Burgman and Lindenmayer, 1998: in Williams, 2001). This is an acceptable approach given that the vegetation of an area represents an integration of environmental features such as climate, soils, topography, previous land-use and site potential (Timberlake and Mapaure, 1992).

Determination of the conservation values of the vegetation mapping units has been based on their individual merits, which considered overall diversity, spatial extent and numbers of unique/ important species in each unit. The principle of complementarity (Vane-Wright et al. 1991) was thought to be not appropriate since selection of subsequent units after the first is based on the fact that one does not wish to replicate taxa which occur in the first choice. It also presupposes a level of the knowledge of species presence/ absence and distribution (Beentje, 1996), which was not the case with our data. Complementarity increases the efficiency of selection of sites or units only when data are more complete (Pressey et al. 1993). Even though the list of important species (endemic, threatened, vulnerable, etc.) given by SABONET (2001) is somewhat preliminary, it gives us a sound basis upon which conservation values can confidently be weighted. Before the preliminary list, there was no Red Data List for plants of Mozambique (see Bandeira et al. 1994). If the whole of Gorongosa National Park were to be included in the analysis, a different picture could emerge since the species diversity and spatial extents of other vegetation types in the park are not known.

Approaches of selection of areas for conservation have often been based on counts of endemic species, especially for faunal species (Pearson and Cassola, 1992). This method can also be applicable to conservation of vegetation (Beentje, 1996). Thus the determination of the conservation importance values of the mapping units presented in this report has been centred on above criteria. Because of the non-availability of a comprehensive list of endemic species, it was only possible to base our evaluations on the identified important species (SABONET, 2001). It has been recommended, however, that in addition to numbers of endemics, scoring systems for sites should include evaluation of threats, appropriate measures of site viability and species richness (Hawksworth and KalinArroyo, 1995). Timberlake et al. (1991) noted that rarity of a vegetation type, high plant species diversity, wide variety of habitats in a limited area and relatively undisturbed condition of a vegetation type were some of the criteria used for selection of areas for conservation. It is also important to consider the vulnerability of sites to ecological perturbations, 
anthropogenic and natural threats as well as the functional significance of each site and the ecological processes involved. For instance, the functional importance of the wetland areas in general, as discussed by Whitlow (1985), Matiza (1992) and Breen et al. (1997) may far outweigh the biodiversity values. Whilst such considerations are desirable, it was beyond our ability to evaluate (and perhaps, quantify) ecological processes.

The major threats to biodiversity conservation in both Muredzi and Nhanchururu relate mainly to agricultural activities. We foresee an extensification of cropping and expansion of households in Muredzi while intensification of agricultural production is predicted in Nhanchururu in the long-term. Signs of the expansion of agricultural fields are already evident in Muredzi, and this may significantly reduce the spatial extents of the Combretum adenogonium-Sclerocarya birrea, and Acacia polyacantha-Piliostigma thonningii mixed woodlands, in particular. Though quite variable in species richness and dominance, the Combretum adenogonium-Sclerocarya birrea woodland contains sites, such as termitaria, with high species diversity, and are of high conservation importance. The dry forests in Muredzi, due to the relatively poor agricultural potential of the sandy soils on which they occur, may not be at an immediate risk of clearance for fields but extraction of targeted species may negatively impact on the biodiversity within them. In addition to their high species diversity, their limited spatial extent and the occurrence of important species make them somewhat ecologically special.

In addition to agricultural intensification in Nhanchururu, the other major threats to vegetation are commercial timber exploitation, wide-spread fires and uncontrolled small-scale timber extraction. No evidence has, however, been gathered on how much change has occurred in species diversity and structure of the woodlands resulting from the disturbance factors discussed above. Compared to miombo woodlands in Muredzi, in Nhanchururu, miombo woodlands are richer and more diverse in species. It is possible, therefore, that previous logging and fire regimes in Nhanchururu have been of intermediate nature (compared to Muredzi) such that diversity was higher than expected. We, however, also note that apart from differences in disturbance regimes other factors such as rainfall patterns, geological and altitudinal differences may play (interactively or individually) important roles in the dynamics of the woodlands. 


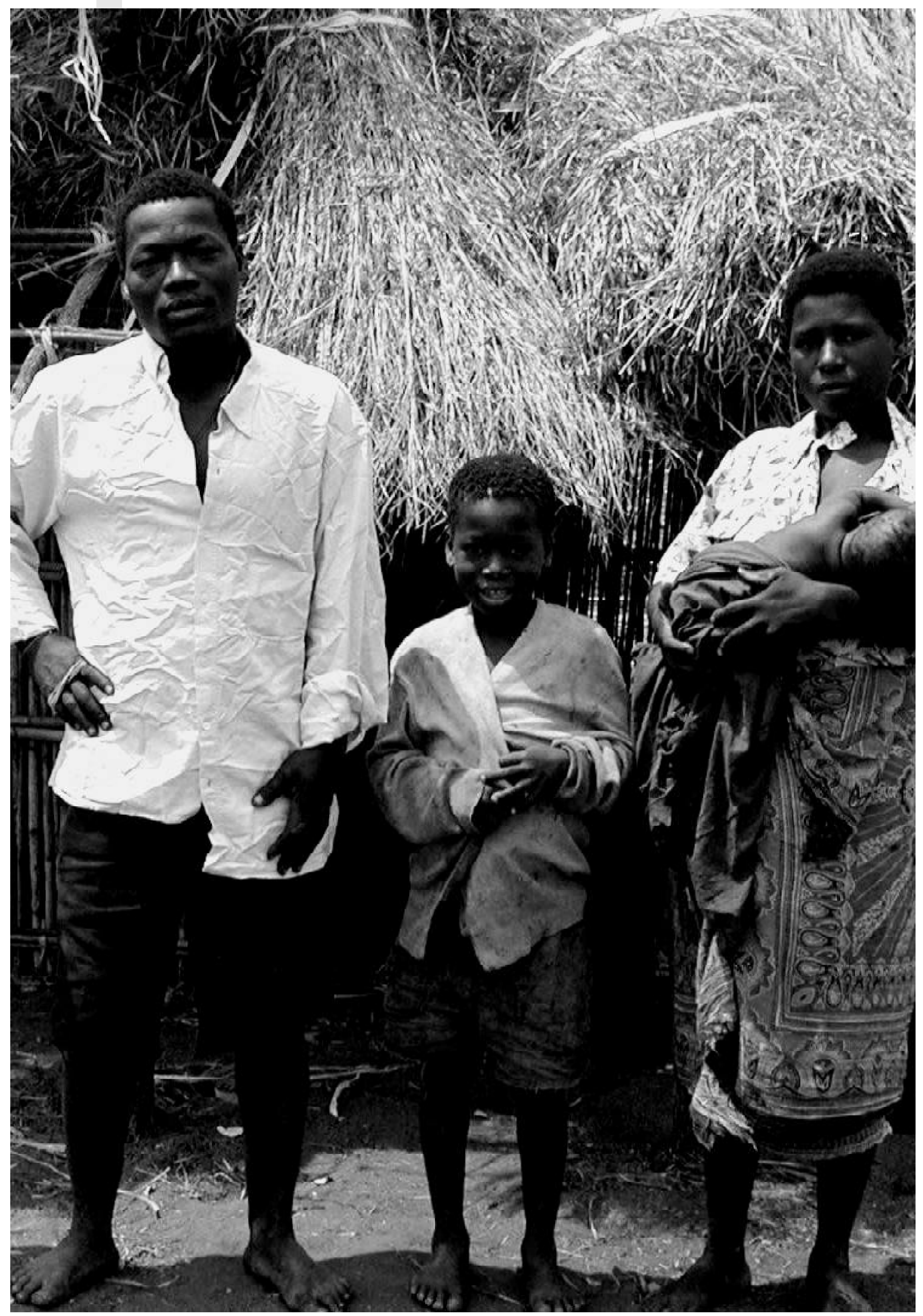




\section{Overlay of community valuations and conservation valuations}

\section{A. Introduction}

An important output of this project's activities was the production of maps in which the estimated local community valuation of landscape elements was overlain with the estimated conservation value of each landscape unit. This would enable both GNP management and the local communities to identify locations that were of high value to both groups and hence required special management attention and possibly the development of co-management arrangements. The greatest difficulty in achieving this objective was the production of maps by the local community. In Mauredzi this was feasible because the structure of the vegetation communities and hence the landscapes was such that they could be easily mapped in a geo-referenced format from the sketch maps of the CRUAT. Basically there was very good correspondence between the vegetation maps developed from the Landsat 7 imagery and the Mauredzi CRUAT sketch maps such that the TREP team's map (from Landsat 7 imagery) could be used as the CRUAT map. This was not the case in Nhanchururu. The vegetation types described by the CRUAT in Nhanchururu as well as by the TREP team formed a mosaic of types that the CRUAT claimed they could not map and the TREP team also could not differentiate adequately (even using Landsat 7 imagery) except at a very coarse resolution. The maps for Nhanchururu are therefore, less than satisfactory.

Despite this difficulty we present both sets of maps and use them to identify locations that are likely to be in high demand for both sites. However, although we believe the resulting product for Mauredzi is of high quality and hence very useful we would rather use the models of section 3 for Nhanchururu than these maps.

\section{B. Methods}

As far as was possible the BBN models developed for each site were used to guide the generation of final landscape valuation maps for each site. Although the calculations for generating the final maps were simplifications of the calculations used in the models the general approach and principles were the same; the final valuation map was developed as a ratio of the benefits to costs. Benefits were calculated as the weighted sum of scores of the benefits that the CRUAT identified as being derived from each vegetation type. The weightings were the CRUAT relative importance weights (RIW) as used in the BBN. For each site the developed vegetation maps were converted into raster maps with square cells. These dimensions were selected because they were the same size as the sample plots for field confrontation. 
The cost maps were a little more difficult to generate. Firstly the distance from household cost raster was generated as a buffer raster of distance from the households noted in each site. The distance classes that were used were the same as those used in the field confrontation estimates. As in the BBN distances were estimated along paths and assigned cost values based on the proportional costs allocated to this distance function by the CRUAT in each site. Then distance from paths was estimated using a buffer from the mapped paths (these were mapped using handheld GPS' sand the results converted into vectors). Again the distance classes developed in the field were used to assign costs to these buffers. The total distance cost was then estimated as the sum of the costs of the on path and off path distance maps.

In general the regulations governing access to resources played only a very small part in determining the costs of resource use. The exception was the strong government regulation set that was enforced to varying extents in GNP. It was difficult to estimate the actual values of these costs. For Mauredzi this figure was selected as an arbitrarily high number (100) because there seemed to be a complete prohibition on the use of resources across the Urema River thus across this boundary the Regulation cost was made to be very high. The same was done along the GNP boundary for Nhanchururu.

It was not feasible to derive cost estimates for the danger component of the model that was notable in Nhanchururu. This aspect of the spatial model was therefore ignored.

The final landscape valuation scores for each cell in the landscape maps was calculated as the ratio of the benefit map to the cost map. From the resulting values the higher the value the greater the estimated value of the landscape unit.

The development of maps for the vegetation types has been described previously (Section III.A). This will not be repeated. For each vegetation type that was mapped a conservation score was generated (Table 62 and 65) and these scores were assigned to each of the polygons of that vegetation type in the map. The conservation value maps were therefore, maps of the different vegetation types with conservation scores assigned to each vegetation type.

\section{Results}

\section{Mauredzi}

The predicted cost surface for Mauredzi could be visualised as a bowl with the households of

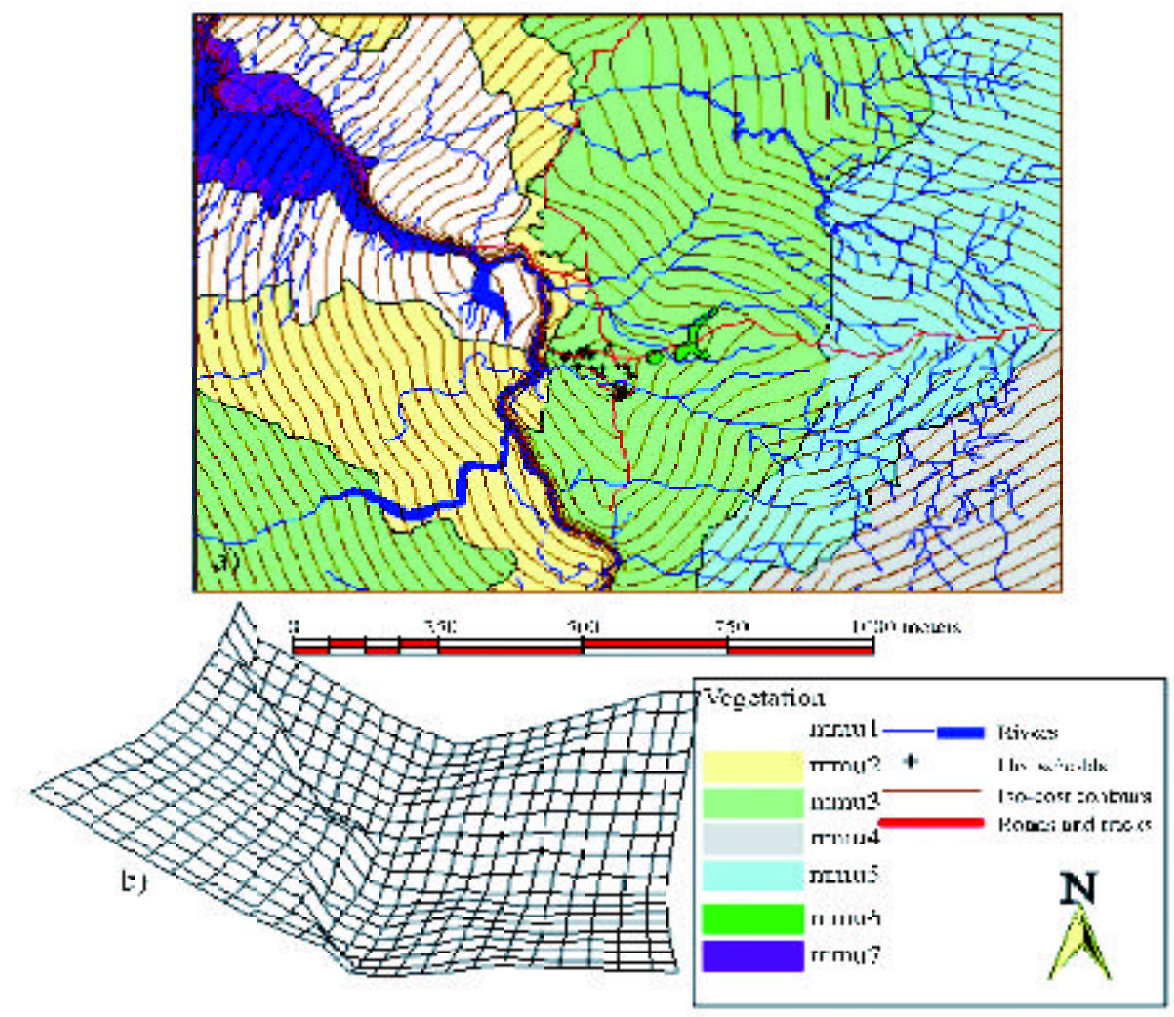

Figure 28a. Two-dimensional map of the Mauredzi site showing the major vegetation units, main rivers and Lake Urema and the positions of mapped households. The contour lines are iso-cost lines that reflect the predicted costs, to local villages of procuring resources. The dense array of countours to the west of the village lie along the Urema River and hence mark the boundary where Park regulations of no entry and no resource use are strictly enforced.

Figure 28b. A three dimensional wire-frame surface of the cost pattern shown in Figure 28a. 


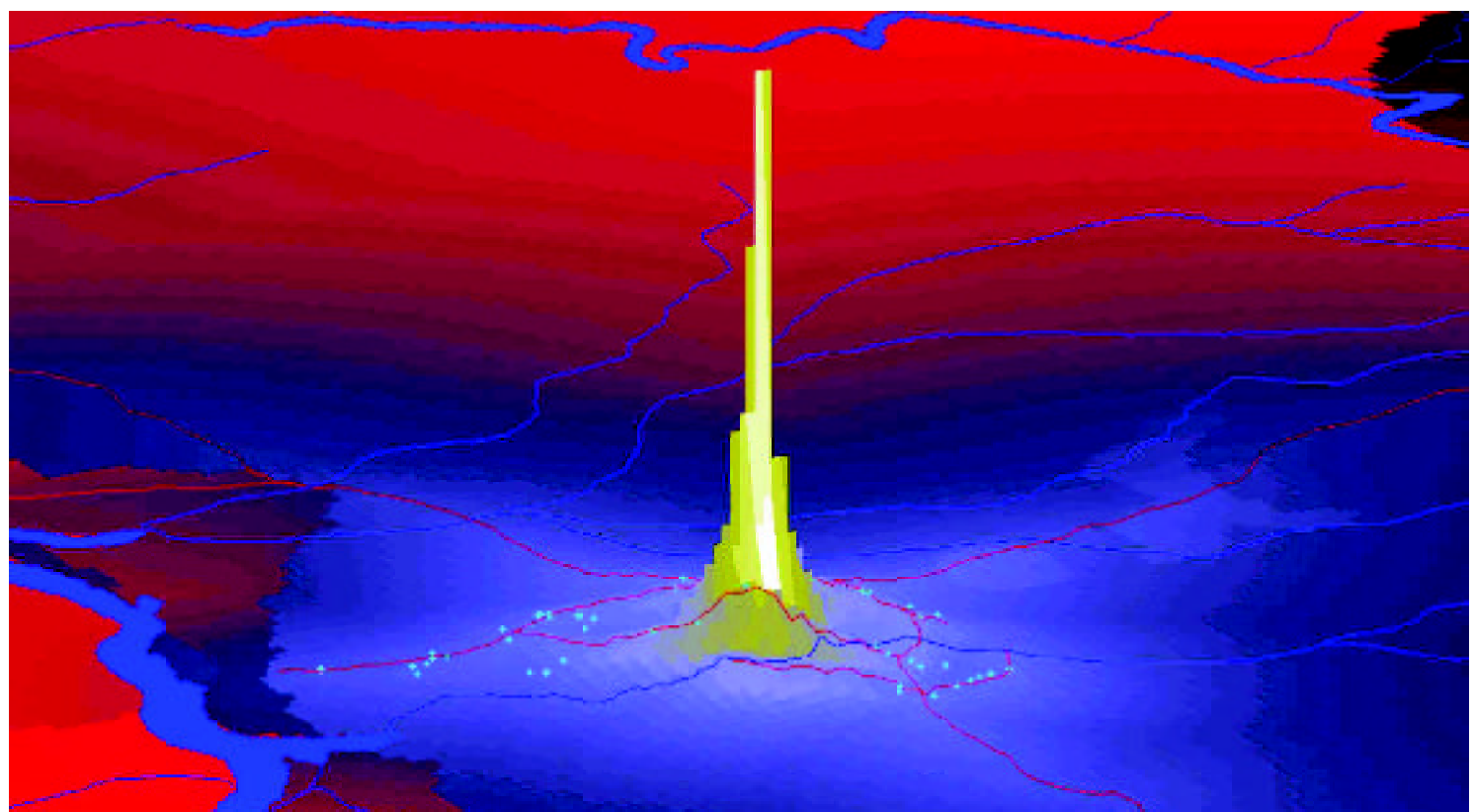

Figure 29. Three-dimensional view of the Mauredzi village area taken from the south-west. The z-axis is magnified 10 times to highlight the spatial variation in predicted landscape value. The landscape colouring represents the predicted B/C (i.e. value) of the landscape to local community members. Highest value units in the landscape those in white and gold (the peak in the centre of the image). Thereafter areas in light to darker blue and then red to dark red reflect decreasing landscape value. The major routes and tracks are marked in thin red lines with the households of the village marked in light blue. The blue swath of the Urema River is evident in the bottom left corner and the Mauredzi River crosses from right (east) to left (west) just to the foreground side of the village area. The two light blue patches to the east of the village area (along the main road to Muanza) are patches of dry forest that are of very high value to the community.

the village in the centre and then the sides of increasing cost rising in all directions (Figure $28 \mathrm{a}$ and $28 \mathrm{~b})$. Along the major routes leading away from the village the sides of the bowl were incised reflecting the lower costs of procuring resources along these routes. The Urema River and eastern edge of Lake Urema mark a boundary, to the west of which, villagers were not allowed to collect or use resources.

When the calculation is made of the benefit/ cost ratio a very sharp peak of high value lies in the centre of the village where the model predicts low costs and also relatively high benefits due to the relatively high value of the Combretum adenagonium vegetation type in which the village is situated (Figure 29). In the rather surreal colouring of the 3-dimensional view of the central village area of Mauredzi shown in Figure 29 the gold and white colours represent the areas of highest value (greatest $\mathrm{BC}$ ratio). The next highest value class are those areas shown in light blue with the lowest value areas (generally with a B/ C ratio much less than 1 ) are shown in very dark red (as in the top right corner of the image). The view is taken from the southwest, looking towards the north-east.

The spatial model predictions of landscape unit values were reasonably well correlated with the actual values developed by the CRUAT for Mauredzi (Pearson correlation coefficient $=0.54$; Figure 30).

When the model predicted value of the landscape was combined with the conservation

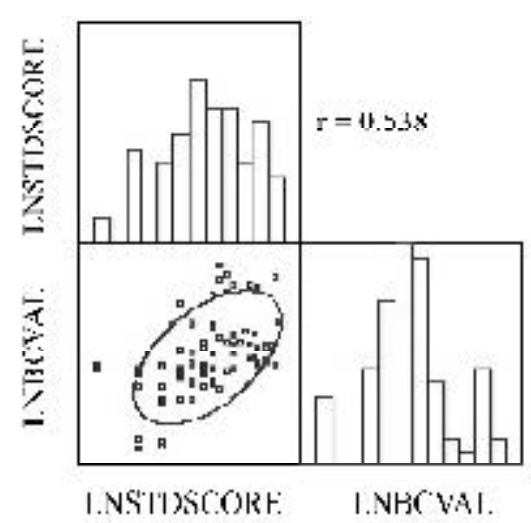

Figure 30. Correlation between the natural log of the model predicted landscape unit value (LNBCVAL) and the local community value (LNSTDSCORE) for Mauredzi.

value map of the Mauredzi site (the two were simply multiplied together) the resulting map (Figure 31) shows the areas that both the community and conservationists value most highly. For both groups the small patches of dryforest (Nsitu to the Mauredzi community, Map unit MMU6, Figure 23) were easily the most valuable. From the community perspective these patches were close to the village area and also along the major road to Muanza. The patches also provided a great number of highly valued goods (Tables 2, 8 and 9). These forest areas are therefore, likely to be under greatest threat from use by the local community and would require special attention from GNP management 


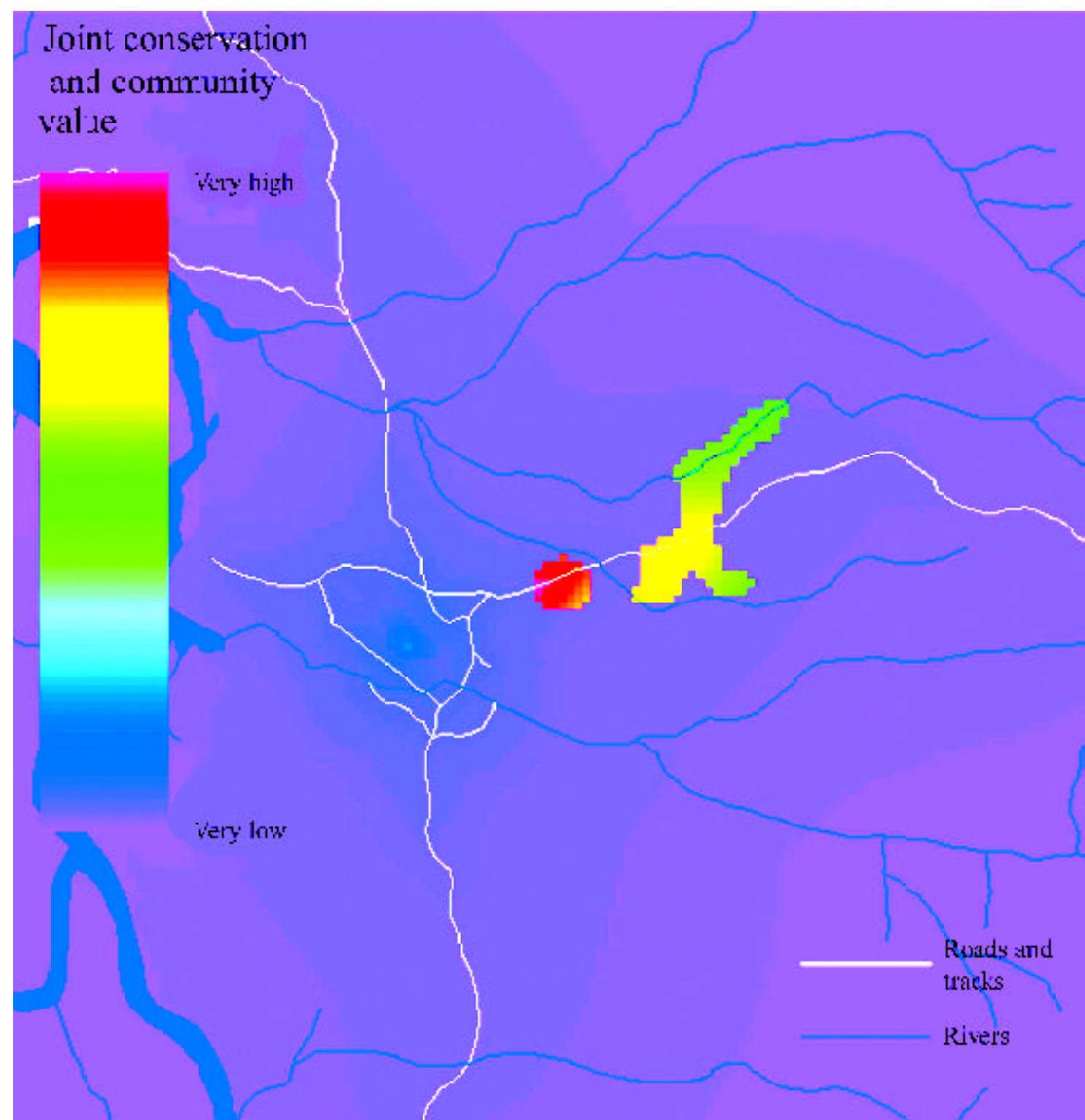

Figure 31. Mauredzi site with shading showing the range in values of the joint conservation and community use data. Major tracks and roads and rivers shown for reference purposes. The two highest value patches to the east of the village area were two small dry-forest patches (Nsitu or MMU6).

to develop co-management practices to ensure that they are sustained as both a source of goods for the community as well as a source of conservation importance for GNP.

\section{Nhanchururu}

With households in Nhanchururu more widely dispersed than in Mauredzi the cost surface was similarly more complex (Figure 32). However the cost surface is still predicted to be bowl-shaped with the households in the centre of the bowl and lower points in the sides of the bowl occurring along tracks and roads.

The benefit/cost ratio map developed for Nhanchururu shows again a higher degree of complexity than that developed for Muaredzi. The positions of households mark the centres of peaks of high values for the benefit/ cost ratio-indicating predicted high values from the model (Figure 33). The benefit side of the Nhanchururu model was less well developed than that for Muaredzi with large areas of the vegetation in Nhanchururu being relatively poorly differentiated in the mapping exercise. Thus the benefits assigned to a give land unit were homogenous over large areas. The cost relationships have therefore contributed most to the values given to different land units. Given the results of the model confrontation with local values presented in section 3 of this report and our recognition that the costs component of the model did not contribute as we had predicted the surfaces that result may be distorted by the cost surfaces generated. 


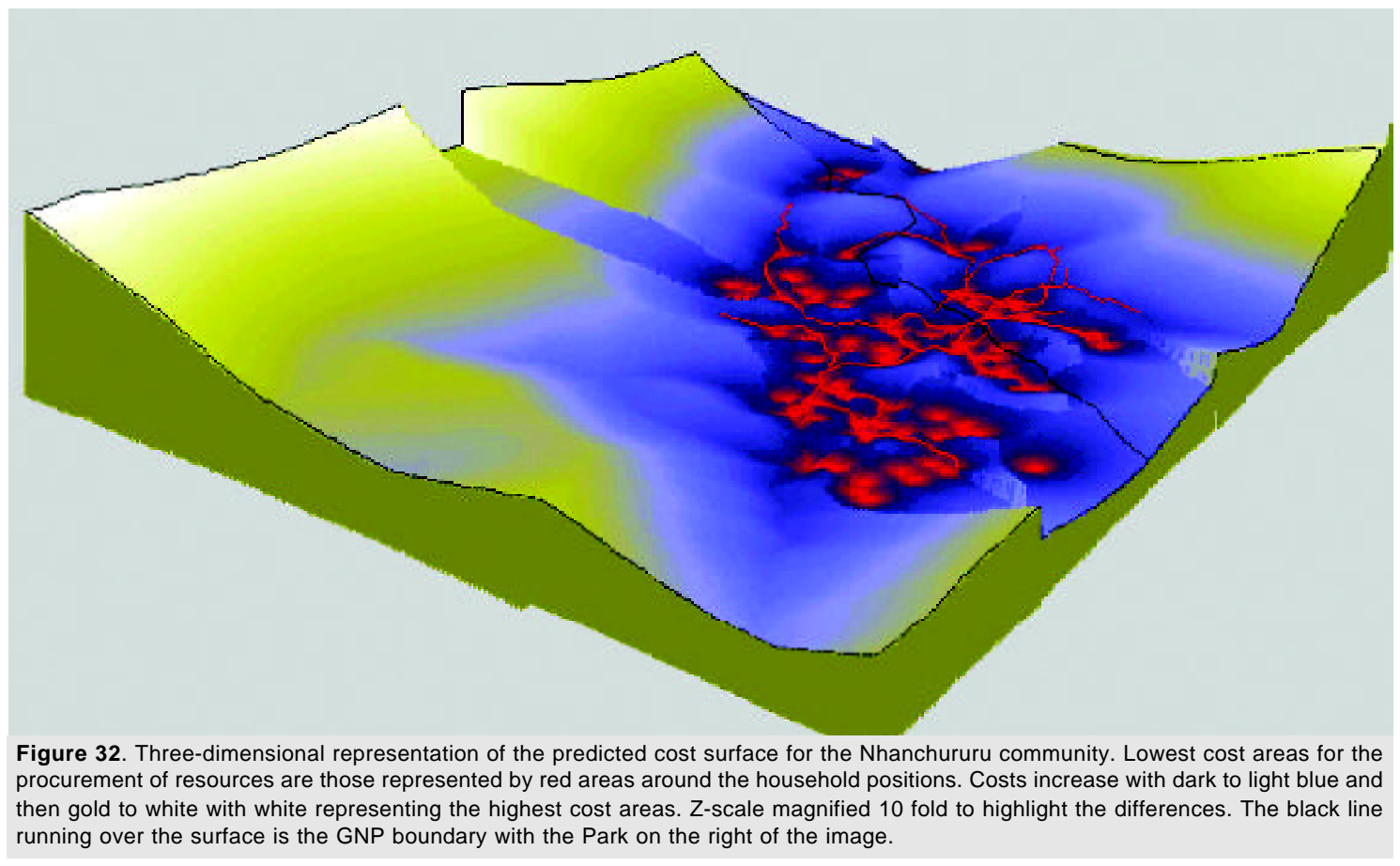

The spatial model and local valuations for Nhanchururu were not as well correlated as they were for Mauredzi. Given the weakness of the scoring data for Nhanchururu this is not unexpected. The correlation coefficient of 0.3 indicates that there was considerable noise in the relationship between model predicted values and those allocated to the same locations by CRUAT members (Figure 34). We recognise that much of this variance is attributable to the differences in scoring among enumerators.

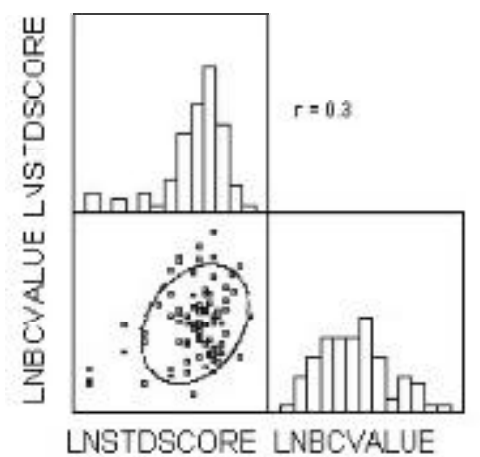

Figure 34. Correlation between the natural logarithm of model predicted landscape unit value (LNBCVALUE) and the natural logarithm of the standardised scores allocated to each location by Nhanchururu CRUAT.

The overlain maps of local values and conservation values show a more broadly distributed set of areas that might be of concern to the Park and to the local community (Figure 35). This is clearly related to the more distributed pattern of household settlement in Nhanchururu when compared to Muaredzi. It is clear from this analysis that the Nhanchururu community has extended itself to well within the boundary of GNP. There are areas within the park that are of higher conservation importance and it is likely to be these areas that would be of greatest concern to the management of GNP.

\section{Discussion and conclusions}

The overlay of community values with conservation values identifies sites of both Muaredzi and Nhanchururu that are most likely to be the source of conflict between GNP management and the two communities. Both communities valued sites for their use value, thus it is the stream of direct benefits that household use from each site that is of value to them. This is in direct contrast to the GNP objectives of conservation, which is more of an option value.

We feel more comfortable with the results of the analysis from Muaredzi. The units identified as being of greatest concern to GNP management and the Muaredzi community were reliably identified from analyses that were robust and yielded results in which we had a high degree of belief.

We feel less comfortable with the results from Nhanchururu. In part this is attributable to the poorer community valuation results from Nhanchururu and in part it is attributable to the difficulty of developing a reasonable map of the vegetation types for Nhanchururu that reflected the units that people valued. Despite this the results are likely to be useful in identifying where there are likely to be problems as well as highlighting the need for reasonably fine resolution 


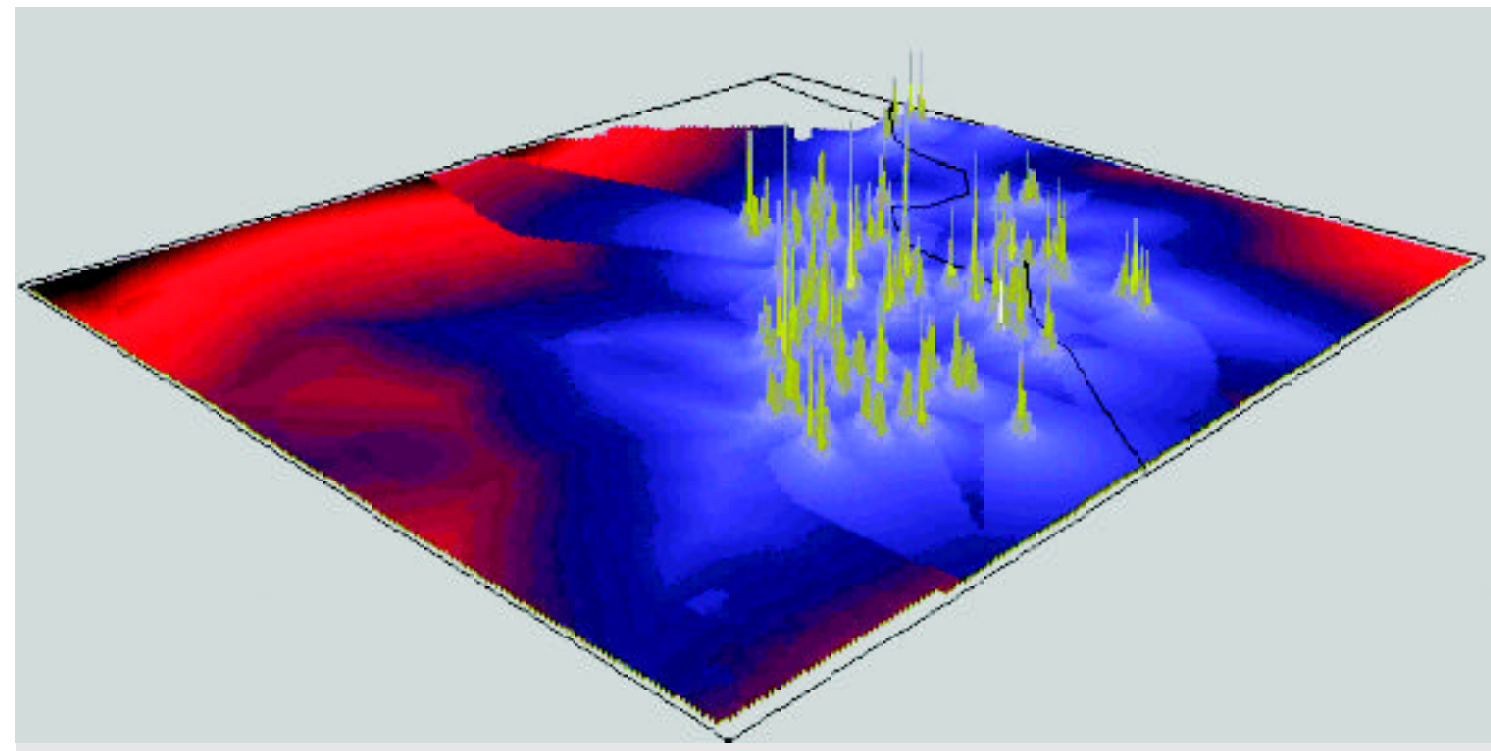

Figure 33. Benefit/cost ratio map for Nhanchururu. Highest BC values are shown in white and gold with decreasing values shown by light to dark blue and then light to dark red. Black line running over the surface is the GNP boundary.

maps of vegetation types to enable the development of benefit stream data sets.

In both cases we believe the cost estimates from the model have had a greater impact on the spatial representations than the BBN model analysis suggested was reasonable. This effect was exacerbated by the lack of resolution in the benefit side of the maps-we had no data on the density of resources in each site (except from the field confrontation data). Thus the cost side of the spatial models was resolved to 60 m cells but the benefit side of the spatial models was only resolved to the level of the vegetation map unit. We suspect that it would be possible to use NDVI measured to provide the much-needed spatial differentiation of resource availability. Unfortunately this was not possible in the scope of this project.

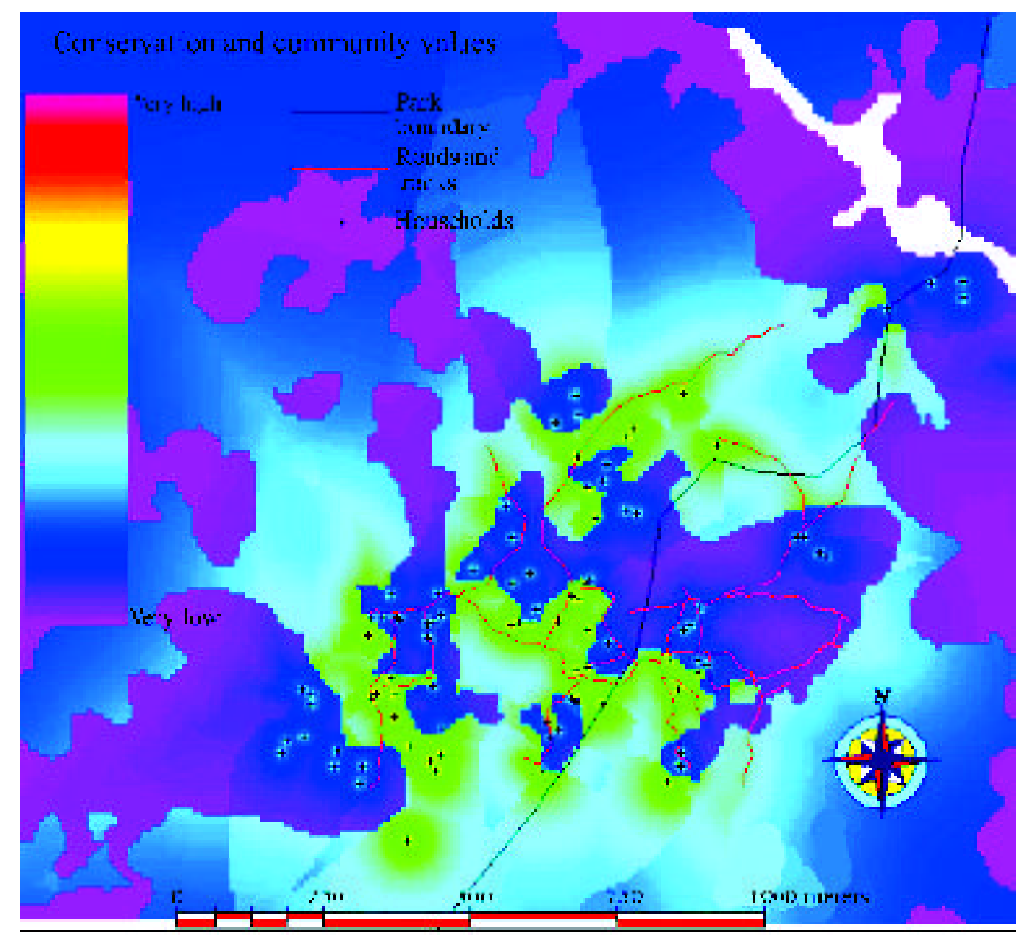

Figure 35. Nhanchururu site with shading showing the range in values of the joint conservation and community use data. Major tracks and roads shown for reference purposes. Areas with the highest joint value (shown in light green to yellow) are generally those in close proximity to the households within the miombo vegetation type. The larger patches of mauve to dark blue are generally cultivated areas and hence have low conservation value. 


\section{Implications for land use planning}

The purpose of this section is to draw attention to the implications of our research findings as regards land use planning for the GNP region. The project included limited provision for feeding results into the ongoing planning process, in the form of reporting to relevant Mozambican authorities, as well as a small workshop. Rather more effective has been the direct involvement of one project member (Dr. T. Lynam) in the GNP planning process, through other projects. This has provided opportunity to interpret and make results directly available to planners.

The remainder of this section examines individually the four principal elements of the research work (community evaluations, biodiversity evaluations, modelling and overlay of community and biodiversity results), and then attempts to draw these together into a concluding synthesis, as regards issues raised of relevance to land use planning.

\section{A. Community Evaluations}

Muaredzi. The key perspective to emerge from the Muaredzi community evaluations was that the community members want to be able to stay where they are, and not be forced to move. Attempts have been made to relocate this community in the past, and members are nervous that the GNP authorities may attempt to do so again in the future. Lack of security of tenure obviously weighs heavily on these people and conversely the GNP feels apprehensive for these people to remain in the park.

The area is relatively rich in terms of the principal resources sought by the community (water, land for housing and cultivation, fish, construction materials, firewood). This provides a strong incentive for the community to seek to remain where they are. The community appears to show a high degree of willingness to comply with existing restrictions on resource use, imposed by the GNP, as long as they can remain where they are. Greater flexibility by the GNP authorities on certain issues would, however, be appreciated.

It is interesting to note that Costa \& Vogt (1998) report that a considerable proportion of the younger community members does not see a future for themselves in Muaredzi. This was not explored under the current study.

Muaredzi has previously been described as being a fishing community. Our results show that although fishing is an important livelihood component, agricultural production is consistently given a higher rating. The community appears to be in a state of transition from a fishing village to a more conventional agro-based community. One possible cause for this may be the restrictions imposed by GNP on fishing activities (e.g. types of canoes, where fishing can take place, fish to be taken out the 
park for marketing). Another possibility is the apparent lack of any restrictions concerning cultivation, whereas in the past the GNP may have maintained tighter control over the opening of new fields. At the time of the study numerous new fields were observed being opened up.

Continuation of this trend will result in the clearing of ever-greater areas around the village, presumably within the surrounding planicie area, and consequent destruction of the natural resources of these areas.

Wildlife populations during the prolonged civil war were reduced to very low levels, but now appear to be building up again. Assuming that wildlife populations do gradually increase, there is likely to be growing conflict between wildlife and the Muaredzi community, particularly in the form of elephant damage to crops.

A principal constraint, in terms of meeting the basic needs of the community, is the lack of facilities and infrastructure (shops, school, clinic). Whilst this is partly a result of restrictions imposed by the GNP (particularly restrictions on traders coming in from the outside), it is equally difficult to see how the desired infrastructural developments (e.g. school and clinic) could be justified for such a small and isolated community.

Overall, the outlook for the Muaredzi community is one of increasing conflict, characterised by continued tenurial uncertainty, continued absence of key infrastructure, and increasing conflict with wildlife. GNP management, on the other hand, are likely to become increasingly disaffected with the further expansion of agricultural activities, and attendant destruction of resources, within the heart of their conservation area.

Nhanchururu. The Nhanchururu community is far more secure and confident about their tenure, despite an apparent discrepancy between the official GNP boundary and their perception of the boundary. The villagers have a definite concept of where the boundary is on the ground, and appear willing to respect GNP's authority to the east of this line. They also appear confident that the GNP will not interfere with their activities to the west of this line, and particularly that there will not be any suggestion or attempt for any community members to move.

Nhanchururu village is also relatively well endowed with natural resources. The community is relatively sparsely settled over a considerable area. The future is likely to see further opening of new fields within the existing village area, thus leading to a situation of more intensive cultivation, as already exists in neighbouring villages closer to Villa Gorongosa.

Compared to Muaredzi, the Nhanchururu area is situated at higher altitude and thus experiences higher and, importantly, more reliable, rainfall such that the community appears more secure in terms of crop and food production. A key constraint to future development is the poor access and lack of transport to Villa Gorongosa. Thus, while the village appears capable of producing considerable agricultural surpluses, there is little opportunity for transporting crops to markets outside of the village area. Assuming that this situation was to be addressed, this would act as a significant incentive to increase crop production within this community.

The community does already use some resources from within the park area. As the village population increases, and the cropping situation intensifies, this demand can be expected to increase, in terms of both the quantities of resources harvested and the types of resources sought.

A key threat to future wellbeing is land degradation. With relatively steep slopes and relatively high rainfall, the risk of erosion is high, and signs of erosion are already evident. Current cultivation occurs predominantly on the more level ground found on the tops of slopes and on the lower lying baixa areas. Future expansion will necessitate expanding onto steeper, less favourable localities, which will carry a higher risk of erosion. Increased erosion will also impact on the hydrological regime downstream within the park.

Coupled with agricultural growth and wealth creation, there is likely to be a build up of livestock, particularly the introduction of cattle, which at present are virtually absent. The introduction of livestock might lead to conflicts with the park such as losses of animals to predators, spread of diseases, and competition for grazing resources. As compared to Muaredzi, wildlife populations within the vicinity of Nhanchururu are relatively low, and are not likely to pose any significant conflicts with the Nhanchururu community.

\section{B. Biodiversity Evaluations}

Biodiversity evaluations were limited to vegetation analyses, and to a large extent to woody species. One of the interesting results was the recording of more species from Nhanchururu (246 species) than Muaredzi (231 species), these coming from similar numbers of plots (50 for Nhanchururu versus 47 for Muaredzi). This is surprising given the limited differentiation of types within Nhanchururu (7 vegetation types) as compared to the 13 types identified for Muaredzi. One explanation for this, is that the range of structural types was 
similar for both sites, varying from grasslands (relatively extensive floodplain and palm savannas for Muaredzi, versus much narrower strips along watercourses in Nhanchururu); through various woodlands (occupying the bulk of both sites), to thickets and forests (very limited in extent for both sites). Other causative factors could be differences in rainfall and fire regimes. Both sites contained comparable numbers of species of interest.

Evaluation of the conservation significance of the various types was hampered by the lack of a wider perspective, for example of the GNP as a whole. This was recognised as a constraint from the outset, but there were insufficient resources to address it. However, the results do suggest that the key vegetation types for both sites are the thicket and forest communities. These stand out in terms of the relatively high species diversity, high occurrence of species of interest and, particularly, their highly restricted occurrence. This result would probably be upheld within context of the park as a whole.

The other limitation acknowledged with respect to the conservation valuations is that, apart from being based only on a single group of organisms (woody plants), it omits consideration of other perspectives such as the delivery of ecological services. For example, the floodplain communities are of little biodiversity interest in terms of woody plants, but in terms of other taxa such as herbivores, or birds, and from a functional perspective, will be of much greater importance. This restriction is recognised, but again there were insufficient resources to address it under this study.

\section{Modelling}

The modelling component proved extremely useful in conceptualising the study, and structuring and informing the data gathering activities. It has also provided a useful tool for assessing the validity of community landscape values.

Similar results were obtained for both Muaredzi and Nhanchururu. A key finding was that landscape values are primarily a function of potential benefits, with the cost factors being of relatively little importance. Confrontation of the respective models with field data, suggest a reasonable degree of belief in the models, and that the adopted approach is reasonably robust.

It is important to realise that the results obtained relate to this particular point in time, and can be expected to vary with time. Both sites are relatively resource rich. As resources become less readily abundant, it is possible that cost factors, such as the distance functions, may become more significant.

\section{Overlay of Community and Biodiversity Evaluations}

The process of overlaying community and biodiversity evaluations produced more mixed results. This worked reasonably well for Muaredzi, where there was good correspondence between vegetation map units and the landscape units identified and mapped by the CRUAT. For Nhanchururu, the overlay results are presented with a lower degree of belief. The baixa, planicie and planalto types identified by the CRUAT occur as a matrix of small interspersed portions, which would be extremely difficult to map at this scale. Furthermore, the satellite imagery was too poor to enable the effective identification and separation of woodland types (although this in itself is an interesting result).

The biodiversity conservation valuations did not include any consideration of threat. The overlays make this possible, at least for Muaredzi. Here the forest types (MMU6) were allocated the highest conservation value, and were also ranked by the CRUAT as being of high value during both the initial scoring exercises and subsequent field evaluations. This is where the greatest conflict can be anticipated between competing uses for conservation purposes and for multiple use by the Muaredzi community, and thus should be a logical focus for any local conservation efforts.

Planalto vegetation, comprising Combretum zeyheri-Acacia complexes (MMU5) and miombo woodlands (MMU4), were identified as being of next highest conservation value. The CRUAT, however, consistently rated planalto as being of least value, such that little conflict can be anticipated here.

The Setaria-Hyphaene open community (MMU2), which corresponds to thando, was rated as being of intermediary value in terms of both the biodiversity conservation and CRUAT ratings.

The final two map units, planicie (MMU3) and floodplain or gombe/madimba communities (MMU1) were considered to be of lowest conservation value, but were both identified by the CRUAT as being of relatively high value. Thus, although significant impacts to natural resources can be anticipated for these areas, it appears that these should not be of major significance as regards conservation concerns.

\section{E. Synthesis}

Each aspect of the study has yielded useful insights as regards potential future scenarios for Muaredzi and Nhanchururu. Key aspects for land use planning are summarised below. Hopefully these can inform and steer the 
development paths for these sites to the mutual advantage of both the communities and the park.

Muaredzi. Settlement of the issue of tenure and whether the community are to stay in place or move to elsewhere. The resolution of this issue is critical to both the community being able to develop their lives, and for the park management. Non-resolution will be destructive to both parties. Assuming that the community remains in place, the park will need to engage more actively with the community to develop a more functional relationship, possibly resulting in some form of co-management.

Expansion of agricultural activities. Assuming that the community remains in place, the park will need to devise a strategy for managing future expansion of cropping areas.

Provision of infrastructure. Assuming that the community remains in place, the park will need to consider how the community's requirements for infrastructure and facilities can or can not be met.

Fishing activities. Fishing is an important livelihood activity, and which seems possible to regulate and continue on a sustainable basis. Guaranteeing continued access to fishing rights could provide a valuable incentive were the community to relocate to elsewhere.

Protection of forest communities. The small forest patches harbour valuable resources in terms of both biodiversity conservation and also of use to the community. It is here that the greatest conflict can be expected in terms of use by the community and conservation values.

Human wildlife conflicts. Continued build up of wildlife populations, coupled with expansion of cultivation, can be anticipated to result in increasing levels of conflict between the community and park.

Nhanchururu. Land use planning for this area should take place within the context of the community remaining in place where they are, although there may be need to clarify their position relative to the park boundary. The obvious implication is that the park needs to engage with this community and ensure the development of a sound functional relationship.

Intensification of cultivation. It is likely that cultivation will continue to expand, such that there is likely to be gradual development of a much harder edge between the village area and adjacent park area.

Improved access to Vila Gorongosa. Enhancing access to markets is seen as being crucial to the future development and prosperity for this village.

Introduction of cattle. Assuming that the community does prosper and become wealthier, it can be anticipated that livestock populations will increase, and that cattle are likely to be introduced. The park needs to consider the various potential implications of this.

Use of resources within the park. There is already some use of resources by community members within the park. Assuming a gradual hardening of the boundary between the village and park areas, the demand on resources within the park is likely to grow.

Management of Gorongosa mountain. The park has long been aware of the importance of Gorongosa Mountain and the adjacent foothills to the hydrological cycle within the park. This was one of the motivations for Tinley' $s$ " mountain to mangrove" vision. Assuming that the situation within Nhanchururu is typical of neighbouring villages, it seems that the opportunity for including Gorongosa Mountain and the intervening area within the park is no longer attainable. However, the substance of the vision still remains valid, but will need to be pursued under the guise of community rather than park management. This is a key area for the development of comanagement arrangements between GNP and the communities living around the mountain. 


\section{Acknowledgements}

The TREP team gratefully acknowledge the key contributions made to the project by a wide variety of people, without whose inputs it would not have been possible to carry out the work. The CRUAT members played an essential role as regards the collection of field data within the two communities. For Muaredzi, we gratefully acknowledge the willing input of the following 26 informants:

António Armindo, Fieda Betchane, J oão Botão, Inês Chuva, Rosário Diogo, Chanaze Fazenda, Mateus Fazenda, Rosa Fazenda, Nina Fernando, Florindo J ambo, Maria J ambo, Pascua J ambo, Anita J oão, Augusto J oão, Costamina J oão, Diogo J oão, Pedro J oão, Tima J oão, Zelinha Luis, Virgínia Macamero, J osé Mairosse, Celina Manuel, Maria Manuel, Inês Melo, Salita Pita and Fazenda Sixpence,

and for Nhanchururu village the following 20 members:

Cassenguere Almeida, J anita Almeida, Ricardo Almeida, Lúcia António, Anita Baptista, Eusébio Fernando, Henriques Fernando, Pureja Fombe, Victória Francisco, José Carlos Fredi, Sarga J oalinho, Laurita J oão, Melita J osé, Pureja Matequesse, J osé Moises, Joalinho Murungo, Rodito Pureja, Fairita Saimone, Manuel Verniz Sandramo, and Melisa Zeca.

Accessing the community data required continual translations from Sena to Portugese and English and facilitation. We thank Mr. Pedro Dique Camissa, Mr. Euzebio Simao Sizinho, Mr. Reginaldo Alberto Casse and Ms. Fatima de J esus Pereira, and Mr. Atanasio J ujuman for capably providing these inputs.

The project would not have been possible without the logistical, technical and moral support of Roberto Zolho, Administrator of Gorongosa National Park. We are extremely grateful to him. Brit Reichelt has consistently provided us with the most remarkable administrative support in Mozambique. We are equally grateful for the very able field assistance provided by numerous field staff of the park, particularly those of Muaredzi and Nhanchururu Posts, who facilitated our stays in the field, and played an important role in passing important communications to and from the park headquarters and in passing messages to community members.

We thank the District Administrators of Muanza and Gorongosa Districts for giving their permission to implement the project within their respective districts.

In Zimbabwe, we thank the administrative staff of TREP for their ongoing support to the project; Ms. Astrid Huelin for assistance with procuring and processing the satellite imagery, and Mr. Isau Bwerinofa for extensive assistance with digital mapping.

The TREP team gratefully acknowledges the financial support of CIFOR. We are most grateful to Wil de J ong for his continued encouragement and support, and to Doug Sheil and Miriam Van Heist for sharing their experiences from Indonesia and for contributing towards the initial shaping of the study. 


\section{References}

Aronson, J.A. 1989. Haloph, a data base of salt tolerant plants of the world. Office of Arid Land Studies, University of Arizona, Tucson. www.ussl.ars.usda.gov/ pls/ caliche/ halophyte

Bandeira, S. O., Hatton, J.C., Munisse, P. and Izidine, S. 1994. The ecology and conservation status of plant resources in Mozambique. Strelitzia 1: 105-115.

Beentje, H.J . 1996. Centres of plant diversity in Africa. In: van der Maesern, L.J .G., van der Burgt, X.M. and van Medenbach de Rooy, J.M. The biodiversity of African plants. Proceedings of the XIVth AETFAT Congress; 22-27 August 1994 Wageningen. Kluwer Academic Publishers, Dordrecht, London.

Breen, C. M., Quinn, N.W. and Mander, J.J . (eds) 1997. Wetlands conservation and management in southern Africa: Challenges and opportunities. IUCN-ROSA, Harare.

Burgman, M.A. and Lindenmayer, D.B. 1998. Conservation biology for the Australian environment. Surrey Beatty and Sons, Sydney.

Conor, E. F. and McCoy, E.D. 1979. The statistics and biology of the species-area relationship. American Naturalist 113, 791-833.

Costa, P and Vogt, F. 1998. Gorongosa National Park and Muaredzi Community Interrelationship. Unpublished report, Brunel University, England.

Cumming, D.H.M., Mackie, C., Magane, S. and Taylor, R.D. 1994. Aerial census of large herbivores in the Gorongosa National Park and Marromeu area of the Zambezi Delta in
Mozambique: J une 1994. Consultants report to IUCN-ROSA and DNFFB, Maputo.

Frost, P. 1996. The ecology of miombo woodlands. In: Campbell, B. (ed.). The miombo in transition: Woodlands and welfare in Africa. pp. 11-57. Centre for International Forestry Research (CIFOR), Bogor.

Frost, P.G.H. and Robertson, F. 1987. The ecological effects of fire in savannas. In: Walker, B.H. (ed. ). Determinants of Tropical Savannas, pp. 93-141. IUBS Monograph Series No. 3. IRL Press, Oxford.

Gauch, H.G.Jr. 1982. Multivariate analysis in community ecology. Cambridge Press, Cambridge.

Hawksworth, D.L. and Kalin-Arroyo, M.T. 1995. Magnitude and distribution of biodiversity. In: Heywood, V.H. (ed.). Global Biodiversity assessment, pp 107-191. UNEP, Cambridge University Press, Cambridge.

Ludwig, J . A. and Reynolds, J.F. 1988. Statistical ecology: A primer on methods and computing. J ohn Wiley \& Sons, New York.

Lynam, T.J .P. 2001. Participatory systems analysis - an introductory guide. IES Special Report No. 22. Institute of Environmental Sciences (IES), University of Zimbabwe, Harare, Zimbabwe and Centre for International Forestry Research (CIFOR), Bogor, Indonesia.

Magurran, A. 1988. Ecological diversity and its measurement. Croom Helm, London.

Mapaure, I. 2001. The influence of elephants and fire on the structure and dynamics of miombo 
woodland in Sengwa Wildlife Research Area, Zimbabwe. Doctor of Philosophy Thesis, University of Zimbabwe, Harare.

Matiza, T. (ed.) 1992. Wetlands of Zimbabwe: Report of the Zimbabwe Wetlands Conservation Seminar. IUCN-ROSA, Harare.

McNeely, J.A., Gadgil, M., Leveque, C., Padoch, C. and Redford, K. 1995. Human influences on biodiversity. In: Heywood, V.H. (ed.). Global Biodiversity assessment, pp 711-821. UNEP, Cambridge University Press, Cambridge.

Minitab Inc. 2000. MINITAB Statistical Software. State College, PA. USA.

Mueller-Dombois, D. and Ellenberg, H. 1974. Aims and Methods of Vegetation Ecology. John Wiley $\&$ Sons, New York.

Pearson, D. L. and Cassola, F. 1992. World-wide species richness patterns of tiger beetles (Coleoptera: Cicinidelidae): indicator taxon for biodiversity and conservation studies. Conservation Biology 6: 376-391.

Pratt, D.J., Greenway, P.J. and Gwynne, M.D. 1966. A classification of East African rangeland. J ournal of Applied Ecology 3, 369-382.

Pressey, R. L., Humphries, C.R. and Margules, R.I. 1993. Beyond opportunism: key principles for systematic reserve selection. Trends in Ecology and Evolution 8: 124-128.

SABONET southern Mozambique wxpedition 2001. SABONET News (March) 7(1):6-18.

ter Braak, C.J .F. 1986. Canonical correspondence analysis: A new eigenvector technique for multivariate direct gradient analysis. Ecology 67, 1167-1179.

ter Braak, C.J.F. 1988. CANOCO - an extension of DECORANA to analyse species-environment relationships. Vegetatio 75, 159-160.

ter Braak, C.J.F. 1991. CANOCO - a Fortran program for canonical community ordination by [partial] [detrended] [canonical] correspondence analysis, principal components analysis and redundancy analysis (Version 3.12). Agricultural Mathematics Group, Technical Report, Wagenigen.

ter Braak, C.J .F. 1995. Ordination. In: J ongman, R.H.G., ter Braak, C.J.F. and van Tongeren, O.F.R. (eds). Data analysis in community and landscape ecology, pp. 91-173. Cambridge University Press, Cambridge.

Ter Braak, C.J .F. and Smilauer, P. 1997. CANOCO Reference Manual and User's Guide to Canoco for Windows: Software for Canonical Community Ordinations Version 4. Centre for Biometry Wageningen (Wageningen NL) and Microcomputer Power, Ithaca, New York.
Timberlake, J. and Mapaure, I. 1992. Vegetation and its conservation in the eastern midZambezi Valley, Zimbabwe. Transactions of the Zimbabwe Scientific Association 66: 1-14.

Timberlake, J.R., Nobanda, N., Mapaure, I. and Mhlanga L. 1991. Sites of interest for conservation in Zimbabwe's communal lands. Vegetation Survey of the Communal Lands Report No. 1. Ecology unit, National Herbarium $\&$ Botanic Garden, Harare.

Timberlake, J.R., Nobanda, N. and Mapaure, I. 1993. Vegetation Survey of the Communal Lands - North and West Zimbabwe. Kirkia 14, 171-270.

Tinley, K.L. 1977. Framework of the Gorongosa ecosystem. D.Sc. Thesis, University of Pretoria, South Africa.

Trollope, W.S.W. 1982. Ecological effects of fire in South African savannas. In: Huntley, B.J . and Walker, B.H. (eds). Ecology of tropical savannas. Ecological Studies 42, pp. 292-306. Springer-Verlag, Berlin, New York.

Trollope, W.S.W. 1984. Fire in savanna. In: Booysen, P. de V. and Tainton, N.M. (eds). Ecological effects of fire in South African ecosystems. Ecological Studies 48, pp. 149-176. Springer-Verlag, Berlin, New York.

UNEP 1996. Assessment of biological diversity and methodologies for future assessments. Convention of Biodiversity Report UNEP/ CBD/ SBSTTA/ 2/ 2.UNEP

Vane-Wright, R. I., Humphries, C.J . and Williams, P.H. (1991). What to protect?-systematics and the agony of choice. Biological Conservation 55: 235-254.

Van Tongeren, O,F.R. 1995. Cluster Analysis. In: J ongman, R.H.G., ter Braak, C.J .F. and van Tongeren, O.F.R. (eds). Data analysis in community and landscape ecology, pp. 174212. Cambridge University Press, Cambridge.

Whitlow, J.R. 1985. Dambos in Zimbabwe: a review. Zeitschrift fur Geomorphologie Supplementband 52: 115-146.

Williams, J. 2001. State of the environment Australia 2001. Biodiversity theme report. Commonwealth of Australia, Canbera.

Yeaton, R.I. 1988. Porcupines, fire and the dynamics of the tree layer of Burkea africana savanna. J ournal of Ecology 76: 1017-1029.

Zolho, R., Nyaunga, F.C., Fonseca, A.M.L. and Chicote, E.A.J . 1998. Projecto Communitario Pesqueiro de Muaredzi e Dingue Dingue. 1a Conferencia Nacional sobre Maneio Communitario dos Recursos Naturias, Maputo. 


\section{Appendices}

Appendix 1. Data sheets used for field sampling for model confrontation

CIFOR/TREP GORONGOSA RESEARCH PROJ ECT 2001/2002 CONFRONTATION OF BENEFIT-COST MODEL

\begin{tabular}{|c|c|c|c|c|c|c|}
\hline SAMPLE NUMBEI & & Field: M & & Final: & & \\
\hline LOCATION & & Muaredzi & & & & \\
\hline RECORDER & & & & & & \\
\hline DATE & & July 2002 & & & & \\
\hline GPS COORDINATT & & No: & s: & B: & & \\
\hline LAND TYPE & & & & & & \\
\hline SOIL TYPE & & & & & & \\
\hline VEGETATION TY & & & & & & \\
\hline Dominant Specics & & & & & & \\
\hline Total Woody Cover: & & & Height of dominant trees: & $\mathrm{m}$ & & \\
\hline $\begin{array}{l}\text { GOODS AND SERV } \\
\text { (Good = 3, Moderat }\end{array}$ & $\begin{array}{l}\text { VICES } \\
e=2, P\end{array}$ & 1, None $=0$ & $\begin{array}{l}\text { COST FACTORS } \\
\text { (Good }=3 \text {, Moderate }=2 \\
\text { (Very } \operatorname{Far}=4, \text { Far }=3, \mathrm{C}\end{array}$ & $\begin{array}{l}\text { Poor }=1, N \\
\text { lose }=2, \text { Very }\end{array}$ & $\begin{array}{l}\text { None }=0 \\
\text { y elose }=\end{array}$ & 0) \\
\hline Firewood & & $\begin{array}{llll}3 & 2 & 1 & 0\end{array}$ & Physical barriers & & $\begin{array}{lll}3 & 2 & 1\end{array}$ & 10 \\
\hline Construction materia & & $\begin{array}{llll}3 & 2 & 1 & 0\end{array}$ & Institutional barriers & & $\begin{array}{lll}3 & 2 & 1 \\
\end{array}$ & 10 \\
\hline Wild fruits & & $\begin{array}{llll}3 & 2 & 1 & 0\end{array}$ & Government regulations & & $\begin{array}{lll}3 & 2 & 1\end{array}$ & 10 \\
\hline Traditional medieine: & & $\begin{array}{llll}3 & 2 & 1 & 0\end{array}$ & & & & \\
\hline Palm leaf products (s & estaria) & $\begin{array}{llll}3 & 2 & 1 & 0 \\
\end{array}$ & Distance along path & & $4 \quad 32$ & 21 \\
\hline Palm wine & & $\begin{array}{llll}3 & 2 & 1 & 0\end{array}$ & Distance off path & & 432 & 21 \\
\hline Grinding sticks/bowl & & \begin{tabular}{|llll}
3 & 2 & 1 & 0 \\
\end{tabular} & & & & \\
\hline Land for cultivation & & $\begin{array}{|llll|}3 & 2 & 1 & 0 \\
\end{array}$ & Land for houses & & $\begin{array}{lll}3 & 2 & 1 \\
\end{array}$ & 10 \\
\hline Fish & & $\begin{array}{|llll|}3 & 2 & 1 & 0 \\
\end{array}$ & & & & \\
\hline Well sites / water & & $\begin{array}{llll}3 & 2 & 1 & 0\end{array}$ & & & & \\
\hline Wild foods & & $\begin{array}{llll}3 & 2 & 1 & 0\end{array}$ & & & & \\
\hline Honcy & & $\begin{array}{llll}3 & 2 & 1 & 0 \\
\end{array}$ & & & & \\
\hline Clay for pots & & $\begin{array}{|llll|}3 & 2 & 1 & 0 \\
\end{array}$ & & & & \\
\hline Grinding stones & & $\begin{array}{llll}3 & 2 & 1 & 0\end{array}$ & & & & \\
\hline $\begin{array}{l}\text { Overall Landscape } \\
\text { Value }\end{array}$ & NOTE: & $y$ other resour & Ser cost factors? & & & \\
\hline
\end{tabular}


CIFOR/TREP GORONGOSA RESEARCH PROJ ECT 2001/2002 CONFRONTATION OF BENEFIT-COST MODEL

\begin{tabular}{|c|c|c|c|c|c|c|c|c|c|}
\hline SAMPLE NUMBE & & Field: N & & & Final: & & & & \\
\hline LOCATION & & Nhanchar & & & & & & & \\
\hline RECORDER & & & & & & & & & \\
\hline DATE & & July 2 & 2002 & & & & & & \\
\hline GPS COORDINA & & No: & & s: & E: & & & & \\
\hline LAND TYPE & & Baixa & & Planalto & Montzahas & & & & \\
\hline SOIL TYPR & & & & & & & & & \\
\hline VEGETATION TY & & & & & & & & & \\
\hline Dominant Species & & & & & & & & & \\
\hline Total Woody Cover & 9 & & & Height of dominant trees: & m & & & & \\
\hline GOODS AND SER & VICRS: & $\operatorname{de}=3, \operatorname{Mod}$ & lera & $e=2$, Poor $=1$, None $=0$ ) & & & & & \\
\hline Firewood & & $\begin{array}{lll}3 & 2 & 1 \\
\end{array}$ & & Land for houses and fields & & 32 & 21 & 16 & 0 \\
\hline Wood for bandles & & 3221 & & Water & & 32 & 21 & 1 & 0 \\
\hline Wood grinding sti & kshowls & $\begin{array}{lll}3 & 2 & 1\end{array}$ & & Cultivated fruits & & 32 & 21 & 1 & 0 \\
\hline Wood far timber (pl) & mika) & $\begin{array}{lll}3 & 2 & 1 \\
\end{array}$ & & Grinding stones & & 32 & 2 & 1 & 0 \\
\hline Poles & & $\begin{array}{lll}3 & 2 & 1\end{array}$ & & Clay for pots (dongo) & & & 2 & 1 & 0 \\
\hline Bamboo & & $\begin{array}{lll}3 & 2 & 1 \\
\end{array}$ & & Matope (mud for cultivation & & & 21 & 1 & 0 \\
\hline Bark for rope & & $\begin{array}{lll}3 & 2 & 1\end{array}$ & & Nongo (clay for caltivation) & & 32 & 2 & 1 & 0 \\
\hline Thatching grass & & $\begin{array}{lll}3 & 2 & 1 \\
\end{array}$ & 0 & Sand & & 32 & 21 & 1 & 0 \\
\hline Reeds for constructi & & $\begin{array}{lll}3 & 2 & 1 \\
\end{array}$ & 0 & COST FACTORS & & & & & \\
\hline Reeds for sleeping 1 & & $\begin{array}{lll}3 & 2 & 1 \\
\end{array}$ & 0 & (High = 3, Moderate = 2, I & Cow $=1$, None $=$ & $=0$ ) & & & \\
\hline Traditional medicin & & $\begin{array}{lll}3 & 2 & 1\end{array}$ & & (Very far $=4$, Far $=3$, Clo & se $=2$, Very elo & & & & \\
\hline Wild fruits & & $\begin{array}{lll}3 & 2 & 1 \\
\end{array}$ & 0 & Traditional regulations & & 32 & 21 & 1 & 0 \\
\hline Wild foods & & $\begin{array}{lll}3 & 2 & 1\end{array}$ & 0 & Government regulations & & 32 & 21 & 1 & 0 \\
\hline Honey (all types) & & $\begin{array}{lll}3 & 2 & 1 \\
\end{array}$ & & Dangers (parigos) & & 32 & 21 & 1 & 0 \\
\hline Aquatic plants for $\mathrm{f}$ & & $\begin{array}{|lll|}3 & 2 & 1 \\
\end{array}$ & & & & & & & \\
\hline Fish/other aquatic a & imnls & $\begin{array}{lll}3 & 2 & 1 \\
\end{array}$ & 0 & Distance along path & & 43 & 32 & 2 & 1 \\
\hline Willife & & $\begin{array}{lll}3 & 2 & 1\end{array}$ & & Distance off path & & 43 & 32 & 2 & 1 \\
\hline Grazing for livestoc & & $\begin{array}{lll}3 & 2 & 1 \\
\end{array}$ & 0 & & & & & & \\
\hline $\begin{array}{l}\text { Overall } \\
\text { Landseape Value }\end{array}$ & NOTES & Slope, VeB & etat & on condition, resouree use, c & & & & & \\
\hline
\end{tabular}




\section{Appendix 2. Land types identified by the Muaredzi CRUAT}

Whilst carrying out GPS mapping, team members were asked, along most routes, to identify the land type for the area immediately surrounding each recorded point. Seven of the eight principal land types were encountered during this process (nsitu, chipale, planicie, thando, madimba, gombe and murmuchea), the exception being planalto. The following brief descriptions draw heavily on these observations.

Gombe equates to areas where water is found, principally the lake, rivers and permanent pans, but in a relatively narrow sense. Thus seasonally flooded areas are included under thando rather than gombe.

Madimba is specific and very confined in extent. It is defined as wet areas which are suitable for particular crops such as bananas and madumbe, and the production of other crops during the dry season. Within Muaredzi it isfound only in association with the Muaredzi and Urema rivers.

Thando comprises more open areas than planicie, and mainly occurs as an irregular belt between the Urema river and adjacent planicie areas. It includes floodplain grassland areas, but is more complicated than this. It also includes open woodland areas with scattered trees, as well as areas of clumped vegetation comprising densely wooded clumps interspersed by open grassy areas. The main distinction between thando and planicie appears to be the abundance of woody vegetation, although this was not always clear, and it is possible that different informants may have different interpretations of these units. Regardless of the density of woody vegetation, any areas that are prone to seasonal flooding are likely to be included as part of thando rather than planicie.

Planicie comprises the woodland area that makes up the bulk of the floodplain. The village households and adjacent fields (machambas) fall entirely within planicie.

Nsitu (forest) appears to be characterized by a marked thickening of vegetation in response to localized sandy soils. Species composition is markedly different from adjacent planicie or planalto areas. This is not an extensive type, occurring rather as a series of small discrete patches, particularly between the planicie and planalto, but extending throughout the planicie. Some of the nsitu forest patches are extremely small (down to less than 1 ha), but are still recognized by the community as comprising "little nsitu".

Chipale refers to small localized patches of bare ground, or where the plant cover comprises particularly short grasses. It is commonly found in proximity to nsitu patches, but also occurs in association with planicie and thando. Its occurrence appears to have more to do with localized soil conditions (possibly saline soils) than with flooding or water logging. Patches are typically very small, often being less than 1 ha in extent.

Planalto: My expectation of planalto was that it would correspond to the well developed tall miombo woodland that covers the sandy Cheringoma plateau. However, the Muaredzi community give it a considerably wider interpretation. Two different groups of informants both showed the boundary as corresponding to the geological divide between in situ rock outcrops and the sediment filled Urema basin. In practical terms, as one drives out from Muaredzi towards Mwanza, this is immediately after the last of the dense forest patches, and well before the prominent little hill (known as "Chitundo tcha magale"). The planalto thus includes portions of open Combretum woodland, like that found within parts of the planicie; the J ulbernadia communities found on the transitional foothills and escarpment zone (rocky in places); and then extends back into the tall Brachystegia woodlands of the plateau area.

Murmuchea are termite mounds. These occur commonly within planalto, nsitu, planicie and, to a lesser extent, thando areas, but appear to be absent from gombe, madimba and chipale. The types of termites appear to vary. Key resources here are the clay soils, and certain plants and insects that appear to be specifically associated with the anthills. 


\section{Appendix 3. Summary of 75 Muaredzi field samples for model confrontation}

\section{CIFOR/TREP GORONGOSA RESEARCH PROJ ECT CONFRONTATION OF MODEL \\ MUAREDZI (75 Samples collected J uly 2002)}

Std

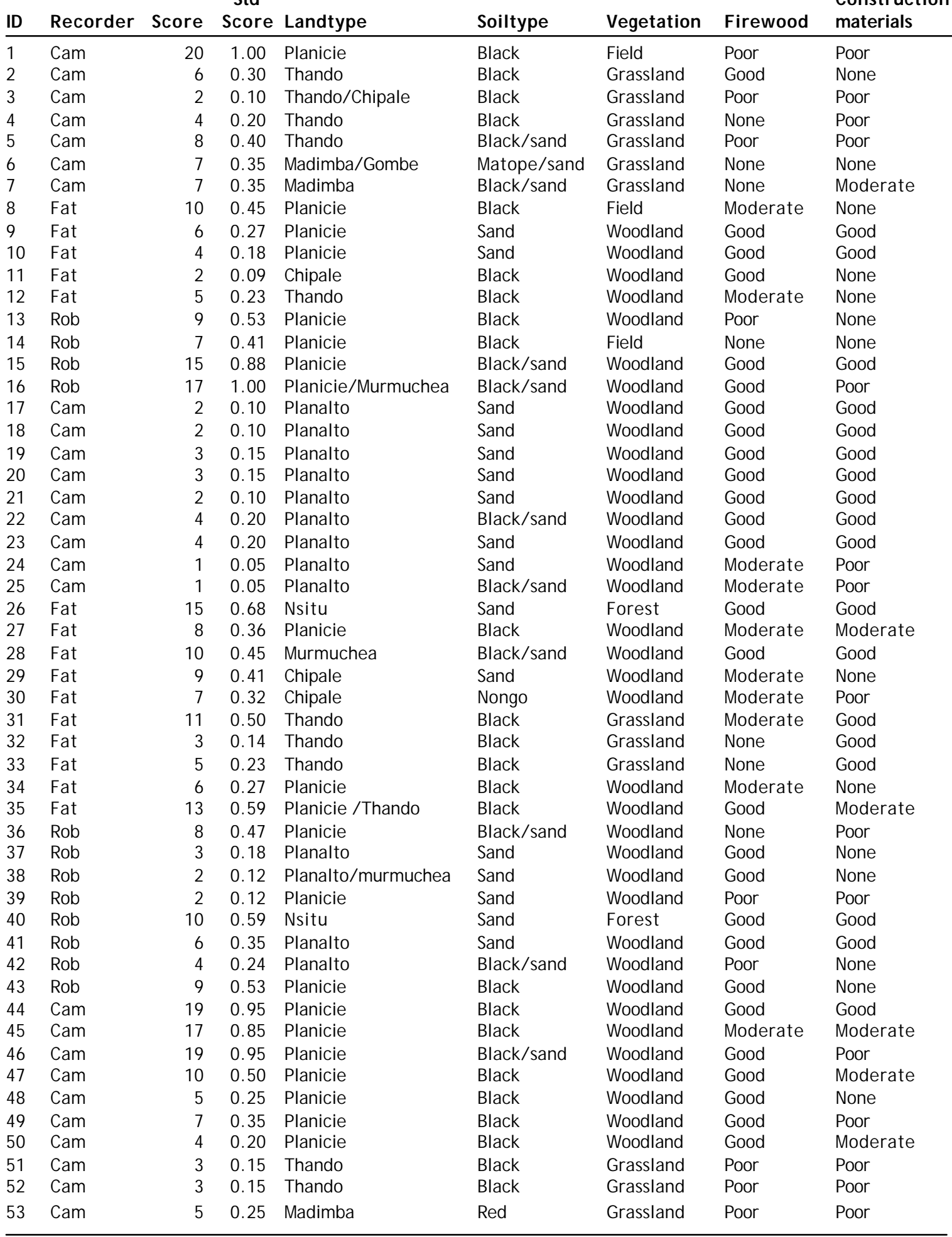

Page 1/6

Construction . 


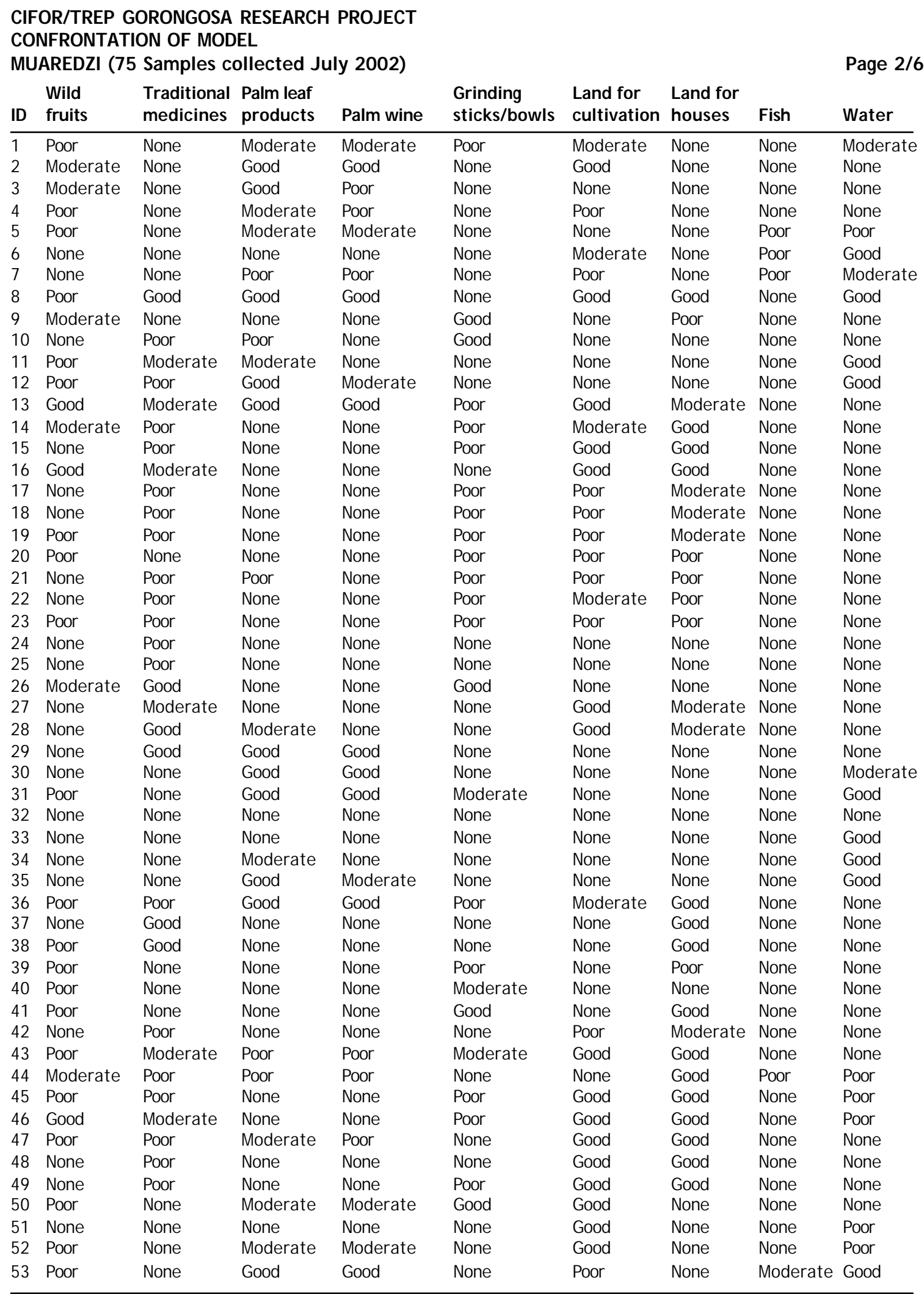




\begin{tabular}{|c|c|c|c|c|c|c|c|c|c|}
\hline \multicolumn{10}{|c|}{$\begin{array}{l}\text { CIFOR/TREP GORONGOSA RESEARCH PROJ ECT } \\
\text { CONFRONTATION OF MODEL }\end{array}$} \\
\hline ID & $\begin{array}{l}\text { Wild } \\
\text { foods }\end{array}$ & Honey & $\begin{array}{l}\text { Clay for } \\
\text { pots }\end{array}$ & $\begin{array}{l}\text { Grinding } \\
\text { stones }\end{array}$ & $\begin{array}{l}\text { Physical } \\
\text { barriers }\end{array}$ & $\begin{array}{l}\text { Institutional } \\
\text { barriers }\end{array}$ & $\begin{array}{l}\text { Government } \\
\text { regulations }\end{array}$ & $\begin{array}{l}\text { Distance } \\
\text { along Path }\end{array}$ & $\begin{array}{l}\text { Page } 3 / 6 \\
\text { Distance } \\
\text { off Path } \\
\end{array}$ \\
\hline 1 & Moderate & None & None & None & None & None & None & Close & VeryClose \\
\hline 2 & None & Poor & None & None & None & None & None & VeryFar & VeryClose \\
\hline 3 & None & None & None & None & None & None & High & VeryFar & Close \\
\hline 4 & None & None & None & None & None & None & High & VeryFar & Far \\
\hline 5 & None & None & None & None & High & None & Low & VeryFar & VeryClose \\
\hline 6 & None & None & None & None & Low & None & Low & Far & VeryClose \\
\hline 7 & None & None & None & None & None & None & Low & Far & VeryClose \\
\hline 8 & None & None & None & None & None & None & None & VeryClose & VeryClose \\
\hline 9 & None & Poor & None & None & None & None & High & VeryFar & VeryFar \\
\hline & None & None & None & None & None & None & Moderate & VeryFar & VeryFar \\
\hline & None & None & None & None & None & None & Moderate & VeryFar & VeryFar \\
\hline 12 & None & None & None & None & None & None & Moderate & VeryFar & Far \\
\hline 13 & None & None & None & None & None & None & High & VeryClose & Close \\
\hline & None & None & Poor & None & None & None & High & VeryClose & VeryClose \\
\hline & None & None & None & None & None & None & High & Far & Far \\
\hline & None & None & None & None & None & None & High & Close & Far \\
\hline 17 & None & Good & None & None & None & None & Moderate & VeryFar & Close \\
\hline 18 & None & Good & None & None & None & None & Moderate & VeryFar & Close \\
\hline & None & Good & None & None & None & None & Moderate & VeryFar & Close \\
\hline 20 & None & Good & None & None & None & None & Moderate & VeryFar & Close \\
\hline & None & Good & None & None & None & None & Moderate & VeryFar & Close \\
\hline 22 & None & Good & None & None & None & None & Moderate & VeryFar & Close \\
\hline 23 & None & Moderate & None & None & None & None & Moderate & VeryFar & Far \\
\hline 24 & None & None & None & None & None & None & High & Far & Close \\
\hline 25 & None & None & None & None & None & None & None & VeryFar & VeryClose \\
\hline 26 & Good & Good & None & None & None & None & Moderate & VeryFar & VeryClose \\
\hline 27 & None & None & None & None & None & None & Moderate & VeryFar & VeryFar \\
\hline 28 & None & Moderate & None & None & None & None & Moderate & VeryFar & VeryFar \\
\hline 29 & Moderate & None & None & None & None & None & Moderate & VeryFar & Far \\
\hline 30 & None & None & None & None & None & None & Moderate & VeryFar & Close \\
\hline 31 & None & None & None & None & None & None & Moderate & VeryFar & VeryFar \\
\hline 32 & None & None & None & None & None & None & Moderate & VeryFar & Far \\
\hline 33 & None & None & None & None & None & None & Moderate & VeryFar & VeryFar \\
\hline 34 & None & None & None & None & None & None & Moderate & VeryFar & VeryClose \\
\hline 35 & None & None & None & None & None & None & Moderate & VeryFar & VeryClose \\
\hline 36 & None & None & None & None & High ?? & None & High & VeryClose & Close \\
\hline 37 & None & None & None & None & None & None & High & VeryClose & Far \\
\hline 38 & None & None & None & None & None & None & High & Far & Far \\
\hline 39 & None & None & None & None & None & None & High & VeryFar & VeryFar \\
\hline 40 & None & None & None & None & None & None & High & Far & Far \\
\hline 41 & None & None & None & None & None & None & High & Far & Far \\
\hline 42 & None & None & None & None & None & None & High & VeryFar & VeryFar \\
\hline 43 & None & None & None & None & None & None & High & VeryFar & VeryFar \\
\hline 44 & None & Poor & None & None & Low & None & Moderate & Far & Close \\
\hline 45 & None & Poor & None & None & None & None & Moderate & Far & Far \\
\hline 46 & None & Poor & None & None & None & None & Moderate & VeryFar & VeryFar \\
\hline 47 & None & Poor & None & None & None & None & Moderate & VeryFar & VeryFar \\
\hline 48 & None & Poor & None & None & None & None & Moderate & VeryFar & VeryFar \\
\hline 49 & Poor & Poor & None & None & None & None & Moderate & VeryFar & VeryFar \\
\hline 50 & Poor & Poor & None & None & None & None & Moderate & VeryFar & VeryFar \\
\hline 51 & None & None & None & None & Moderate & None & High & VeryFar & VeryFar \\
\hline 52 & Poor & None & None & None & Low & None & Moderate & VeryFar & VeryFar \\
\hline 53 & None & None & None & None & High & None & Moderate & VeryFar & VeryFar \\
\hline
\end{tabular}


CIFOR/TREP GORONGOSA RESEARCH PROJ ECT

CONFRONTATION OF MODEL

MUAREDZI (75 Samples collected J uly 2002)

Page 4/6

Std

\begin{tabular}{|c|c|c|c|c|c|c|c|c|}
\hline ID & Recorder & Score & $\begin{array}{c}\text { std } \\
\text { Score }\end{array}$ & Landtype & Soiltype & Vegetation & Firewood & $\begin{array}{l}\text { Construction } \\
\text { materials }\end{array}$ \\
\hline 54 & Soz & 10 & 0.71 & Planicie & Black & Woodland & Good & Good \\
\hline 55 & Soz & 5 & 0.36 & Planicie & Black & Woodland & Good & None \\
\hline 56 & Soz & 7 & 0.50 & Planicie/ Murmuchea & Black & Woodland & Good & None \\
\hline 57 & Soz & 4 & 0.29 & Gombe & Sand & Woodland & Poor & None \\
\hline 58 & Soz & 6 & 0.43 & Planicie & Black & Woodland & Good & None \\
\hline 59 & Soz & 14 & 1.00 & Nsitu & Sand & Forest & Good & Good \\
\hline 60 & Fat & 15 & 0.68 & Planicie & Black/ sand & Field & Good & Moderate \\
\hline 61 & Fat & 22 & 1.00 & Planicie & Black & Household & Good & Poor \\
\hline 62 & Fat & 12 & 0.55 & Planicie & Black & Field & Moderate & Moderate \\
\hline 63 & Fat & 10 & 0.45 & Thando & Sand & Woodland & Good & Moderate \\
\hline 64 & Fat & 20 & 0.91 & Madimba & Black & Woodland & Moderate & Moderate \\
\hline 65 & Fat & 13 & 0.59 & Planicie & Black/ sand & Field & Good & None \\
\hline 66 & Fat & 8 & 0.36 & Planicie & Black & Field & Moderate & Moderate \\
\hline 67 & Fat & 9 & 0.41 & Planicie & Black & Field & Good & None \\
\hline 68 & Fat & 5 & 0.23 & Planicie & Black & Woodland & None & None \\
\hline 69 & Fat & 6 & 0.27 & Planicie & Black & Woodland & Good & Moderate \\
\hline 70 & Rob & 17 & 1.00 & Planicie & Black & Woodland & Good & None \\
\hline 71 & Rob & 13 & 0.76 & Nsitu/ Murmuchea & Sand & Forest & Good & Good \\
\hline 72 & Rob & 14 & 0.82 & Planicie & Black & Woodland & Good & None \\
\hline 73 & Rob & 13 & 0.76 & Planicie & Black & Woodland & Good & None \\
\hline 74 & Rob & 14 & 0.82 & Planicie & Black & Woodland & Good & Good \\
\hline 75 & Rob & 4 & 0.24 & Gombe/ Madimba & Sand & Reeds & None & None \\
\hline
\end{tabular}




\begin{tabular}{|c|c|c|c|c|c|c|c|c|c|}
\hline \multicolumn{9}{|c|}{$\begin{array}{l}\text { CIFOR/TREP GORONGOSA RESEARCH PROJ ECT } \\
\text { CONFRONTATION OF MODEL } \\
\text { MUAREDZI ( } 75 \text { Samples collected J uly 2002) }\end{array}$} & \multirow{2}{*}{$\begin{array}{l}\text { Page 5/6 } \\
\text { Water }\end{array}$} \\
\hline ID & $\begin{array}{l}\text { Wild } \\
\text { fruits }\end{array}$ & $\begin{array}{l}\text { Traditional } \\
\text { medicines }\end{array}$ & $\begin{array}{l}\text { Palm leaf } \\
\text { products }\end{array}$ & $\begin{array}{l}\text { Palm } \\
\text { wine }\end{array}$ & $\begin{array}{l}\text { Grinding } \\
\text { sticks/bowls }\end{array}$ & $\begin{array}{l}\text { Land for } \\
\text { cultivation }\end{array}$ & $\begin{array}{l}\text { Land for } \\
\text { houses }\end{array}$ & Fish & \\
\hline 54 & Good & Moderate & None & None & Poor & Good & Poor & None & None \\
\hline 55 & None & None & None & None & Poor & Good & Poor & None & None \\
\hline 56 & None & Poor & Poor & None & None & Good & Poor & None & None \\
\hline 57 & None & None & Poor & None & None & Moderate & None & None & Good \\
\hline 58 & None & None & Poor & None & None & Good & Poor & None & None \\
\hline 59 & Good & Good & None & None & Good & None & Poor & None & None \\
\hline 60 & Good & Good & Good & Good & Poor & Good & Good & None & Good \\
\hline 61 & Poor & Good & Good & Good & None & Good & Good & Moderate & Good \\
\hline 62 & None & Good & None & None & None & Good & Good & Moderate & Good \\
\hline 63 & None & None & Good & Moderate & None & None & None & Good & Good \\
\hline 64 & None & None & Moderate & None & None & Good & None & Good & Good \\
\hline 65 & None & Good & Good & Good & Moderate & Good & Good & None & Good \\
\hline 66 & None & None & Good & Good & None & Good & Moderate & None & Poor \\
\hline 67 & None & Good & Good & Good & None & Good & Moderate & None & Moderat \\
\hline 68 & None & None & Poor & None & None & Moderate & Moderate & None & None \\
\hline 69 & None & None & None & None & None & Good & None & None & None \\
\hline 70 & Good & Good & None & None & None & Good & Good & None & None \\
\hline 71 & Good & Good & None & None & Poor & None & None & None & None \\
\hline 72 & Moderate & Good & None & None & Poor & Good & Good & None & None \\
\hline 73 & None & Good & None & None & Moderate & Good & Good & None & None \\
\hline 74 & None & Good & None & None & None & Good & Good & None & None \\
\hline 75 & None & None & None & None & None & Moderate & None & Moderate & Good \\
\hline
\end{tabular}


CIFOR/TREP GORONGOSA RESEARCH PROJ ECT

CONFRONTATION OF MODEL

MUAREDZI (75 Samples collected J uly 2002)

Page 6/6

\begin{tabular}{|c|c|c|c|c|c|c|c|c|}
\hline $\begin{array}{l}\text { Wild } \\
\text { ID foods }\end{array}$ & Honey & $\begin{array}{l}\text { Clay for } \\
\text { pots }\end{array}$ & $\begin{array}{l}\text { Grinding } \\
\text { stones }\end{array}$ & $\begin{array}{l}\text { Physical } \\
\text { barriers }\end{array}$ & $\begin{array}{l}\text { Institutional } \\
\text { barriers }\end{array}$ & $\begin{array}{l}\text { Government } \\
\text { regulations }\end{array}$ & $\begin{array}{l}\text { Distance } \\
\text { along Path }\end{array}$ & $\begin{array}{l}\text { Distance } \\
\text { off Path }\end{array}$ \\
\hline 54 None & None & None & None & None & None & High & VeryFar & VeryFar \\
\hline 55 None & None & None & None & None & None & High & VeryFar & VeryFar \\
\hline 56 Poor & None & None & None & None & None & High & VeryFar & VeryFar \\
\hline 57 None & None & None & None & None & None & High & VeryFar & VeryFar \\
\hline 58 None & None & None & None & None & None & High & VeryFar & VeryFar \\
\hline 59 Good & None & None & None & None & None & High & VeryFar & VeryFar \\
\hline 60 None & None & None & None & None & None & Moderate & Close & VeryClose \\
\hline 61 None & None & Good & Good & None & None & Moderate & VeryClose & VeryClose \\
\hline 62 None & None & Good & None & None & None & Moderate & VeryClose & VeryClose \\
\hline 63 None & None & Good & None & None & None & Moderate & Close & VeryClose \\
\hline 64 None & None & Good & None & None & None & Moderate & Far & Far \\
\hline 65 None & None & None & None & None & None & Moderate & VeryClose & VeryClose \\
\hline 66 None & None & None & None & None & None & Moderate & Far & Close \\
\hline 67 Moderate & None & None & None & None & None & Moderate & Close & VeryFar \\
\hline 68 None & None & None & None & None & None & Moderate & VeryFar & VeryFar \\
\hline 69 None & None & None & None & None & None & Moderate & VeryFar & VeryFar \\
\hline 70 None & None & None & None & None & None & High & VeryClose & Far \\
\hline 71 None & None & None & None & None & None & High & VeryClose & Far \\
\hline 72 None & None & None & None & None & None & High & Far & Far \\
\hline 73 None & None & None & None & None & None & High & VeryFar & VeryFar \\
\hline 74 None & None & None & None & None & None & High & VeryFar & VeryFar \\
\hline 75 None & None & None & None & Moderate & None & High & VeryClose & Close \\
\hline
\end{tabular}




\section{Appendix 4. Summary of 82 Nhanchururu field samples for model confrontation}

\section{CIFOR/TREP GORONGOSA RESEARCH PROJ ECT \\ CONFRONTATION OF MODEL}

NHANCHURURU DATA: (82 samples collected J uly 2002)

Page 1/8

\begin{tabular}{|c|c|c|c|c|c|c|c|c|c|}
\hline ID & Recorder & Score & $\begin{array}{l}\text { Std } \\
\text { score }\end{array}$ & Landtype & Soiltype & Vegetation & Firewood & $\begin{array}{l}\text { Wood for } \\
\text { handles }\end{array}$ & $\begin{array}{l}\text { Grinding } \\
\text { sticks } \\
\end{array}$ \\
\hline 1 & Cam & 10 & 0.71 & Planicie & Red/ black & Field & Poor & None & None \\
\hline 2 & Fat & 6 & 0.24 & Planalto & Black/ stones & Thicket & Good & Good & None \\
\hline 3 & Rob & 12 & 0.60 & Planalto & Black/ sand & Thicket & Good & High & None \\
\hline 4 & Rob & 10 & 0.50 & Planalto & Black/ stones & Woodland & Moderate & Poor & None \\
\hline 5 & Fat & 6 & 0.24 & Baixa & Black/ sand & ?ffield & Poor & None & None \\
\hline 6 & Fat & 8 & 0.32 & Planalto & Sand/ stones & $? ?$ & Moderate & Poor & None \\
\hline 7 & Fat & 9 & 0.36 & Baixa & Black/ sand & $? ?$ & Good & Poor & None \\
\hline 8 & Fat & 7 & 0.28 & Baixa & Black/ sand & $? ?$ & Good & Good & Poor \\
\hline 9 & Fat & 12 & 0.48 & Montanhas & Black/ sand & $? ?$ & Good & Moderate & None \\
\hline 10 & Fat & 15 & 0.60 & Planicie & Red & $? ?$ & Good & Moderate & None \\
\hline 11 & Rob & 9 & 0.45 & Baixa & Black/stons & Woodland & Poor & None & None \\
\hline 12 & Soz & 11 & 0.61 & Planalto & Black & Woodland & Moderate & Poor & None \\
\hline 13 & Soz & 9 & 0.50 & Baixa & Black/ red & River/grassland & None & None & None \\
\hline 14 & Rob & 8 & 0.40 & Baixa & Black/ sand & Field & None & Poor & None \\
\hline 15 & Rob & 14 & 0.70 & Planalto & Black & Woodland & Good & Good & None \\
\hline 16 & Rob & 13 & 0.65 & Planalto & Black/ stones & Woodland & Good & Good & None \\
\hline 17 & Cam & 10 & 0.71 & Planicie & Black/ sand & Woodland & Good & Poor & None \\
\hline 18 & Cam & 5 & 0.36 & Baixa & Black & Woodland & Poor & None & None \\
\hline 19 & Cam & 6 & 0.43 & Planalto & Black/ sand & Woodland & Good & Poor & None \\
\hline 20 & Cam & 4 & 0.29 & Planicie & Black/ sand & Woodland & Poor & Poor & None \\
\hline 21 & Cam & 8 & 0.57 & Planicie & Black/ sand & Woodland & Poor & Poor & Poor \\
\hline 22 & Cam & 3 & 0.21 & Planicie & Black/ sand & Woodland & Moderate & None & None \\
\hline 23 & Cam & 7 & 0.50 & Planicie & Black/ sand & Woodland & Poor & None & None \\
\hline 24 & Cam & 2 & 0.14 & Planicie & Black/ sand & Woodland & Poor & Poor & None \\
\hline 25 & Cam & 2 & 0.14 & Planicie & Black/ sand & Field & Moderate & None & None \\
\hline 26 & Cam & 11 & 0.79 & Baixa & Sand/ stones & Field & Poor & None & None \\
\hline 27 & Cam & 7 & 0.50 & Baixa & Sand & Woodland & Poor & None & None \\
\hline 28 & Cam & 14 & 1.00 & Planicie & Black/ sand & Woodland & Poor & Poor & None \\
\hline 29 & Soz & 12 & 0.67 & Planalto & Black/ sand & Woodland & Poor & Poor & None \\
\hline 30 & Soz & 6 & 0.33 & Planicie & Black/ stones & Woodland & Poor & None & Poor \\
\hline 31 & Soz & 8 & 0.44 & Planicie & Black & $?$ & Moderate & Poor & None \\
\hline 32 & Soz & 5 & 0.28 & Baixa & Black & $?$ & Moderate & Poor & None \\
\hline 33 & Soz & 17 & 0.94 & Planicie & Black/ sand & $?$ & Moderate & Moderate & None \\
\hline 34 & Soz & 3 & 0.17 & Planicie & Black/ stones & $?$ & None & Poor & None \\
\hline 35 & Rob & 15 & 0.75 & Baixa & Black & RiverWood & Good & Good & None \\
\hline 36 & Rob & 12 & 0.60 & Planalto & Black/ sand & Woodland & Good & Good & None \\
\hline 37 & Rob & 12 & 0.60 & Planalto & Black/ stones & Woodland & Good & Good & None \\
\hline 38 & Rob & 13 & 0.65 & Planicie & Black/ sand & Woodland & Moderate & Moderate & Moderate \\
\hline 39 & Rob & 11 & 0.55 & Baixa & Black/ sand & Field & Poor & Poor & None \\
\hline 40 & Rob & 20 & 1.00 & Planicie & Red & Thicket & Good & Good & Moderate \\
\hline 41 & Fat & 12 & 0.48 & Planicie & Black/ sand & Household & Moderate & Poor & None \\
\hline 42 & Fat & 7 & 0.28 & Planalto & Black/ sand & Woodland & Moderate & Poor & None \\
\hline 43 & Fat & 9 & 0.36 & Planalto & Black/ stones & Field & Good & Moderate & None \\
\hline 44 & Fat & 5 & 0.20 & Baixa & Black/ stones & Woodland & Moderate & None & None \\
\hline 45 & Fat & 6 & 0.24 & Planicie & Black/ sand & Woodland & Poor & Poor & None \\
\hline 46 & Fat & 10 & 0.40 & Planicie & Black/ sand & Woodland & Moderate & Poor & None \\
\hline 47 & Soz & 9 & 0.50 & Planicie & Black/ sand & Woodland & Poor & Poor & None \\
\hline 48 & Soz & 12 & 0.67 & Planicie & Black/ sand & Woodland & Poor & Poor & None \\
\hline 49 & Soz & 5 & 0.28 & Planicie & Black & Woodland & None & None & None \\
\hline 50 & Soz & 3 & 0.17 & Planicie & Black & Woodland & None & None & None \\
\hline 51 & Soz & 7 & 0.39 & Baixa & Black/ sand & Woodland & Poor & Poor & None \\
\hline 52 & Rob & 13 & 0.65 & Planicie & Black/ stones & Woodland & Good & Good & Moderate \\
\hline 53 & Rob & 11 & 0.55 & Baixa & Black & Woodland/thicket & Good & Good & None \\
\hline
\end{tabular}


CIFOR/TREP GORONGOSA RESEARCH PROJ ECT

CONFRONTATION OF MODEL

NHANCHURURU DATA: (82 samples collected J uly 2002)

Page 2/8

\begin{tabular}{|c|c|c|c|c|c|c|c|c|c|}
\hline ID & Timber & Poles & Bamboo & Bark & $\begin{array}{l}\text { Thatching } \\
\text { grass }\end{array}$ & $\begin{array}{l}\text { Reeds for } \\
\text { construction }\end{array}$ & $\begin{array}{l}\text { Reeds for } \\
\text { sleeping mats }\end{array}$ & $\begin{array}{l}\text { Traditional } \\
\text { medicines }\end{array}$ & $\begin{array}{l}\text { Wild } \\
\text { fruits }\end{array}$ \\
\hline 1 & None & None & None & None & None & None & None & Poor & None \\
\hline 2 & None & None & None & Poor & None & Poor & None & Poor & Poor \\
\hline 3 & None & Poor & None & None & None & Poor & None & Poor & None \\
\hline 4 & None & Poor & None & None & None & None & None & Poor & Poor \\
\hline 5 & None & None & None & Poor & Poor & None & None & Poor & None \\
\hline 6 & None & Poor & None & Good & None & None & None & Poor & Poor \\
\hline 7 & None & Moderate & None & None & None & None & None & Poor & Good \\
\hline 8 & Poor & Moderate & None & Poor & None & None & None & Moderate & $*$ \\
\hline 9 & Moderate & Moderate & Poor & Good & Good & None & None & Poor & Moderate \\
\hline 10 & None & Poor & None & Good & Poor & None & None & Poor & None \\
\hline 11 & None & None & None & Poor & Moderate & None & None & Poor & Poor \\
\hline 12 & None & Moderate & None & Good & Poor & Poor & None & Moderate & None \\
\hline 13 & None & None & None & None & Poor & Poor & None & None & None \\
\hline 14 & None & Poor & None & None & Poor & None & Poor & None & None \\
\hline 15 & None & Good & None & Good & Good & None & None & Good & Moderate \\
\hline 16 & Good & Good & None & Good & Good & None & None & Good & Poor \\
\hline 17 & None & Poor & None & Poor & Poor & None & None & Poor & None \\
\hline 18 & Poor & Poor & Poor & Poor & Poor & None & None & Poor & None \\
\hline 19 & None & Poor & None & Poor & None & None & None & Poor & None \\
\hline 20 & Poor & Poor & None & Poor & Good & None & None & Poor & None \\
\hline 21 & Poor & None & None & Poor & Good & None & None & Poor & None \\
\hline 22 & None & Poor & None & None & Poor & None & None & Poor & None \\
\hline 23 & None & Poor & None & Poor & None & None & None & Poor & Poor \\
\hline 24 & None & Poor & None & None & None & None & None & Poor & None \\
\hline 25 & None & None & None & None & None & None & None & Poor & None \\
\hline 26 & None & Poor & Poor & Poor & None & None & Poor & Poor & None \\
\hline 27 & None & None & None & Poor & None & None & Moderate & Poor & None \\
\hline 28 & None & None & None & None & None & None & None & Poor & None \\
\hline 29 & None & Moderate & None & Good & None & Poor & None & Poor & None \\
\hline 30 & None & Poor & None & Poor & Poor & Poor & None & Poor & None \\
\hline 31 & None & Poor & None & Poor & None & Poor & None & Poor & None \\
\hline 32 & None & Moderate & None & Moderate & None & Poor & None & Poor & Poor \\
\hline 33 & Good & Good & None & Good & Good & Moderate & None & Moderate & None \\
\hline 34 & None & None & None & None & None & None & None & Poor & None \\
\hline 35 & Moderate & Good & None & Good & Good & Good & Moderate & Moderate & Good \\
\hline 36 & None & Good & None & Good & None & None & None & Good & None \\
\hline 37 & None & Good & None & Good & None & None & None & Good & Poor \\
\hline 38 & None & Poor & None & Good & Good & None & None & Poor & None \\
\hline 39 & None & Poor & Moderate & Good & Moderate & None & None & Poor & None \\
\hline 40 & None & Moderate & None & Moderate & None & None & None & Poor & Moderate \\
\hline 41 & None & Poor & None & Poor & Poor & None & None & Moderate & None \\
\hline 42 & None & Poor & None & None & None & None & None & Poor & None \\
\hline 43 & None & Moderate & None & Good & None & None & None & Poor & None \\
\hline 44 & None & Poor & None & Good & None & None & None & Poor & None \\
\hline 45 & None & Poor & None & Moderate & None & None & None & Poor & None \\
\hline 46 & None & Moderate & None & None & Poor & None & None & Moderate & None \\
\hline 47 & None & Poor & None & Poor & Moderate & None & None & Poor & None \\
\hline 48 & None & Moderate & None & Moderate & Poor & Moderate & None & Poor & None \\
\hline 49 & None & None & None & None & Good & None & None & Poor & None \\
\hline 50 & None & None & None & Poor & Poor & None & None & Poor & None \\
\hline 51 & None & Poor & Moderate & Poor & None & Poor & None & Moderate & None \\
\hline 52 & None & Good & None & Good & Good & None & None & Poor & Poor \\
\hline 53 & None & Good & Moderate & Good & Moderate & None & None & Good & Moderate \\
\hline
\end{tabular}


CIFOR/TREP GORONGOSA RESEARCH PROJ ECT

CONFRONTATION OF MODEL

NHANCHURURU DATA: (82 samples collected J uly 2002)

\begin{tabular}{|c|c|c|c|c|c|c|c|c|c|c|}
\hline ID & $\begin{array}{l}\text { Wild } \\
\text { foods }\end{array}$ & Honey & $\begin{array}{l}\text { Aquatic } \\
\text { food plants }\end{array}$ & Fish & Wildlife & Livestock & $\begin{array}{l}\text { Land for } \\
\text { houses }\end{array}$ & $\begin{array}{l}\text { Land for } \\
\text { fields }\end{array}$ & Water & $\begin{array}{l}\text { Cultivated } \\
\text { fruits }\end{array}$ \\
\hline 1 & None & None & None & None & None & Poor & Good & Poor & None & Poor \\
\hline 2 & None & None & None & None & None & None & Poor & Poor & None & Poor \\
\hline 3 & None & None & None & None & Poor & None & Good & Good & None & None \\
\hline 4 & Poor & None & None & None & None & Poor & Poor & Poor & None & None \\
\hline 5 & None & None & None & None & None & Good & None & Good & None & Good \\
\hline 6 & None & None & None & None & Poor & Poor & None & Moderate & None & Good \\
\hline 7 & None & None & None & None & Poor & Poor & None & Poor & None & Good \\
\hline 8 & Poor & None & None & None & None & Good & None & Good & None & None \\
\hline 9 & Poor & None & None & None & Poor & Good & None & Good & None & Good \\
\hline 10 & None & None & None & None & None & Poor & Good & Good & None & Moderate \\
\hline 11 & None & None & None & None & None & Good & Poor & Poor & None & Poor \\
\hline 12 & None & None & None & None & None & Poor & Poor & Moderate & None & None \\
\hline 13 & None & None & None & None & None & Moderate & None & Moderate & None & None \\
\hline 14 & None & None & Poor & None & None & Poor & None & Moderate & None & Good \\
\hline 15 & None & Poor & None & None & Good & Good & Good & Good & None & None \\
\hline 16 & Poor & Poor & None & None & Good & Good & None & Moderate & None & None \\
\hline 17 & None & None & None & None & None & Good & Good & Good & None & None \\
\hline 18 & None & None & None & None & $*$ & Moderate & None & Poor & None & None \\
\hline 19 & None & None & None & None & None & None & Good & Poor & None & Poor \\
\hline 20 & None & None & None & None & None & Poor & Moderate & None & None & None \\
\hline 21 & None & None & None & None & None & Poor & Good & None & None & None \\
\hline 22 & None & None & None & None & None & $*$ & Moderate & None & None & None \\
\hline 23 & Poor & None & None & None & None & None & Moderate & Poor & None & None \\
\hline 24 & None & None & None & None & None & None & Moderate & None & None & None \\
\hline 25 & None & None & None & None & None & $*$ & Moderate & Poor & None & None \\
\hline 26 & None & None & Poor & None & None & Poor & None & Poor & None & None \\
\hline 27 & None & None & Moderate & None & None & $*$ & None & Poor & None & Poor \\
\hline 28 & None & None & None & None & None & Poor & Good & Moderate & None & Moderate \\
\hline 29 & None & None & None & None & None & Poor & Good & Good & None & None \\
\hline 30 & None & None & None & None & None & Moderate & Poor & Poor & None & None \\
\hline 31 & None & None & None & None & None & Moderate & None & Good & None & None \\
\hline 32 & None & None & None & None & $*$ & Poor & None & Moderate & None & None \\
\hline 33 & None & None & None & None & None & Good & Poor & Poor & None & None \\
\hline 34 & Poor & None & None & None & $*$ & Poor & Poor & Poor & None & None \\
\hline 35 & None & Poor & Good & Good & Poor & Good & None & None & Good & None \\
\hline 36 & Moderate & None & None & None & Good & None & Poor & None & None & None \\
\hline 37 & Poor & None & None & None & Poor & None & None & None & None & None \\
\hline 38 & Poor & None & None & None & Good & Good & Good & Poor & None & None \\
\hline 39 & Moderate & None & None & None & Moderate & Good & None & Good & None & Good \\
\hline 40 & Good & None & None & None & Good & None & Good & Good & None & None \\
\hline 41 & None & None & None & None & None & Moderate & Moderate & None & None & Good \\
\hline 42 & Moderate & None & None & None & None & Poor & None & Good & None & Moderate \\
\hline 43 & None & None & None & None & None & None & None & Poor & None & None \\
\hline 44 & None & None & None & None & None & Poor & None & Moderate & None & Poor \\
\hline 45 & None & None & None & None & None & Good & None & Moderate & None & None \\
\hline 46 & None & None & None & None & None & Moderate & Moderate & None & None & None \\
\hline 47 & None & None & None & None & None & Moderate & Moderate & Poor & None & None \\
\hline 48 & None & None & None & None & None & Moderate & Poor & Poor & None & None \\
\hline 49 & None & None & None & None & None & Moderate & Poor & Poor & None & None \\
\hline 50 & None & None & None & None & None & Moderate & Poor & Poor & None & None \\
\hline 51 & None & None & None & None & None & Moderate & None & Poor & None & None \\
\hline 52 & None & None & None & None & Good & Good & Moderate & Moderate & None & None \\
\hline 53 & Moderate & None & None & None & Good & Good & None & Moderate & None & None \\
\hline
\end{tabular}




\section{CIFOR/TREP GORONGOSA RESEARCH PROJ ECT \\ CONFRONTATION OF MODEL \\ NHANCHURURU DATA: (82 samples collected J uly 2002)}

Grinding Clay for Mud for Clay for

ID stones pots culti- cultivation vation

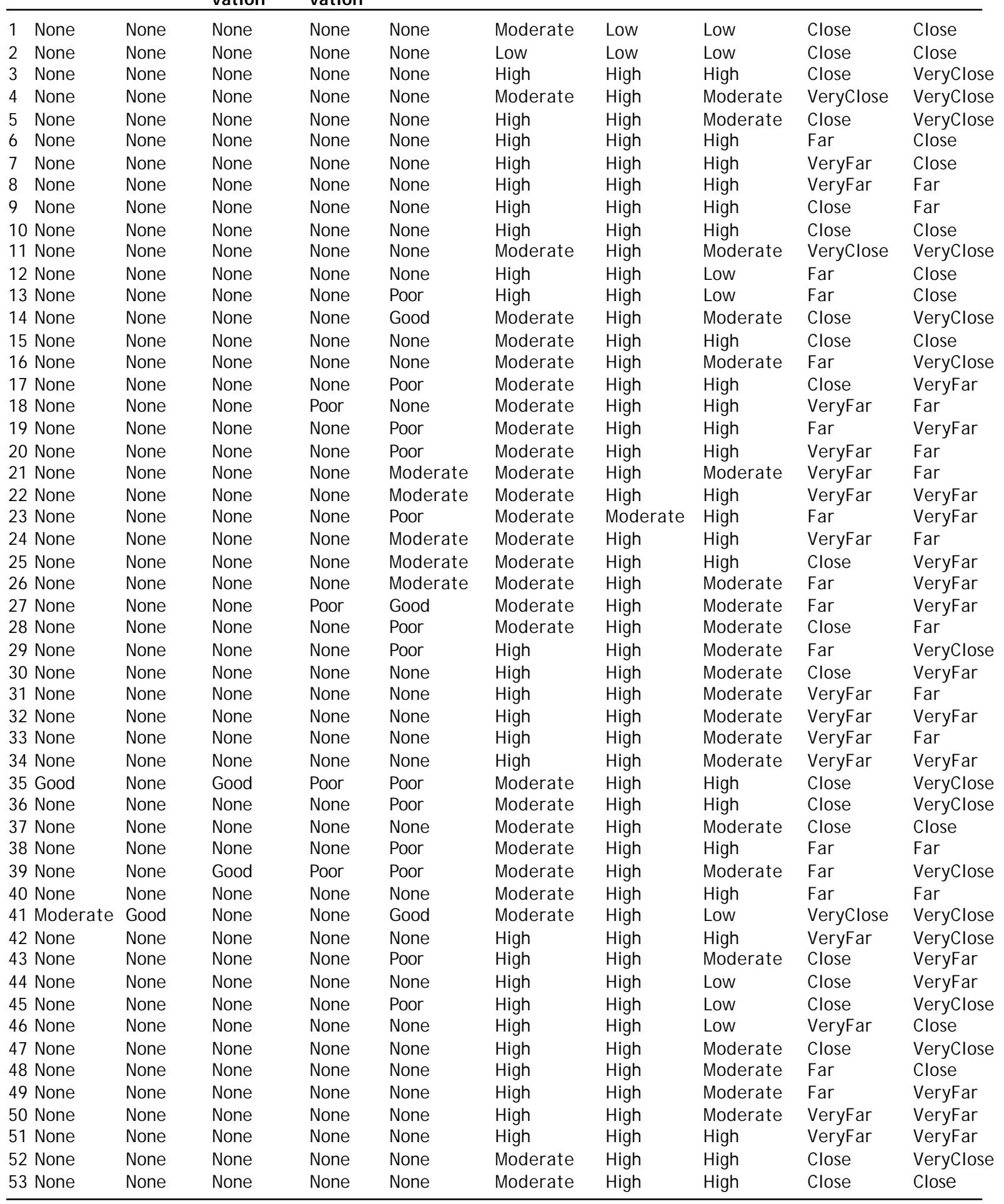

Page 4/8

Traditional Govt regulations regs

Distance Distance

Dangers along path off path

(1)

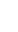


CIFOR/TREP GORONGOSA RESEARCH PROJ ECT

CONFRONTATION OF MODEL

NHANCHURURU DATA: (82 samples collected J uly 2002)

Page 5/8

Std

ID Recorder Score

Score Landtype

Soiltype

Vegetation

Wood for

Grinding

54 Rob

55 Rob

0.50 Planicie

Black/ sand

Woodland

Black/stones Woodland

Black/stones

Thicket-riverine

Black/sand

Woodland

Black/sand

Woodland

Black/stones Woodland

$58 \mathrm{Soz}$

0.05 Baixa

0.72 Planalto

0.28 Montanhas

0.50 Planicie

Black/stones

Woodland

$\begin{array}{ll}60 & \mathrm{SOz} \\ 61 \mathrm{Soz} & \end{array}$

1.00 Planicie

Black/sand

Woodland

$62 \mathrm{Soz}$

63 Fat

$\begin{array}{lll}15 & 0.83 \quad \text { Baixa }\end{array}$

64 Fat

65 Fat

0.36 Planicie

Black/ stones

Woodland

Sand

Woodland

Black/ sand

Woodland

? Woodland

0.32 Planalto

Black/ sand

Black

Woodland

67 Fat

$140.56 \quad$ Planalto

0.24 Baixa

0.80 Planicie

Black/sand

Field

68 Fat

$\begin{array}{lll}25 & 1.00 & \text { Planicie }\end{array}$

$\begin{array}{ll}69 & \text { Fat } \\ 70 \text { Rob }\end{array}$

1.00 Planicie
0.65 Planicie

Sand/ stones

Woodland

Black

Woodland

Black/ sand

Woodland

0.65 Planicie

0.60 Baixa

Black

Woodland

Woodland

Black

Black

Woodland

0.45 Planalto

Black

Woodland

Black/ stones Field

75 Rob

76 Rob

77 Fat

78 Fat

79 Fat

80 Fat

0.50 Baixa

0.55 Planicie

0.40 Planicie

Sand

Field

0.48 Planicie

Black

Field

0.60 Planicie

Sand

Woodland

Black/stones

Field

Black/stones

Woodland

0.32 Baixa

Sand/ stones

Woodland

Firewood handles sticks

Moderate Poor None

Good

Good

Good

Good

Moderate

Poor None

Good None

Moderate None

Moderate Moderate

82 Fat

$\begin{array}{lll}7 & 0.28 & \text { Planicie }\end{array}$

Woodland

Good

Good

None None

Moderate Moderate

Good

Good

None

Moderate

Moderate

Good

Moderate Moderate None

Good Good None

Poor None None

Poor Moderate Poor

Good Moderate None

Good Good None

Good Good None

Good Good None

Good None None

Good Good None

None None None

Poor None None

Good Poor Poor

Good Good None

Good

Moderate

Moderate

Poor

$\mathrm{m}$

Moderate

None

Moderate

Moderate

None 
CIFOR/TREP GORONGOSA RESEARCH PROJ ECT

CONFRONTATION OF MODEL

NHANCHURURU DATA: (82 samples collected J uly 2002)

Page 6/8

\begin{tabular}{|c|c|c|c|c|c|c|c|c|c|}
\hline ID & Timber & Poles & Bamboo & Bark & $\begin{array}{l}\text { Thatching } \\
\text { grass }\end{array}$ & $\begin{array}{l}\text { Reeds for } \\
\text { construction }\end{array}$ & $\begin{array}{l}\text { Reeds for } \\
\text { sleeping mats }\end{array}$ & $\begin{array}{l}\text { Traditional } \\
\text { medicines }\end{array}$ & $\begin{array}{l}\text { Wild } \\
\text { fruits }\end{array}$ \\
\hline 54 & None & Poor & None & Good & Moderate & None & None & Moderate & Moderate \\
\hline 55 & Good & Moderate & None & Moderate & Good & None & None & Poor & Poor \\
\hline 56 & Good & Moderate & None & None & Moderate & None & None & Good & Good \\
\hline 57 & Good & Good & None & Moderate & Moderate & None & None & Moderate & None \\
\hline 58 & Good & Moderate & None & Good & Poor & Poor & None & Poor & None \\
\hline 59 & None & Poor & None & Moderate & Good & None & None & Poor & Moderate \\
\hline 60 & None & Good & None & Good & Moderate & Poor & None & Good & None \\
\hline 61 & None & Good & None & Good & Good & Moderate & None & Good & Moderate \\
\hline 62 & Moderate & Good & None & Good & Good & Moderate & None & Moderate & Moderate \\
\hline 63 & Poor & Moderate & None & Good & None & None & None & Poor & None \\
\hline 64 & Moderate & Moderate & None & Good & Moderate & None & None & Poor & None \\
\hline 65 & None & Good & None & None & None & None & None & Moderate & None \\
\hline 66 & None & Good & None & Good & Poor & None & None & Moderate & None \\
\hline 67 & Poor & Poor & None & Poor & Moderate & Moderate & None & Poor & None \\
\hline 68 & None & Moderate & None & Good & Good & None & None & Poor & None \\
\hline 69 & None & Moderate & None & Good & Moderate & None & None & Moderate & Moderate \\
\hline 70 & None & Good & None & Good & Good & None & None & Moderate & Good \\
\hline 71 & Poor & Good & None & None & Good & None & None & Poor & Moderate \\
\hline 72 & None & Poor & Good & Poor & Good & None & Good & Good & Good \\
\hline 73 & None & Moderate & Good & Good & Good & None & None & Good & None \\
\hline 74 & Poor & Good & None & Good & Poor & None & None & Moderate & None \\
\hline 75 & None & None & None & None & Good & None & Moderate & Poor & None \\
\hline 76 & None & None & None & None & None & None & None & Poor & None \\
\hline 77 & None & Moderate & None & Moderate & None & None & None & Poor & None \\
\hline 78 & None & Good & None & Good & Moderate & None & None & Poor & None \\
\hline 79 & Moderate & Moderate & None & Moderate & Poor & None & None & Poor & Moderate \\
\hline 80 & None & Moderate & None & Good & None & None & None & Moderate & None \\
\hline 81 & None & Moderate & None & Good & Moderate & None & None & Poor & Moderate \\
\hline 82 & None & Poor & None & Good & Poor & None & None & Moderate & Poor \\
\hline
\end{tabular}


CIFOR/TREP GORONGOSA RESEARCH PROJ ECT

CONFRONTATION OF MODEL

NHANCHURURU DATA: (82 samples collected J uly 2002)

Wild

Aquatic

collected J uly 2002)

ID foods Honey food plants

$\begin{array}{ll}\text { Fish } & \text { Wildlife } \\ \text { None } & \text { Moderate }\end{array}$

Livestock

Land for Land for

Page 7/8

54 Moderate None None

55 Poor

$56 \mathrm{~g}$

None

None

None Good

Moderate

houses

fields

Cultivated

57 None

g None

None Good

58 None

g None

None Good

59 None

None

None

Good

Poor

Good

Good

None

Good

Poor

None

Moderate

Good

Good

None None

60 None

None None

61 Moderate None

None

None None

62 None

None None

63 None

None

None None

None None

64 None

None

None

None None

66 None

None

None

None None

67 None

None

None None

68 None

None

None

None None

69 None

None

None

None None

None None

None Poor

Good

Poor

None

Poor

Moderate

None

Poor

Moderate Poor

Moderate

Poor

Poor

Poor

None

Poor

Poor

Moderate

None None

71 Poor

None

None

None Moderate

Good

Good

None Moderate

Good

None Moderate

None None

None

Poor

Good

Poor

Good

None

None None

76 None

None

Poor

None None

None None

78 None

None

None

None None

Moderate

Moderate

Good

Poor

None None

Moderate

Poor

Poor

Poor

Poor

None

None

Good

Poor

Poor

Poor

None

None

None

None

Poor

Good

Moderate None

Poor

Poor

Moderate

Poor
None

\section{Good}

None

Good

Moderate

None

None

Good

Moderate

Good

Moderate Moderate

Moderate
Moderate

Good

80 None

None

None

None None

Moderate None

None

None

None

None

None
fruits

82 None None None

Poor

None
None

\begin{tabular}{l} 
None \\
None \\
None \\
None \\
None \\
None \\
None \\
None \\
None \\
None \\
None \\
None \\
None \\
None \\
Moderate \\
None \\
Poor \\
None \\
None \\
None \\
None \\
Moderate \\
Poor \\
Moderate \\
None \\
None \\
None \\
None \\
None \\
\hline
\end{tabular}


CIFOR/TREP GORONGOSA RESEARCH PROJ ECT

CONFRONTATION OF MODEL

NHANCHURURU DATA: (82 samples collected J uly 2002)

Grinding Clay

ID stones
Mud for Clay for

for pots culti-

vation

vation

54 None

55 None

56 None

57 None

58 None

59 None

60 None

61 None

62 None

63 None

64 None

65 None

66 None

67 Poor

68 None

69 None

70 None

71 None

72 None

73 None

74 None

75 None

76 None

77 None

78 None

79 None

80 None

81 None

82 None

None

None

None

None

None

None

None

None

None

None

None

None

None

None

None

None

None

None

None

None

None

None

None

None

None

None

None

None

None

None None

None None

None None

None None

None None

None None

None None

None None

None None

None None

None None

None None

None None

None None

None None

None None

None None

None None

None None

None None

Poor None

Poor

None

None

None

None

None

None $\mathrm{m}$

None

None

None

None

None

None
None None
Traditional Govt

regulations regs

Good Moderate

Good Moderate

None Moderate

None Moderate

Moderate Moderate

Poor High

None High

None High

Moderate High

None High

Good Moderate

None Moderate

None Moderate

None Moderate

None Moderate

None Moderate

None Moderate

None Moderate

Poor Moderate

Good Moderate

Poor Moderate

Poor Moderate

None Moderate

None Moderate

Good Moderate

Moderate Moderate

Good Moderate

None Moderate

None Moderate

None Moderate

\begin{tabular}{|c|c|c|c|}
\hline High & High & Close & Far \\
\hline High & High & Far & Close \\
\hline High & High & Far & VeryFar \\
\hline High & High & Far & VeryClose \\
\hline High & High & VeryFar & VeryFar \\
\hline High & High & VeryFar & VeryFar \\
\hline High & High & VeryFar & VeryFar \\
\hline High & High & VeryFar & VeryFar \\
\hline High & High & VeryFar & Far \\
\hline High & Low & Close & VeryClose \\
\hline High & Moderate & VeryFar & VeryFar \\
\hline High & Low & VeryFar & VeryFar \\
\hline High & Low & VeryFar & VeryFar \\
\hline High & Low & Far & VeryFar \\
\hline High & Moderate & VeryClose & VeryFar \\
\hline High & Moderate & Close & VeryClose \\
\hline High & Moderate & VeryClose & VeryClose \\
\hline High & High & VeryClose & Close \\
\hline High & High & VeryClose & Far \\
\hline High & Moderate & VeryClose & VeryFar \\
\hline High & High & Close & VeryFar \\
\hline High & Moderate & Far & VeryFar \\
\hline High & $*$ & VeryClose & VeryClose \\
\hline High & High & VeryClose & VeryClose \\
\hline High & High & Close & VeryClose \\
\hline High & High & Far & VeryClose \\
\hline High & High & Close & VeryClose \\
\hline High & Moderate & Close & Far \\
\hline High & High & VeryFar & VeryClose \\
\hline
\end{tabular}


Appendix 5. GPS point data for the vegetation inventory sites in Muredzi and Nhanchururu

MUREDZI

\begin{tabular}{|c|c|c|}
\hline SAMPLE NUMBER & LATITUDE & LONGITUDE \\
\hline MOI & $-18,929653$ & 34,551857 \\
\hline $\mathrm{MO2}$ & $-18,931605$ & 34,553118 \\
\hline Mos & $-18,932614$ & 34,555746 \\
\hline $\mathrm{MOS}$ & $-18,932171$ & 34,561776 \\
\hline Mos & $-18,928505$ & 34,566073 \\
\hline $\mathrm{MOS}$ & $-18,925629$ & 34,566979 \\
\hline $\operatorname{mog}$ & $-18,908914$ & 34,561872 \\
\hline nos & $-18,876363$ & 34,560274 \\
\hline $\operatorname{mog}$ & $-18,874973$ & 34,554791 \\
\hline$M 10$ & $-18,896592$ & 34,552662 \\
\hline M11 & $-18,900604$ & 34,554690 \\
\hline$M 12$ & $-18,942973$ & 34,571754 \\
\hline$M 13$ & $-18,944517$ & 34,571582 \\
\hline$M 14$ & $-18,953589$ & 34,569125 \\
\hline$M 15$ & $-18,910132$ & 34,543022 \\
\hline$M 16$ & $-18,917658$ & 34,558595 \\
\hline$M 17$ & $-18,986768$ & 34,569377 \\
\hline м18 & $-18,976082$ & 34,569200 \\
\hline$M 19$ & $-18,966190$ & 34,572875 \\
\hline MzO & $-18,957671$ & 34,570745 \\
\hline M21 & $-18,931584$ & 34,643170 \\
\hline$M 22$ & $-18,934274$ & 34,615098 \\
\hline$M 23$ & $-18,932694$ & 34,613022 \\
\hline$M 24$ & $-18,929417$ & 34,603280 \\
\hline$M 25$ & $-18,93290 s$ & 34,589489 \\
\hline $\mathrm{M} 26$ & $-18,93,4561$ & 34,586409 \\
\hline$M 27$ & $-18,936943$ & 34,578094 \\
\hline M28 & $-18,934169$ & 34,552243 \\
\hline$M 29$ & $-18,934615$ & 34,550119 \\
\hline Maso & $-18,93728$ & 34,560971 \\
\hline Mas & $-18,935315$ & 34,552864 \\
\hline Maz & $-18,93150 \mathrm{~A}$ & 34,552086 \\
\hline $\operatorname{ma3}$ & $-18,931728$ & 34,551313 \\
\hline M34 & $-1 \mathrm{a}, 924517$ & 34,566167 \\
\hline M35 & $-18,918691$ & 34,563544 \\
\hline M36 & $-18,926459$ & 34,554275 \\
\hline$m a 7$ & $-11,935397$ & 34,576515 \\
\hline$M 38$ & $-18,935403$ & 34,576520 \\
\hline$m 39$ & $-18,936894$ & 34,578398 \\
\hline$M 40$ & $-18,935193$ & 34,579540 \\
\hline MA1 & $-18,928035$ & 34,588525 \\
\hline M42 & $-18,926653$ & 34,590929 \\
\hline$M 43$ & $-18,933343$ & 34,586728 \\
\hline$M 44$ & $-18,928466$ & 34,596448 \\
\hline M45 & $-18,968332$ & 34,573243 \\
\hline$M 46$ & $-18,966352$ & 34,572787 \\
\hline MA7 & $-18,965462$ & 34,572663 \\
\hline
\end{tabular}

NHANCHURURU

\begin{tabular}{|c|c|c|}
\hline SAMPLE NUMBER & LATITUDE & LONGITUDE \\
\hline No1 & $-18,625192$ & 34,254219 \\
\hline $\mathrm{NOZ}$ & $-18,621667$ & 34,256016 \\
\hline nos & $-18,622756$ & 34,249193 \\
\hline NOA & $-18,622107$ & 34,246416 \\
\hline NoS & $=18,629205$ & 34,266567 \\
\hline No6 & $-18,627129$ & 34,269142 \\
\hline No7 & $-18,620991$ & 34,260184 \\
\hline Nos & $-18,620514$ & 34,261563 \\
\hline NOS & $-18,619720$ & 34.263590 \\
\hline N10 & $-18,620991$ & 34,260463 \\
\hline$N 11$ & $-18,621463$ & 34,258301 \\
\hline $\mathbf{N 1 2}$ & $-18,624967$ & 34,258001 \\
\hline $\mathrm{N13}$ & $-18,642536$ & 34,256338 \\
\hline $\mathbf{N 1 4}$ & $-18,642204$ & 34,255249 \\
\hline N15 & $-18,635240$ & 34,254857 \\
\hline$\$ 16$ & $-18,637778$ & 34,253919 \\
\hline N17 & $-18,630331$ & 34,253661 \\
\hline N18 & $-18,634414$ & 34,258677 \\
\hline N19 & $-18,626882$ & 34,259932 \\
\hline Nzo & $-18,616758$ & 34,267265 \\
\hline $\mathbf{N 2 1}$ & $-18,609307$ & 34,269507 \\
\hline N22 & $-18,604779$ & 34,263783 \\
\hline $\mathrm{N} 23$ & $-18,605621$ & 34,2663774 \\
\hline N24 & $-18,606227$ & 34,267007 \\
\hline N25 & $-18,594618$ & 34,279447 \\
\hline N26 & $-18,600213$ & 34,279948 \\
\hline $\mathrm{N} 27$ & $-18,620144$ & 34,255812 \\
\hline N28 & $-18,620530$ & 34,256123 \\
\hline N29 & $-18,620819$ & 34,262973 \\
\hline N30 & $-18,623 \times 21$ & 34,273906 \\
\hline N31 & $-18,630868$ & 34,260012 \\
\hline $\mathrm{N} 32$ & $-18,630160$ & 34,262475 \\
\hline$N 33$ & $-18,576914$ & 34,158789 \\
\hline N34 & $-18,594312$ & 34,167903 \\
\hline N635 & $-18,592944$ & 34,179194 \\
\hline N36 & $-18,606694$ & 34,209878 \\
\hline 1037 & $-18,632939$ & 34,2644631 \\
\hline N38 & $-18,637633$ & 34,263574 \\
\hline N139 & $-18,642670$ & $34,26230 \mathrm{~B}$ \\
\hline $\mathrm{N} 40$ & $-18,653186$ & 34,261230 \\
\hline N41 & $-18,632928$ & 34,264266 \\
\hline$N 42$ & $-18,630144$ & 34,268273 \\
\hline$N 43$ & $-18,609920$ & 34,178079 \\
\hline N44 & $-18,596774$ & 34,178095 \\
\hline$N 45$ & $-18,613459$ & 34,218257 \\
\hline$N 46$ & $-18,630696$ & 34,209819 \\
\hline$\$ 47$ & $-18,600019$ & 34,236120 \\
\hline $\mathrm{N} 48$ & $-18,616624$ & 34,229903 \\
\hline$N 49$ & $-18,626603$ & 34,240234 \\
\hline NSO & $-18,629038$ & 34,263424 \\
\hline
\end{tabular}




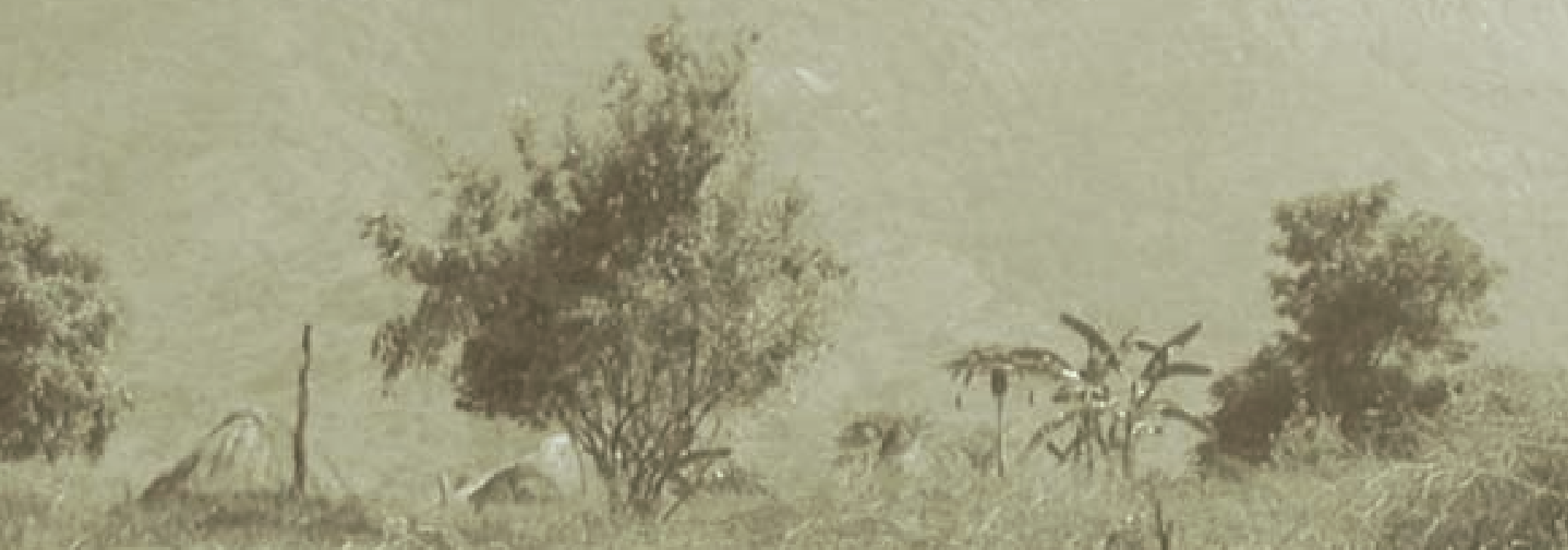

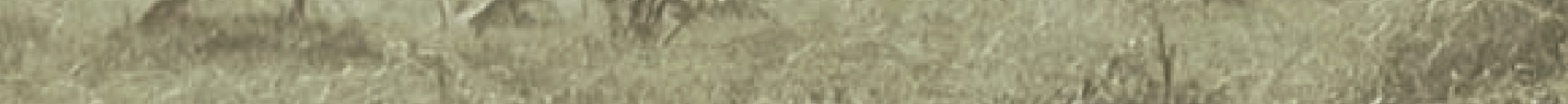

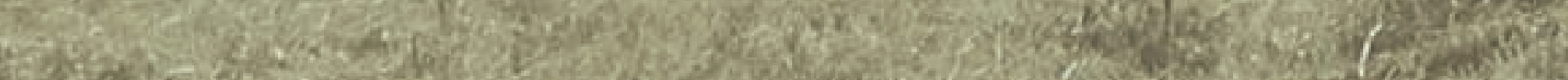
Waris 2 ISBN 979-3361-11-5

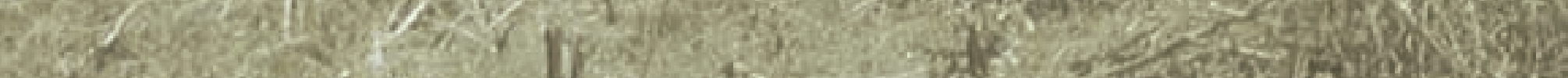

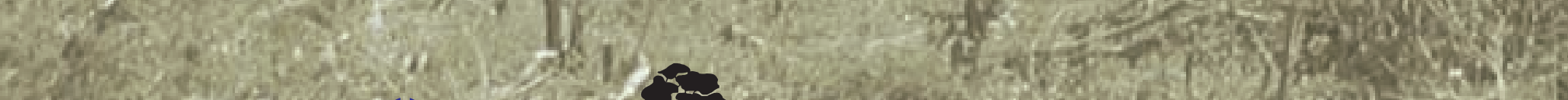

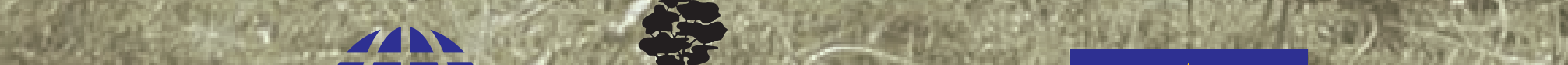

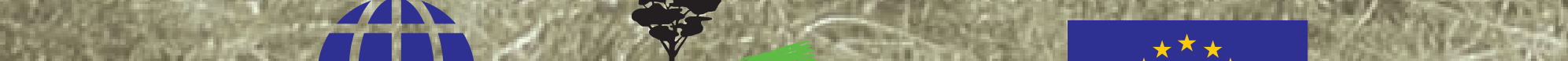

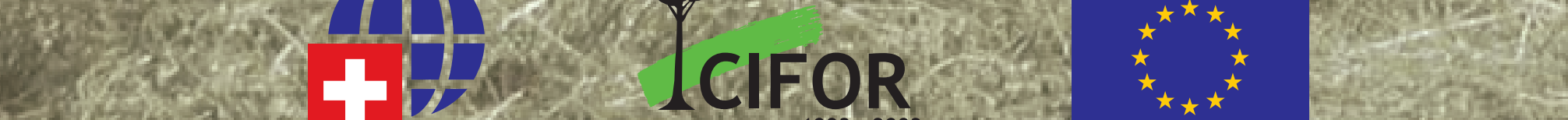

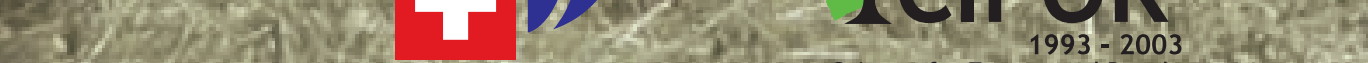

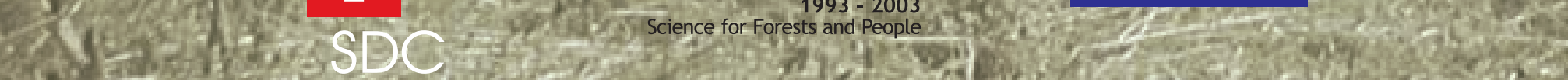

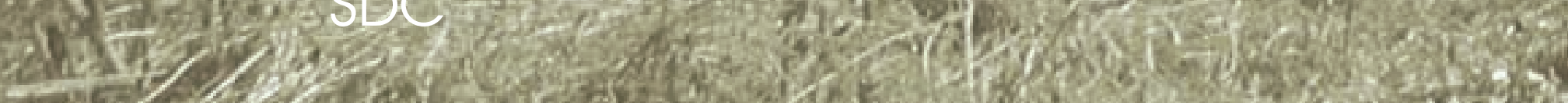

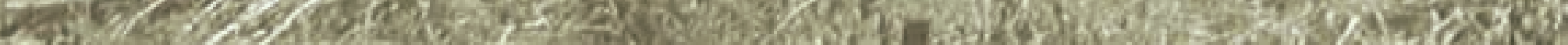

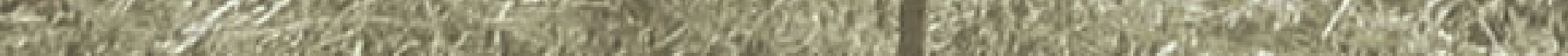

